$$
\begin{aligned}
& \text { José Luis Terrón, } \\
& \text { Carmen Penafiel y } \\
& \text { Daniel Catalán }
\end{aligned}
$$$$
\text { (Coordinadores) }
$$

Prólogo de Miguel Muñoz-Cruzado

\title{
Avances en investigación
} y buenas prácticas en comunicación y salud

Cuadernos Artesanos de Comunicación, CAC 123

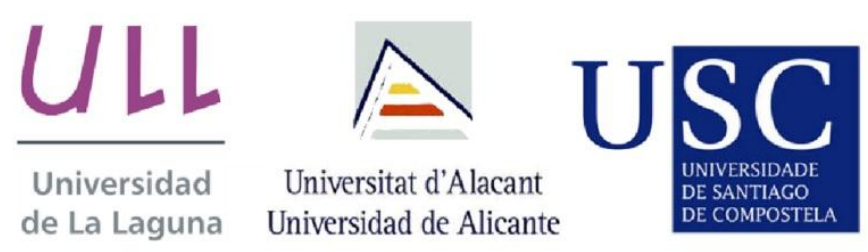

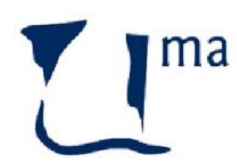

UNIVERSIDAD

DE MÁLAGA

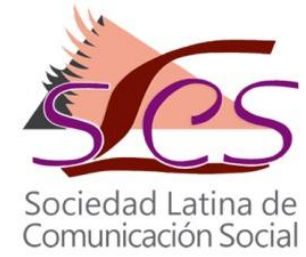




\section{Cuadernos Artesanos de Comunicación}

Coordinador editorial: José Manuel de Pablos - jpablos@ull.edu.es

Comité Científico

Presidencia: José Luis Piñuel Raigada (UCM)

Secretaría: Alberto Ardèvol (ULL)

- Maricela López-Ornelas (Universidad Autónoma de Baja California, AUBC)

- Javier Marzal (Universidad Jaume I, UJI)

- José Antonio Meyer (Benemérita Universidad Autónoma de Puebla, BUAP)

- Ramón Reig (Universidad de Sevilla, US)

- Miquel Rodrigo Alsina (Universidad Pompeu Fabra, UPF)

- Xosé Soengas (Universidad de Santiago de Compostela)

- José Miguel Túñez (Universidad de Santiago de Compostela, USC)

- Victoria Tur (Universidad de Alicante, UA)

- Miguel Vicente (Universidad de Valladolid, UVA)

- Ramón Zallo (Universidad del País Vasco, UPV-EHU)

- Núria Almiron (Universidad Pompeu Fabra, Barcelona, UPF)

- Francisco Campos Freire (Universidad de Santiago de Compostela)

- José Cisneros (Benemérita Universidad Autónoma de Puebla, BUAP)

- Bernardo Díaz Nosty (Universidad de Málaga, UMA)

- Carlos Elías (Universidad Nacional de Educación a Distancia, UNED)

- Paulina B. Emanuelli (Universidad Nacional de Córdoba, UNC)

- Marisa Humanes (Universidad Rey Juan Carlos, URJC)

- Juan José Igartua (Universidad de Salamanca, USAL)

- Xosé López (Universidad de Santiago de Compostela)

* Queda expresamente autorizada la reproducción total o parcial de los textos publicados en este libro, en cualquier formato o soporte imaginables, salvo por explícita voluntad en contra del autor o autora o en caso de ediciones con ánimo de lucro. Las publicaciones donde se incluyan textos de esta publicación serán ediciones no comerciales y han de estar igualmente acogidas a Creative Commons. Harán constar esta licencia y el carácter no venal de la publicación.

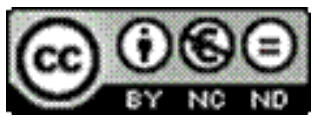

Este libro y cada uno de los capítulos que contiene (en su caso), así como las imágenes incluidas, si no se indica lo contrario, se encuentran bajo una Licencia Creative Commons Atribución-No

Comercial-Sin Derivadas 3.0 Unported. Puede ver una copia de esta licencia en http://creativecommons.org/licenses/by-nc-nd/3.0/ Esto significa que Ud. es libre de reproducir y distribuir esta obra, siempre que cite la autoría, que no se use con fines comerciales o lucrativos y que no haga ninguna obra derivada. Si quiere hacer alguna de las cosas que aparecen como no permitidas, contacte con los coordinadores del libro o con el autor del capítulo correspondiente.

* La responsabilidad de cada texto es de su autor o autora. 
José Luis Terrón, Carmen Peñafiel y Daniel Catalán

(Coordinadores)

Prólogo de Miguel Muñoz-Cruzado

\section{Avances en investigación y buenas prácticas en comunicación y salud}

José Luis Terrón, Carmen Peñafiel, Daniel Catalán, Miguel MuñozCruzado, Lizandro Angulo, Elena Becerra, María Antonia Calleja, Miguel Cembellín, Lázaro Echegaray, Víctor García, Antonio López, Luisa Fernanda Giraldo, Liliana Gutiérrez, Yahira R. Guzmán, Andrea Langbecker, Paloma López, Carolina Menezes, Antonia Moreno, Raquel Rodríguez, Milagros Ronco, Andrea Salgado.

Cuadernos Artesanos de Comunicación, CAC 123

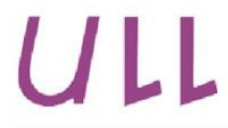

Universidad de La Laguna

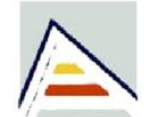

Universitat d'Alacant Universidad de Alicante

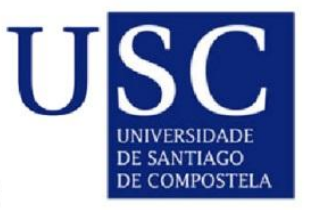

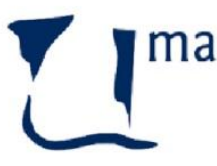

UNIVERSIDAD DE MALAGA

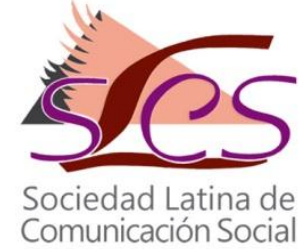


CAC- $123^{\circ}$ Avances en investigación y buenas prácticas en comunicación y salud

José Luis Terrón, Carmen Peñafiel y Daniel Catalán (Coords.)

| Precio social: $10,15 €$ | Precio en librería: 13,20 € |

Editores: Javier Herrero y Milena Trenta

Diseño: F. Drago

Ilustración de portada: Fragmento del cuadro Mujer con bernegal, de Pedro de Guezala (1958).

Imprime y distribuye: F. Drago. Andocopias S. L.

c/ La Hornera, 41. La Laguna. Tenerife.

Teléfono: 922250554 | fotocopiasdrago@telefonica.net

Edita: Sociedad Latina de Comunicación Social - edición no venal La Laguna (Tenerife), 2017 - abril - Creative Commons

http://www.revistalatinacs.org/14SLCS/portada2017.html

Descargar en pdf:

http://www.cuadernosartesanos.org/\#123

Protocolo de envío de manuscritos

http://www.cuadernosartesanos.org/protocolo.html

ISBN - 13: 978-84-16458-80-6

DL: TF-648-2017

DOI: $\underline{10.4185 / \operatorname{cac} 123}$ 


\section{Índice}

Prólogo Miguel Muñoz-Cruzado

1. Aspectos éticos en la comunicación de los resultados derivados de ensayos clínicos Miguel Cembellín y Daniel Catalán.................... 13

2. La comunicación institucional del virus del ébola en España: análisis de la gestión estratégica online y offline de la crisis María Antonia Calleja-Reina y Elena Becerra Muñoz

3. La importancia del blog de salud para los pacientes con enfermedades minoritarias Paloma López Villafranca.....

4. Análisis etnográfico en la búsqueda de información de salud por parte de jóvenes $\mathbf{y}$ adolescentes vascos Milagros Ronco, Carmen Peñafiel y Lázaro Echegaray.....

5. Salud 2.0: la sostenibilidad de los servicios de cardiología a través de la comunicación remota Antonio López y Daniel Catalán

6. Las secciones de salud en los periódicos brasileños: el caso del diario Folha de São Paulo Andrea Langbecker y Daniel Catalán.103

7. Riesgos y oportunidades del enfoque humano en la cobertura de salud mental de la prensa colombiana Víctor García, Liliana Gutiérrez, Yahira Guzmán y Andrea Salgado

8. El dengue y la importancia de su comunicación como factor de prevención y control en la ciudad de Bucaramanga, Colombia Antonia Moreno y Lizandro Angulo....

9. El tratamiento de la obesidad en los diarios brasileños: $O$ Globo y Folha de S. Paulo Carolina Menezes y José Luis Terrón 177

10. Los medios de comunicación y la cobertura de medicamentos Daniel Catalán y Carmen Peñafiel

11. Prensa, Alzheimer y funeral de Estado: El caso de Adolfo Suárez Luisa Fernanda Giraldo y Raquel Rodríguez 


\title{
Avances en investigación y buenas prácticas en comunicación y salud
}

\begin{abstract}
:
Esta obra trata del importante rol que la Comunicación y la Salud juegan en la sociedad actual. La salud ocupa un papel muy importante en la sociedad debido a que tanto el crecimiento económico como social de un país está directamente ligado a la salud y bienestar de su población. Por ello, el objetivo principal de este libro es avanzar en el conocimiento y la divulgación de la Comunicación en Salud y así compartir las buenas prácticas desarrolladas a nivel internacional.

En el libro se abordan temas tales como la comunicación efectiva en salud, la comunicación entre el profesional de la salud con el paciente o usuario, el rol de los medios de comunicación y sus contenidos sobre salud, la comunicación 2.0 en salud, la salud pública, la comunicación de crisis durante emergencias sanitarias, los portales web, la tele-salud, la representación de la salud en los medios y su calidad y en él se incluyen investigaciones sobre estos asuntos, sustentadas, como no podía ser de otra forma, en una teoría que no sólo contextualiza a las investigaciones sino que, además, hace progresar el campo de la Comunicación y Salud. La Comunicación y Salud es un fenómeno complejo y esta complejidad sólo puede ser entendida mediante el abordaje multidisciplinar y la colaboración entre investigadores de países e instituciones diversas. Este libro, por tanto, pretende ser, por un lado, un ejemplo de multidisciplinariedad, colaboración y divulgación y, por otro, una nueva aportación para el asentamiento de la Comunicación y Salud como campo de estudio.
\end{abstract}

\section{Keywords:}

Salud y comunicación; salud pública; salud 2.0; comunicación de crisis; ébola; enfermedades minoritarias; obesidad; nutrición; representación; web; jóvenes; adolescentes; calidad; telemedicina; marcapasos; salud mental; dengue; Alzheimer; medicamentos.

\section{Forma de citar este libro}

Autores del capítulo, en (2017): Avances en investigación y buenas prácticas en comunicación y salud. José Luis Terrón, Carmen Peñafiel y Daniel Catalán (Coords.). Cuadernos Artesanos de Comunicación, 123. La Laguna (Tenerife): Latina. 


\section{$\triangle$}

\section{Prólogo}

\section{Miguel Muñoz-Cruzado}

CUANDO los coordinadores de este libro me encargaron elaborar su prólogo, no dejé de sentir una repentina sensación de extrañeza, pues la norma indica la tácita conveniencia de que los libros, de no ser prologados por sus autores, lo sean por personajes eminentes en el área de conocimiento de la materia de que en ellos se trate, y yo, humildemente proclamo, me siento incapaz de conocer todos los campos de la comunicación que en esta obra se tratan. Sin embargo, el respeto a los que me mantienen en el cargo de Presidente de la Asociación Española de Comunicación Sanitaria me impulsó a aceptar la invitación, esperando poder cumplir el encargo con un mínimo de dignidad.

Decía el crítico literario y ensayista estadounidense Edmund Wilson (1895-1972) que no hay dos personas que lean el mismo libro, en clara alusión a la cantidad de componentes culturales, ideológicos, semánticos y anímicos que influyen en la lectura y posterior asimilación de las ideas expresadas en cada texto. De ello, deduciremos que cada libro será motivo de tantos mensajes como veces sea leído, y digo veces que sea leído en lugar de individuos que lo lean porque, como decía anteriormente, los estados anímicos van a ser pieza clave en la interpretación de sus mensajes.

Partiendo de estas premisas, me dispuse a leer los diversos capítulos que componen este nuevo número de Cuadernos Artesanos de Comunicación, titulado Avances en investigación y buenas prácticas en comunicación y salud, coordinado por Carmen Peñafiel, Daniel Catalán y José Luis Terrón, ya que entendí que, como introductor a la obra, mi primera condición debía ser su conocimiento. 
La sola lectura de su índice me hizo tener una leve idea de la gran tarea de coordinación que habrá requerido un libro que, como el presente, ha sido realizado por autores de las más diversas áreas de la comunicación, a las que cada uno de ellos ha inferido su impronta personal, pues es tarea de los coordinadores conseguir un sentido de "unidad de la obra" respetando la "diversidad de la autoría", algo que mi experiencia me ha demostrado ser tarea nada fácil, ya que, como afirmaba Aitor Ugarte en el prólogo del anterior número de estos cuadernos, el proceso de coordinación requiere, entre otros, el establecimiento de un orden adecuado de los capítulos, de manera que “...el libro adquiera un sentido por sí mismo que vaya más allá de la mera suma de sus partes" (sic), pudiendo afirmar que en este caso, la coordinación resulta perfecta.

Y no pudieron los coordinadores tener mejor idea para comenzar la recopilación de interesantísimos capítulos de este texto que hacerlo con uno, especialmente seductor, referido a ese reto que aún sigue suponiendo los aspectos éticos en la comunicación de los resultados de ensayos clínicos.

A continuación, se pone de manifiesto la cantidad de desaciertos comunicacionales en momentos de crisis en el sector de la salud llevados a cabo por las diversas administraciones que en España son y han sido, con la introducción del atrayente capítulo titulado "La comunicación institucional del virus del Ébola en España: Análisis de la gestión estratégica online y offline de la crisis". La comunicación sanitaria, llevada a cabo por políticos con intereses partidistas, cuando no por periodistas con escasos conocimientos sobre salud o por sanitarios sin la necesaria formación en comunicación, es con frecuencia causa de desinformación y descoordinación, creando en la población española, en principio y con frecuencia, pánico social, y, posteriormente, un enorme desprestigio de las instituciones sanitarias, encargadas precisamente de mantener el mejor estado de Salud Pública posible a través, entre otros, de la comunicación sanitaria y la confianza en las instituciones. Los autores concluyen en que el pánico social que puede acompañar a un problema de salud, tiene con frecuencia su etiología en la desinformación sobre el problema y la descoordinación informativa llevada a cabo. 
Asimismo, es de destacar el capítulo referido a un estudio relativo a la importancia del blog de salud para afectos de enfermedades raras o minoritarias, ya que, según concluye, dado el poco interés investigador demostrado por estas patologías, debido, sobre todo, a la escasa frecuencia con que se presentan, supone un necesario y útil vehículo comunicativo de experiencias íntimas entre pacientes, que es utilizado para cubrir necesidades emocionales más que informativas.

A veces, me pregunto si será el enmarcado negro de las pantallas de televisión y del ordenador o las radiaciones por estos aparatos emitidas lo que genera esa abducción del gran público hacia los individuos que aparecen en esos medios y/o a sus mensajes. A este respecto, recuerdo la cantidad de enteros sociales que crecí en mi pueblo cuando comencé a presentar y dirigir un programita de televisión local. Gente para la que hasta entonces pasaba desapercibido, comenzó a demostrar un cierto interés por contactar directamente conmigo porque "salía en la televisión". Y el fenómeno se repite día a día en ese execrable invento de la televisión basura, en donde no importa qué o quién lo diga, "lo ha dicho la televisión", se nos dice, como si de la propia Biblia se tratara. En este sentido, resulta enormemente interesante el capítulo titulado "Análisis etnográfico en la búsqueda de información de salud por parte de jóvenes y adolescentes vascos", estudio que viene a demostrar la enorme influencia en la salud del fenómeno Internet, y especialmente el Dr. Google, del que una buena parte de la sociedad afirma "si lo ha dicho Google, es cierto", hecho éste que, lejos de ser una simpática anécdota, crea muchísimos problemas de credibilidad a los diagnósticos, consejos y terapéuticas sanitarias, aunque lo encontrado no tenga el menor atisbo científico. En este capítulo, los autores ponen especial énfasis en destacar la necesidad de ir programando y dirigiendo la formación del espíritu crítico de los niños a lo largo de su formación educativa, de manera que lleguen a ser jóvenes culturalmente formados para que su elección sobre la información ofrecida en Internet sea la adecuada, pues no es suficiente que ésta sea atractiva ni que la interfaz empleada permita una gran funcionalidad. 
Por su lado, la lectura del atractivo capítulo titulado "Salud 2.0: la sostenibilidad de los servicios de cardiología a través de la comunicación remota", reafirma mi convencimiento de que estamos en la sociedad de la Telesalud. El uso de las herramientas telemáticas constituye una eficaz, útil y eficiente forma de proporcionar servicios sanitarios alternativos al modelo convencional de seguimiento de pacientes. En este caso, se ha estudiado la monitorización a distancia (telemonitorización) de los pacientes portadores de marcapasos, permitiendo esta aplicación de la telemedicina observaciones profesionales sobre el estado del paciente sin que éste tenga consciencia de que su función cardiaca está siendo observada.

Asimismo, resulta enriquecedora la reflexión de los autores acerca del enfoque que sobre la salud adoptan las distintas sesiones que abordan temas de salud en el diario brasileño Folha de São Paulo, precedido de una breve descripción de las secciones de salud que aparecen en los principales medios de comunicación y en las revistas especializadas en salud de aquel país.

Por otra parte, se presenta un estudio descriptivo-correlacional, aplicando la técnica de análisis de contenido, acerca del tratamiento que sobre la Salud Mental se está llevando a cabo en Colombia, concluyendo sus autores que en el tratamiento de las psicopatías escasamente se emplea un idioma asequible al gran público, lo que requiere mayor atención formativa de los periodistas para que sus informaciones puedan ser asequibles a personas de mediana instrucción.

Y más que interesante, me resultó necesario encontrar en este número de Cuadernos Artesanos de Comunicación un capítulo dedicado al Dengue, tropezando con el magnífico trabajo encaminado a determinar el grado de conocimiento que sobre esta enfermedad, sus manifestaciones y factores de transmisión y prevención tienen los habitantes de la ciudad colombiana de Bucaramanga a través de los medios, realizando un extraordinario trabajo de campo a través de encuestas que llevan a conclusiones muy válidas, demostrando que los medios de comunicación suponen unas 
magníficas herramientas para modificar conductas y favorecer los procesos de prevención y tratamiento de la enfermedad.

También es de tener en cuenta el atractivo estudio acerca del tratamiento que de la obesidad realizan las dos publicaciones brasileñas $O$ Globo y Folha de S. Paulo, en el que los autores diferencian dos grandes bloques de artículos: los que refieren el problema como puramente estético y los que lo contemplan como un verdadero problema de salud, valiéndose para ello de la observación de diversas variables.

Por otro lado, no se nos debe escapar que tiene una gran importancia analizar los estudios sobre la cobertura de medicamentos que hacen los medios de comunicación. Para lo cual, los autores desarrollan una revisión de literatura en las bases de datos Pubmed y Google Académico desde 2012 a 2017, exponiendo unos resultados que exigen a los medios de comunicación un mayor compromiso en este asunto.

Y muy en consonancia con el objetivo de diversificar los análisis de la comunicación de diversos autores, es de agradecer la inclusión del capítulo final titulado "Prensa, Alzheimer y funeral de Estado: El caso de Adolfo Suárez", en el que sus autoras resaltan el oportunismo comunicacional que para la enfermedad de Alzheimer supuso el fallecimiento del que fuera Presidente del Gobierno español D. Adolfo Suárez, claro ejemplo del aprovechamiento de una noticia para aumentar el conocimiento que sobre determinada cuestión -en este caso, la Enfermedad de Alzheimer- se ofrece a la población general.

Se trata, por tanto, de un Cuaderno Artesano de Comunicación en el más puro sentido de la denominación, pues, aunque elaborado por distintos autores, la magnífica labor de sus coordinadores ha dado como resultado esta obra, en la que, siendo distinto cada capítulo de los siguientes, han conseguido un sentido de totalidad que la hace merecedora del apellido "artesano", siendo un libro para leerlo y para tenerlo como referencia para futuros estudios que pretendan comparar tanto los fenómenos analizados en distintas sociedades, 
como la evolución de las diversas sociedades contempladas por estos autores con respecto a los fenómenos por ellos analizados.

Y finalizo este prólogo agradeciendo a los coordinadores de la obra su encargo, pues si bien cuando recibí la invitación sentí el natural vértigo de la responsabilidad y la duda acerca de mis posibilidades como prologuista, la lectura pormenorizada de cada uno de los apartados de la obra ha ido aumentando mis conocimientos al respecto, lo que me hace extender mi agradecimiento a los autores, verdaderos artífices de mi formación adquirida.

En Torre del Mar, 15 de marzo de 2017 


\title{
Aspectos éticos en la comunicación de los resultados derivados de ensayos clínicos
}

\author{
Miguel Cembellín Fernández $\mathcal{C}$ Universidad de Alcalá \\ Daniel Catalán Matamoros $G$ Universidad Carlos III de \\ Madrid
}

\section{Resumen}

Introducción: La comunicación pública de los ensayos clínicos constituye un requerimiento ético importante adicional a los ya habituales según las normas de buena práctica clínica. Objetivos. Analizar las publicaciones científicas que hayan analizado las publicaciones en revistas científicas de ensayos clínicos. Metodología. Búsqueda en Pubmed y Google Académico de aquellos artículos que desde 2006 analizan la comunicación pública de los ensayos clínicos. Resultados. La búsqueda arrojó 199 resultados. Tras descartar los que no se adaptaban a la temática y duplicados la muestra final estuvo compuesta por 21 artículos. Conclusiones. La comunicación pública de los resultados derivados de ensayos clínicos continúa siendo un reto desde la perspectiva ética de la investigación clínica.

Palabras clave: bioética; comunicación; publicación; resultados; ensayos clínicos. 


\section{Introducción}

Un hombre sin ética es una bestia salvaje soltada a este mundo. Albert Camus (1913-1960)

T A COMUNICACIÓN pública de los ensayos clínicos (en 1 adelante $\mathrm{EC}^{1}$ ) constituye un requerimiento ético importante adicional a los ya habituales según las normas de Buena Práctica Clínica (BPC²). En el artículo de Chalmers de 1990 Under reporting research is scientific misconduct se ponía de manifiesto que muchos de los resultados de los EC nunca se publicaban. A este hecho, además, se añade la existencia del sesgo de publicación en cuanto a publicar más los resultados considerados "positivos".

Dada que la finalidad de todo EC es determinar por ejemplo si un fármaco o procedimiento quirúrgico funciona $\mathrm{o}$ no, se hace indispensable que sus resultados sean compartidos con el resto de la comunidad científica y con la sociedad, al ser éstos últimos, los futuros beneficiarios de dichas investigaciones.

Esos resultados, además de ser remitidos a los distintos organismos regulatorios, han de ser publicados en fuentes de información, tales como revistas científicas especializadas, bases de datos, libros, etc. con tal de que sean comprensibles, transparentes y accesibles de forma pública para la sociedad.

La transparencia de los resultados de los EC se consolida como un aspecto fundamental de todo EC ya que se garantiza el derecho a los ciudadanos de acceder a esta información, además de determinar las

1 En base al art. 2 del Real Decreto 1090/2015 se entiende como EC un estudio clínico relativo a personas cuya finalidad puede ser: a) descubrir o comprobar los efectos clínicos, farmacológicos o demás efectos farmacodinámicos de uno o más medicamentos, b) identificar cualquier reacción adversa a uno o más medicamentos; o c) estudiar la absorción, la distribución, el metabolismo y la excreción de uno o más medicamentos, con el objetivo de determinar la seguridad y/o eficacia de dichos medicamentos.

${ }^{2}$ Normas para el diseño, dirección, realización, monitorización, auditoria, registro, análisis e informe del ensayo clínico que garantizan que los datos y los resultados obtenidos son precisos y creíbles, y que se han protegido los derechos, la integridad y la confidencialidad de los sujetos del ensayo. 
consecuencias jurídicas que pueden derivarse de su incumplimiento por parte de los investigadores y promotores del $\mathrm{EC}^{3}$.

Por lo tanto, todo EC ha de cumplir con un doble requerimiento: a) haber sido registrado previamente en una base de datos de un organismo regulatorio, y b) publicar los resultados que se deriven de los EC tras su finalización, independientemente de cuál sea su naturaleza.

En 2001 el Comité Internacional de Editores de Publicaciones Médicas (International Committee of Medical Journal Editors, ICMJE) impuso la obligación que todo EC de fase II, III y IV desarrollado a partir de 2005 tenía que ser registrado previo a su inicio. La guía de la Buena Práctica Clínica de la Conferencia Internacional de Armonización (International Conference on Harmonization, $\mathrm{ICH}^{4}$ ) hace referencia a que todo $\mathrm{EC}$ debe estar registrado en una base de datos accesible al público antes de la captación del primer sujeto, añadida en el artículo 35 de la versión de la Declaración de Helsinki de $2013^{5}$.

En cuanto a la publicación de los resultados, el principal problema radica en que no todos los EC que se llevan a cabo terminan siendo publicados en revistas científicas especializadas u otros medios de comunicación, sino que además tampoco se remiten a los organismos regulatorios donde previamente habían sido registrados. El motivo fundamental que esgrimen para esa "no-publicación" es que los resultados que obtienen son negativos (por ejemplo, el fármaco no es efectivo para el fin que perseguían) o no todo lo positivos que los investigadores desearían (por ejemplo, cuando el fármaco aunque tiene un grado de éxito considerable tiene efectos secundarios adversos).

\footnotetext{
${ }^{3}$ En base a la Ley 19/2013, de 9 de diciembre, de Transparencia, Acceso a la Información Púbica y Buen Gobierno.

${ }^{4}$ Proyecto colaborativo entre las entidades reguladoras de medicamentos de Europa, Japón y Estados Unidos para la calidad ética y científica aplicable al diseño, realización, registro y comunicación de los EC en los que participen seres humanos. Su principal resultado son las directrices de la BPC.

${ }^{5}$ Promulgada por la Asociación Médica Mundial (World Medical Association, WMA), es considerado como el documento más importante en la ética de la investigación con seres humanos. Es una guía de principios éticos que han de guiar a los investigadores que realizan EC con personas.
} 
Por ello, el Reglamento (EU) no 536/2014 del Parlamento Europeo y del Consejo ${ }^{6}$, de 16 de abril de 2014, sobre ensayos clínicos de medicamentos de uso humano establece, en su art. 67, la creación de una base de datos de acceso público en la que se registren todos los EC que se lleven a cabo en territorio europeo y se incluya toda la información relativa al EC: resumen, objeto y justificación de la investigación, protocolo de actuación. Lo más relevante de dicho reglamento es la obligación que impone que en el plazo de un año desde la finalización del EC se remitan a esas bases de datos los resultados, independientemente de si éstos son positivos o negativos.

De esta forma se consigue la difusión de los resultados del EC, y en caso de que éstos sean negativos, se evita que en un futuro se pueda volver a realizar dicho EC con el consiguiente gasto de recursos (humanos, tiempo, dinero, etc.).

A nivel nacional, el Real Decreto 1090/20157, de 4 de diciembre, por el que se regulan los ensayos clínicos con medicamentos, los Comités de Ética de la Investigación con medicamentos y el Registro Español de Estudios Clínicos va más allá del Reglamento 536/2014, ya que además de establecer en su art. 42 como requisito la remisión de los resultados del EC al Registro Español de Ensayos Clínicos ${ }^{8}$, redactados en un lenguaje sencillo y accesible al ciudadano sin especiales conocimientos científicos, obliga, según dicta el art. 48 a su publicación en revistas científicas, incluso siendo negativos.

\footnotetext{
${ }^{6}$ Deroga la Directiva 2001/20/CE del Parlamento Europeo y del Consejo, de 4 de abril de 2001, relativa a la aproximación de las disposiciones legales reglamentarias y administrativas de los Estados miembros sobre la aplicación de buenas prácticas clínicas en la realización de ensayos clínicos de medicamentos de uso humano.

${ }^{7}$ Deroga el Real Decreto 223/2004, de 6 de febrero, por el que se regulan los ensayos clínicos con medicamentos, en cuyo art. 27.3 se obligaba al promotor del EC a remitir a la Agencia Española de Medicamentos y Productos Sanitarios (AEMPS) y a los Comités Éticos de Investigación Clínica implicados un resumen del informe final sobre los resultados obtenidos en el plazo de un año desde la finalización del EC.

${ }^{8}$ Base de datos pública, de acceso libre y gratuito, dependiente de AEMPS.

Contiene la información de todos los EC con medicamentos realizados en

España, y una de sus funciones principales es garantizar que los resultados tanto positivos como negativos de los EC realizados están a disposición de la sociedad. Página-web: https://reec.aemps.es
} 
También encontramos esta obligación de informar sobre los resultados de los EC en la Ley 14/2007, de 3 de julio, de Investigación Biomédica en su art. 27.3

En EE.UU, la Agencia de Alimentos y Medicamentos (Food and Drug Agency, FDA ), promulgó la Public Law 110-85 en 2007, en la que además de desarrollar qué EC han de ser registrados en la base de datos de ClinicalTrials.gov, obliga a publicar los resultados obtenidos y los acontecimientos contrarios al EC dentro del año de su finalización.

Por lo tanto, el objetivo principal de esta investigación es doble. Por un lado, a través de los artículos que se han seleccionado y que analizan las publicaciones científicas derivadas de los resultados de los EC, determinar cuál es el grado de implementación de las políticas de publicación de resultados. Y, por otro lado, ver cuál es el tiempo que transcurre desde que finaliza un EC hasta que los investigadores hacen público los resultados, así como cuáles serían los motivos que condicionan que haya $\mathrm{EC}$ que finalmente no se publiquen.

De forma secundaria, pero no por ello, menos importante, se han analizado otras variables como son el tipo de revistas científicas en donde se hacen las publicaciones de los resultados, las posibles discrepancias entre el registro y la publicación del EC, o la veracidad de la naturaleza de los EC.

\section{Método}

\subsection{Estrategia de búsqueda}

La búsqueda de artículos se realizó durante el mes de noviembre de 2016 en las bases de datos de Pubmed (https://www.ncbi.nlm.nih.gov/pubmed/) y Google Académico (https://scholar.google.es/?hl=es). Para ello se procedió a lo siguiente: a) una estrategia de búsqueda (ver Tabla 1), b) determinar el campo de búsqueda ("Título"), y c) determinar los operadores booleanos (AND y OR).

\footnotetext{
${ }^{9}$ Agencia gubernamental responsable de la regularización de alimentos, medicamentos, cosméticos, aparatos médicos, productos biológicos y derivados sanguíneos.
} 


\section{Tabla 1. Estrategia de Búsqueda en Pubmed}

\begin{tabular}{|ll|}
\hline$N^{\circ}$. & Término de búsqueda \\
\hline \#1 & Publication \\
\hline \#2 & Dissemination \\
\hline$\# 3$ & Communication \\
\hline \#4 & $\# 1$ OR \#2 OR \#3 \\
\hline \#5 & "Randomised Clinical Trial” OR “EC” \\
& $\begin{array}{l}\text { OR "Controlled Study" OR } \\
\text { "Randomised Study" }\end{array}$ \\
\hline \#6 & \#4 AND \#5 \\
\hline
\end{tabular}

Fuente: elaboración propia

Los criterios de inclusión de los artículos fueron: a) que estuvieran publicados en revistas científicas ${ }^{10}$; b) que fueran estudios observacionales $^{11}$; c) que estuvieran escritos en lengua castellana $\mathrm{o}$ inglesa; y d) que la fecha de publicación fuera a partir de 2006, para comprobar, a nivel europeo, si la obligación impuesta por el art. 15.1 de la Directiva 2001/20/CE de cumplir con las BPC; y a nivel estatal, por el RD 223/2004, estaban siendo cumplidas por los investigadores.

\subsection{Variables analizadas}

Una vez seleccionados los artículos se analizaron las siguientes variables: a) características del estudio (autor, año, metodología y

\footnotetext{
${ }^{10}$ Se considera revista científica aquella publicación periódica en la que se intenta recoger el progreso de la ciencia a través de artículos originales, reseñas y monografías de un campo específico, los cuales son publicados por instituciones académicas o editoriales, y son revisados por un comité de especialistas antes de su publicación (peer review).

${ }^{11}$ Estudios de caracteres estadísticos y demográficos, ya sean de tipo sociológico o biológico -estudios epidemiológicos- en los que no hay intervención por parte del investigador, y éste se limita a medir las variables que define en el estudio.
} 
muestra), y b) análisis y principales resultados de las variables (variable analizada, resultados principales, y conclusiones).

\section{Resultados}

La búsqueda arrojó un total de 199 artículos, que tras eliminar los artículos duplicados en ambas bases de datos se redujeron a 170 . Después de revisar el título y/o resumen para confirmar su relación al tema de esta investigación, se excluyeron 141 artículos, y se procedió a revisar los textos completos de los 29 restantes. De éstos se tuvieron que eliminar 2 porque estaban escritos en japonés, otros 2 por estar en alemán, y 3 por no tener resumen o texto completo. Por lo tanto, los artículos analizados en esta revisión fueron finalmente 21 (ver figura 1).

\section{Figura 1. Diagrama de flujo PRISMA del proceso de selección de los artículos}

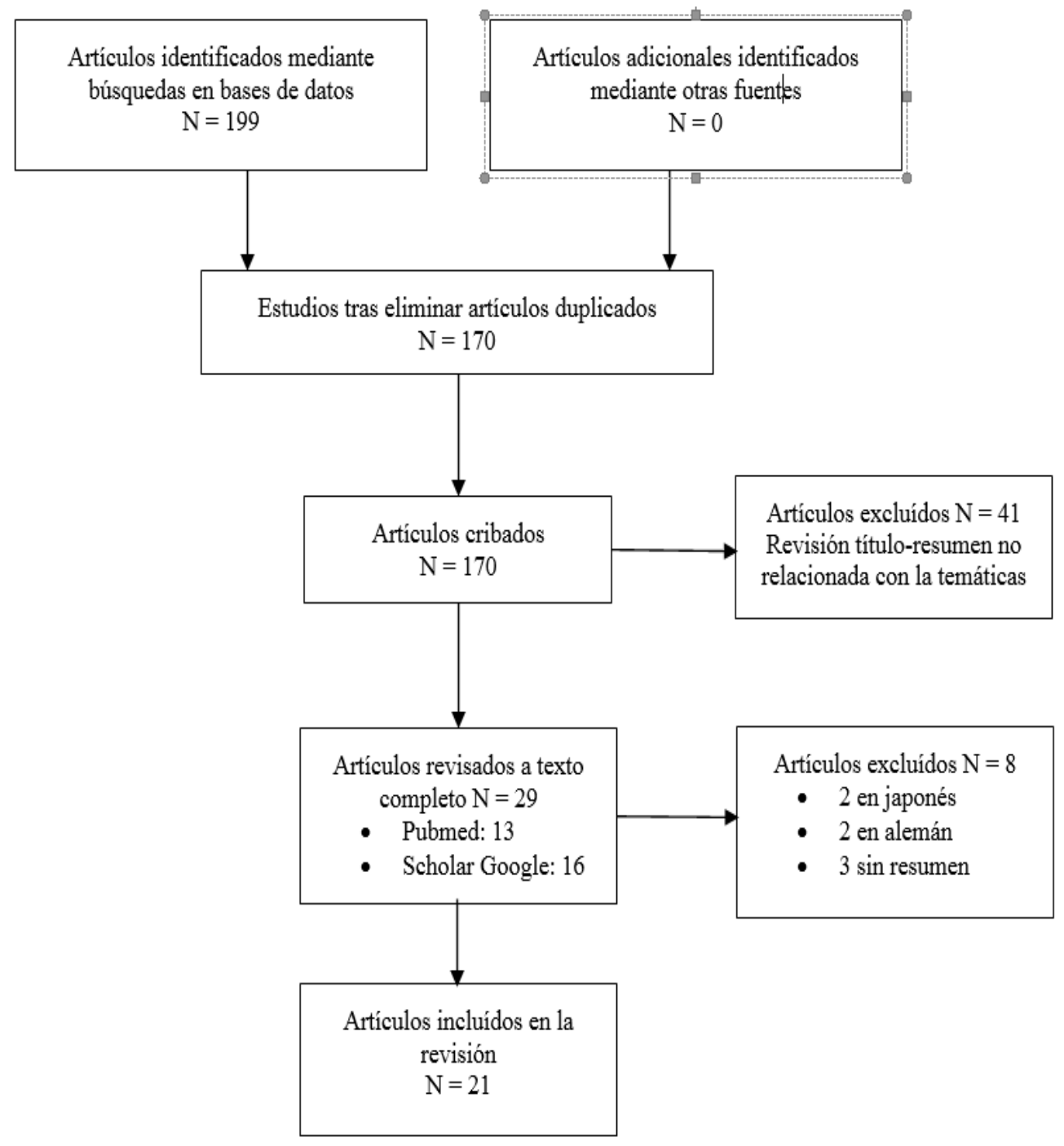




\subsection{Características de los estudios seleccionados}

La metodología que llevaron a cabo los artículos seleccionados se pueden agrupar en tres grupos:

Búsqueda en bases de datos: Medline, Pubmed, Cochrane, ClincialTrials.gov, Plos, etc.

Búsqueda en revistas científicas de alto factor de impacto (Impact Factor, $\left.\mathrm{IF}^{12}\right)$ : American Journal of Orthodontics and Dentofacial Orthopedics ${ }^{13}$, the British Journal of Oral and Maxilofacial Surgery ${ }^{14}$, the Journal of Endodontics $^{15}$, the Journal of the American Medical Association ${ }^{16}$, o la British Medical Journal ${ }^{17}$ entre otras ${ }^{18}$.

Recopilación de abstracts de EC que fueron remitidos a organizaciones, congresos o seminarios, como la Society of MaternalFetal Medicine, la Digestive Dissease Week, o el National Institute for Health Research.

La distribución de los años de publicación de los artículos seleccionados se distribuyen de la siguiente forma: 1 artículo en 2010 y 2015; 2 artículos en 2007, 2008 y 2014; 3 artículos en 2009, 2013 y 2016; y 4 artículos en 2012. En 2006 y 2011 no hay artículos publicados dentro de esta selección.

Las muestras que los autores analizaron para sus artículos varían de un estudio a otro, desde los $64 \mathrm{EC}$ en el artículo de Prenner et al. (2012) hasta los 1.336 EC en el de Ross et al. (2013). Por último, de los 21 artículos seleccionados sólo uno se escribió en castellano, Pérez-Mañá et al (2012).

\footnotetext{
${ }^{12} \mathrm{El}$ IF mide la repercusión que tiene una revista dentro de su comunidad científica comparándola con el resto de revistas ese mismo campo científico. Es calculado cada año por el Instituto para la Información Científica (Institute for Scientific Information, ISI).

${ }^{13}$ IF: $1.690, \mathrm{Q} 2$.

${ }^{14} \mathrm{IF}: 1.2378, \mathrm{Q} 3$.

${ }^{15} \mathrm{IF}: 2.904, \mathrm{Q} 1$.

${ }^{16} \mathrm{IF}: 27.684, \mathrm{Q} 1$.

${ }^{17} \mathrm{IF}: 19.697, \mathrm{Q} 1$.

${ }^{18} \mathrm{El}$ IF de estas revistas están extraídos del ISI Journal Citation Report de 2015.
} 
Tabla 2. Características de los artículos

\begin{tabular}{|c|c|c|}
\hline REF, AÑO & METODOLOGÍA & MUESTRA \\
\hline $\begin{array}{l}\text { Bhinder et } \\
\text { al, } 2014\end{array}$ & $\begin{array}{l}\text { Búsqueda de EC de cardiología que } \\
\text { tuvieran } 2 \text { o más publicaciones en } \\
\text { revistas indexadas }\end{array}$ & $72 \mathrm{EC}$ \\
\hline $\begin{array}{l}\text { Blackwell, } \\
2009\end{array}$ & $\begin{array}{l}\text { Abstracts de EC de la Society of Materna- } \\
\text { Fetal Medicine entre } 2000-2002\end{array}$ & 2012 abstracts \\
\hline $\begin{array}{l}\text { Hoeg et al, } \\
2009\end{array}$ & $\begin{array}{l}\text { Abstracts de EC de } 1997,1999 \text { y } 2001 \text { de } \\
\text { la American Asociation of Clinical Oncology }\end{array}$ & $559 \mathrm{EC}$ \\
\hline $\begin{array}{l}\text { Hopewell et } \\
\text { al, } 2009\end{array}$ & $\begin{array}{l}\text { Búsqueda Cochrane, Medline, Embase y } \\
\text { Scienc Citation Index }\end{array}$ & No suministrada \\
\hline $\begin{array}{l}\text { Hopewell et } \\
\text { al, } 2007\end{array}$ & $\begin{array}{l}\text { Búsqueda Cochrane, Medline, Embase y } \\
\text { Scienc Citation Index }\end{array}$ & $196 \mathrm{EC}$ \\
\hline $\begin{array}{l}\text { Hurley et al, } \\
2012\end{array}$ & $\begin{array}{l}\text { Búsqueda en "ClinicalTrial.gov" } 1998 \text { - } \\
2010 .\end{array}$ & $142 \mathrm{EC}$ \\
\hline $\begin{array}{l}\text { Jones et al, } \\
2013\end{array}$ & $\begin{array}{l}\text { Búsqueda en PubMed, Google Scholar y } \\
\text { Embase de EC con más de } 500 \\
\text { participantes. }\end{array}$ & $585 \mathrm{EC}$ \\
\hline $\begin{array}{l}\text { Koletsi et al, } \\
2012\end{array}$ & $\begin{array}{l}\text { Búsqueda de EC en bases de datos de } \\
\text { diferentes revistas científicas. }\end{array}$ & 222 EC. \\
\hline $\begin{array}{l}\text { Kottachchi } \\
\text { et al, } 2010\end{array}$ & $\begin{array}{l}\text { Abstracts de EC de fase II de la Digestive } \\
\text { Disease Week (1998 - 2003) }\end{array}$ & $82 \mathrm{EC}$ \\
\hline $\begin{array}{l}\text { Lee } e t \text { al, } \\
2008\end{array}$ & $\begin{array}{l}\text { Búsqueda de los EC aprobados por la } \\
\text { FDE sobre medicamentos entre } 1998- \\
2000\end{array}$ & $909 \mathrm{EC}$ \\
\hline $\begin{array}{l}\text { Pérez-Mañá, } \\
2012\end{array}$ & $\begin{array}{l}\text { Búsqueda de los registros primarios en } \\
\text { bases de datos. }\end{array}$ & No suministrada \\
\hline $\begin{array}{l}\text { Prenner et } \\
\text { al, } 2012\end{array}$ & $\begin{array}{l}\text { Búsqueda de EC en la base de datos de } \\
\text { ClinicalTrials.gov }\end{array}$ & $64 \mathrm{EC}$ \\
\hline $\begin{array}{l}\text { Ross et al, } \\
2013\end{array}$ & $\begin{array}{l}\text { Búsqueda de EC de } 2009 \text { en Medline } \\
\text { registrados en ClinicalTrials.gov }\end{array}$ & $1336 \mathrm{EC}$ \\
\hline $\begin{array}{l}\text { Sibanda et al, } \\
2016\end{array}$ & $\begin{array}{l}\text { Búsqueda deEC registrados en } 2009 \text { y } \\
2010 \text { en bases de datos: Medline, Plos, } \\
\text { SAMJ, etc. }\end{array}$ & $79 \mathrm{EC}$ \\
\hline
\end{tabular}




\begin{tabular}{|c|c|c|}
\hline REF, AÑO & METODOLOGÍA & MUESTRA \\
\hline $\begin{array}{l}\text { Scott et al, } \\
2015\end{array}$ & $\begin{array}{l}\text { EC publicados entre } 01 / 01 / 2009- \\
31 / 07 / 2013 \text { en } 5 \text { revistas científicas de } \\
\text { psiquiatría adheridas al ICMJE, y } \\
\text { llevados a cabo a partir de } 01 / 07 / 2005 \text {. }\end{array}$ & $181 \mathrm{EC}$ \\
\hline $\begin{array}{l}\text { Son et al, } \\
2016\end{array}$ & $\begin{array}{l}\text { Búsqueda de EC en ClinicalTrials.gov } \\
\text { sobre enfermedades degenerativas de la } \\
\text { espina dorsal. }\end{array}$ & No suministrada \\
\hline $\begin{array}{l}\text { Tompson et } \\
\text { al, } 2016\end{array}$ & $\begin{array}{l}\text { Búsquedas en instituciones respaldadas } \\
\text { por la NIHR. }\end{array}$ & $286 \mathrm{EC}$ \\
\hline $\begin{array}{l}\text { Turer et al, } \\
2007\end{array}$ & Búsqueda de EC aprobados en 1998. & $217 \mathrm{EC}$ \\
\hline $\begin{array}{l}\text { Vawdrey et } \\
\text { al, } 2013\end{array}$ & $\begin{array}{l}\text { Búsqueda en Clinica'Trials.gov de EC de } \\
\text { registros electrónicos en salud }\end{array}$ & No suministrada \\
\hline $\begin{array}{l}\text { Von Elm et } \\
\text { al, } 2008\end{array}$ & $\begin{array}{l}\text { Análisis de los EC remitidos al Comité } \\
\text { Ético de la Universidad de Bernentre } \\
1988 \text { - } 1998 .\end{array}$ & $\begin{array}{l}451 \text { protocolos } \\
\text { de EC y } 375 \\
\text { artículos }\end{array}$ \\
\hline $\begin{array}{l}\text { Walker et al, } \\
2014\end{array}$ & $\begin{array}{l}\text { Búsqueda de EC en las bases de datos } \\
\text { del BMJ y del JAMA. }\end{array}$ & $\begin{array}{l}76 \text { EC ( } 40 \mathrm{BMJ} \\
\text { y } 36 \text { JAMA) }\end{array}$ \\
\hline
\end{tabular}

Fuente: elaboración propia

\subsection{Características de las variables analizadas}

Las variables que se han analizado en los artículos seleccionados fueron las siguientes:

\section{A. Grado de publicación de los resultados de los EC}

La mitad de los artículos seleccionados trata de forma principal esta variable, y a la conclusión a la que llegan es que la ratio de publicación oscila entre el 50\% - 60\%, salvo casos concretos que llegan al 70\%.

Los artículos cuya ratio de publicación no superaba el $25 \%$ son los de Blackwell et al. (2009) con un 2,5\% y el de Pérez-Mañá et al. (2012) con ese $25 \%$. Los que estaban entre el 25 y el $50 \%$ son los de Lee et al. (2008), Hurley et al. (2012) y Sibanda et al. (2016) con una ratio del $43 \%, 44 \%$ y $48 \% \%$, respectivamente. Son 6 artículos los que conforman el grupo cuya ratio de publicación oscila entre el 50 y el 
75\%, Turer et al (2007) con un 50'7\%; Von Elm et al. (2008) con un $51 ' 7 \%$; Prenner et al. (2011) con un 54\%; Tompson et al. (2016) con un 56\%; Hoeg et al. (2009) con un 60\% $\%$; y Jones et al. (2013) con un $70{ }^{\prime} 7 \%$. El único artículo cuyos EC analizados superaban la barrera del $75 \%$ es el de Vawdrey et al. (2013), con un $76 \%$ de ratio de publicación.

\section{B. Tiempo transcurrido para la publicación desde la finalización del EC}

Ya hemos visto al inicio la existencia de normativa legal que obliga a la publicación de los resultados de los EC. Sin embargo, muy pocos investigadores cumplen con este requerimiento, y los que lo hacen no cumplen el plazo establecido; un año desde la finalización del EC.

Los artículos que tratan esta variable se agrupan en continuación en función de los meses que tardaron en publicarse los resultados de los estudios que analizaron:

Dentro de los 12 primeros meses a la finalización de la investigación están los artículos de Pérez-Mañá et al. (2013) y el de Tompson et al. (2016). Entre los 12 y los 36 meses; los artículos de Ross et al. (2013) con 21 meses, y Hurley et al. (2013) con 36 meses. Por último, a partir de los 36 meses tras su finalización, los artículos de Hoeg et al. (2009) con 41 meses, y Jones et al. (2013) con 60 meses.

\section{Factores influyentes en la publicación de los resultados del EC}

Según los artículos analizados el principal condicionante para que un EC se publique es el resultado que se ha obtenido. Es decir, un estudio con resultados positivos tiene más posibilidades de ser publicado frente a otro con resultados negativos, o que esos resultados no sean lo suficientemente positivos para los investigadores. Esta no publicación contraviene uno de los requisitos que hacen que un EC sea ético, según Ezekiel Emanuel en su artículo "What makes clinical research ethicl?," ya que para que dicho EC tenga validez científica, es decir, que produzca hechos científicos, los investigadores se han de asegurar la publicación de los resultados, independientemente de su naturaleza. 
Hopewell et al. (2009) determinaron que el 73\% de los EC que analizaron en bases de datos como Medline o Embase tenían resultados positivos frente al $41 \%$ con resultados negativos. Anteriormente Hopewell et al. (2007) vieron que un EC que tenía resultados positivos se publicaba a los 4 años de haber sido realizado, y en cambio se tardaba hasta 8 años en publicar si el EC tenía resultados negativos.

En Kottachchi et al. (2010) concluyeron que los EC que habían sido remitidos a la Digestive Diseasse Week entre 1998 - 2003) y que tenían resultados negativos tenían más posibilidades de no ser publicados al menos en los dos primeros años tras su finalización. Vawdrey et al. (2013) vieron que de todos los EC que se habían publicado el 74\% tenían resultados positivos, el 21\% resultados neutros, y el 5\% resultados negativos.

Otro factor que puede influir a la hora de publicar es el origen de la financiación del EC, por lo que hay artículos que intentan determinar esta hipótesis. En Son et al. (2016) vieron si había diferencia en cuanto a la ratio de publicación de EC sobre enfermedades degenerativas de la espina dorsal que se incluyen en ClinicalTrials.gov en función de su financiación. El resultado que obtuvieron fue que había un 37'8\% de EC publicados cuya financiación provenía de la industria farmacéutica, frente a un $40{ }^{\prime} 5 \%$ que no tenían financiación de este tipo.

En el estudio de Turer et al. (2007) además de determinar la ratio de publicación, concluyeron que aquellos EC que tenían una financiación interna tenían una baja ratio de publicación de aproximadamente el 50\%. Von Elm et al. (2008) encontraron que 336 EC publicados fueron financiados por la industria farmacéutica y 47 EC tuvieron únicamente financiación interna.

\section{Tipo de revistas científicas que publican los resultados de $\operatorname{los} \mathrm{EC}$}

En el artículo de Bhinder et al. (2014) se calcula cuál es el IF de las revistas científicas en las que se publican por primera vez los resultados de los EC, siendo éste de 27,01. En cambio, si había una segunda publicación, la revista en la que se publicaba tenía un 11,72 de IF, es decir, el factor de impacto de la revista bajaba. 


\section{E. Discrepancias entre el registro y la publicación}

Walker et al. (2014) determinaron que en el 47\% de los EC de la base de datos British Journal Medicine (BJM) había discrepancias entre lo que se había registrado al comienzo del EC en cuanto a los protocolos ${ }^{19}$ de actuación que iban a seguir en comparación con los protocolos que siguieron y que quedaron reflejados en la publicación correspondiente. En cambio, en los EC del Journal of the American Medical Association (JAMA), estas discrepancias sólo se daban en un $19 \%$.

\section{F. Veracidad de la naturaleza de los EC}

Koletsi et al. (2012) analizaron los EC en revistas científicas como the Journal of Endodontics, la American Journal of Orthodontics o la British Medical Journal entre otras. Determinaron que sólo 88 de los 222 eran realmente EC, más de la mitad, 107, eran de un "estatus difuso" por una inadecuada descripción de información, y el resto, 27, no correspondían a EC.

\section{Tabla 3. Análisis y principales resultados de las variables evaluadas}

\begin{tabular}{|c|c|c|c|}
\hline $\begin{array}{l}\text { REF, } \\
\text { AÑO }\end{array}$ & $\begin{array}{l}\text { VARIABLE } \\
\text { ANALIZADA }\end{array}$ & $\begin{array}{l}\text { RESULTADOS } \\
\text { PRINCIPALES }\end{array}$ & CONCLUSIONES \\
\hline $\begin{array}{l}\text { Bhinder et } \\
\text { al, } 2014\end{array}$ & $\begin{array}{l}\text { Valorar el IF entre } \\
\text { la revista donde } \\
\text { primero fue } \\
\text { publicado el EC } \\
\text { respecto de las } \\
\text { siguientes revistas } \\
\text { donde también se } \\
\text { haya publicado. }\end{array}$ & $\begin{array}{l}\text { El IF de las } \\
\text { primeras revistas } \\
\text { donde se publicaba } \\
\text { era de } 27.01 \\
\text { mientras que en las } \\
\text { siguientes } \\
\text { publicaciones era } \\
\text { de } 11,72 \text {. }\end{array}$ & $\begin{array}{l}\text { La primera } \\
\text { publicación de los } \\
\text { resultados de los EC } \\
\text { se hace en revistas con } \\
\text { alto IF. }\end{array}$ \\
\hline $\begin{array}{l}\text { Blackwell, } \\
2009\end{array}$ & $\begin{array}{l}\text { Determinar la ratio } \\
\text { abstracts } \\
\text { presentados en el } \\
\text { congreso anual con } \\
\text { su estado de } \\
\text { publicación }\end{array}$ & $\begin{array}{l}50 \text { abstracts fueron } \\
\text { publicados como } \\
\text { artículos científicos }\end{array}$ & $\begin{array}{l}\text { Hay un sesgo positivo } \\
\text { en la medicina } \\
\text { materno-fetal. }\end{array}$ \\
\hline
\end{tabular}

${ }^{19}$ Documento de vital importancia en el que se recoge cuál es su objetivo, qué diseño tendrá, cómo se analizarán los datos, y hasta que no es aprobado por un comité no puede iniciarse el EC. 


\begin{tabular}{|c|c|c|c|}
\hline $\begin{array}{l}\text { REF, } \\
\text { AÑO }\end{array}$ & $\begin{array}{l}\text { VARIABLE } \\
\text { ANALIZADA }\end{array}$ & $\begin{array}{l}\text { RESULTADOS } \\
\text { PRINCIPALES }\end{array}$ & CONCLUSIONES \\
\hline $\begin{array}{l}\text { Hoeg et al, } \\
2009\end{array}$ & $\begin{array}{l}\text { Si los abstracts } \\
\text { remitidos a la } \\
\text { American Asociation } \\
\text { of Clinical Oncology se } \\
\text { habían publicado }\end{array}$ & $\begin{array}{l}\text { El 60’8\% se } \\
\text { publicó en una } \\
\text { media de } 41 \text { meses. } \\
\text { A los } 5 \text { años se } \\
\text { habían publicado } \\
\text { un } 65^{\prime} 9 \%(1997) \text {, } \\
627 \%(1999) \text { y } \\
57 \%(2001) .\end{array}$ & $\begin{array}{l}\text { Al menos la mitad de } \\
\text { los EC en fase II } \\
\text { seguían sin publicarse } \\
\text { a los } 10 \text { años de su } \\
\text { finalización. }\end{array}$ \\
\hline $\begin{array}{l}\text { Hopewell } \\
\text { et al, } 2009\end{array}$ & $\begin{array}{l}\text { Determinar si } \\
\text { influyen los } \\
\text { resultados } \\
\text { obtenidos en un } \\
\text { EC (2007) a la hora } \\
\text { de publicarse. }\end{array}$ & $\begin{array}{l}\text { El } 73 \% \text { de los EC } \\
\text { con resultados } \\
\text { positivos se } \\
\text { publicaban, frente } \\
\text { al } 41 \% \text { de } \\
\text { resultados } \\
\text { negativos. }\end{array}$ & $\begin{array}{l}\text { Los EC con resultados } \\
\text { positivos tienen más } \\
\text { posibilidades de ser } \\
\text { publicados que los de } \\
\text { resultados negativos }\end{array}$ \\
\hline $\begin{array}{l}\text { Hopewell } \\
\text { et al, } 2007\end{array}$ & $\begin{array}{l}\text { Determinar si } \\
\text { influyen los } \\
\text { resultados } \\
\text { obtenidos en un } \\
\text { EC (2005) a la hora } \\
\text { de publicarse. }\end{array}$ & $\begin{array}{l}\text { Un EC con } \\
\text { resultados } \\
\text { positivos se } \\
\text { publica a los 4- } \\
\text { 5años, frente a los } \\
\text { 6-8años de los de } \\
\text { resultado } \\
\text { negativos. }\end{array}$ & $\begin{array}{l}\text { Los EC con resultados } \\
\text { positivos tienen más } \\
\text { posibilidades de ser } \\
\text { publicados que los de } \\
\text { resultados negativos }\end{array}$ \\
\hline $\begin{array}{l}\text { Hurley et } \\
\text { al, } 2012\end{array}$ & $\begin{array}{l}\text { Grado de } \\
\text { publicación de EC } \\
\text { de fibrosis quística. }\end{array}$ & $\begin{array}{l}\text { Sólo } 62 \text { se habían } \\
\text { publicado en un } \\
\text { plazo de } 3 \text { años }\end{array}$ & $\begin{array}{l}\text { Se tarda bastante } \\
\text { tiempo en publicar los } \\
\text { resultados y no todos } \\
\text { se publican. }\end{array}$ \\
\hline $\begin{array}{l}\text { Jones et al, } \\
2013\end{array}$ & $\begin{array}{l}\text { Cuánto tiempo } \\
\text { transcurre en } \\
\text { publicarse los EC } \\
\text { registrados en } \\
\text { ClinicalTrials.gov }\end{array}$ & $\begin{array}{l}171 \text { EC estaban sin } \\
\text { publicar, y el } \\
\text { tiempo medio } \\
\text { estimado era de } 60 \\
\text { meses. }\end{array}$ & $\begin{array}{l}\text { Era común } \\
\text { encontrarse con EC } \\
\text { no publicados. }\end{array}$ \\
\hline $\begin{array}{l}\text { Koletsi et } \\
\text { al, } 2012\end{array}$ & $\begin{array}{l}\text { Si los EC } \\
\text { publicados en las } \\
\text { revistas científicas } \\
\text { son realmente EC. }\end{array}$ & $\begin{array}{l}88 \text { eran realmente } \\
\text { EC; } 107 \text { eran de un } \\
\text { estatus confuso; y } \\
27 \text { no eran EC. }\end{array}$ & $\begin{array}{l}\text { Es necesario que haya } \\
\text { un riguroso y claro } \\
\text { registro de EC. }\end{array}$ \\
\hline
\end{tabular}




\begin{tabular}{|c|c|c|c|}
\hline $\begin{array}{l}\text { REF, } \\
\text { AÑO }\end{array}$ & $\begin{array}{l}\text { VARIABLE } \\
\text { ANALIZADA }\end{array}$ & $\begin{array}{l}\text { RESULTADOS } \\
\text { PRINCIPALES }\end{array}$ & CONCLUSIONES \\
\hline $\begin{array}{l}\text { Kottachchi } \\
\text { et al, } 2010\end{array}$ & $\begin{array}{l}\text { Si la publicación de } \\
\text { los abstracts de los } \\
\text { EC puede reducir la } \\
\text { negativa a publicar } \\
\text { los resultados. }\end{array}$ & $\begin{array}{l}\text { Los abstracts con } \\
\text { resultados } \\
\text { negativos tienen } \\
\text { más posibilidades } \\
\text { de no ser } \\
\text { publicados, al } \\
\text { menos en los dos } \\
\text { primeros años tras } \\
\text { su finalización. }\end{array}$ & $\begin{array}{l}\text { El uso de los abstracts } \\
\text { puede reducir el sesgo } \\
\text { que existe en la } \\
\text { publicación de los } \\
\text { resultados de los EC. }\end{array}$ \\
\hline $\begin{array}{l}\text { Lee et al, } \\
2008\end{array}$ & $\begin{array}{l}\text { La proporción de } \\
\text { EC sobre } \\
\text { medicamentos que } \\
\text { se publican } \\
\text { aprobados por la } \\
\text { FDA. }\end{array}$ & $\begin{array}{l}\text { El } 43 \% \text { de esos } \\
\text { EC estaba } \\
\text { publicados. }\end{array}$ & $\begin{array}{l}\text { Más de la mitad de los } \\
\text { EC siguen sin } \\
\text { publicarse pasados } 5 \\
\text { años de su aprobación. }\end{array}$ \\
\hline $\begin{array}{l}\text { Pérez- } \\
\text { Mañá, } \\
2012\end{array}$ & $\begin{array}{l}\text { El registro de EC y } \\
\text { su posterior ratio de } \\
\text { publicación. }\end{array}$ & $\begin{array}{l}\text { Solo un } 25 \% \text { de los } \\
\text { EC de } \\
\text { ClinicalTrials.gov } \\
\text { están publicados al } \\
\text { año de su } \\
\text { finalización }\end{array}$ & $\begin{array}{l}\text { El registro y } \\
\text { publicación de los EC } \\
\text { tendría que ser de } \\
\text { obligado } \\
\text { cumplimiento a nivel } \\
\text { mundial. }\end{array}$ \\
\hline $\begin{array}{l}\text { Prenner et } \\
\text { al, } 2012\end{array}$ & $\begin{array}{l}\text { Evaluar el ratio de } \\
\text { publicación de los } \\
\text { EC sobre la } \\
\text { degeneración } \\
\text { macular derivado } \\
\text { por la edad }\end{array}$ & $\begin{array}{l}\text { El 54\% fue } \\
\text { publicado. }\end{array}$ & $\begin{array}{l}\text { Se publicó algo más de } \\
\text { la mitad de los EC } \\
\text { sobre la degeneración } \\
\text { macular. }\end{array}$ \\
\hline $\begin{array}{l}\text { Ross et al, } \\
2013\end{array}$ & $\begin{array}{l}\text { Cuánto tardaban en } \\
\text { publicarse los } \\
\text { resultados de los } \\
\text { EC de } 2009 .\end{array}$ & $\begin{array}{l}\text { La media de } \\
\text { publicación era de } \\
21 \text { meses, y la } \\
\text { mayoría eran } \\
\text { financiados por } \\
\text { organización no } \\
\text { comerciales. }\end{array}$ & $\begin{array}{l}\text { De media se tardan } 2 \\
\text { años en publicar los } \\
\text { resultados. }\end{array}$ \\
\hline $\begin{array}{l}\text { Sibanda et } \\
\text { al, } 2016\end{array}$ & $\begin{array}{l}\text { La ratio de } \\
\text { publicación de los } \\
\text { EC llevados a cabo } \\
\text { en Sudáfrica. }\end{array}$ & $\begin{array}{l}\text { Sólo el } 48,6 \% \text { se } \\
\text { había publicado, y } \\
\text { de ellos el } 82,9 \% \\
\text { tenía resultados } \\
\text { positivos. }\end{array}$ & $\begin{array}{l}\text { Ausencia de } \\
\text { información completa } \\
\text { proveniente de los EC. }\end{array}$ \\
\hline
\end{tabular}




\begin{tabular}{|c|c|c|c|}
\hline $\begin{array}{l}\text { REF, } \\
\text { AÑO }\end{array}$ & $\begin{array}{l}\text { VARIABLE } \\
\text { ANALIZADA }\end{array}$ & $\begin{array}{l}\text { RESULTADOS } \\
\text { PRINCIPALES }\end{array}$ & CONCLUSIONES \\
\hline $\begin{array}{l}\text { Scott et al, } \\
2015\end{array}$ & $\begin{array}{l}\text { Determinar si los } \\
\text { EC publicados en } \\
\text { las revistas de } \\
\text { ICMJE se habían } \\
\text { registrado } \\
\text { previamente, si } \\
\text { había discrepancia } \\
\text { con lo publicado, y } \\
\text { si había relación } \\
\text { entre su registro y } \\
\text { su fuente de } \\
\text { financiación. }\end{array}$ & $\begin{array}{l}\text { El 11'6\% no } \\
\text { estaban } \\
\text { registrados, y el } \\
33^{\prime} 7 \% \text { estaban } \\
\text { registrados con } \\
\text { anterioridad a su } \\
\text { comienzo. } \\
\text { El 20’4\% tenía un } \\
\text { POMs y de ellos se } \\
\text { había seleccionado } \\
\text { los resultados a } \\
\text { publicar en un } \\
27^{\prime} 6 \% \text {. }\end{array}$ & $\begin{array}{l}\text { Menos del 15\% de los } \\
\text { EC fueron registrados } \\
\text { sin cambios en su } \\
\text { POMs. Además hay } \\
\text { que esforzarse en } \\
\text { resaltar el valor del } \\
\text { registro de los EC. }\end{array}$ \\
\hline $\begin{array}{l}\text { Son } e t \\
\text { al,2016 }\end{array}$ & $\begin{array}{l}\text { Si el tipo de } \\
\text { financiación del EC } \\
\text { influye a la hora de } \\
\text { publicar. }\end{array}$ & $\begin{array}{l}\text { Un } 37^{\prime} 8 \% \text { de los } \\
\text { EC financiado por } \\
\text { la industria } \\
\text { farmacéutica } \\
\text { estaba publicado, } \\
\text { frente a un } 40 \text { '5\% } \\
\text { que no tenía } \\
\text { financiación. }\end{array}$ & $\begin{array}{l}\text { No hay diferencia en } \\
\text { las ratios de } \\
\text { publicación de los EC } \\
\text { en función de su } \\
\text { fuente de financiación. }\end{array}$ \\
\hline $\begin{array}{l}\text { Tompson } \\
\text { et al, } 2016\end{array}$ & $\begin{array}{l}\text { Determinar la } \\
\text { proporción de EC } \\
\text { registrados que se } \\
\text { acaban publicando. }\end{array}$ & $\begin{array}{l}\text { Un } 1 ’ 4 \% \text { no } \\
\text { estaban } \\
\text { registrados, pero sí } \\
\text { publicados. Un } \\
56 \% \text { estaban } \\
\text { publicados, y de } \\
\text { esos un } 25 \% \\
\text { dentro de los } \\
\text { primeros } 12 \text { meses. }\end{array}$ & $\begin{array}{l}\text { Hay establecida una } \\
\text { auditoría interna en } \\
\text { NIHR que obliga al } \\
\text { registro de los EC. }\end{array}$ \\
\hline
\end{tabular}




\begin{tabular}{|c|c|c|c|}
\hline $\begin{array}{l}\text { REF, } \\
\text { AÑO }\end{array}$ & $\begin{array}{l}\text { VARIABLE } \\
\text { ANALIZADA }\end{array}$ & $\begin{array}{l}\text { RESULTADOS } \\
\text { PRINCIPALES }\end{array}$ & CONCLUSIONES \\
\hline $\begin{array}{l}\text { Turer et al, } \\
2007\end{array}$ & $\begin{array}{l}\text { La ratio de } \\
\text { publicación de los } \\
\text { EC, así como qué } \\
\text { factores están } \\
\text { asociados en su } \\
\text { difusión. }\end{array}$ & $\begin{array}{l}110 \text { EC habían } \\
\text { sido publicados. } \\
52 \text { de los } 87 \text { no } \\
\text { publicados no } \\
\text { había información } \\
\text { alguna. } \\
\text { Los EC } \\
\text { financiados } \\
\text { internamente } \\
\text { tenían una ratio de } \\
\text { publicación baja. }\end{array}$ & $\begin{array}{l}\text { Mecanismos para } \\
\text { asegurar los resultados } \\
\text { de los EC son } \\
\text { necesarios. }\end{array}$ \\
\hline $\begin{array}{l}\text { Vawdrey et } \\
\text { al, } 2013\end{array}$ & $\begin{array}{l}\text { La ratio de EC no } \\
\text { publicados sobre } \\
\text { registros } \\
\text { electrónicos, y } \\
\text { tratar su posible } \\
\text { sesgo a la hora de } \\
\text { publicar }\end{array}$ & $\begin{array}{l}\text { Un } 76 \% \text { tenía } \\
\text { publicaciones con } \\
\text { sus resultados } \\
\text { ( } 74 \% \text { positivo, } \\
21 \% \text { neutro, } 4 \% \\
\text { negativo) }\end{array}$ & $\begin{array}{l}\text { La ratio de no } \\
\text { publicaciones en este } \\
\text { campo es similar a la } \\
\text { de otros campos } \\
\text { médicos }\end{array}$ \\
\hline $\begin{array}{l}\text { Von Elm } \\
\text { et al, } 2008\end{array}$ & $\begin{array}{l}\text { Ver la ratio de } \\
\text { publicación de EC } \\
\text { e identificar } \\
\text { factores que } \\
\text { influyen en su } \\
\text { publicación o no } \\
\text { publicación. }\end{array}$ & $\begin{array}{l}233 \text { protocolos } \\
\text { tuvieron al menos } \\
1 \text { publicación; } 366 \\
\text { tuvieron } \\
\text { financiación } \\
\text { comercial, y } 47 \\
\text { ningún tipo de } \\
\text { financiación }\end{array}$ & $\begin{array}{l}\text { Sólo la mitad de los } \\
\text { EC fueron publicados. } \\
\text { Un ECde financiación } \\
\text { no comercial tiene } \\
\text { posibilidades de ser } \\
\text { publicado. }\end{array}$ \\
\hline $\begin{array}{l}\text { Walker et } \\
\text { al, } 2014\end{array}$ & $\begin{array}{l}\text { Determinar el } \\
\text { grado de } \\
\text { consistencia entre la } \\
\text { información } \\
\text { contenida en el EC } \\
\text { y la información } \\
\text { contenida en su } \\
\text { publicación. }\end{array}$ & $\begin{array}{l}\text { El 98\% de los EC } \\
\text { se había registrado } \\
\text { antes de su } \\
\text { publicación. } \\
\text { Había un } 47 \% \text { de } \\
\text { discrepancias en } \\
\text { los del BJM y un } \\
\text { 19\% en los del } \\
\text { JAMA. }\end{array}$ & $\begin{array}{l}\text { No tiene sentido } \\
\text { obligar al registro de } \\
\text { los EC si hay } \\
\text { discrepancia entre lo } \\
\text { que se registra y lo que } \\
\text { se publica, salvo que } \\
\text { se reporte esa } \\
\text { modificación }\end{array}$ \\
\hline
\end{tabular}

Fuente: elaboración propia 


\subsection{Conclusiones de los artículos seleccionados}

Las conclusiones principales que se pueden extraer de esta revisión son que hay un doble sesgo: a) en función de la publicación o no de los resultados de la investigación; y b) en función de su publicación tras la finalización de los EC, si se produce de forma inmediata o se demora en el tiempo. Ambos sesgos son provocados fundamentalmente por la naturaleza de los resultados: si han sido positivos o negativos.

Para cumplir con las obligaciones éticas y legales habría que a) establecer un registro obligatorio para todo EC que se celebre y b) que el público tuviera acceso a los resultados del EC a través de fuentes como las bases de datos de los organismos donde se registran usando un lenguaje comprensible ya que no todos los potenciales usuarios pueden tener conocimientos científicos concretos.

Vemos también que aquellos investigadores que deciden dar a conocer los resultados de sus investigaciones tienden a publicar en revistas científicas con un alto IF. Esto es de vital importancia para el desarrollo profesional de los investigadores a la hora de adquirir reputación académica a nivel internacional.

Estableciendo ese registro obligatorio, se favorecería que no hubiera discrepancias entre lo que se registra previamente en el protocolo del EC con lo que se termina publicando ya que todo cambio en el protocolo tiene que ser notificado al organismo donde se ha registrado y lo ha validado, ya que se puede amenazar los intereses de los pacientes, se devalúa el trabajo realizado, y es una pérdida de recursos humanos y económicos.

Y como última conclusión a la que se llega es que hay muchos EC que no cumplen los requisitos establecidos en las distintas normas legales, por lo que no tendrían que haber sido considerados como tales ni haber sido llevados a cabo hasta que hubieran sido subsanadas esas deficiencias.

\section{Discusión}

\subsection{Aspectos a destacar}

Los resultados negativos o poco favorecedores de los EC condicionan que no se acaben publicando, o en caso de que se publiquen, sea pasando muchos meses tras su finalización. Esto 
provoca, entre otras cosas, posibles repeticiones del mismo EC por otros investigadores con el consiguiente gasto de recursos, tiempo y dinero, y además, ayudaría a que los investigadores, tanto los que llevan a cabo el EC como el resto de investigadores, aprendieran de esos errores.

Para evitar ese sesgo a la hora de publicar los resultados, se hace indispensable un registro exhaustivo y firme de los EC. De esta forma, se pueden controlar todos los EC que se están desarrollando y obligando a la publicación de sus resultados en el plazo legal establecido, independientemente de cuál sea su naturaleza.

\subsection{Recomendaciones}

Dentro del protocolo del EC se debería establecer una obligación de publicar los resultados obtenidos, independientemente de su naturaleza o del grado de satisfacción de los investigadores.

Una segunda obligación debería consistir en informar al registro de EC sobre todas aquellas publicaciones que se deriven del EC, para que el acceso y difusión a esos resultados sea más accesible no sólo a la comunidad científica, sino al resto de la sociedad.

Aunque hay imposiciones legales para registrar y publicar los resultados de los EC, no hay imposición de sanciones de ningún tipo por su incumplimiento. Esto favorece este sesgo ya que los investigadores que obtengan resultados negativos decidirán no publicar al no haber sanciones (pecuniarias, administrativas, etc.).

\subsection{Limitaciones}

Las limitaciones de este son que a la hora de hacer la estrategia de búsqueda no se ha realizado ningún tipo de truncamiento en los términos para poder obtener un mayor número de resultados. También no haber seleccionado los artículos anteriores a 2006 y aquellos que no fueran en los idiomas seleccionados (español e inglés).

En futuros análisis se aconseja la utilización de truncamientos y no discriminar por año de publicación o idioma del artículo para un mejor análisis de resultados y conclusiones. 


\section{Conclusiones}

La comunicación pública de los resultados derivados de EC continúa siendo un reto desde la perspectiva ética de la investigación clínica. Tanto los comités éticos como las agencias reguladoras y las instituciones donde se realizan los EC deberían fomentar y velar por la comunicación pública de los resultados.

El número de ensayos clínicos registrados sigue siendo muy superior al número de ensayos clínicos publicados en revistas científicas. En este sentido, el sesgo positivo de publicación continúa siendo uno de los mayores retos éticos en relación a la publicación de ensayos clínicos. Por otro lado, la comunicación de resultados de ensayos clínicos no se debe limitar a la publicación en actas de jornadas o congresos, sino a la publicación en revistas científicas.

\section{Bibliografía}

Bhinder, J, Chatterjee, S y Messerli, F H (2014). Abstract 12662:

"Differences in Journal Impact Factor(IF) Between Initial and Subsequent Publication of Cardiovascular Clinical Trials-An Analysis From the ClinicalTrials.gov Repository". Circulation, 130(Suppl 2).

Blackwell, S, Thompson, L y Refuerzo, J (2009). "Full Publication of Clinical Trials Presented at a National Maternal-Fetal Medicine Meeting: Is There a Publication Bias?". American Journal of Perinatology, 26(9), 679-682.

Chalmers, I (1990). "Underreporting research is scientific misconduct". JAMA, 263(10), 1405-8.

Hoeg, R T et al (2009). "Publication Outcomes of Phase II Oncology Clinical Trials". American Journal of Clinical Oncology, 32(3), 253-257.

Hopewell, S, Clarke, M J, Stewart, L y Tierney, J (2007). "Time to publication for results of clinical trials". En S Hopewell (Ed.), Cochrane Database of Systematic Reviews. Chichester, UK: John Wiley \& Sons, Ltd. 
Hopewell, S, Loudon, K, Clarke, M J, Oxman, A D y Dickersin, K (2009). "Publication bias in clinical trials due to statistical significance or direction of trial results". En S Hopewell (Ed.), Cochrane Database of Systematic Reviews. Chichester, UK: John Wiley \& Sons, Ltd.

Hurley, M N, Prayle, A P y Smyth, A R (2012). "Delayed publication of clinical trials in cystic fibrosis". Journal of Cystic Fibrosis, 11(1), 14-17.

Jones, C W et al (2013). "Non-publication of large randomized clinical trials: cross sectional analysis". BMJ (Clinical Research Ed.), 347, f6104.

Koletsi, D, Pandis, N, Polychronopoulou, A y Eliades, T (2012). "Mislabeling controlled clinical trials (CCTs) as "randomized clinical trials (RCTs)" in dental specialty journals". Journal of Evidence-Based Dental Practice, 12(3), 124-130.

Kottachchi, D y Nguyen, G C (2010). "Quality and publication success of abstracts of randomized clinical trials in inflammatory bowel disease presented at Digestive Disease Week". Inflammatory Bowel Diseases, 16(6), 993-8.

Lee, K, Bacchetti, P y Sim, I (2008). "Publication of Clinical Trials Supporting Successful New Drug Applications: A Literature Analysis". PLoS Medicine, 5(9), e191.

Pérez-Mañá, C, Llonch, C y Farré, M (2012). "Transparencia en la investigación clínica: Registro de los ensayos clínicos y publicación de resultados". Medicina Clinica, 139(13), 593-597.

Prenner, J L, Driscoll, S J, Fine, H F, Salz, D A y Roth, D B (2011). "Publication Rates of Registered Clinical Trials in Macular Degeneration". Retina, 31(2), 401-404.

Ross, J S, Mocanu, M, Lampropulos, J F, Tse, T y Krumholz (2013). "Time to publication among completed clinical trials". JAMA Internal Medicine, 173(9), 825-8. 
Sibanda, M, Summers, R S y Meyer, J C (2016). "Publication trends of clinical trials performed in South Africa". South African Medical Journal, 106(5), 519.

Son, C, Tavakoli, S y Bartanusz, V (2016). "No publication bias in industry funded clinical trials of degenerative diseases of the spine". Journal of Clinical Neuroscience, 25, 58-61.

Tompson, A C, Petit-Zeman, S, Goldacre, B y Heneghan, C J (2016). "Getting our house in order: an audit of the registration and publication of clinical trials supported by the National Institute for Health Research Oxford Biomedical Research Centre and the Musculoskeletal Biomedical Research Unit". BMJ Open, 6(3), e009285.

Turer, A T, Mahaffey, K W., Compton, K L, Califf, R M y Schulman, K.A (2007). "Publication or presentation of results from multicenter clinical trials: Evidence from an academic medical center". American Heart Journal, 153(4), 674-680.

Vawdrey, D K y Hripcsak, G (2013). "Publication bias in clinical trials of electronic health records". Journal of Biomedical Informatics, 46(1), 139-141.

Von Elm, E, Röllin, A, Blümle, A, Huwiler, K, Witschi, M y Egger, M (2008). "Publication and non-publication of clinical trials: Longitudinal study of applications submitted to a research ethics committee". Swiss Medical Weekly, 138(13-14), 197-203.

Walker, K F, Stevenson, G y Thornton, J G (2014). "Discrepancies between registration and publication of randomised controlled trials: an observational study". JRSM Open, 5(5), 2042533313517688. 


\title{
La comunicación institucional del virus del ébola en España: Análisis de la gestión estratégica online y offline de la crisis
}

\author{
Calleja-Reina, Ma Antonia (1) Universidad de Málaga, UMA \\ Becerra Muñoz, Elena (D) Universidad de Málaga, UMA
}

\section{Resumen}

Introducción: En octubre de 2014, España vivió una de las situaciones más críticas en materia sanitaria desde hace años: el virus del ébola. Tras los casos de encefalopatía espongiforme bovina (EEB) o «enfermedad de las vacas locas» confirmado en España por primera vez en el año 2000 o el brote de H5N1 o «gripe aviar» en 2006, entre otros; nuestro país se enfrentó a una de las mayores crisis sanitarias de su historia, la crisis del ébola. Objetivos y Metodología. Con este estudio se pretende conocer la gestión de la comunicación, offline y online, de la crisis por parte del Ejecutivo español a través de un análisis de artículos científicos más representativos publicados a lo largo de 2014 y 2015 referentes a esta crisis. Resultados. Esta crisis suscitó mucho interés, no sólo en los medios tradicionales y digitales, sino también, en el ámbito de la investigación. Todos coinciden en que se cometieron muchos errores en términos de comunicación: una reacción tardía e ineficiente, una falta de transparencia y de liderazgo, entre otros. Conclusiones. Del análisis de la literatura surgida de esta crisis se concluye que los medios de comunicación, y especialmente las redes sociales, amplificaron los efectos negativos de una crisis mal gestionada.

Palabras clave: relaciones públicas; comunicación sanitaria; comunicación de crisis; redes sociales; ébola; portavocía. 


\section{Introducción}

TRAS los casos del Síndrome del Aceite Tóxico (SAT) o la 1 «enfermedad de la colza», surgido en España en el 1981; el de la encefalopatía espongiforme bovina (EEB) o «enfermedad de las vacas locas» confirmado en el territorio español por primera vez en el año 2000; el brote de H5N1 o «gripe avian» en 2006; la crisis de la bacteria Escherichia coli, comúnmente conocida como «E. coli», en 2011; nuestro país se enfrentó en octubre de 2014 con otro posible caso de pandemia en nuestras fronteras, el ébola.

España a pesar de haber experimentado varias crisis a lo largo de los últimos años; y aunque éstas suelan tener elementos comunes; no supo afrontar esta nueva amenaza. Castillo advierte que "no todas las crisis son iguales ni afectan de idéntica manera a las organizaciones" (Castillo, 2010: 205).

$\mathrm{Y}$ es que nuestro país se ha enfrentado a numerosas crisis de salud pública, entendidas como "aquella situación que ha provocado o se prevé que pueda provocar un peligro para la salud de los ciudadanos, por lo que exige, por parte de las instituciones, una actuación pública intervencionista (mediante protocolos de protección, de seguridad y de vigilancia) y un flujo de comunicación actualizada y constante con la sociedad" (Costa, 2010).

Ante estas situaciones, la institución pertinente debe poner en marcha su plan de comunicación en crisis. De acuerdo con González Herrero, la comunicación en crisis es "la capacidad de una organización de reducir o prever los factores de riesgo e incertidumbre respecto al futuro, de forma que se capacite a la misma para asumir de manera rápida y eficaz las operaciones de comunicación necesarias que contribuyan a reducir o eliminar los efectos negativos que una crisis puede provocar sobre su imagen y reputación” (González Herrero, 1998: 38).

Otros, la definen como "la recopilación y procesamiento de la información por parte del equipo de toma de decisión en crisis junto 
con la creación de mensajes de crisis a personas fuera del equipo" (Commbs y Holladay, 2012).

En este sentido, un buena comunicación en crisis, según Seeger y Reynolds (2008), busca explicar el evento específico, identificar posibles consecuencias y resultados, y proporcionar información específica que reduzcan el daño a las comunidades afectadas de una manera honesta, sincera, rápida, precisa y completa.

Una comunicación del riesgo eficaz es un elemento esencial de la gestión de un brote, ya que "una comunicación proactiva anima al público a adoptar comportamientos de protección, facilita mayor vigilancia de las enfermedades, reduce la confusión y permite un mejor uso de los recursos - todos los necesarios para una respuesta eficaz" (World Health Organization, 2008).

Sin duda, en la gestión de la crisis del ébola las redes sociales han jugado un papel esencial. "Los grupos de interés o de presión tienen una rapidez para comunicar mayor a la de muchas empresas o instituciones. Nunca antes un individuo había tenido acceso a tanta gente o a tanta información. Es necesario utilizar las nuevas tecnologías durante las crisis" (Saura, 2005).

Si bien, todas las plataformas de redes sociales permiten fácilmente producir, intercambiar y consumir contenido generado por el usuario sin muchos conocimientos técnicos.

"Las redes sociales han añadido un nuevo plano para ampliar la visión de las crisis. Los gestores están muy sensibles al hecho de que las amenazas de la crisis, especialmente aquellas que perjudican a las reputaciones, puedan emerger y crecer rápidamente online (...) Hay una necesidad creciente de monitorizar las redes sociales y de decidir cómo integrarlas en las respuestas a crisis" (Coombs, 2015: 15).

Los medios tradicionales, y de igual manera, los medios digitales, incluidas las redes sociales, mostraron un gran interés en la crisis del ébola en España. 
Como consecuencia, son numerosas las investigaciones centradas en las acciones comunicativas de la crisis institucional ocasionada por el brote de ébola en España durante octubre de 2014.

Este capítulo pretende hacer un repaso por la gestión de la crisis en nuestro país, a través de los diferentes artículos científicos publicados al respecto, para poder, así, analizarla desde diferentes perspectivas.

\subsection{La crisis contada paso a paso}

Muchos comienzan a hablar de la crisis del ébola a partir del 6 de octubre de 2014, momento en el que la auxiliar de enfermería, Teresa Romero, se contagió tras haber asistido a Manuel García Viejo, misionero repatriado desde Sierra Leona. Este misionero falleció días antes a causa del virus. Sin embargo, la crisis podría datarse de una fecha anterior.

Fue el 8 de agosto de 2014, cuando la Directora General de la Organización Mundial de la Salud (OMS) declaró que el brote de ébola en África Occidental constituía una Emergencia de Salud Pública de Importancia Internacional. Las organizaciones internacionales ya lo advertían: "La enfermedad por el virus del ébola es una de las más mortíferas del mundo para el ser humano". El virus que la ocasiona, descubierto en 1976, es altamente infeccioso y tiene una tasa de letalidad que puede llegar al 90 por ciento de las personas infectadas (Médicos Sin Fronteras, 2014).

Pero es el 10 de octubre cuando el Gobierno de España crea el Comité Especial para la Gestión del Ébola. Es decir, dos meses después de ese anuncio por parte de la OMS, cuando ya habíamos presenciado la muerte de los dos religiosos, Miguel Pajares y Manuel García Viejo; la ejecución del perro de la auxiliar, Excálibur; el contagio de la propia trabajadora sanitaria que asistió a uno de los afectados, Teresa Romero; y cuando habíamos detectado una enorme alarma social entre toda la población.

A continuación, se presenta una tabla con la cronología donde se enumeran los hitos de la crisis. 


\section{Tabla 1. Cronología de la crisis}

\begin{tabular}{|c|c|}
\hline Fecha & Hitos de la crisis \\
\hline 8 de agosto & $\begin{array}{l}\text { OMS declara que el brote de ébola en África Occidental } \\
\text { constituía una Emergencia de Salud Pública de Importancia } \\
\text { Internacional. }\end{array}$ \\
\hline 12 de agosto & $\begin{array}{l}\text { El primer paciente repatriado a España, el religioso Miguel } \\
\text { Pajares, muere. }\end{array}$ \\
\hline 25 de agosto & $\begin{array}{l}\text { El sacerdote Manuel García Viejo, extraditado desde Sierra } \\
\text { Leona, muere. }\end{array}$ \\
\hline $\begin{array}{l}6 \text { de octubre } \\
(\sim 18: 00 \mathrm{pm})\end{array}$ & $\begin{array}{l}\text { Se declara el primer contagio en España. Teresa Romero, la } \\
\text { auxiliar de enfermería que cuidaba a García Viejo. }\end{array}$ \\
\hline $\begin{array}{l}6 \text { de octubre } \\
(\sim 20: 00 \mathrm{pm})\end{array}$ & $\begin{array}{l}\text { La Ministra de Sanidad, Ana Mato, acompañada por seis } \\
\text { altos cargos del Ministerio ofrece una rueda de prensa. }\end{array}$ \\
\hline 9 de octubre & El perro de la auxiliar, Excálibur, es sacrificado. \\
\hline 9 de octubre & $\begin{array}{l}\text { El Consejero de Sanidad de Madrid, Javier Rodríguez, } \\
\text { declara: "no hace falta hacer un máster para ponerse el } \\
\text { traje". }\end{array}$ \\
\hline 10 de octubre & Se crea el Comité Especial para la Gestión del Ébola. \\
\hline 10 de octubre & $\begin{array}{l}\text { La vicepresidenta del Gobierno, Soraya Sáenz de Santamaría, } \\
\text { asume el gabinete de crisis }\end{array}$ \\
\hline $\begin{array}{l}14 \text { de octubre } \\
(5: 26 \mathrm{am})\end{array}$ & Se lanza la cuenta oficial de Twitter @info_ebola_es \\
\hline 21 de octubre & $\begin{array}{l}\text { Se lanza la web oficial del Comité Especial para la Gestión } \\
\text { del Ébola - infoebola.gob.es/ }\end{array}$ \\
\hline 27 de octubre & $\begin{array}{l}\text { Javier Limón, el marido de Teresa Romero, y otros diez } \\
\text { pacientes que estaban en observación, reciben el alta médica }\end{array}$ \\
\hline 5 de noviembre & Teresa Romero abandona el Hospital Carlos III. \\
\hline 26 de noviembre & La Ministra de Sanidad, Ana Mato, dimite. \\
\hline 2 de diciembre & OMS declara el fin del brote del ébola en España. \\
\hline 5 de diciembre & El consejero de Sanidad es destituido. \\
\hline
\end{tabular}

Fuente: elaboración propia 


\section{Objetivos e hipótesis de investigación}

Esta investigación tiene por objetivo conocer cómo se gestionó la comunicación en la crisis del ébola desde el Gobierno de España, tanto offline como online.

La hipótesis de esta investigación fue que desde el Ejecutivo español y, más concretamente, desde el Ministerio de Sanidad, Servicios Sociales e Igualdad, no se gestionó de manera eficaz la crisis. La hipótesis fue confirmada.

\section{Metodología de investigación}

Con el fin de analizar cómo se llevó a cabo la gestión del ébola en España, hemos decidido analizar los artículos científicos más representativos publicados a lo largo de 2014 y 2015. De este modo, realizaremos un estudio del estado del arte de la crisis, a modo de investigación documental que nos permita el estudio del conocimiento acumulado a través de los escritos de la gestión de la comunicación en la crisis del ébola.

\section{Resultados de la investigación}

Como comentábamos con anterioridad, esta crisis suscitó mucho interés, no sólo en los medios tradicionales y digitales, sino también, en el ámbito de la investigación. El estudio pormenorizado de cada una de las decisiones y acciones llevadas a cabo por el Ejecutivo, así como la reacción por parte de familiares, personal sanitario, vecinos de la enferma, han dado como resultado artículos científicos que presentamos a continuación:

Por un lado, algunos expertos analizaron las primeras declaraciones institucionales y el tratamiento que los periódicos españoles de mayor tirada en España realizaron sobre aquéllas (Micaletto Belda y Gallardo Vera, 2015).

Por otro lado, otro estudio se centraba en el uso de Twitter por parte del Gobierno español durante la crisis, la cantidad y el tipo de 
información facilitada y la respuesta que la cuenta oficial, @Info_Ebola_Es, recibía por los internautas (Díaz Cerveró y Vázquez Barrio, 2015). O incluso, en el análisis de la web del Comité Especial para la gestión del ébola, así como la evolución de la crisis en las redes sociales (Calleja Reina, 2015).

Jurado Galván y Jurado Izquierdo (2014) analizaron, por su parte, los principios teóricos de manual básico de actuación en las crisis informativas, incluidas las sanitarias. Estos principios se aplican, a continuación, a la crisis del ébola.

\section{Tabla 2. Manual de crisis y acciones concretas}

\begin{tabular}{|l|l|}
\hline Manual de Crisis y ... & Acciones concretas \\
\hline $\begin{array}{l}1 \cdot \text { Portavoz único, cualificado y } \\
\text { creíble }\end{array}$ & Ana Mato, entonces ministra de Sanidad \\
\hline $\begin{array}{l}2 \cdot \text { Con toda la información } \\
\text { disponible }\end{array}$ & $\begin{array}{l}\text { Imposible: incluso la OMS desconoce } \\
\text { todavía muchos extremos de la enfermedad } \\
\text { (origen, vías de contacto, fármaco eficaz) }\end{array}$ \\
\hline $3 \cdot$ Marcando los tiempos & $\begin{array}{l}\text { Los tiempos los han marcado: la paciente } \\
\text { infectada, la urgencia de los medios, la } \\
\text { enfermedad }\end{array}$ \\
\hline $\begin{array}{l}\text { 4· Mensajes únicos, simples y } \\
\text { sencillos }\end{array}$ & $\begin{array}{l}\text { Descontrol político, correcto mensaje } \\
\text { técnico }\end{array}$ \\
\hline $\begin{array}{l}5 \cdot \text { Intentar reducir la alarma } \\
\text { social: procurar reducir los } \\
\text { bulos, pero aceptar su } \\
\text { imposibilidad en las redes } \\
\text { sociales }\end{array}$ & $\begin{array}{l}\text { Dispersión de portavoces, mensajes. Los } \\
\text { medios no ayudan: show audiovisual; redes } \\
\text { sociales, ingobernables }\end{array}$ \\
\hline $\begin{array}{l}\text { 6· Eficacia organizativa: los } \\
\text { protocolos }\end{array}$ & $\begin{array}{l}\text { Errores organizativos (protocolo sin ensayar, } \\
\text { formación insuficiente, ambulancia sin } \\
\text { protección) }\end{array}$ \\
\hline $\begin{array}{l}7 \cdot \text { Creación de un gabinete de } \\
\text { crisis }\end{array}$ & $\begin{array}{l}\text { Se tarda cinco días en crear el gabinete bajo } \\
\text { la presidencia de Sáenz de Santamaría, y } \\
\text { comité científico }\end{array}$ \\
\hline
\end{tabular}

Fuente: Jurado Galván, E y Jurado Izquierdo, M (2014: 95)

Igualmente, un grupo de expertos analizó el contenido transmedia ofrecido por Elpaís.com en la cobertura del ébola. Así, "la web 
incluye el contenido más completo a nivel multimedia (fotos, imágenes, hipervínculos) y es el que sale difundido antes (en cuanto a la hora de publicación) y el más compartible (en redes sociales o por correo electrónico)". Como refleja la Tabla 3, a partir de ahí los contenidos se procesan para los otros canales-plataformas como son las teléfonos inteligentes, las tabletas, y la web móvil; a continuación, en un tercer nivel, se adapta el contenido a las redes sociales (CostaSánchez, Rodríguez-Vázquez y López-García, 2015: 287).

\section{Tabla 3. Jerarquía en los canales-plataformas de difusión del relato}

\begin{tabular}{|c|c|c|c|c|}
\hline Primer nivel & \multicolumn{4}{|c|}{ WWWW (Elpais.com) } \\
\hline Segundo nivel & Smartphone & Table & & Web móvil \\
\hline \multirow{3}{*}{ Tercer nivel } & \multicolumn{4}{|c|}{ Twitter } \\
\hline & \multicolumn{4}{|c|}{ Facebook } \\
\hline & LinkedIn & Google+ & Eskup & Tuenti \\
\hline
\end{tabular}

Fuente: Costa-Sánchez, C.; Rodríguez-Vázquez, A I y López-García, (2015: 287)

Según Micaletto Belda y Gallardo Vera (2015), la rueda de prensa ofrecida por la Ministra de Sanidad, Ana Mato, "presentó notables y numerosos errores de gestión comunicativa". Tras su análisis concluyeron que hubo falta de organización, de portavoz único, ausencia de respuestas a algunas cuestiones, lo que generaron confusiones y contradicciones que desembocaron en falta de credibilidad. En este sentido, "el Gobierno no comunicó de la mejor manera los hechos en la rueda de prensa que convocó ese mismo día" (Díaz Cerveró y Vázquez Barrio, 2015: 247).

Por otro lado, se analizaron 36 mensajes publicados por los dos periódicos más leídos entre la población española, El País y El Mundo. Así, "las 17 publicaciones de El País desaprobaron la comparecencia, mientras que 5 de El Mundo la aprobaron y 14 la desaprobaron" (Micaletto Belda y Gallardo Vera, 2015: 106).

En otro de los estudios se vio cómo el Ministerio creó una web específica para la crisis, infoebola.gob.es/, que funcionaba desde el 21 de octubre. $\mathrm{Y}$ aunque contaba cuenta con información actualizada, 
artículos de investigación internacionales, recursos gráficos como imágenes y vídeos, en español e inglés. Aun así, se echaban en falta los iconos de las redes sociales, o incluso un teléfono o email de contacto.

La cuenta oficial de Twitter de Comité, @Info_Ebola_Es, también fue objeto de estudio. Creada el 14 de octubre, consiguió alrededor de 22.000 seguidores y tuvo un alcance de más de 100.000 cuentas.

De acuerdo al estudio de Díaz Cerveró y Vázquez Barrio (2015), @Info_Ebola_Es publicó un total de 86 mensajes, de los un 72 por ciento generó comentarios, sin embargo, no hay ni uno solo de sus tweets que provocó una respuesta totalmente positiva por parte de los internautas. Es más, todo lo contrario, ya que predominaron los comentarios desfavorables con improperios e insultos. Por su parte, según Calleja Reina (2015: 80), hashtags como \#anamatodismisión y \#SalvemosaExcálibur llegaron a ser tendencia en Twitter a nivel mundial.

Por último, Costa-Sánchez et al. (2015: 287), analizaron las 16 piezas informativas que Elpais.com difunde el día 6 de octubre. "La participación de las audiencias se canaliza principalmente por medio de las redes sociales Facebook, Twitter, Google+, LinkedIn y Eskup (red social creada por El país en 2010)" (Costa-Sánchez, RodríguezVázquez, \& López-García, 2015, pág. 287). Según este estudio, Facebook era la herramienta que mayor participación generaba entre los usuarios, muy por delante de Twitter.

\section{Discusión y conclusiones}

Con motivo del XI Congreso de la Asociación Nacional de Informadores de la Salud, que tuvo lugar en Oviedo, en abril de 2015, se concluyó que la gestión de la crisis del ébola en nuestro país, en términos de comunicación, fue deficiente. Según los intervinientes, faltó transparencia, proactividad, reacción rápida y eficiente, liderazgo, coordinación, una adecuada portavocía, colaboración con agentes del sector, pero, fundamentalmente faltó información clara a la sociedad. 
Este trágico ejemplo revela una vez más que la comprensión de la retórica utilizada por personal sanitario es tan importante para el control de epidemias como lo es la comprensión el virus en sí (Condit, 2015). De hecho, hubo tanta especulación, rumores y opiniones que el ciudadano tenía miedo de poder contagiarse, lo que generó una gran alarma social.

Y es que, como afirmaba Nespereira-García (2015: 230), "la reciente crisis sanitaria y de comunicación (...) ha evidenciado las limitaciones de los modelos tradicionales de la comunicación del riesgo sanitario".

En relación a lo anterior, y de acuerdo con Jurado Galván y Jurado Izquierdo:

“(...) Las autoridades sanitarias hicieron todo lo contrario de lo razonable en una crisis: no hubo un solo portavoz, la entonces ministra de Sanidad (máxima autoridad sanitaria) era todo menos creíble y cualificada, se tardó toda una semana en crear un comité de crisis; la dispersión de las fuentes informativas fue evidente, el consejero de Sanidad de la Comunidad de Madrid generó más alarma que certezas... Desastre absoluto" (Jurado Galván y Jurado Izquierdo, 2014: 91-92).

"Hubo mucha alarma social porque parecía que había inconsistencia, se generó pánico pero lo que había que hacer estaba claro desde el primer momento" (De Lara González, 2015: 26).

Pero, en esta crisis, las redes sociales jugaron un papel crucial en el desarrollo y efectos de la misma. Sin embargo, no se les dio la importancia que merecían. Por lo que las consecuencias fueron nefastas.

Resulta interesante ver cómo el Gobierno español eligió Twitter como única red social para informar a la población sobre esta pandemia. Dejando de apostar por plataformas como Facebook, Google+, Tumblr, Pinterest o Instagram, entre otras. 
Conforme al estudio Social Media 2015 de la OBS Business School, en España 17 millones de usuarios utiliza activamente las redes sociales mensualmente en 2014. El 88\% de los españoles que utilizan Internet, según este estudio, tiene cuenta en Facebook frente al 56\% en Twitter (Purita, 2015).

De hecho, existe una investigación de la Virginia Commonwealth University sobre el uso de las plataformas Instagram y Twitter por parte de tres organizaciones mundiales de salud pública ${ }^{20}$ durante la crisis del ébola. Entre otros resultados, concluyeron que Instagram suscitaba un mayor engagement que Twitter, especialmente cuando se comparaban las variables como los retweets y likes. Parece que Instagram juega un papel cada vez más importante en la participación de usuarios activos (Neubaum, G, Rösner, L, Rosenthal-von der Pütten, A M, Krämer, N C, 2014).

Después de repasar la bibliografía científica existente, todos coinciden que el Ejecutivo español, a través del Ministerio de Sanidad, actuó tarde no sólo a la hora de comunicar los avances del virus, sino también en la creación del Comité Especial, la puesta en marcha de la web oficial, y la cuenta oficial de Twitter.

En este sentido, concluyen que el Gobierno (...) "tampoco aprovechó la oportunidad que ofrecen las redes sociales para responder con rapidez y eficacia a la demanda de información que existía. La cuenta oficial de Twitter se puso en marcha muy tarde" (Díaz Cerveró y Vázquez Barrio, 2015: 247).

Pronto empezaron a surgir desinformaciones y rumores. "A través de una sutileza exquisita se consigue introducir la desinformación, aspecto coadyuvado por la existencia de una creciente rapidez e inmediatez en el proceso comunicativo que imposibilita la plena contrastación de los acontecimientos" (Barquero Cabrero y Castillo

\footnotetext{
${ }^{20}$ La Organización Mundial de la Salud, Médicos Sin Fronteras y el Centro para el Control y la Prevención de Enfermedades de los Estados Unidos (CDC, American Centre for Disease Control).
} 
Esparcia: 49). De hecho, fue tal la poca actuación por parte del Ministerio que incluso las fuerzas de seguridad del Estado tuvieron que dar la voz de alarma ante la aparición de numerosos bulos y las mentiras en las redes sociales. De acuerdo con Coombs (2015: 13), "esto demuestra cómo las redes sociales tienen el potencial de crear una crisis o de amenazar una crisis".

En conclusión, "toda esta desinformación y descoordinación fue la causa del pánico social que se sufrió durante unas semanas, creando rechazo y el estigma social, en lugar de informar sobre la enfermedad y ayudar, así, a neutralizar los efectos de la misma" (Calleja-Reina, 2015: 83).

\section{Bibliografía}

Barquero Cabrero, J y Castillo Esparcia, A (s.f.). Marco teórico y práctico de las Relaciones Públicas. Barcelona: Furtwangen Editores.

Calleja Reina, M (2015). La pantalla insomne.: Cuadernos Artesanos de Comunicación. La Laguna: Latina.

Castillo, A (2010). Introducción a las Relaciones Públicas. Málaga: Editorial Instituto de Investigación en Relaciones Públicas.

Condit, C (2015). The spread of Ebola. How the World Health Organization's rhetoric contributed to virus transmission. METODE Science Studies Journal, Monograph.

Coombs, W. (2015). Ongoing Crisis Communication. Planning, Managing, and Responding. Florida: Sage.

Coombs, W y Holladay, S (2012). The Handbook of Crisis Communciation. Malden: Wiley-Blackwell .

Costa, C (2010). "Crisis de salud pública. El derecho de los ciudadanos a estar informados". Diálogos de la Comunicación, 82, 1-6. 
Costa-Sánchez, C, Rodríguez-Vázquez, A y López-García, X (2015).

"Del periodismo transmedia al replicante. Cobertura informativa del contagio de ébola en España". El profesional de la información, 24(3), 282-290.

De Lara González, A (2015). "José Joaquín Mira: "Comprobar la viabilidad de los protocolos en la práctica resulta crucial ante un virus como el Ébola"”. UMH Sapiens: divulgación cientifica, 11, 26-27. Disponible en: https://issuu.com/umhsapiens/docs/sapiens11 05oct

(fecha de consulta: 14/4/2016).

Díaz Cerveró, E y Vázquez Barrio, T (2015). "El uso de Twitter por parte del Gobierno español durante la crisis del ébola”. Miguel Hernández Communication Journal, 6, 241-259.

González Herrero, A (1998). Marketing preventivo: la comunicación de crisis en la empresa. Barcelona: Bosch.

Guidry, J P, Messner, M, Jin, Y, Meganck, S y Niyirora, J (2015). "\#Ebola on Instagram and Twitter: How health organizations address the health crisis in their social media engagement". Institute for Public Relations' 17th International Public Relations Research Conference. Miami.

Jurado Galván, E y Jurado Izquierdo, M (2014). Los errores de comunicación en la crisis del ébola. Cuaderno de periodistas. Disponible en: http://www.cuadernosdeperiodistas.com/media/2015/02/90-99_ SALVAN-Y-JURADO.pdf

(fecha de consulta: 14/4/2016).

Micaletto Belda, J y Gallardo Vera, L (2015). La comunicación institucional en la crisis del ébola en Europa: el caso de la crisis española de 2014 en sus inicios". Revista Internacional de Relaciones Públicas, V(9), 89-110. 
Nespereira-García, J (2015). "La retórica como herramienta para la gestión y la comunicación del riesgo sanitario". Revista Española de Comunicación en Salud, 6(2), 222-233.

Neubaum, G, Rösner, L, Rosenthal-von der Pütten, A M, Krämer, N C. (2014). "Psychosocial functions of social media usage in a disaster situation: A multi-methodological approach". Computers in Human Behavior, 34, 28-38.

Purita, G. (2015). Análisis de las Tendencias de uso y participación en las redes sociales a nivel Mundial en España. Barcelona: Online Business School. Disponible en: http://www.obs-edu.com/noticias/estudioobs/espana-aumenta-el-numero-de-usuarios-activos-en-redessociales-en-2014-y-llega-los-17-millones/ (fecha de consulta: 14/4/2016).

Saura, P (2005). La gestión y la comunicación de crisis en el sector de alimentación y bebidas. Madrid: Universidad Pontificia Comillas.

Seeger, M y Reynolds, B (2008). "Crisis Communication and the Public Health: Integrated Approaches and New Imperatives". En Seeger, Sellnow y Ulmer (Edits.), Crisis Communication and the Public Health, 320. Cresskill, New Jersey: Hampton Press.

World Health Organization. (2008). World Health Organization Outbreak Communication Planning Guide. Geneva, Switzerland: WHO.

\section{Otras referencias}

Médicos Sin Fronteras. (20 de agosto de 2014). wnw.msf.es. Disponible en: http://www.msf.es/noticia/2014/que-es-el-ebola (fecha de consulta: $14 / 4 / 2015)$.

XI Congreso ANIS. (2015). Mesa: Crisis del Ébola. Disponible en: https://www.youtube.com/watch?v=R4nFTZFv9ro (fecha de consulta: 14/42015). 


\title{
La importancia del blog de salud para los pacientes con enfermedades minoritarias
}

\author{
Paloma López Villafranca \\ Universidad de Málaga-Andalucía Tech (UMA)
}

\section{Resumen}

Introducción: El blog es una de las herramientas más utilizadas en la eSalud o comunicación sanitaria 2.0. Los pacientes suelen consultar estas páginas, que elabora la comunidad científica, revistas de divulgación científica o los propios pacientes. Cuando quienes padecen estas enfermedades no cuentan con suficiente información de la patología por ser desconocida, como es el caso de los pacientes con enfermedades raras, suelen crear sus páginas web y blogs para recopilar, compartir y difundir toda aquella información que no logran obtener por cauces tradicionales. No hay que olvidar que estas patologías las padecen menos de 5 personas por cada 10.000 habitantes. Objetivo. En este capítulo analizamos 25 blogs de organizaciones de pacientes con enfermedades minoritarias de las organizaciones ámbito nacional que están inscritas en CREER (Centro de Referencia Estatal de Enfermedades Raras en España). Metodología. En este análisis descriptivo abordamos los temas que más interesan a las organizaciones, el tratamiento de estos temas, si se personaliza en una historia concreta o se generaliza sobre la enfermedad, la autoría de los mismos, si está enlazado a alguna página web o se difunde a través de redes sociales, interacción con otros usuarios que comentan los mismos, el tono que se utiliza y el tipo de mensaje que se lanza a los usuarios. Resultados. Como conclusión fundamental, destacamos que la temática principal de los blogs se basa en experiencias personales. Se trata de blogs escritos por los propios pacientes con carácter informativo, pero teniendo presente la sensibilización de quienes lo leen y la constante apelación a la 
solidaridad. Más de la mitad están enlazados a la web y cerca de la mitad se comparten en redes sociales, un porcentaje insuficiente si quieren llegar a sus públicos de forma eficaz.

Palabras claves: enfermedades raras; blog; salud; pacientes; minoritarias; 2.0.

\section{Introducción}

T OS PACIENTES con enfermedades minoritarias se encuentran $\perp$ con una doble problemática. Por una parte, se encuentran en una situación sanitaria compleja, sin recursos ni personal especializado para tratar las patologías. Y por otra parte, sufren el desamparo de las administraciones y farmacéuticas, puesto que tal y como afirma Ribes (2012: 136), "su baja prevalencia ha condicionado hasta no hace mucho tiempo que se investiguen poco y que los tratamientos en la mayoría de los casos sean inexistentes".

El papel de los pacientes es esencial para obtener información y difundirla, ya que "estas asociaciones son las que luchan porque la enfermedad rara no lo sea, al menos a ojos de las administraciones y de otros ciudadanos" (Castillo et al, 2015: 678).

Internet se ha convertido en la plataforma ideal para compartir conocimientos, difundir información científica de la enfermedad, poner en común experiencias sanitarias y personales. El blog, además supone un espacio económico, sin el coste de mantenimiento de una página web. Es fácil de editar y seguir por los usuarios, con capacidad de alojar estos contenidos en un espacio atractivo que, además, se puede compartir en redes sociales, aunque no todos los blogs tengan relación directa con la web de la organización o una web de la enfermedad.

\subsection{La evolución del blog de salud}

El blog es una herramienta que se utiliza en el ámbito sanitario como un instrumento para difundir información y experiencias personales. 
Orihuela (2006: 34) define el blog o weblog como un "sitio web que se compone de entradas individuales llamadas anotaciones o historias dispuestas en orden cronológico inverso".

Buis y Carpenter (2009) califican los blogs de salud o medblogs como artífices y principales protagonistas de la medicina 2.0. Sin embargo, Hurley $(2007)^{21}$ reconoce que han sido relegados a un segundo plano tras la aparición de las redes sociales.

Valverde (2008: 73) señala la importancia de los blogs de salud, como una de las primeras aplicaciones de la Web 2.0 en aparecer con "valor terapéutico, al menos como un elemento coadyuvante más". Es indiscutible que, a pesar de ser cuestionados, sobre todo los blogs realizados por los propios pacientes, se han convertido en un foro indispensable para poner el altavoz en ciertas cuestiones que preocupan al enfermo.

La web y el blog de salud han crecido de forma paralela. En España, las asociaciones con pocos recursos utilizan el blog como herramienta para comunicarse con otros pacientes y compartir de esta forma su experiencia.

Según March (2012: 1), la información que aparece tanto en la web como en el blog, además de haberse convertido en la principal fuente de información en salud, está "reemplazando a los profesionales sanitarios en esta función, a pesar de ser los médicos la fuente de información más creíble". El principal obstáculo es que, tal y como afirma López Villafranca (2015: 1040), "sólo escogidos profesionales especialistas en la materia pueden tratar estas patologías" y es por ello que cada vez se acude a más fuentes de información en la red y, en concreto a páginas y blogs de pacientes que suelen recopilar la información científica más relevante en estos espacios virtuales. El blog es fuente de información importante para el paciente, donde se almacena la literatura de la patología encontrada hasta el momento y donde es posible conocer la impresión de otros pacientes.

${ }^{21}$ Citado por Torres y Robinson (2012: 43). 
Podemos realizar una clasificación de los blog de salud, atendiendo a los criterios que establecen Torres-Salinas y Robinson (2012:43) que diferencia tres tipos, en función de su creador. Por una parte, los blogs realizados por médicos, en segundo lugar, los que se generan en un entorno académico, "que tienen una intención muy diferente y en el que se prescinde por completo de la relación médico-paciente" y, por último, los blogs de pacientes, en los que centramos esta investigación.

Tenemos que destacar el caso de cibermedios o páginas web especializadas en salud en los que se enlaza el blog como herramienta para conocer con mayor profundidad la impresión de quienes tratan estas enfermedades o de quienes las padecen. Es el caso del blog de Diario médico, Medicablogs y de otros tantos importantes especializados en temas médicos y que utilizan lengua inglesa como PsyBlog, The Patient Experience, Maternity Matters, Bad Medicine, Disabled People Against Cuts (DPAC), Dr. Grumble, Aspie in the Family, Bah to Cancer, Purple Noiseb y Frontier Psychiatrist (González Pacanowski y Medina Aguerrebere, 2014).

\subsection{Blogs y enfermedades raras}

Las herramientas de Social Media son imprescindibles en la actualidad para llegar a los grupos de interés y el blog se presenta como una de las que ofrece más posibilidades en este sentido. Para Aced (2013: 47) los medios sociales (blogs y redes sociales) se presentan de forma muy útil para que las organizaciones se comuniquen con sus públicos. Entre las reglas que Aced (2013) señala, destaca la rapidez, la brevedad, la comunicación directa, la desaparición del intermediario o el hecho de que el internauta puede ponerse en contacto directamente con la organización. Pero para la autora, los blogs y las redes sociales no sustituyen a los medios de comunicación tradicionales, como la prensa, radio, televisión, sino que los complementan. Es necesario destacar la figura de los bloggers o personas que escriben en un blog, que también pueden tener gran influencia o pueden favorecer que las estrategias de comunicación sean más efectivas. En el caso de los blogs que son objeto de estudio, los bloggers son pacientes activos, que utilizan este espacio en sus estrategias comunicativas. 
La complejidad de las enfermedades raras, las dificultades de los pacientes para obtener información, la inexistencia de tratamientos y especialistas, genera un amplio movimiento asociativo y una creciente actividad en Internet en búsqueda de información. Este colectivo satisface esas necesidades de información de los pacientes y familiares mediante la publicación de páginas en Internet, la difusión de artículos académicos, la creación de blogs y grupos en redes sociales, además de, entre otras actividades, conferencias, eventos, congresos y talleres que llevan a cabo con este fin.

"A través de esta meritoria tarea han informado básicamente a otros afectados de los problemas asistenciales y sociales que rodean a algunas de estas enfermedades o grupos de ER aproximándose a una descripción de las características principales de las mismas, así como de los recursos diagnósticos y terapéuticos fundamentales, aunque carezcan, en ocasiones, de una visión general del problema" (Avellaneda, Izquierdo y Torrent, 2007:181).

Una de las enfermedades poco frecuentes que más impacto ha tenido en los medios de comunicación por su repercusión mediática, la ELA, Escleorosis Lateral Amiotrófica cuenta con un espacio en esta comunidad de bloggers. Sin embargo, según González- Pacanowski y Medina-Aguerreberre (2011:654) "los blogs personales redactados por pacientes carecen en ocasiones de precisión informativa y de fiabilidad". Por ello, consideran que no hay que otorgarles credibilidad, pero sí convertirlos en referentes como "vehículo de difusión de experiencias médicas personales, pero no para otros fines como por ejemplo aconsejar a pacientes sobre el uso de medicamentos". Entender bien este concepto y la utilidad de estos blogs para los pacientes es el objeto principal de este estudio.

\section{Objetivos}

El objetivo principal del estudio es analizar los blogs de las organizaciones de pacientes con enfermedades raras para comprobar la temática predominante y autoría de los mismos. 
Con relación a este objetivo general, establecemos una serie de objetivos específicos como son:

1. Analizar el tratamiento de la enfermedad

2. Comprobar la interacción con el resto de pacientes y usuarios

3. Averiguar la relación del blog con la web 2.0

\section{Metodología}

Se realiza un análisis descriptivo de 25 blogs de 140 organizaciones nacionales de pacientes con enfermedades minoritarias o raras que están inscritas en CREER, (Centro de Referencia Estatal de Enfermedades Raras). Sólo el 18\% de las organizaciones tiene blog.

Para establecer la muestra se ha realizado una búsqueda entre las webs de las asociaciones o en diversos buscadores con el motor de búsqueda del nombre de la organización.

\section{Blogs analizados:}

\section{Nombre de la asociación}

1. Alianza Española de

Familias de Von Hippel

Lindau

2. Asociación Española de Esclerosis Lateral Amiotrófica

3. Asociación de Afectados por Displasia Ectodérmica

4. Asociación de Nevus

Gigante Congénito

5. Asociación de Pacientes

Deficitarios de GH - Adultos

(APDGH)

6. Asociación de Enfermos

\section{Url blog}

http://vonhippel-lindau.blogspot.com.es/

http:/ / adelamicro.blogspot.com.es/

http://aadespain.blogspot.com.es/

http://www.asonevus.org/blog/

https://deficitgh2.wordpress.com/

http://manutais.blogspot.com.es/2010/1 
de Patología Mitocondrial

7. Asociación de Nevus

Gigante Congénito

8. Asociación Española contra la Leucodistrofia

9. Asociación Española de

Aniridia

10. Asociación Española de Ictiosis

11. Asociación Española de la http://www.behcet.es/wordpress/ Enfermedad de Behçet

12. Asociación Española de

Osteocondromas Múltiples

Congénitos

13. Asociación Española para el Síndrome de Prader Willi

14. Asociación Española para la Investigación y Ayuda al Síndrome de Wolfram

15. Asociación Nacional Afectados Síndromes de Ehlers-Danlos e Hiperlaxitud

16. Asociación para

Problemas de Crecimiento

17. Asociación Síndrome de Peutz Jeghers

18. Asociación Síndrome de Williams

19. Federación Española de Asociaciones de Espina

Bífida e Hidrocefalia

20. Fundación Atrofia

Muscular Espinal 0/aepmi-asociacion-de-enfermos-de.html http://www.asonevus.org/blog/

http:/ / bloguerosdeela.blogspot.com.es/

http://blog.aniridia.es/

http:/ /asociacionasic.blogspot.com.es/ http://aeomc.blogspot.com.es/

https://praderwillimasteree.wordpress.co $\underline{\mathrm{m} /}$

http://sindromedewolfram.blogspot.com. es/

https://asedh.wordpress.com/

http://www.asociacioncrecer.blogspot.co m.es/

http://sindromedepeutzjeghers.blogspot.c om.es/

http://mihijoconsindromedewilliams.blog spot.com.es/

http://www.febhi.org/actualidad/noticias $-2 /$

https://curaame.wordpress.com/ 
21. Fundación Síndrome de Moebius

22. Asociación Púrpura

Trombocitopénica Idiopática

Española "Corazones

Púrpuras" (APTIE)

\section{ANAHO}

24. La casa de Aaron

25. Asociación DEDINES http:/ / mimoebiusblog.blogspot.com.es/

http://purpuratrombocitopenica.blogspot. com.es/

http://www.holt-oram.es/blog/

http://www.lacasadeaaron.org/blog-2/

http://asociaciondedines.blogspot.com.es $/ \mathrm{p} /$ dedines.html

Las variables utilizadas podemos clasificarlas en dos grupos:

a) Variables cualitativas: relacionadas con el contenido, donde se analiza la temática (científica, comunicación interna de la organización, subvenciones y ayudas, experiencias de pacientes, personalización, otros), el tono (formal, informal), el tipo de mensaje (informativo, solidario, sensibilizador), finalidad (para todos los públicos, para los pacientes, para recaudar fondos, otros), y la autoría del blog (paciente, miembro del sector sanitario, familiar, otros).

b) Variables cuantitativas: número de blogs enlazados en la web, número de posts de los blogs, número de comentarios recibidos (internos, externos y del propio autor), compartidos en redes sociales.

\section{Resultados}

Los resultados del análisis de contenido muestran que el tratamiento de los blogs refleja de forma mayoritaria experiencias personales de los pacientes. Se trata de experiencias psicológicas, relacionadas con los tratamientos y síntomas de la patología. Estas experiencias personales se reflejan en el 68\% de los blogs, otro $68 \%$ tratan temas de diversa índole que afectan a la asociación pero no se catalogan dentro de un grupo específico. El $60 \%$ son temas científicos fundamentalmente relacionados con la investigación de la enfermedad, el 32\% son blogs personalizados con nombres de los pacientes o historias personales. Es el ejemplo de uno de los blogs de 
la Asociación Síndrome de Williams, en el que se plasman historias de niños que padecen la enfermedad y tiene un tono intimista y muy cercano, con un claro objetivo de servir de apoyo psicológico al resto de padres que tienen hijos con el síndrome. Historias personales sobre rutinas, relación con el entorno y retos de sus protagonistas.

\section{Imagen 1. Blog dirigido a familiares de niños con Síndrome de Williams}

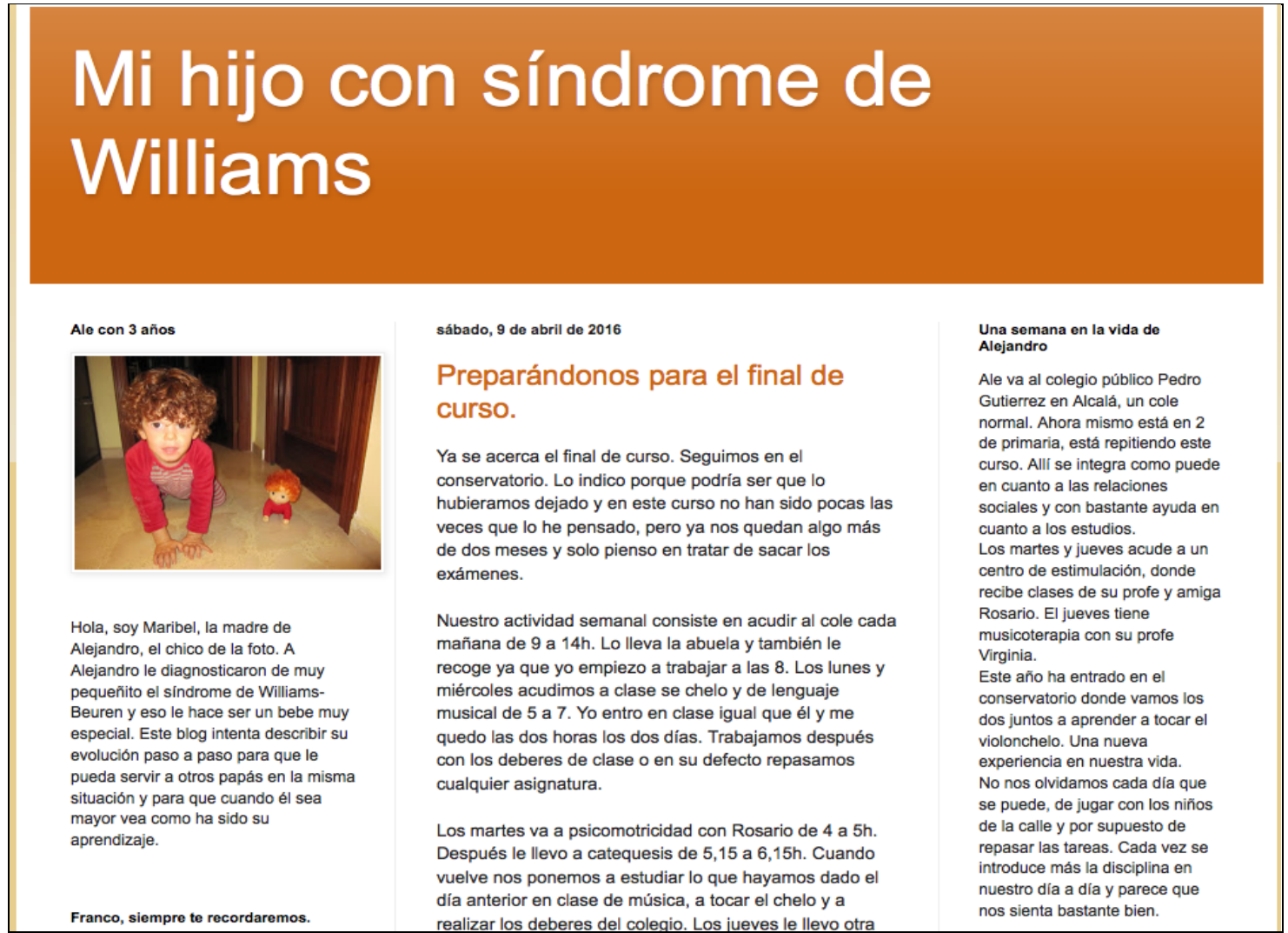

Fuente: http:/ / mihijoconsindromedewilliams.blogspot.com.es/

Otra temática que se aborda en el 12\% de los blogs son subvenciones y ayudas relacionadas con la discapacidad que padecen los afectados o los recursos para poder solicitar ayudas relacionadas con los tratamientos. El 4\% son temas internos de las organizaciones, dirigidos a los socios de la organización de forma exclusiva. Las experiencias y otras temáticas son los temas más comunes, tal y como apreciamos en el gráfico 1. 


\section{Gráfico 1. Temática de los blogs}

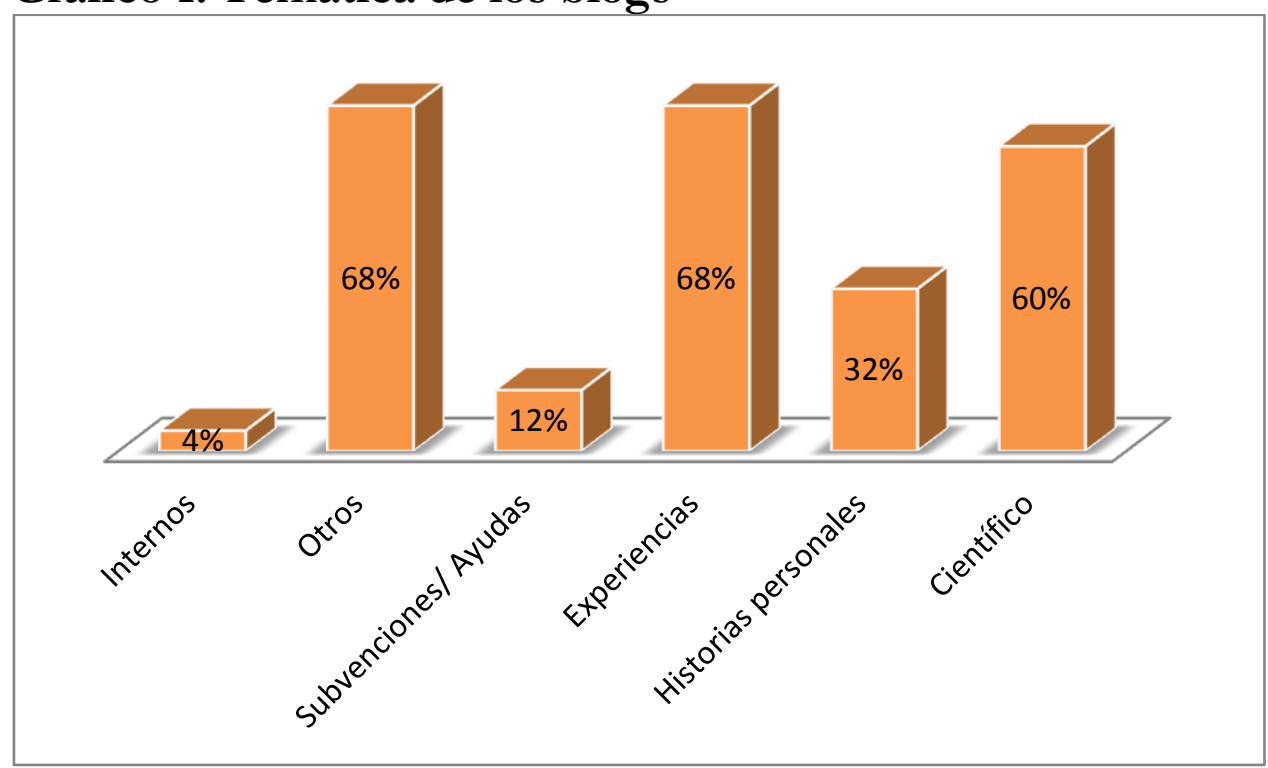

Fuente: elaboración propia

El 68\% de los blogs tienen un tono informal y el 32\% un tono formal. La mayoría están escritos por los propios pacientes. Se trata de un 76\% de blogs que elaboran los pacientes, frente a un mínimo porcentaje de blogs que tienen la autoría de médicos o personal del sector sanitario y el resto los elaboran familiares, como se refleja en el gráfico 2. Habitualmente estos familiares son padres de niños con enfermedades minoritarias que ni siquiera tienen un nombre por su rareza y se identifican con el nombre del menor que tiene dicha patología.

El 80\% de los mensajes que se emiten en el blog son informativos, intentan dar difusión de algún tema de interés para los pacientes, hay un $68 \%$ de mensajes que pretenden sensibilizar al internauta y un $36 \%$ de mensajes solidarios, cuyo fin es la búsqueda de participación activa en actos solidarios.

El 80\% de los blogs se destinan a los pacientes y el 20\% a todos los públicos. Hay un $20 \%$ de blogs que tienen como finalidad principal recaudar fondos y un $12 \%$ tiene otras finalidades.

Un 44\% de los blogs no tienen comentarios, un 32\% comentarios internos, un $24 \%$ comentarios externos y un $40 \%$ comentarios del propio autor del blog. 
Gráfico 2. Autores de los blogs

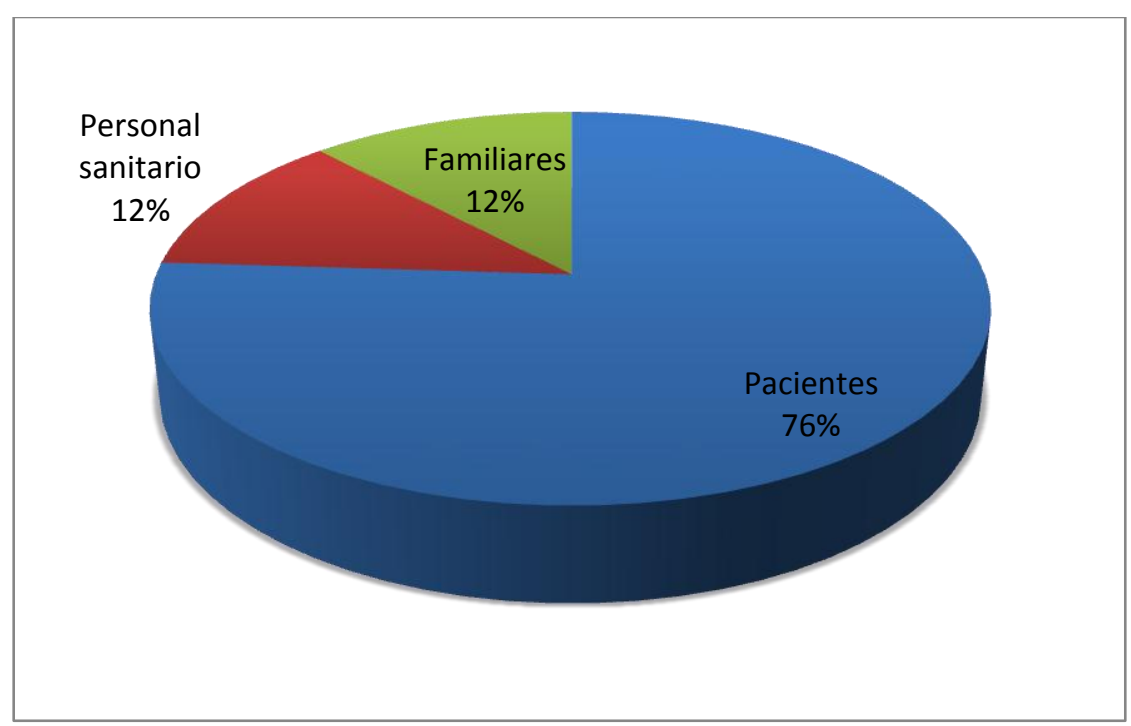

Fuente: elaboración propia

Gráfico 3. Mensajes de los blogs

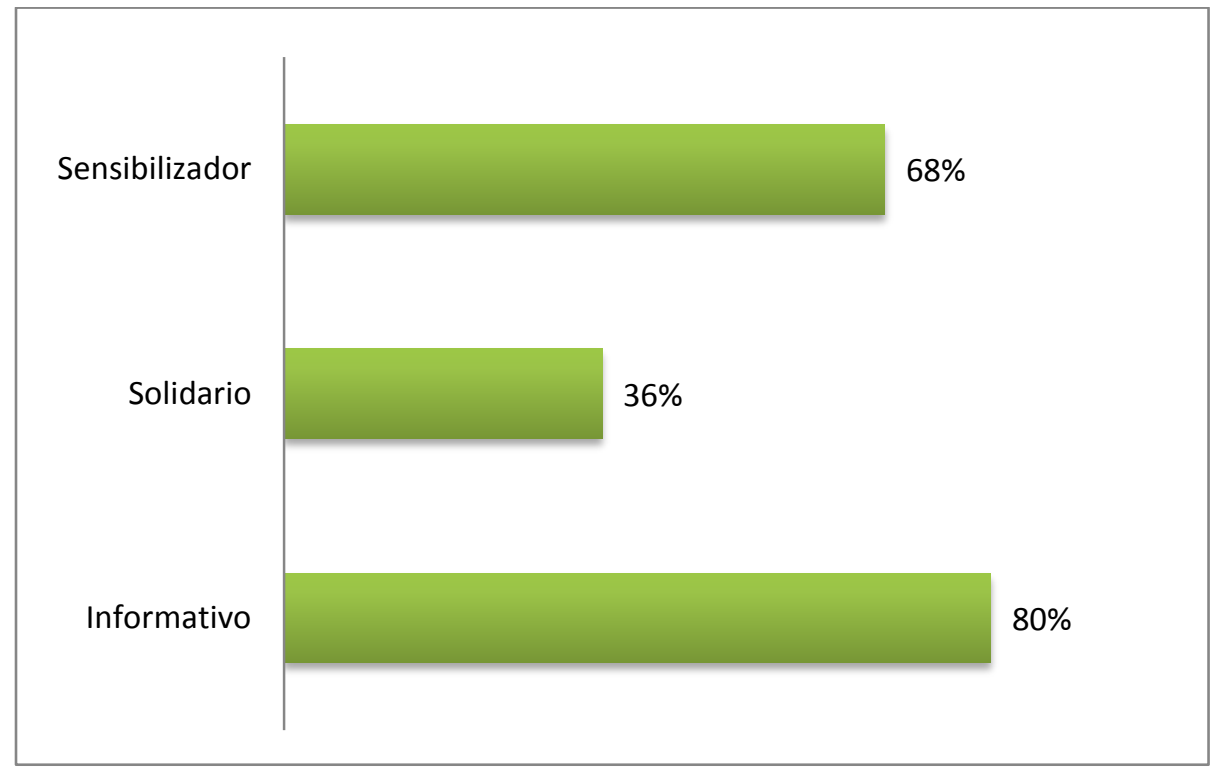

Fuente: elaboración propia

El 68\% de los blogs analizados está enlazado a la web, se puede acceder al blog a través de la web de la organización. El 44\% de los contenidos de los blogs se comparten en redes sociales. 


\section{Discusiones y conclusiones}

Este análisis aporta a los estudios llevados a cabo, una nueva perspectiva sobre la utilización de esta herramienta entre los pacientes de un colectivo cuyas líneas estratégicas de comunicación se centran en Internet. Así lo confirman Castillo et al. (2015) en investigaciones previas. Descubrimos la importancia del blog desde el punto de vista psicológico y emocional para los pacientes y familiares de estas organizaciones de enfermedades minoritarias.

Atendiendo a los objetivos, podemos concluir que el blog es una herramienta que utilizan los pacientes con un tono informal para compartir experiencias personales relacionadas con la enfermedad. Aunque también se utiliza para compartir contenido científico, pero en menor medida que la página web. Bien es cierto, que lo que se pretende es informar, pero de una forma distinta a la web, puesto que los contenidos son muy específicos, se personaliza y se abunda en las historias de los pacientes o familiares que utilizan el blog como desahogo o para compartir situaciones cotidianas.

Los pacientes se suelen relacionar a través del blog, aunque no hay muchos comentarios externos y, en su defecto, hay comentarios internos de los propios miembros de la organización. El autor de estos blogs participa, suele comentar los posts e interactuar con los internautas que visitan el mismo.

El 68\% de los blogs está enlazado a la web, es decir que desde la web se redirecciona al blog. Aunque es un porcentaje alto, sería aconsejable que todos los blogs tuvieran una relación directa con la web de la organización, ya que contaría con un mayor número de seguidores. Los autores de estos espacios podrían también considerar que aumentara el número de blogs que tuvieran la posibilidad de compartir post en redes sociales, por este mismo motivo.

En resumen, podríamos concluir que el blog para las organizaciones de pacientes con enfermedades raras es una herramienta para compartir experiencias, en la mayoría de las ocasiones personales, por encima del contenido científico. No es la principal herramienta que 
utilizan para informarse, puesto que para eso ya tienen la página web. Aunque los mensajes son informativos, también tienen carácter sensibilizador y solidario en busca de participación para causas sociales y solidarias con objeto de recaudar fondos para la investigación de estas patologías. El blog de estos pacientes tiene un carácter intimista y está dirigido fundamentalmente a otros pacientes que padecen la enfermedad y que necesitan esta herramienta como elemento de desahogo, evasión y en búsqueda de apoyo y comprensión. Es un elemento que utilizan para cubrir necesidades emocionales más que informativas.

No es la herramienta más utilizada, hay un porcentaje ínfimo de blogs frente a páginas web, el $18 \%$ de las entidades analizadas cuenta con blog entre sus herramientas de comunicación, mientras que el 99\% tienen web propia. Promocionar el blog en la web y redes sociales haría llegar estos mensajes sensibilizadores a más público, de forma que se obtendría un mayor apoyo y empatía con los objetivos que persiguen estas organizaciones.

\section{Bibliografía}

Aced, C (2013). Relaciones públicas 2.0. Cómo gestionar la comunicación corporativa en el entorno digital. Barcelona: Editorial UOC.

Avellaneda, A, Izquierdo, M, Torrent-Farnell, J y Ramón, J R (2007). "Enfermedades raras: enfermedades crónicas que requieren un nuevo enfoque sociosanitario". Anales del Sistema Sanitario Navarra, 30(2), 177-190.

Buis, L R y Carpenter, S (2009). "Health and medical blog content and its relationships with blogger credentials and blog host". Health Communication, 24(8), 703-710.

Castillo Esparcia, A, López Villafranca, P y Carretón Ballester, M C (2015): "La comunicación en la red de pacientes con enfermedades raras en España". Revista Latina de Comunicación Social, 70, 673-688. 
González-Pacanowski, T y Medina-Aguerrebere, P (2011). "Blogs para pacientes como nueva fuente de información de salud". El profesional de la información, 20(6), 652-658.

López Villafranca, P (2015). “Análisis de las campañas de comunicación de pacientes con enfermedades raras en España”. Opción, 31(1), 1039-1055.

March, J C (2014). "La salud 2.0, los blogs y las revistas científicas". Revista de Calidad Asistencial, 29(1), 1-2.

Orihuela, J L (2008). Internet: la era de las redes sociales. Conferencia presentada en el Programa de Doctorado sobre la Sociedad de la Información y el Conocimiento, Universitat Oberta de Catalunya, España.

Ribes, M G (2012). "Genética: raras y no tan raras...”. AMF, 8, 135141.

Torres-Salinas, D y Robinson-García, N (2012). "Los blogs de salud y la gestión online de información médica”, 51-56.

En Medina Aguerrebere, PabO Y González Pacanowski (eds), La comunicación médica interactiva: el desafio de Internet. Madrid: Fragua.

Valverde, J. A. (2008). "Oportunidades y retos de la Web2. 0 para la salud: blogs”. Bit, 170, 72-75. 


\title{
Análisis etnográfico en la búsqueda de información de salud por jóvenes y adolescentes vascos
}

\author{
Milagros Ronco \\ Universidad del País Vasco \\ Euskal Herriko Unibertsitatea, UPV/EHU \\ Carmen Peñafiel \\ Universidad del País Vasco \\ Euskal Herriko Unibertsitatea, UPV/EHU \\ Lázaro Echegaray Eizaguirre \\ Escuela Universitaria de la Cámara de \\ Comercio de Bilbao, EUCCB
}

\section{Resumen}

Introducción: Nuestro objeto de estudio se sitúa en torno a las búsquedas que realizan los jóvenes y adolescentes en Internet sobre temas relacionados con la salud, conocidas como 'hábitos de vida saludable'. Objetivos. Nos planteamos conocer, a través de una observación directa, si los jóvenes y adolescentes consideran que las webs cumplen con los criterios de 'calidad' de la información, analizar su experiencia de navegación, así como determinar hasta qué punto estiman que es importante el criterio de confidencialidad. Metodología. Se realiza un estudio etnográfico con grabación en vídeo a jóvenes y adolescentes que consideramos representativos. Conclusiones. Comprobamos el criterio principal de 'calidad' que se le otorga a la fiabilidad así como, en general, la falta de planteamiento 
de estrategias previas cara a las búsquedas. Por último, comprobamos su criterio sobre la confidencialidad que deben guardar las webs.

Palabras clave: investigación cualitativa; estudio etnográfico; salud y jóvenes; salud y adolescentes; webs de salud; calidad.

\section{Introducción. Justificación del entorno}

\section{L}

AS DENOMINACIONES 'Generación Net', 'Generación interactiva', 'Generación digital' o 'Generación i'/'Generación byte' para los nacidos entre 1994 y 2004, son términos con los que se designa a los jóvenes que han crecido rodeados de nuevas tecnologías que utilizan en su día a día para comunicarse, formarse, entretenerse, y que suponen el segmento de población más activo a la hora de su utilización. A partir de la llegada de Internet, las generaciones jóvenes viven en permanente búsqueda de información.

Puede decirse que, por primera vez, son los individuos más jóvenes los que toman la iniciativa, actuando como conductores (drivers) en lo que se refiere al empleo de las TIC y las funciones que emprenderán de forma intercomunicada (Rubio Gil, 2010: 201). Internet facilita el aprendizaje entre iguales porque es un entorno propicio a los procesos informales de aprendizaje. En Internet el conocimiento social, cultural, profesional y/o técnico se comparte de manera informal y merece el reconocimiento de todos los implicados (Fernández-Ardévol, 2012: 19).

Los nuevos medios de comunicación en la Red se han convertido en un lugar de socialización y educación para las generaciones más jóvenes. Contribuyen a la socialización y son por sí mismos medios en los que hay que saber desenvolverse, de manera que es necesario adquirir competencias para gestionarlos adecuadamente. Parte de la socialización secundaria, la que se produce después de los primeros años de infancia y a lo largo de toda la vida, pasa actualmente por estos nuevos medios.

$\mathrm{Y}$ en ese ámbito es en el que puede abordarse el camino del empoderamiento en salud. La necesidad de adquirir hábitos 
saludables surge como un tema de gran interés para los jóvenes y que tiene un componente cultural: se aprende principalmente en el hogar, se refuerza en el colegio y en las relaciones con los grupos de iguales. Los medios de comunicación -especialmente Internet- juegan un papel importante a la hora de que los jóvenes interpreten la salud. La educación sigue siendo la clave y la información entre los más jóvenes debe tener una función preventiva a partir de la infancia para reforzarla en las sucesivas etapas evolutivas. Para ello, hay que primar el enfoque educativo, entendiéndolo como la divulgación de una información veraz fomentando los hábitos saludables, explicando los riesgos de una mala alimentación, de enfermedades nuevas, la importancia del deporte para la salud y el desarrollo de habilidades que ayuden a comportarse de manera saludable (Peñafiel, Ronco, Echegaray, 2015: 319).

\section{Objetivos e Hipótesis 2.1. Objetivos}

¿Qué les preocupa a los jóvenes?, ¿dónde acuden para buscar información o pedir ayuda?, ¿qué tipo de información buscan?, ¿qué calidad tiene esta información? Dado que Internet se está convirtiendo en una de las principales fuentes de información y recursos, es importante y necesario conocer el uso que adolescentes y jóvenes hacen en relación a la salud como paso previo al diseño de estrategias dirigidas a la mejora de la información, el acceso a los recursos de salud y, en definitiva, de su calidad de vida (Guillamón, Martínez, 2012: 103).

El porcentaje de usuarios que realiza búsquedas sobre temas de salud en 2015 es el 67,7\%, y es una cifra que no deja de crecer. Según los datos del ONTSI, en 2013 el porcentaje de internautas españoles que realizaron búsquedas sobre temas de salud era del 65,20\%. Los estudiantes y las personas con estudios universitarios, así como los jóvenes de 16 a 24 años, prácticamente han llegado al 100\% en cuanto al porcentaje de internautas semanales se refiere, según se expone en el Informe anual 2015 del ONTSI. 
Figura 1. Porcentaje de internautas en cada categoría por edad (\%)

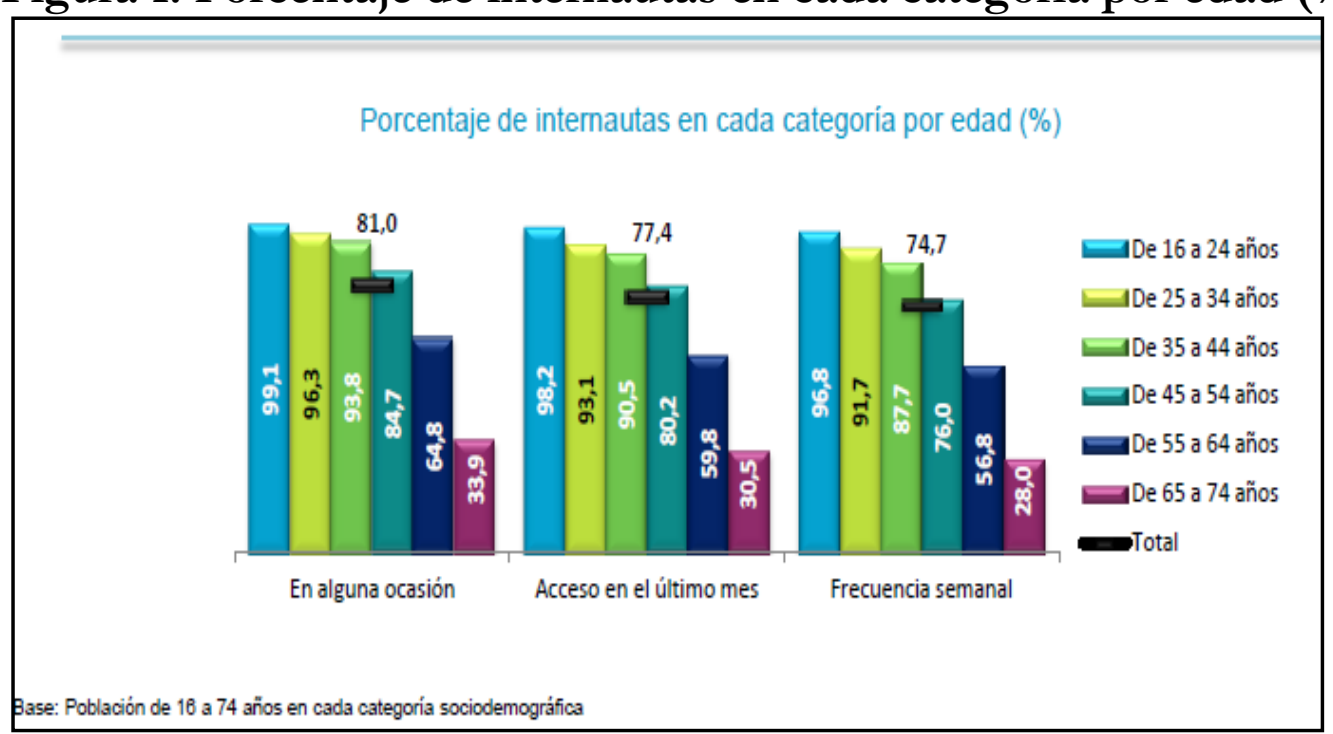

Fuente: ONTSI, enero 2016

Para estas generaciones la vida online tiende a ser, en la mayoría de casos, una extensión de la vida offline (Tabernero, Aranda, SánchezNavarro, 2010: 94). Gracias a las TIC, las comunidades de jóvenes y adolescentes son, ahora, comunidades de práctica a tiempo completo (Castells, Fernández-Ardèvol, Qiu, Sey, 2006) en las que la localización de los individuos ya no limita las comunicaciones.

Así pues, nos planteamos conocer 'desde dentro' y a través de la observación directa y participante, si los jóvenes y adolescentes consideran que la estructura de las webs y los contenidos cumplen con los criterios de calidad de la información y si consideran que las webs de salud tienen una perspectiva educativa en hábitos de vida saludable. Junto a esto, pretendemos determinar hasta qué punto consideran que es importante y si se cumple el criterio de confidencialidad, de no invasión de su intimidad durante el proceso de navegación y búsqueda de información.

En cuanto a los objetivos específicos, pretendemos analizar su experiencia de navegación, las posibles relaciones e interacciones entre pares existentes en ella, así como la existencia de complicidades en el plano de la confidencialidad durante el proceso de navegación. 


\subsection{Hipótesis}

Según reflexiona Ángeles Rubio (2010: 218), las personas jóvenes han integrado Internet en sus vidas mucho más allá de las funciones recreativas con las que tal medio suele asociarse y a las que se añaden otras como son la información, la integración/socialización, el acceso a la industria cultural y a la formación. Jóvenes y adolescentes mantienen unas pautas concretas de uso de Internet, que describen nuevos patrones de ocio y de acercamiento a la información

En consecuencia, podemos decir que se parte de la premisa de que todos los jóvenes/adolescentes tienen un amplio dominio en el uso de la tecnología y que la aprovechan en todos los ámbitos. No obstante, existen puntos cuestionables como sería el caso del interés por las búsquedas de temas de salud. Los datos oficiales confirman ese interés al alza, pero debemos tener en cuenta que la horquilla de edad entre 12 y 24 años no contempla los problemas de salud como algo habitual. En ese sentido, formulamos las siguientes hipótesis:

1. Los jóvenes opinan que las webs de salud cumplen solo en parte con los criterios de calidad de la información, sobreentendiendo la calidad, ante todo, como fiabilidad en el recurso.

2. La experiencia de navegación es amplia, pero las búsquedas las hacen por intuición y costumbre, no mediante el planteamiento de estrategias previas.

3. Consideran imprescindible el criterio de confidencialidad.

\section{Estado del arte}

Los métodos cualitativos de recolección de datos como son las entrevistas y la observación, entran de lleno en lo que se conoce como métodos etnográficos. La observación, en especial la observación participante, ha sido utilizada en varias disciplinas como instrumento de la investigación cualitativa para recoger datos sobre la 
gente, los procesos y las culturas (Kawulich, 2005). El trabajo de Bárbara Kawulich proporciona una revisión de varias definiciones de la observación participante, la historia de su utilización, los objetivos para los cuales se ha usado, las posturas del observador y cuándo, qué y cómo observar. Se discute, asimismo, la información para tomar y escribir notas de campo.

Los métodos de observación son útiles a los investigadores en una variedad de formas. Proporcionan métodos para revisar expresiones no verbales de sentimientos, determinan quién interactúa con quién, permiten comprender cómo los participantes se comunican entre ellos y verifican cuánto tiempo se está invirtiendo en determinadas actividades (Schmuck, 1997). A su vez, DeWalt y DeWalt (2002: 92) creen que "la meta para el diseño de la investigación usando la observación participante como un método, es desarrollar una comprensión holística de los fenómenos en estudio que sea tan objetiva y precisa como sea posible, teniendo en cuenta las limitaciones del método". Ambos autores sugieren que la observación participante sea usada como una forma de incrementar la validez del estudio, como observaciones que puedan ayudar al investigador a tener una mejor comprensión del contexto y el fenómeno en estudio. La validez es mayor con el uso de estrategias adicionales que se puedan utilizar junto a la observación. Teniendo esto en cuenta, hemos recogido también algunas fuentes que utilizan técnicas cualitativas de entrevista o similares, como el caso de los grupos de discusión.

En España se han realizado pocos estudios etnográficos para conocer los patrones de búsqueda de información de salud en Internet y la percepción sobre la calidad de estos recursos que tienen los jóvenes. Por lo que podemos percibir, es una técnica especialmente aplicada al ámbito de la educación y la psicología. Esta situación nos permite estar dentro del grupo pionero en este tipo de investigación. Hemos encontrado muchos análisis etnográficos hechos a jóvenes y adolescentes, pero en su inmensa mayoría eran estudios con finalidad pedagógica o psicológica, sin mención a las TIC. Enfocados hacia Internet hemos hallado otra parte importante de los estudios etnográficos localizados sobre jóvenes y adolescentes, que se centra en los peligros de adicción y de carencia de socialización, del 
aislamiento que se le atribuyen a las nuevas tecnologías y, por lo tanto, entran en juego las consideraciones de salud en el campo psicológico; se incide muy especialmente en el tema de redes sociales. Una obra que emplea esta técnica cualitativa y entra de lleno en nuestra consideración es la tesis doctoral (UPV-EHU) de Lucía Merino (2011a), así como uno de sus trabajos publicado en diciembre de 2011(2011b). En la misma línea están Adriana Gil, Joel Feliu, Isabel Rivero y Eva Patricia Gil (2003) y la obra coordinada por Adriana Gil y Montse Vall-Llovera (2006).

A nivel internacional, destaca el trabajo de Mizuko Ito et al (2008) promovido por la Fundación MacArthur y que se inicia en 2005. Este trabajo es único en su amplitud, debido al número de estudios de caso que abarca. Comprende veintitrés estudios de caso sobre prácticas, poblaciones y sitios webs juveniles distintos, principalmente en Estados Unidos, y resume los resultados de un estudio etnográfico de tres años con el examen de la participación de los jóvenes en la nueva ecología de los medios. Representa una versión condensada de un tratamiento más prolongado de los resultados del proyecto.

En 2008, a raíz de su publicación, los autores especificaban que aunque el Reino Unido había financiado algunos estudios cualitativos a gran escala sobre la implicación de la juventud con los nuevos medios (Holloway y Valentine, 2003; Livingstone, 2002) en los Estados Unidos no existían estudios comparables que abarcasen diferentes poblaciones y prácticas con nuevos medios. "Lo que falta en la literatura de investigación en general, y en la de Estados Unidos en particular, es un entendimiento sobre cómo las prácticas con nuevos medios están incrustadas dentro de una ecología social y cultural más amplia" (Ito et al, 2008: 5).

En 2010, Mizuko Ito y su equipo de investigación vuelven a publicar otra obra, utilizando las mismas técnicas etnográficas, que ha tenido una gran repercusión internacional: Hanging out, messing around, and geeking out: kids living and learning with new media. Este libro se basa en un trabajo que abarca 20 proyectos de investigación distintivos que se enmarcaron dentro de cuatro áreas principales: hogares y barrios, 
espacios institucionales, sitios web y grupos de interés ${ }^{22}$. En esta obra proponen una clasificación basada en las prácticas comunes y las categorías culturales que estructuran la participación de los jóvenes en los nuevos medios. Se trata de una clasificación de los modos de participación a través de esos nuevos medios, que están cambiando la forma en que los jóvenes aprenden, juegan, se socializan y participan en la vida cívica.

Un tema especialmente importante dentro del ámbito de la salud y para cuya exposición y control hemos comprobado que se emplea la técnica etnográfica, es el de las adicciones a las drogas. Es el caso de la obra Tecnologías de la comunicación, jóvenes y promoción de la salud (2012), editada por la Consejería de Salud y Servicios Sociales del Gobierno de la Rioja y coordinada por Laura Pérez, Cristina Nuez y Juan Del Pozo. Otro tema importante por los problemas que conlleva (VIH, embarazos no deseados y a edad temprana, agresiones sexuales, etc.) es el de la educación sexual. Utilizando técnicas cualitativas, entre ellas las etnográficas, la Fundación Salud y Comunidad ha presentado a finales de 2015 Noctámbul@s, Informe sobre drogas y sexualidad 2014-15 del Proyecto Cualitativo sobre la Relación entre el Consumo de Drogas y los Abusos sexuales en Espacios de Ocio nocturno llevado a cabo por el Observatorio Cualitativo en torno a la relación entre el consumo de drogas y los abusos sexuales. Su actividad se inscribe en una línea de trabajo sobre la interacción entre las violencias de género y las drogas. El estudio se enmarca en una línea de prevención y reducción de riesgos, partiendo de un enfoque basado en acciones de intervención universal y selectiva. El Observatorio, financiado por el Plan Nacional sobre Drogas, inició su andadura en 2013. El informe está basado en los resultados obtenidos entre octubre de 2014 y septiembre de 2015. En nuestro campo de estudio entran también diversos temas que acoge el Centro Reina Sofía sobre Adolescencia y Juventud $^{23}$. No obstante, entre las técnicas empleadas en las

\footnotetext{
${ }^{22}$ Descripciones completas de las investigaciones individuales de los miembros de Digital Youth Project se pueden consultar en http://digitalyouth.ischool.berkeley.edu/report

23 De la Fundación de Ayuda contra la Drogadicción. Su objetivo es la promoción y el desarrollo de análisis multidisciplinares sobre el contex to social y cultural de adolescentes y jóvenes y sobre su socialización y los
} 
investigaciones propiciadas en este Centro no se encuentra el análisis etnográfico.

\section{Metodología}

Dentro de las diferentes metodologías que manejamos a lo largo de nuestra investigación, el trabajo que ahora presentamos se centra en el análisis etnográfico. Con la finalidad de incardinar su papel en nuestro estudio, haremos mención de las opciones generales elegidas. La metodología propuesta para el conjunto del trabajo de investigación es del tipo mixto, ya que utilizamos métodos y técnicas de investigación cualitativas y cuantitativas. El universo de sitios web está conformado por todos aquellos recursos en español y en euskera mostrados en la Red y dirigidos a jóvenes y adolescentes en el ámbito del País Vasco y de Navarra. La investigación se ha llevado a cabo en 5 fases: a) entrevistas en profundidad; b) análisis de contenido de las webs seleccionadas; c) establecimiento de grupos de discusión (focus group); d) análisis etnográfico y e) encuesta a una muestra representativa de jóvenes y adolescentes.

El análisis etnográfico busca aproximarse a la realidad de una manera flexible y enfocada a estudiar a las personas en relación a su cotidianidad y su entorno mediante la recolección de datos a través de un trabajo de campo que tiene lugar en su contexto natural. El investigador se involucra personalmente en el entorno objetivo del estudio, observa y acumula información. En consecuencia, hemos profundizado en el estudio de las reacciones de jóvenes y adolescentes frente a la información de salud ofrecida en Internet (Peñafiel, Camacho, Pastor, 2013: 10; Peñafiel, Ronco, Echegaray, Camacho, 2014: 304; Peñafiel et al, 2015: 319). Para el cumplimiento de este apartado de la investigación hemos seleccionado una muestra mediante muestreo no probabilístico de bola de nieve; dos unidades de cada una de las tipologías determinadas: hombre y mujer en los sectores de edad 12-17/18-24 respectivamente, cuatro jóvenes estudiantes de los que dos corresponden a Enseñanza Secundaria y

riesgos que amenazan a ésta.

http://adolescenciayjuventud.org/es/publicaciones/monografias-y-estudios/2 
dos a Enseñanza Universitaria. Esta fase se desarrolló en tres partes durante los meses de noviembre y diciembre de 2014 y enero de 2015.

Esta metodología utiliza básicamente la entrevista, pero también exige observación y grabación (Silverman, 2013: 213). Así pues, el guión establecido se ha soportado en las grabaciones directas y en cuadernos de campo en los que se ha tomado nota de todas aquellas acciones interesantes y espontáneas. De esta forma, "el guión sirve para poder realizar preguntas a la vez que enmarca el cuadro de atención de la observación" (Silverman, 2013: 217).

Como establece el método, se preparó un guión para aplicar tanto al estudio etnográfico como al de encuesta. En conjunto planteamos una batería de 57 preguntas para la fase de encuesta ${ }^{24}$. Las preguntas fueron distribuidas en cinco bloques con contenidos que giraban en torno a las opiniones y costumbres personales sobre la salud y sobre el uso de Internet por parte de los jóvenes y adolescentes.

De la batería de preguntas inicial que debían ser respondidas mediante encuesta, seleccionamos un total de 26 para que fueran respondidas por los/las estudiantes del apartado etnográfico y le añadimos 5 preguntas últimas que debían responder solamente los participantes en el análisis etnográfico. Las distribuimos en dos bloques, dejando un tercer bloque para la experiencia de navegación y preguntas libres (observación participante) por parte del investigador:

1.- Seguimiento básico (26 preguntas).

2.- Grabación individual de la búsqueda de información. Preguntas puntuales según se fuera desarrollando la búsqueda.

3.- Conclusiones y valoración final tras la grabación individual (5 preguntas).

\footnotetext{
${ }^{24}$ Se cumplimentaron 250 cuestionarios distribuidos en las Comunidades Autónomas del País Vasco y Navarra durante los meses de noviembre y diciembre de 2014.
} 
Mediante este tipo de análisis hemos pretendido observar las características básicas de navegación de los jóvenes que componen el universo del estudio, a la vez que se les preguntaba sobre los pasos dados. La finalidad era conocer su experiencia de navegación y sus reacciones ante la información a la que iban accediendo. En este momento el proceso de investigación ha viajado de la fase grupal, en la que se desarrollaba la etapa anterior, a la individual, obteniendo valoraciones referentes a la navegación, acceso, interacción, atención, nivel de respuesta etc. La información resultante ha sido recogida en formato de vídeo/audio, así como en anotaciones en 'cuadernos de campo’. El tiempo de búsqueda se estableció en unos 40 minutos, pero se les permitió continuar si esa era su elección. El tiempo máximo utilizado fue de 75 minutos frente a un mínimo de 35. En todos los casos, se ha mantenido el anonimato.

\section{Resultados del análisis etnográfico}

Los participantes en el estudio han tenido libertad para elegir los temas de sus búsquedas. No ha habido interferencias por nuestra parte ni indicaciones acerca de determinados temas preferentes. Han argumentado adecuadamente la elección del tema en cada caso, así como de las fuentes a las que han accedido para conseguir la información. Han respondido en todo momento a las cuestiones que sucesivamente les hemos ido planteando dado nuestro carácter de observadores participantes. Los temas abordados han sido:

$\checkmark$ Chica adolescente. Nerea, 17 años. Alimentación sana/nutrición saludable y dietética.

$\checkmark$ Chico adolescente. Gorka, 17 años. Personalidad límite.

$\checkmark$ Chica universitaria. Leire, 24 años. Enfermedad de Crohn.

$\checkmark$ Chico universitario. Gaspar, 20 años. Nutrición para conseguir definición de masa muscular. 


\subsection{Utilización de recurso}

A la hora de buscar ayuda y consejo en temas de salud, todos ellos han acudido de forma automática y en primer lugar a fuentes de información no humana: concretamente a Internet. Ahora bien, si lo consideraban muy preocupante, acudían en primer lugar a la familia y en segundo lugar al médico. Internet, en todo caso, nunca ha sido una fuente definitiva, ni la única, ni la han considerado la mejor. Pero ha sido la que estaba 'más a mano'.

Todos ellos han utilizado Google como principal motor de búsqueda. Como canal de vídeo aparece en primer lugar YouTube. Las redes sociales no han sido apenas utilizadas en las búsquedas que les hemos solicitado sobre temas de salud, excepto en el caso de la chica adolescente, que utilizó Instagram para buscar temas de alimentación, nutrición y ejercicio y que lo utiliza habitualmente, junto con YouTube, porque considera que son de rápido acceso. En algún caso no explican el motivo por el que no utilizan las redes sociales para búsqueda de temas de salud. En otros, la respuesta es que las redes no les parecen los sitios adecuados para encontrar información de este tipo de temas, así que no los buscan en esos ámbitos. Los foros y los blogs tampoco han sido apenas utilizados, exceptuando al chico universitario que considera que en los blogs existe interés y preparación y se molestan en responder. Pero nunca los utilizaría en temas en los que quisiera mantener la confidencialidad, porque potencialmente lo está viendo mucha gente; otra cosa es consultar webs especializadas, o incluso a especialistas que respondan personalmente a cada usuario. El adolescente acude a los blogs o a los foros de forma muy esporádica: no le parecen fiables, no hay filtros. Ninguno de ellos deja nunca comentarios en la Red, bien sea porque no les interesa, bien porque se requiere el abrir una cuenta que, aunque sea gratuita, les supone pérdida de tiempo para la escasa utilización que hacen de esos recursos. Las chicas no reparan en los blogs ni en los foros para estos temas. 
Tabla 1. Utilización de los recursos web para la búsqueda de información en salud

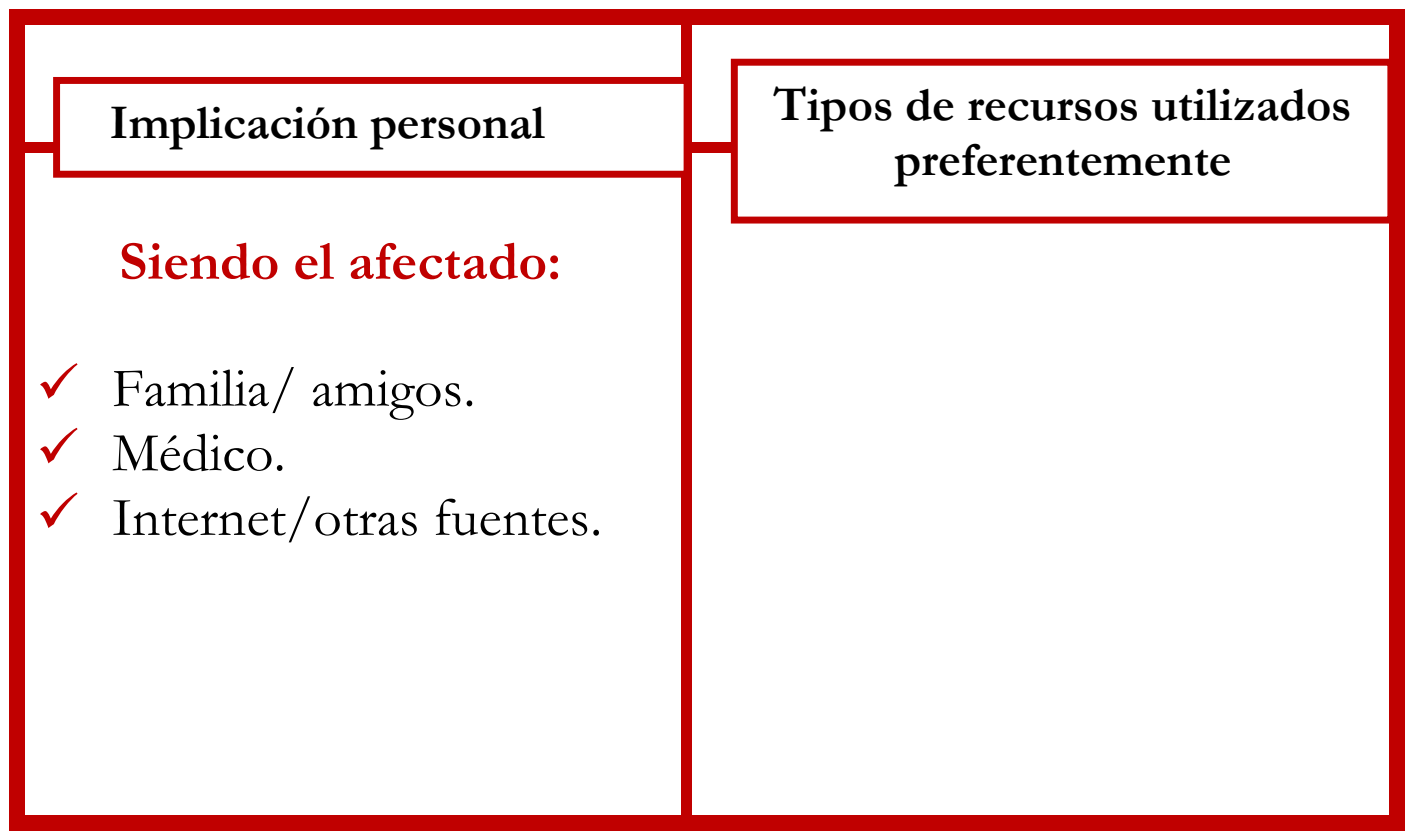

Fuente: elaboración propia

\section{2. ¿Informan bien los Medios de Comunicación sobre lo que interesa a los jóvenes?}

Hay disparidad de opiniones. En general opinan que la información que de verdad interesa es escasa y, cuando se necesita algo, cada uno tiene que buscarla por su cuenta. En uno de los casos, se opina que no es responsabilidad de los medios el informar sobre salud y que, cuando informan, no deberían tener motivaciones más allá de lo que es noticia. No consideran que los Medios deban cumplir con un papel de educación y concienciación sobre la propia salud. El chico adolescente echa en falta una adecuada explicación sobre la información: "normalmente me quedo 'a medias'. Explican parte pero no explican por qué. Por eso vuelvo a buscar. Me dicen algo, pero no me quedo del todo satisfecho".

A la pregunta de si los medios tienden a informar de una manera alarmista sobre salud, todos opinan que sí, pero que informan en general solo de lo que es noticia y -salvo en opinión del chico universitario- hay otros temas que no son noticia y necesitarían que se 'alarmase' más a la población para tomar conciencia. Opinan que de 
los temas más profundos de salud, no se informa bien; que se quedan en lo 'superficial': cómo estar bien físicamente (el aspecto), la alimentación, la estética... Creen que los temas en los que hay una alarma son puntuales. En palabras de la universitaria:

"Los Medios a veces me parecen un poco alarmistas, pero otras veces deberían sensibilizarnos sobre determinados temas y quizá no se hace. Por ejemplo, el problema de las drogas es un problema significativo en los adolescentes $\mathrm{y}$, sin embargo, no creo que sea algo que estemos oyendo continuamente y habría que alarmar un poco más. Creo que los temas en los que hay una alarma son más esporádicos, puntuales, y no tanto temas realmente importantes a lo largo del tiempo".

El chico universitario lo considera parte del negocio de los Medios:

"Generalmente sí, porque al final son los que tienen mayor voz y la tienen precisamente porque hacen eso. Puede haber otros Medios de comunicación que cuando informan sobre la salud lo hacen de manera seria y rigurosa (...) Ocurre que los que no lo hacen por informar, sino por amarillismo, al final suelen tener mayor difusión, porque la gente suele caer con mayor facilidad".

\subsection{Nivel de fiabilidad que les merece Internet}

Hay diferencia de apreciaciones entre las respuestas de los adolescentes respecto a los universitarios. Los adolescentes responden de forma ecléctica, pero con el mínimo contenido. Según la chica, "se puede encontrar de todo. Puedes encontrar información muy contrastada y especializada o poco fiable". Según el chico, "es difícil decir que lo que encuentras en Internet es altamente fiable. En un principio es medianamente fiable y, luego, ya depende de la página”.

La reacción de los universitarios hace que sus respuestas y puntualizaciones se extiendan bastante más. Ambos consideran que Internet es fiable, pero no por sí mismo. Que hay que saber hacer la búsqueda y tener criterio y que, si se es capaz de identificar la información con visos de ser buena, se puede encontrar mejor que en 
cualquier otro lugar. Es decir, cargan la responsabilidad de la fiabilidad en el usuario, nunca en la fuente.

"Es muy importante la experiencia y el sentido crítico de quien busca la información, porque puede haber información muy buena o no, fiable y no fiable, lo importante es que quien la consume sea crítico y sepa identificar las fuentes; la información y el por qué de esa información".

A mayor abundamiento, el entrevistado universitario puntualiza:

"No le pediría ningún control a las webs, no es su responsabilidad. Quien tiene que tener esa responsabilidad y sentido crítico es el que consume el contenido y debe saber identificar lo fiable".

Considera que el principal problema es que la información esté desubicada y que eso ocurre en muchas ocasiones. Puede ser de muy buena calidad y muy fiable, pero que no responda a lo que se pide.

\subsection{Internet como complemento de información de salud}

En general, consideran que su salud no es lo que más les preocupa actualmente que, en todo caso, son temas puntuales. Por iniciativa propia buscan temas que les llamen la atención, por curiosidad cultural y también para mantener la salud, para conocer hábitos de vida saludable. En el terreno de preparar la visita al médico y complementar su información después, todos dicen que sí, que lo hacen, aunque depende del problema. En el primer caso admiten que, si algo les preocupa, buscan previamente información, aunque muchas veces son problemas recurrentes y ya no les hace falta buscar. Lo mismo sucede con el complemento de información tras la visita al médico. En todo caso, siempre entran en más de una web para informarse y contrastar la información.

En temas de salud estricta, casi todos ellos buscan en primer lugar para otras personas, no para ellos: familiares, amigos... porque cerca de ellos se ha producido algún caso que afecta a la salud y desconocen su alcance. Incluso la adolescente con diabetes nos dice que los temas 
de salud que le son propios no los consulta por Internet, que está directa y completamente asesorada por sus especialistas.

\subsection{Problemas ocasionados por la información en Internet}

En no pocas ocasiones la información que encontramos en Internet puede ser fiable y cierta, pero no completa. En consecuencia, puede ser inadecuada. A la mayoría de los jóvenes participantes en el estudio ese problema no les ha afectado, pero opinan que sí puede acarrear consecuencias negativas. En este sentido, tenemos la experiencia concreta del chico universitario:

"Mi búsqueda tiene relación con la pregunta $22^{25}$ precisamente emulando las búsquedas que hice en su día sobre temas de nutrición para conseguir definición muscular, porque sí que me hizo daño. Cuando comencé a buscar ese tema aún no tenía idea de cómo conseguirlo, ni si era compatible con ganancia de masa muscular mientras se mejoraba el rendimiento en los entrenamientos... Me guiaba por la idea que hay en general, de cultura general de la población, y la verdad es que hay mucha incertidumbre; es como que hay mucho mito, algo que se escapa de lo exacto".

\subsection{Contenido y aspecto en las páginas web de salud}

A la pregunta de cómo sería una página web atractiva con información de salud, opinan que tiene que ser una página con claridad (texto e imagen); las imágenes tienen que ser de calidad; el tema tiene que estar presentado correctamente, es decir, que se pueda entender sin demasiados términos técnicos pero tampoco en un idioma muy coloquial. Siempre está bien que den la opción de participación a través de comentarios o foros o chats a la gente, aunque no lo utilicen demasiado. Que exista actualización de

\footnotetext{
${ }^{25}$ Pregunta $n^{\circ} 22$ del guión: ¿El hecho de haberme informado en internet sobre salud me ha ocasionado algún problema, bien por usar esa información de manera inadecuada o bien por ser falsa?
} 
contenidos y que permita una navegación e interrelación de temas, usuarios y fuentes de información.

Interrogados sobre el aspecto de la calidad, y solicitando que marquen determinadas casillas que hacen alusión a diferentes tipos de webs de salud, se decantan unánimemente por las webs de organismos oficiales. El entrevistado adolescente, nos comenta: "pienso que cualquiera tiene calidad (en alusión a webs de organismos oficiales); por lo menos tienen rigor, con ganas de querer ayudar y no para venderte algo. Pero entre ellas se pueden diferenciar porque unas estén mejor organizadas que otras".

Consideran, en principio, que cualquier web de un organismo oficial y/o profesional tiene calidad (fiabilidad más bien). Interrogados sobre el aspecto de las páginas web, una parte considera que su diseño es poco atractivo, pero que no les parece necesario que haya más diseño. Un entrevistado considera que son atractivas en general, porque suelen ofrecer una interfaz fluida y suelen ser funcionales. En todos los casos esperan que el contenido sea atractivo, no tanto la apariencia. Aunque la apariencia resulte especialmente importante para los adolescentes.

\subsection{La confidencialidad}

Todos la consideran de cumplimiento obligado para la libertad de búsqueda e, invariablemente, marcan el máximo en el baremo establecido en la pregunta. No obstante lo consideran imprescindible como punto de partida, aunque no lo tienen en cuenta a la hora de la búsqueda. Solo cuando se les menciona la posibilidad de que la confidencialidad falle, se plantean lo que podría acontecer. De hecho, la reacción del entrevistado universitario fue la siguiente: "a mí, en este momento, no me importa mucho. Sí que puedo entender que lo sea para otras personas y para mí en el futuro. Eso no quita para que yo quiera que sean confidenciales. No ahora por mí, sino en general por toda la población. Creo que es imprescindible". 


\section{Discusión y conclusiones}

Hemos comprobado que Internet no es para ellos la fuente definitiva ni la más válida de entrada, ya que, invariablemente, le otorgan mayor confianza humana a la familia y mayor fiabilidad profesional al médico. Esta conclusión no es aplicable a la franja de edad entre 12 y 16 años, que tienen a Internet básicamente como una plataforma lúdica ${ }^{26}$ y para buscar información de los deberes de clase. En esta franja de edad, la fiabilidad se deposita en los padres y madres en primer lugar, en segundo lugar en el médico y de Internet 'se fían poco'. Así pues, en función de las hipótesis planteadas:

1. Comprobamos que el criterio principal de 'calidad' se le otorga a la fiabilidad en la fuente. Valoran otro criterio, que es conocer la autoría de esa fuente, pero es un elemento de calidad que a su vez enlaza con la fiabilidad. Para todos ellos, el elemento de calidad es la propia información, que tenga enlaces interesantes y, para los más jóvenes, es imprescindible que esté bien presentada.

2. Comprobamos, en general, la falta de planteamiento de estrategias previas cara a las búsquedas. Sus actuaciones se guían por la intuición y esperan que los grandes motores (Google principalmente) respondan a sus demandas sin establecer estrategia alguna. De ahí que para ellos sean tan importantes los enlaces y los vídeos relacionados, porque les van orientando hacia distintas posibilidades que no tenían previstas.

3. Consideran absolutamente necesario que una web de salud guarde la confidencialidad. Ni se lo plantean como un elemento más de calidad que podría no existir: se convierte en un requisito obligado.

Hemos comparado las conclusiones del estudio etnográfico que presentamos con aquellas extraídas del análisis de calidad de las webs de salud dirigidas a jóvenes y adolescentes llevadas a cabo en el

\footnotetext{
${ }^{26}$ Tema abordado en un artículo anterior y que se ha estudiado en el mismo Proyecto de Investigación: http://www.revistalatinacs.org/070/paper1048pv/18es.html
} 
Proyecto de investigación al que se alude al final de este apartado. Observamos que una de las principales conclusiones respecto a la calidad, ha sido la confirmación del cumplimiento del objetivo de educación en salud por parte de las webs, ayudar a las generaciones jóvenes a construir estilos de vida saludable, ayudar a prevenir problemas en el futuro. Nuestro estudio ha comprobado que la mayoría de estos recursos, un $83 \%$ de las webs analizadas, cumplen con el objetivo de educación en salud como forma de prevenir comportamientos nocivos.

No obstante, la percepción que tienen los adolescentes y jóvenes de esa realidad, y que manifiestan en el presente estudio, hace que debamos replantearnos no el contenido, sino la forma de transmitir ese contenido con el fin de tener una mayor garantía de que los mensajes no se perderán. A los adolescentes el contenido les entra básicamente por los ojos; aprecian de forma muy especial la apariencia, la forma cuidada y atractiva del recurso. El primer filtro es el del aspecto; su primer criterio de calidad. Es cierto que luego buscan que los contenidos respondan a sus expectativas, que la gente a la que buscan como fuente "tiene que demostrar conocimientos y saber de lo que habla".

Para los jóvenes, en cambio, eso es mucho menos determinante. Lo primero es el contenido, que les sea útil, unido a una interfaz funcional. Si eso se cumple, ya es suficientemente atractivo el recurso. Entre un criterio y otro, las webs de salud deben encontrar el equilibrio para educar en habilidades que ayuden a plantearse estilos de vida y comportamientos saludables desde las primeras etapas de la vida. Si llegan a la etapa de juventud con la idea de que los Medios no tienen ninguna obligación en la construcción de actitudes saludables, algo se ha hecho mal y hay que rectificar los mensajes. Que carguen la responsabilidad sobre ellos mismos y exculpen de responsabilidad a quienes controlan las webs, significa que no confían realmente en los recursos de Internet. Consideran obligado que se tenga 'sentido crítico' a la hora de acercarse a Internet, pero ¿cómo se ha formado ese 'sentido crítico'? Realmente, la educación es la clave de todo. 


\section{Bibliografía}

Castells, M, Fernández-Ardévol, M, Qiu, JL y Sey, A (2006). Mobile Communication and Society: a Global Perspective. Cambridge: MIT Press.

DeWalt, K M y DeWalt, B R (2002). Participant observation: a guide for fieldworkers. Walnut Creek, CA: AltaMira Press.

Echegaray, L, Ronco, M y Camacho, I. (2013). "Desarrollo y explicación de la base metodológica para el análisis de webs de salud dirigidas a jóvenes de la Comunidad Autónoma Vasca y de la Comunidad Foral de Navarra, en castellano y en euskera". Actas del V Congreso Internacional Latina de Comunicación Social. Universidad de La Laguna. Disponible en: http://www.revistalatinacs.org/13SLCS/2013 actas/087 Echeg aray.pdf (fecha de consulta: 20/03/2016).

Fernández-Ardévol, M (2012): “Jóvenes y prácticas comunicativas: Más allá de los datos estadísticos". En Pérez, L, Nuez, C y Del Pozo, J (Coord.): Tecnologías de la comunicación, jóvenes y promoción de la salud. Logroño: Consejería de Salud. Gobierno de la Rioja. Disponible en:

https://dialnet.unirioja.es/servlet/libro?codigo $=560557$ (fecha de donsulta: 13/02/16).

Fundación Salud y Comunidad (2015): Noctámbul@s. Informe sobre drogas y sexualidad 2014-15.-Proyecto Cualitativo sobre la relación entre el consumo de drogas y los abusos sexuales en espacios de ocio nocturno. Barcelona: Ed. Fundación Salud y Comunidad. Disponible en: http://www.pnsd.msssi.gob.es/profesionales/publicaciones/cata logo/bibliotecaDigital/publicaciones/pdf/2015 FSYC. Informe -Noctambulas.pdf (fecha de consulta: 13/02/16).

Gil Suárez, A y Vall-llovera Llovet, M (Coord.) (2006): Jóvenes en cibercafés: la dimensión física del futuro virtual. Barcelona: Ed. UOC.

Gil, A, Feliu, J, Rivero, I y Gil, E (2003). ¿Nuevas tecnologías de la información y la comunicación o nuevas tecnologías de relación? Niños, jóvenes y cultura digital. Barcelona: Editorial UOC. Disponible en: 
http://www.uoc.edu/dt/20347/index.html (fecha de consulta: 20/02/16).

Guillamón, N y Martínez, M (2012): “Uso de Internet y las redes sociales para la salud en adolescentes: Evaluación de necesidades para un servicio online de salud mental”. En Pérez Gómez, L, Nuez Vicente y C., Del Pozo, J. (Coord.): Tecnologías de la comunicación, jóvenes y promoción de la salud. Logroño: Consejería de Salud. Gobierno de la Rioja. Disponible en:

https://dialnet.unirioja.es/servlet/libro?codigo $=560557$ (fecha de consulta: 15/02/16).

Holloway, SL y Gill, V (2003): Cyberkids: Children in the Information Age. London: Routledge Falmer.

Ito, M, Baumer et al (2010): Hanging out, messing around, and geeking out: kids living and learning with new media. Cambridge: MIT Press. Disponible en:

https://mitpress.mit.edu/sites/default/files/titles/free downloa d/9780262013369 Hanging Out.pdf (fecha de consulta: 08/01/16].

Ito, M et al (2008): Viviry Aprender con Nuevos Medios: Resumen de los resultados del Proyecto de la Juventud Digital. Fundación MacArthur. Disponible en: http://publicaciones.zemos98.org/spip.php?article1428 (fecha de consulta:14/01/16).

Kawulich, B B (2005): "La observación participante como método de recolección de datos” Forum: Qualitative Social Research, [Online Journal], 6, (2). Disponible en: http://www.qualitativeresearch.net/index.php/fqs/rt/printerFriendly/466/998 (fecha de consulta: 17/02/16).

Livingstone, S (2002): Young People and New Media. London: UK. Thousand Oaks, Sage.

Merino Malillos, L (2011a): Nativos Digitales: una aproximación a la socialización tecnológica de los jóvenes. Madrid: Instituto de la Juventud. Disponible en:

http://www.injuve.es/sites/default/files/nativos $\% 20$ digitales 0 . pdf (fecha de consulta: 17/02/16). 
Merino Malillos, L (2011b): "Jóvenes en redes sociales: significados y prácticas de una sociabilidad digital". Revista de Estudios de Juventud. 95, 31-43. Disponible en:

http://www.injuve.es/sites/default/files/tema2 revista95.pdf (fecha de consulta: 20/02/16).

Observatorio Nacional de las Telecomunicaciones (2016):

Perfil sociodemográfico de los internautas. Madrid: ONTSI. Disponible en:

http://www.ontsi.red.es/ontsi/sites/default/files/perfil sociode mografico de los internautas. analisis de datos ine 2015.pdf

(fecha de consulta: 15/02/16).

Peñafiel, C, Ronco, M y Echegaray, L (2015): "Estudio de la comunicación científica en salud para jóvenes y valoración de la calidad de los recursos digitales". Revista Latina de Comunicación Social, 70, 300-321. Disponible en:

http://www.revistalatinacs.org/070/paper/1048pv/18es.html (fecha de consulta: consultado el 15/01/16).

Peñafiel, C, Ronco, M, Echegaray, L y Camacho, I (2014):

"Encuestación a los portales temáticos para jóvenes sobre contenido y calidad de la información de salud". Actas del VI Congreso Internacional Latina de Comunicación Social.

Universidad de La Laguna, 1-28. Disponible en:

http://www.revistalatinacs.org/14SLCS/2014 actas/145 Penafi el.pdf (fecha de consulta: 15/01/16).

Peñafiel, C, Camacho, I, y Pastor, J M (2013): “Estudio de las Webs de información de Salud en español y euskera dirigidas a jóvenes y adolescentes". Actas del V Congreso Internacional Latina de Comunicación Social. Universidad de La Laguna, 1-18.

Disponible en:

http://www.revistalatinacs.org/13SLCS/2013 actas/082 Penafi el.pdf (fecha de consulta: 14/02/16).

Pérez, L, Nuez, C y Del Pozo, J (Coord.)(2012): Tecnologías de la comunicación, jóvenes y promoción de la salud. Logroño: Consejería de Salud. Gobierno de la Rioja. Disponible en: 
https://dialnet.unirioja.es/servlet/libro?codigo $=560557$ (fecha de consulta: 13/02/16).

Ronco, M, Peñafiel, C y Pastor, J M (2014): “Análisis de calidad y adecuación de las webs relacionadas con la salud dirigidas a jóvenes y adolescentes en el País Vasco y Navarra”. Actas del VI Congreso Internacional Latina de Comunicación Social. Universidad de La Laguna. Disponible en:

http://www.revistalatinacs.org/14SLCS/2014 actas/144 Ronco .pdf (fecha de consulta: 5/02/16).

Rubio Gil, A (2010): “Generación digital: patrones de consumo de Internet, cultura juvenil y cambio social". Revista de Estudios de Juventud, 88, 201-221. Disponible en:

http://www.injuve.es/sites/default/files/RJ88-14.pdf (fecha de consulta: 29/02/16).

Schmuck, R (1997). Practical action research for change. Arlington Heights, IL: IRI/Skylight Training and Publishing.

Silverman, D (2013): Doing qualitative research. Thousand Oaks, California: Sage Editions.

Tabernero, C, Aranda, C y Sánchez-Navarro, J. (2010): “Juventud y tecnologías digitales: espacios de ocio, participación y aprendizaje". Revista de Estudios de Jwventud, 88: 77-96. Disponible en: https://issuu.com/injuve/docs/revista 88 (fecha de consulta: 29/02/16).

Valles, M S (2007): Entrevistas cualitativas. Madrid: CIS.

$\rightarrow$ Este trabajo recoge resultados del Proyecto de Investigación Estudio de las webs de información de salud en español y euskera dirigidas a jóvenes y adolescentes. La investigación ha sido subvencionada por la Universidad del País Vasco/Euskal Herriko Unibertsitatea (Código EHU 12/12), dirigida por Carmen Peñafiel y en la que se integra el equipo constituido por Milagros Ronco, Idoia Camacho y José María Pastor, profesores de la UPV/EHU, y el profesor Lázaro Echegaray, de la Escuela Universitaria de la Cámara de Comercio de Bilbao. 



\title{
Salud 2.0: la sostenibilidad de los servicios de cardiología a través de la comunicación remota
}

\author{
Antonio López Villegas \\ Instituto de Medicina Clínica, Universidad de Tromsø, Noruega \\ Daniel Catalán Matamoros $\mathbf{G}$ \\ Departamento de Periodismo y Comunicación Audiovisual. \\ Universidad Carlos III de Madrid, España.
}

\section{Resumen}

Introducción: Asegurar la sostenibilidad tanto social como económica del Sistema Nacional de Salud a medio y largo plazo es un objetivo clave en el mantenimiento del estado del bienestar actual. En este sentido la Salud 2.0 o tele-salud, que se apoya en el uso de las Tecnologías de la Información y la Comunicación se configura en una herramienta que puede proporcionar servicios sanitarios alternativos al modelo convencional de seguimiento. Objetivo. Analizar la bibliografía existente sobre la comunicación remota en los servicios de cardiología y su relación con la sostenibilidad, así como presentar el Estudio PONIENTE. Metodología. Se realiza una revisión bibliográfica en las bases de datos Google Académico y Pubmed sin limitaciones de tiempo ni idiomas. Resultados. Diversos autores han estudiado la relación de coste-efectividad de los sistemas de telecomunicación en cardiología aplicados al caso de los marcapasos. Dichos estudios avalan el uso de esta tecnología dado que no hay diferencias significativas en efectividad ni en calidad de vida relacionada con la salud en comparación al seguimiento convencional en el hospital y además se reduce el número de visitas al hospital y los 
costes asociados al seguimiento. Conclusiones. Es preciso profundizar en el estudio de este nuevo fenómeno para avanzar en la implantación de estos modelos de comunicación remota entre los pacientes y los profesionales de la salud.

\title{
Palabras clave: calidad de vida; comunicación; coste- efectividad; marcapasos; monitorización remota; telemedicina.
}

\section{Introducción}

\begin{abstract}
A SEGURAR la sostenibilidad en el tiempo del Sistema Nacional 1 de Salud (SNS) tanto en España como en el resto de países europeos es un objetivo clave en el mantenimiento del actual estado del bienestar. En este sentido, la eSalud o tele-salud que se apoya en el uso de las Tecnologías de la Información y las Comunicaciones (TICs), se configura como una herramienta que unida al constante incremento en la tasa del envejecimiento de la población europea y a la dispersión geográfica, proporciona una serie de servicios sanitarios alternativos al modelo actual que pueden facilitar la sostenibilidad tanto social como económica del SNS.
\end{abstract}

Las Enfermedades Cardiovasculares son responsables del 30\% de la mortalidad global según la Organización Mundial de la Salud (Tarride, Morgan, DesMeules, Luo, y O’Reilly, 2009). El actual envejecimiento de la población y el incremento de la esperanza de vida son factores que influyen en la incidencia de las enfermedades cardiovasculares, siendo en ocasiones necesario que los pacientes con este tipo de patologías precisen de dispositivos electrónicos cardiovasculares implantables (DECI). El número de DECI, que agrupa a los Marcapasos, Desfibriladores Automáticos Implantables (DAI), las Terapias de Resincronización Cardíaca (TRC), y Holters, continúa creciendo a un ritmo exponencial desde que el primer marcapasos (Dubner et al, 2012) fuera implantado en 1958.

El desarrollo y expansión que la telemedicina ha experimentado en los últimos quince años, gracias a los avances en las TIC o tecnologías de la información y las comunicaciones y las tecnologías sanitarias, ha generado la necesidad de realizar estudios que den a conocer las 
novedades en este campo. Recientemente, se han publicado varios estudios que han mostrado que la telemedicina basada en el seguimiento de usuarios con marcapasos se configura como una opción equivalente a la monitorización convencional en el hospital en términos de calidad de vida relacionada con la salud, capacidad funcional, viabilidad, fiabilidad y seguridad y, además, se reducen significativamente el número de visitas al hospital y los costes para el SNS, los pacientes y sus familiares (López-Villegas, CatalánMatamoros, Martín-Saborido, Villegas-Tripiana y Robles-Musso, 2015; López-Villegas, Catalán-Matamoros, Robles-Musso y Peiró, 2015).

\section{Servicios ofrecidos por las TIC en la práctica sanitaria}

Los tipos de servicios que utilizan las TIC en la práctica clínica son los siguientes (eHealthGuru.com, 2015):

1. Historiales Médicos Electrónicos: Registro Electrónico y Centralizado de la Historia Clínica del Paciente que facilita el archivo, consulta, edición y compartición entre profesionales, centros de salud, hospitales, farmacias, etc... de la información del paciente.

2. Telemedicina: hace referencia a la distribución de servicios de salud en la que la distancia es un factor crítico, donde los profesionales de la salud usan información y tecnología de comunicaciones para el intercambio de información válida para el diagnóstico, tratamiento y prevención de enfermedades o daños, investigación y evaluación, y para la educación continuada de los proveedores de salud pública.

3. Medicina basada en la evidencia: La Medicina basada en la Evidencia (MBE) se define como un proceso cuyo objetivo es la selección de los mejores argumentos científicos para la resolución de los problemas que la práctica médica cotidiana plantea.

4. Difusión de Información orientada al ciudadano: Tanto los pacientes como aquellas personas sanas desean ser informados 
sobre temas médicos. Las TIC contribuyen mediante la creación de plataformas de contenido médico accesibles al ciudadano.

5. Difusión de Información orientada al especialista: Servicios de información centrados en las necesidades de los profesionales sanitarios (DSI, clipping, etc.). Estos servicios de información son ofrecidos a través de sistemas de contenido telemático.

6. Equipos virtuales de cuidados sanitarios: A través de los cuales, grupos de profesionales sanitarios colaboran y comparten información sobre pacientes mediante sistemas digitales.

7. mHealth o Salud Móvil: Cuando el soporte a través del cual se ofrece cualquiera de los servicios anteriores es un Smartphone o Tablet en el cual se instala una app específica.

\section{Tele-comunicación en cardiología: el caso de los marcapasos 3.1. Marcapasos cardíacos}

Un marcapasos es un dispositivo electrónico diseñado para producir impulsos eléctricos con el objeto de estimular el corazón cuando falla la estimulación fisiológica o normal (Fundación Española del Corazón, 2016). Entre otras razones, el crecimiento del número de marcapasos implantados en la última década ha llevado a la saturación de las consultas de cardiología (Osca et al, 2009; AlRazzo et al, 2011). El uso clínico de los marcapasos cardíacos (MP) ha experimentado un constante incremento desde que los resultados de diferentes estudios confirmaran que estos dispositivos podían ser utilizados para tratar el bloqueo atrioventricular, las disfunciones del nodo sinusal y otras alteraciones del sistema de conducción cardíaco. Según el Registro Español de Marcapasos durante el año 2013 se implantaron en España, incluyendo recambios, $36.042 \mathrm{MP}$ (755 por millón de habitantes), más de la mitad por bloqueo aurículoventricular (Coma-Samartín, Cano-Pérez y Pombo-Jiménez, 2014). De acuerdo a las guías internacionales de práctica profesional (Epstein et al, 2008; Wilkoff et al, 2008) los pacientes con marcapasos deberían tener una primera visita al hospital entre 3-10 días después del implante, posteriormente deberían realizar una segunda visita 
entre las 2-12 semanas tras el implante. Se recomienda que la tercera y siguientes visitas se realicen en intervalos variables de entre 3 y 12 meses, dependiendo del tipo de marcapasos implantado y circunstancias clínicas. Todas las visitas que se realicen al hospital deberían incluir una evaluación del estado clínico del paciente, funcionamiento del dispositivo, eventos cardiovasculares y, si fuera necesario, realizar una reprogramación del dispositivo o cambios en la medicación (Wilkoff et al, 2008; Mabo et al, 2012; Cronin y Varma, 2012). El control de los posibles problemas cardíacos es una parte integral de la atención a los pacientes con implante de marcapasos (Maisel et al, 2009). Actualmente supone una importante carga de trabajo, consumo de tiempo y costes tanto para el Sistema Nacional de Salud-SNS (De Cock, et al, 2012; Folino, et al, 2012) como para los pacientes y sus familiares (Folino et al, 2013) que deben desplazarse a estas consultas para las sucesivas revisiones.

\subsection{Telemedicina aplicada al seguimiento de dispositivos cardíacos}

La Organización Mundial de la Salud (OMS) define la telemedicina como "el suministro de servicios de atención sanitaria, en los que la distancia constituye un factor crítico, por profesionales que apelan a las tecnologías de la información y de la comunicación con objeto de intercambiar datos para hacer diagnósticos, preconizar tratamientos y prevenir enfermedades y heridas, así como para la formación permanente de los profesionales de atención de salud y en actividades de investigación y evaluación, con el fin de mejorar la salud de las personas y de las comunidades en que viven" (World Health Organization, 2010).

La Telemonitorización (TM) consiste en el uso de equipos electrónicos para observar o registrar procesos fisiológicos mientras el paciente realiza actividades de la vida diaria. Se refiere a la medida de procesos fisiológicos tales como signos vitales (frecuencia cardiaca, respiración, presión arterial) y otras medidas (células sanguíneas, bioquímica hemática, producción renal, etc.) a una distancia usando tecnología digital y analógica (Observatorio de Prácticas Innovadoras en el Manejo de Enfermedades Crónicas 
Complejas. Consejería de igualdad, Salud y Políticas Sociales. Junta de Andalucía, 2016). Esta tecnología tiene su origen en la década de los 70 cuando se introduce la Monitorización Trans-Telefónica (MTT) (Burri, Heidbüchel, Jung y Brugada, 2011) y, a principios del siglo XXI, cuando se implanta el primer marcapasos que puede ser monitorizado de manera remota utilizándose el cable y/o banda ancha (Amala, Turner, Gretton, Baksh, y Cleland, 2003). La MTT tiene la capacidad de proporcionar información básica como el aviso del próximo agotamiento de la batería, pero no notifica problemas en el funcionamiento del dispositivo o control de los parámetros programados de forma errónea. La llegada de la TM ha permitido el acceso a una gran cantidad de información con la ventaja de que puede ser consultado en cualquier momento por los profesionales sanitarios. Desde que los sistemas de seguimiento remoto (SR) o telemonitorización (TM) de marcapasos fueran implantados en los primeros años de este siglo (Amala, Turner, Gretton, Baksh y Cleland, 2003), varios estudios han demostrado que esta tecnología es tan efectiva como el seguimiento realizado en el hospital (Wilkoff et al, 2008; Guédon-Moreau et al, 2013; Varma y Ricci, 2013; LópezVillegas, Catalán-Matamoros, Robles-Musso y Peiró, 2015). Estos sistemas de seguimiento remoto han sido desarrollados para mejorar el seguimiento de pacientes con marcapasos, permitiendo la teletransmisión de la información incluida en la memoria del dispositivo (Ricci, Morichelli y Santini, 2008; Mabo et al, 2012; Perl et al, 2013) como por ejemplo el funcionamiento del dispositivo, voltaje de la batería, características de seguimiento y arritmias, datos de episodios cardiovasculares incluidos los eventos adversos (EA) y, en algunos dispositivos además, ciertos aspectos sobre el estado del paciente (como datos tempranos de descompensación cardíaca, impedancia transtorácica, peso, etc.).

La telemedicina asociada a la cardiología (Osca et al, 2009; De Cock et al, 2012; Perl et al, 2013; Varma y Ricci, 2013; López-Villegas, Catalán-Matamoros, Robles-Musso y Peiró, 2015) permite:

1) Registrar y evaluar el correcto funcionamiento del dispositivo implantado

2) Detectar eventos cardiovasculares tempranos 
3) Conocer problemas relacionados con el estado del dispositivo.

4) Reducir el tiempo de respuesta a problemas técnicos del MP

o cambios en el estado clínico del paciente

5) Incrementar la atención de pacientes de mayor edad y complejidad

6) Aumentar la calidad de vida relacionada con la salud

7) Reducir las cargas de seguimiento tanto a los profesionales sanitarios como a los pacientes y sus cuidadores

8) Disminuir los costes asociados con el seguimiento del paciente

Por lo tanto, la TM debería ser una alternativa útil para disminuir la sobrecarga de las consultas de cardiología, permitiendo optimizar los recursos médicos.

\subsection{Tele-monitorización de marcapasos}

El seguimiento remoto del MP es una tecnología consolidada con más de 900.000 unidades implantadas en todo el mundo desde que en el año 2001 se implantara la primera unidad en Europa. En el año 2013, el 6\% del total de MP convencionales implantados en España y un 39\% de los dispositivos de terapia de resincronización cardíaca, se incluyen en programas de telemonitorización (Coma-Samartín, CanoPére y Pombo-Jiménez, 2014). Esta discreta utilización puede estar relacionada con una menor evidencia científica -al menos por comparación con la TRC (Halimi et al, 2008; Ricci, Morichelli y Santini, 2008; Dubner et al, 2012; Mabo et al, 2012) - sobre la efectividad, seguridad y coste-efectividad de la TM en el caso de los $\mathrm{MP}$, especialmente en lo referente a resultados reportados por los pacientes como Calidad de Vida Relacionada con la Salud (CVRS) y de capacidad funcional.

Los pacientes con implante de marcapasos necesitan de cuidados informales, que en la mayoría de los casos son realizados por sus familiares, parejas y amigos (Kimberlin, Brushwood, Allen, Radson y Wilson, 2004). El cuidado informal es un trabajo físico, emocional y financieramente exigente que en la mayoría de los casos se traduce en una importante carga para el cuidador pudiendo disminuir su calidad 
de vida y teniendo un impacto directo en su salud (Miravitlles, PeñaLongobardo, Oliva-Moreno e Hidalgo-Vega, 2015).

4. El estudio PONIENTE: evaluación económica de los sistemas de comunicación remota en marcapasos

En la última década se ha experimentado un crecimiento extraordinario de la telemedicina aplicada al seguimiento de usuarios portadores de marcapasos cardíacos. Sin embargo, el uso de esta tecnología todavía es limitado en comparación con la modalidad hospitalaria de seguimiento, siendo escasa la evidencia científica que muestre si la telemonitorización de marcapasos presenta una relación de coste-efectividad diferente a la convencional. Por ello, se ha visto oportuno presentar el estudio PONIENTE (López Villegas, 2016) en este capítulo con el fin de mostrar los resultados de comparar ambas modalidades de seguimiento.

El objetivo principal de este estudio fue realizar una comparación de los diferentes sistemas de comunicación y seguimiento de usuarios portadores de marcapasos que existen actualmente en el Sistema Nacional de Salud en España y valorar su sostenibilidad. Para ello se estableció el siguiente objetivo específico:

$\rightarrow$ Hacer una evaluación económica a largo plazo de la telemonitorización de usuarios portadores de marcapasos y comprobar si ofrecía una alternativa coste-efectiva al seguimiento convencional en el hospital.

Para evaluar la efectividad a largo plazo se realizó un ensayo clínico controlado, no aleatorizado ni enmascarado, con recogida de datos pre y post-implante y un seguimiento de 12 meses. Entre octubre de 2012 y noviembre de 2013, 82 usuarios portadores de marcapasos fueron seleccionados, siendo asignados al grupo de TM $(n=30)$ o al grupo de $\mathrm{MH}(\mathrm{n}=52)$ en función de sus características y preferencias personales. Se analizaron las características basales, número de visitas al hospital, viabilidad, fiabilidad, seguridad y se administraron los cuestionarios EuroQol-5D (EQ-5D) para evaluar la calidad de vida 
relacionada con la salud y el Duke Activity Status Index (DASI) para valorar la capacidad funcional.

La estimación de los costes en el estudio PONIENTE se realizó desde las perspectivas del SNS, en el que se incluyeron los costes de personal, mantenimiento de la consulta, transporte y hospitalización y desde la perspectiva del paciente donde se contabilizaron los costes asociados al transporte y pérdida de ingresos por la visita a la consulta de cardiología.

El estudio comparativo de la efectividad a largo plazo mostró en sus resultados que las características basales de los dos grupos del estudio fueron similares tanto para EQ-5D (TM: 0.74; MH: 0.67; $\mathrm{p}=0.404$ ) como para el DASI (TM: 21.42; MH: 19.95; $\mathrm{p}=0.272$ ). La puntuación de las utilidades del EQ-5D mejoró en ambos grupos (TM: 0.91; MH: 0.81; $\mathrm{p}=0.154$ ), a diferencia del EQ-5D VAS $(p=0.043)$. La puntuación del DASI fue similar a la puntuación basal. El número de visitas al hospital fue un $27 \%$ más bajo (3 vs 4; $\mathrm{P}<0.001)$ en el grupo de TM en comparación al grupo hospitalario.

Tabla 1. Calidad de Vida Relacionada con la Salud, Años de Vida Ajustados por Calidad (AVACs) y costes por paciente a los 12 meses de seguimiento

\begin{tabular}{|c|c|c|c|c|}
\hline $\begin{array}{c}\text { Variables de } \\
\text { coste-utilidad }\end{array}$ & $\begin{array}{c}\text { Grupo de } \\
\operatorname{MR}(n=30)\end{array}$ & $\begin{array}{c}\text { Grupo de } \\
\text { MH }(n=52)\end{array}$ & Total & $\begin{array}{c}\mathbf{P} \\
\text { value }\end{array}$ \\
\hline $\begin{array}{l}\text { EQ5D EVA } \\
\text { (media) }\end{array}$ & $\begin{array}{l}77.50(73.55- \\
81.44)\end{array}$ & $\begin{array}{l}71.44(67.55- \\
75.33)\end{array}$ & $\begin{array}{l}73.66(70.78- \\
76.54)\end{array}$ & 0.043 \\
\hline $\begin{array}{l}\text { EQ5D utilidades } \\
\text { (media) }\end{array}$ & $\begin{array}{l}0.91(0.85- \\
0.97)\end{array}$ & $\begin{array}{l}0.81(0.72- \\
0.91)\end{array}$ & $0.85(0.78-0.91)$ & 0.154 \\
\hline AVACs (media) & $\begin{array}{l}0.84(0.77- \\
0.91)\end{array}$ & $\begin{array}{l}0.77(0.71- \\
0.83)\end{array}$ & $0.80(0.75-0.84)$ & 0.146 \\
\hline $\begin{array}{l}\text { SNS - media de } \\
\text { costes por paciente } \\
(€)\end{array}$ & $\begin{array}{l}139.99 \pm \\
66.96\end{array}$ & $\begin{array}{l}385.14 \pm \\
282.47\end{array}$ & $\begin{array}{l}182.04(146.23- \\
217.86)\end{array}$ & $\begin{array}{l}< \\
0.001\end{array}$ \\
\hline
\end{tabular}

Fuente: Antonio López Villegas (2016) 
Valores expresados como media \pm DE o media \pm DE (IC 95\%).

EQ5D: EuroQoL-5D; MH: Monitorización Hospitalaria; SNS: Sistema Nacional de Salud; AVACs: Años de Vida Ajustados por Calidad; MR: Monitorización Remota; EVA: Escala Visual Análoga.

La evaluación económica mostró que hubo un ahorro significativo entre los participantes del grupo de tele-monitorización en comparación a la modalidad hospitalaria (López-Villegas y CatalánMatamoros, 2015). Desde la perspectiva del SNS, los pacientes incluidos en el grupo de tele-monitorización ganaron 0,07 AVACs más que los del grupo hospitalario, con un ahorro del 63,65\% (139.99 $€$ versus $385.14 € ; \mathrm{P}<0.001)$ por paciente y año. $\mathrm{Y}$ además el número de visitas hospitalarias se redujo en un 52,49\% en el grupo remoto. Desde la perspectiva del paciente los costes fueron más bajos en el grupo de TM que en el grupo hospitalario (31.82 € versus 73.48 $€ ; \mathrm{P}<0.001)$.

Figura 1. Media de Costes incurridos por paciente y año desde la perspectiva del Sistema Nacional de Salud

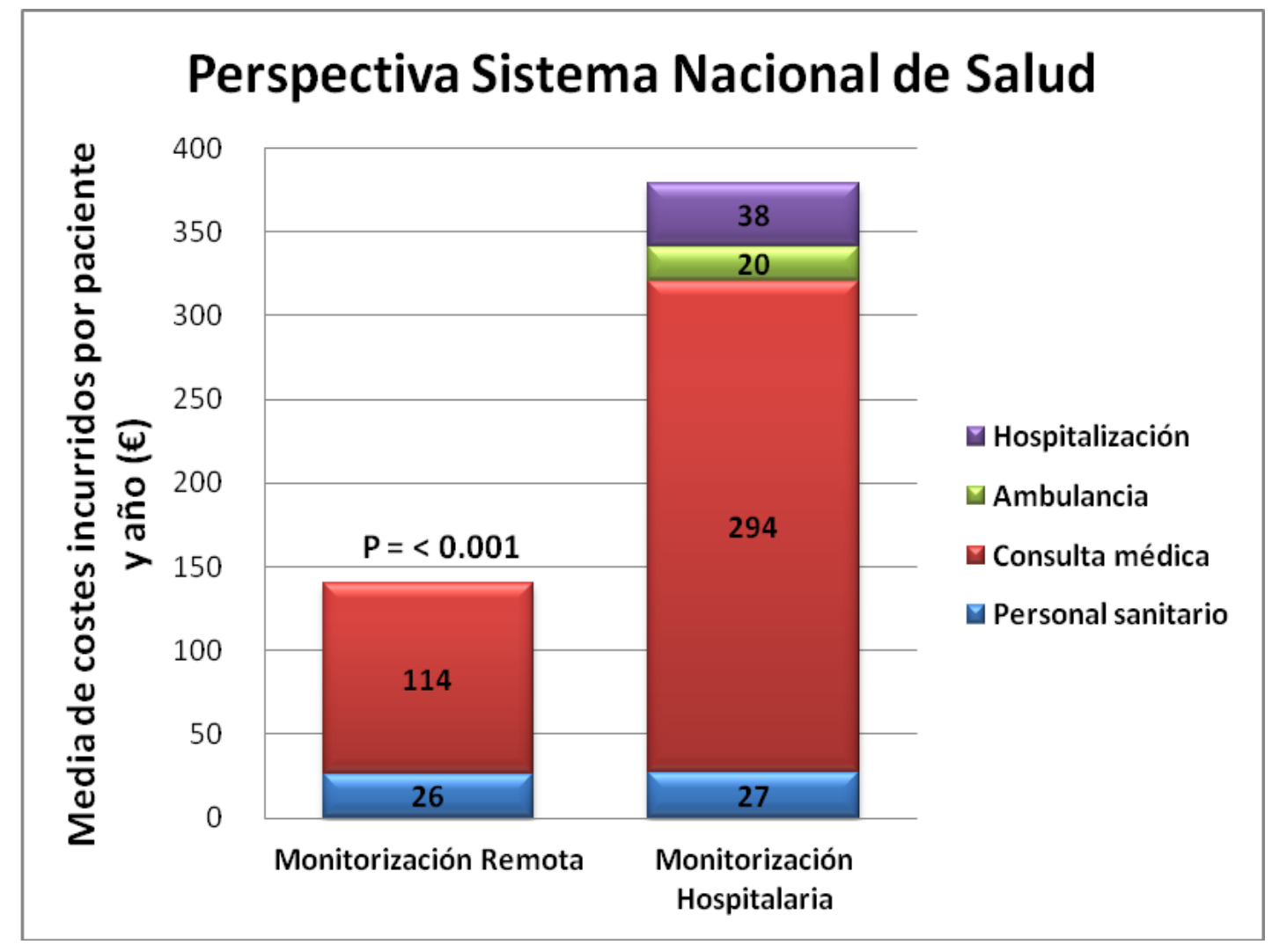

Fuente: Antonio López Villegas (2016) 
A modo de conclusión, los resultados derivados de este estudio confirman que el seguimiento remoto a largo plazo de usuarios portadores de marcapasos se configura como una opción equivalente al seguimiento hospitalario tradicional en términos de calidad de vida relacionada con la salud, capacidad funcional, viabilidad, fiabilidad y seguridad. La tele-monitorización favorece la detección temprana de eventos adversos relacionados o no con el funcionamiento del dispositivo y adicionalmente, reduce significativamente el número de visitas al hospital (López-Villegas, Catalán-Matamoros, RoblesMusso, \& Peiró, Effectiveness of Pacemaker Tele-Monitoring on Quality of Life, Functional Capacity, Event Detection and Workload. The PONIENTE trial, 2015).

Los datos presentados en el estudio PONIENTE muestran que la tele-monitorización es una alternativa más eficiente que el seguimiento convencional realizado en el hospital, implicando un ahorro económico significativo para los pacientes y sus familiares (López-Villegas, Catalán-Matamoros, Robles-Musso y Peiró, Workload, time and costs of the informal cares in patients with telemonitoring of pacemakers. The PONIENTE study, 2015).

\section{Perspectivas y futuras líneas de investigación en la comunicación o seguimiento remoto de marcapasos}

Los resultados del estudio PONIENTE muestran el nivel de eficiencia que la telemedicina aplicada al seguimiento de pacientes puede proporcionar a medio y largo plazo al desarrollo tanto de la ciudadanía en general como de la sostenibilidad de los diferentes servicios públicos de salud. Además ha permitido determinar el grado de ahorro que supone tanto para el Sistema Nacional de Salud como para los pacientes y su entorno.

Con la publicación y posterior difusión de los resultados obtenidos se pretende que puedan servir de ayuda en la toma de decisiones políticas a gestores de servicios sanitarios, usuarios y proveedores de tecnologías sanitarias tanto en España como en el resto de países con características similares o no. Además se desea, debido al carácter 
innovador de esta tecnología en relación a los servicios de control y comunicación remota, que pueda ser útil en otros países, donde el acceso del paciente a los hospitales supone un esfuerzo significativo debido a la orografía, medios de transporte utilizados, proximidad al hospital, capacidad económica, etc.

Con el fin de incrementar el conocimiento de esta nueva tecnología y poder comparar los resultados obtenidos. En futuras líneas de investigación se recomienda realizar estudios multicéntricos basados en evaluaciones económicas donde se comparen ambas modalidades de monitorización de pacientes y donde se analice la calidad de vida relacionada con la salud, los ratios de coste-efectividad y los costes tanto formales como informales asociados al seguimiento.

\section{Bibliografía}

Al-Razzo, O, Gonzáles-Villegas, E, Silvestre-García, J, CabestreroAlonso, D, Represa-Pastor, T, Alejandre-Leyva, M, y Mesa-García, J. M. (2011). "Seguimiento domiciliario como sustitutivo de seguimiento presencial en pacientes portadorees de marcapasos". Cuadernos de Estimulación Cardíaca, 10(4), 57-62.

Amala, A, Turner, T, Gretton, M, Baksh, A y Cleland, J (2003). "A systematic review of telemonitoring for the management of heart failure". European Journal of Heart Failure, 5, 583-590.

Burri, H, Heidbüchel, H, Jung, W y Brugada, P (2011). "Remote monitoring: a cost or an investment?". Europace, 13 (Suppl 2), ii44-48.

Coma-Samartín, R, Cano-Pérez, O y Pombo-Jiménez, M (2014).

"Registro Español de Marcapasos. XI Informe Oficial de la Sección de Estimulación Cardiaca de la Sociedad Española de Cardiología (2013)". Revista Española de Cardiología, 67(12), 10241038. 
Cronin, E y Varma, N (2012). "Remote monitoring of cardiovascular implanted electronic devices: a paradigm shift for the 21st century". Expert Review of Medical Devices, 9(4), 367-376.

De Cock, C, Elders, J, van Hemel, M, van den Broek, K, van Erven, L, de Mol, B y Voogt, W (2012). "Remote monitoring and follow-up of cardiovascular implantable electronic devices in the Netherlands. An expert consensus report of the Netherlands Society of Cardiology". Netherlands Heart Journal, 20(2), 53-65.

Dubner, S, Auricchio, A, Steinberg, J, Vardas, P, Stone, P, Brugada, J y Brignole, M (2012). "ISHNE/EHRA expert consensus on remote monitoring of cardiovascular implantable electronic devices (CIEDs)". Europace, 14(2), 278-293.

Disponible en: http://www.ehealthguru.org/es ES/whats-ehealth/ (fecha de consulta: 28/10/2015)

Epstein, A E et al (2008). “ACC/AHA/HRS 2008 Guidelines for Device-Based Therapy of Cardiac Rhythm Abnormalities: a report of the American College of Cardiology/ American Heart Association Task Force on Practice Guidelines (Writing Committee to Revise the ACC/AHA/NASPE 2002 Guideline Update for Implantation of Cardiac Pacemakers and Antiarrhythmia Devices) developed in collaboration with the American Association for Thoracic Surgery and Society of Thoracic Surgeons". Journal of the American College of Cardiology, 51(21), 1-6.

Folino, A, Breda, R, Calzavara, P, Borghetti, F, Comisso, J, Iliceto, S y Buja, G. (2013). "Remote follow-up of pacemakers in a selected population of debilitated elderly patients". Europace, 15, 382-387.

Folino, A, Breda, R, Calzavara, P, Migliore, F, Iliceto, S y Buja, G (2012). "Inhome controls of pacemakers in debilitated elderly patients". Geriatrics and Gerontology International, 12, 30-35. 
Fundación Española del Corazón. (2016). ¿En qué consiste un marcapasos? Disponible en: http://www.fundaciondelcorazon.com/informacion-parapacientes/tratamientos/marcapasos.html (fecha de consulta: 4/11/2016).

Guédon-Moreau, L, Lacroix, D, Sadoul, N, Clémenty, J, Kouakan, C, Hermida, J (2013). "A randomized study of remote followup of Implantable cardioverter defibrillators: safety and efficacy report of the ECOST trial". European Heart Journal, 34, 605-614.

Halimi, F, Clémenty, J, Attuel, P, Dessenne, X, Amara, W y Investigators, o. b. (2008). "Optimized post-operative surveillance of permanent pacemakers by home monitoring: the OEDIPE trial". Europace, 10, 1392-1399.

Kimberlin, C, Brushwood, D, Allen, W, Radson, E y Wilson, D (2004). "Cancer patient and caregiver experiences: communication and pain management issues". Journal of Pain and Symptom Management, 28(6), 566-578.

López-Villegas, A y Catalán-Matamoros, D (2015). “Evidencebased in remote monitoring of patients with pacemakers: the PONIENTE study". Presentación oral. Health Technology Assessment international (HTAi), $12^{\text {th }}$ Annual Meeting. Oslo, Noruega. Junio, 2015

López-Villegas, A., Catalán-Matamoros, D., Martín-Saborido, C., Villegas-Tripiana, I. y Robles-Musso, E. (2015). "Revisión sistemática de evaluaciones económicas de los sistemas de telemonitorización en los marcapasos". Revista Española de Cardiología, DOI 10.1016/j.recesp.2015.06.021.

López-Villegas, A, Catalán-Matamoros, D, Robles-Musso, E y Peiró, S (2015). "Comparative effectiveness of remote monitoring of people with cardiac Pacemaker versus conventional: Quality of life at the 6 months". Revista Española de Salud Pública, 89, 149-158. 
López-Villegas, A, Catalán-Matamoros, D, Robles-Musso, E y

Peiró, S (2015). "Effectiveness of Pacemaker Tele-Monitoring on Quality of Life, Functional Capacity, Event Detection and Workload. The PONIENTE trial". Geriatrics and Gerontology International, DOI 10.1111/ggi.12612.

López-Villegas, A, Catalán-Matamoros, D, Robles-Musso, E y

Peiró, S (2015). "Workload, time and costs of the informal cares in patients with tele-monitoring of pacemakers. The PONIENTE study". Clinical Research in Cardiology, DOI 10.1007/s00392-015-0921-5.

Mabo, P et al (2012). "A randomized trial of long-term remote monitoring of pacemaker recipients (the COMPAS trial)". European Heart Journal, 33(9), 1105-1111.

Maisel, W et al (2009). "Recommendations from the Heart Rhythm Society Task Force on Lead Performance Policies and guidelines". Heart Rhythm, 6(6), 869-885.

Miravitlles, M, Peña-Longobardo, L, Oliva-Moreno, J y HidalgoVega, A (2015). "Caregivers' burden in patients with COPD". International Journal of Chronic Obstructive Pulmonary Disease, 10, 347-356.

Observatorio de Prácticas Innovadoras en el Manejo de Enfermedades Crónicas complejas. Consejería de igualdad, Salud y Políticas Sociales. Junta de Andalucía. Monitorización Remota (Telemonitorización). Disponible en: http://www.opimec.org/glosario/remote-monitoring/ (fecha de consulta: 19/3/2016).

Osca, J et al (2009). "Fiabilidad técnica y seguridad clínica de un sistema de monitorización remota de dispositivos cardíacos antiarrítmicos". Revista Española de Cardiología, 62(08), 886-895.

Perl, S., Stiegler, P., Rotman, B., Prenner, G., Lercher, P., AnelliMonti, M., \& Pieske, B. (2013). Socio-economic effects and cost saving potential of remote patient monitoring (SAVE-HM trial). International Journal of Cardiology, 169, 402-407. 
Ricci, R, Morichelli, L y Santini, M (2008). "Home monitoring remote control of pacemaker and implantable cardioverter defibrillator patients in clinical practice: impact on medical management and health-care resource utilization". Europace, 10, 164-170.

Tarride, J, Morgan, L, DesMeules, M, Luo, W y O’Reilly, D (2009). "A review of the cost of cardiovascular disease". Canadian Journal of Cardiology, 25(6),195-202.

Varma, N y Ricci, R (2013). "Telemedicine and cardiac implants: what is the benefit?". European Heart Journal, 34(25), 1885-1895.

Wilkoff, B.L, Auricchio, A, Brugada, J, Cowie, M, Ellenbogen, K A, Gillis, A M y Vardas, P E (2008). "HRS/EHRA expert consensus on the monitoring of cardiovascular implantable electronic devices (CIEDs): description of techniques, indications, personnel, frequency and ethical considerations". Heart Rhythm, 5(6), 907-925.

World Health Organization. (2010). Telemedicine: opportunities and developments in Member States: report on the second global survey on eHealth 2009. Disponible en:

http://www.who.int/goe/publications/goe telemedicine 2010. pdf (fecha de ocnsulta). 


\title{
Las secciones de salud en los periódicos brasileños. Un estudio de caso: el diario Folha de São Paulo
}

\author{
Andrea Langbecker $(1)$ \\ CAPES Foundation - Ministry of Education of Brazil \\ Daniel Catalán Matamoros (1) G \\ Departamento de Periodismo y Comunicación Audiovisual. \\ Universidad Carlos III de Madrid
}

\section{Resumen}

Introducción: En los últimos años, los medios de comunicación brasileños han ampliado la cobertura sobre salud. Estos contenidos varían en enfoque, forma y espacios en los que se publican. Objetivo. Analizar los espacios dedicados a salud en los medios brasileños, con énfasis en el periódico Folha de São Paulo para identificar las secciones dedicadas a salud, su creación y cambios que se han producido en las últimas décadas. Metodología. Estudio de caso en el que se ha realizado una búsqueda en la base de datos de Folha de São Paulo, periódico de Brasil que publica numerosas secciones fijas destinadas a salud, desde los años 90. También se analizan las características atendiendo a la definición del periódico, el perfil de los espacios y la concepción de salud adoptada por el periódico. Resultados. Folha ofrece secciones fijas en salud con enfoques específicos, como por ejemplo, dar consejos a los lectores sobre la forma de cuidar de su salud desde una perspectiva individual (sección Equilibrio), o cuando se refieren a estudios científicos (sección Ciência + Salud). Las recomendaciones sobre salud al público general tienen una dimensión 
colectiva, no pertenecen a la sección de salud, sino a Cuaderno Cotidiano, compitiendo por espacio con otros contenidos. Conclusiones: Folha de São Paulo, al organizar y distribuir los contenidos de salud en diferentes espacios, ofrece una visión fragmentada sobre salud, guiada por el perfil editorial de cada sección.

Palabras clave: prensa; salud; secciones; agenda; Folha.

\section{Introducción}

T A SALUD es un concepto amplio, que puede variar 1 dependiendo de quién lo presente y en qué contexto. El concepto de salud recoge varias dimensiones, relacionadas con su compleja naturaleza. Una definición utilizada frecuentemente es la de la Organización Mundial de la Salud de 1946 (OMS, 2014, p. 1): “La salud es un estado de completo bienestar físico, mental y social, y no solamente la ausencia de afecciones o enfermedades". Para Batistella (2007), cuando se propuso este concepto, hubo un intento de ir más allá en una visión negativa de salud difundida por las instituciones sanitarias tradicionales, y destaca la importancia de la promoción de la salud en los servicios sanitarios. Sin embargo, recibió críticas por ser considerado un concepto utópico siendo imposible alcanzar un estado completo de bienestar (Segre y Ferraz, 1997; Batistella, 2007). Tampoco estaría claro el significado del concepto "estado completo" (Almeida Filho, 2000: 5) o incluso cómo se podría medir el nivel de "bienestar" de las personas (Batistella, 2007).

Para Scliar (2007: 30), el concepto de salud "refleja el entorno social, económico, político y cultural" de un tiempo. El autor llama la atención sobre el hecho de que cada época tiene su concepto de salud, haciendo hincapié en que también depende de los valores individuales, científicos, religiosos y opiniones filosóficas.

Tanto conceptualizar la salud como la enfermedad son tareas difíciles, que han sido entendidas de diferente manera en el curso de la trayectoria humana (Scliar, 2007). Para el filósofo Heidegger, cuando 
una persona está enferma no sólo se da la ausencia de "estar bien" y "estar saludable" sino una alteración de esta condición:

"A enfermidade não é a pura negação do estado psicossomático de saúde. A enfermidade é uma privação. Toda privação implica a pertinência essencial de algo ao que lhe faz falta, do que tem necessidade" (Nogueira, 2011: 260).

Hay aún una dimensión subjetiva de la forma en que la población percibe, experimenta y se relaciona con su estado de salud, tanto individual como colectivamente. Es importante tener en cuenta que factores tales como el saneamiento, la calidad de vida, la pobreza y la violencia están relacionados con el nivel de salud y enfermedad en una sociedad (Godoi, 2006).

Los medios de comunicación también tienen su propia forma de entender la salud o la enfermedad según criterios establecidos para la producción de noticias sobre estos temas o para definir las pautas marcadas por la cobertura del medio. La forma en que la prensa presenta el tema también es diversa, como también la importancia dada y el espacio disponible. En los últimos años, acompañando el interés de las personas sobre el tema, la salud comenzó a tener una mayor cobertura: "Nunca houve tanta circulação de conteúdo, nunca houve tanta informação disponível sobre saúde nos meios de comunicação" (Xavier, 2006: 46).

En este capítulo, en primer lugar, se presenta una breve descripción de las secciones de salud publicadas o emitidas en los principales medios de comunicación generalistas de Brasil (periódicos, revistas y televisión) y en las revistas especializadas en salud para el público en general. A continuación, se presenta un estudio de caso, el de Folha de São Paulo, el diario brasileño con más secciones específicas sobre salud. Además, se ha identificado qué cambios han ocurrido en los últimos años relacionados con los espacios destinados, así como el enfoque utilizado. Finalmente, se ha intentado reflexionar sobre cuál es el enfoque sobre salud que adoptan estas secciones. 


\section{Los espacios de salud en los medios de comunicación brasileños}

En Brasil se publican revistas especializadas en salud o con alguna dimensión relacionada con la salud, dirigidas al público general, como Viva Saúde, Saúde, Corpo a Corpo y Boa Forma. Las dos primeras se centran, generalmente, en consejos sobre salud y vida saludable, como actividad física, alimentación y nuevos tratamientos, entre otros. Boa Forma y Corpo a Corpo relacionan belleza con salud, presentando diferentes aspectos sobre estética y salud corporal. Las dos revistas se encuentran en el mercado brasileño desde hace tres décadas y defienden un enfoque sobre el valor de belleza del cuerpo delgado como representación de éxito (Vieira y Bosi, 2013).

En cuanto a los medios de comunicación generalistas, muchos periódicos y revistas publican secciones de salud, así como televisiones que también emiten programas relacionados con este tema. En este capítulo, nos referiremos a algunos de ellos que han sido seleccionados por tener mayor tirada y audiencia en la población de Brasil. Al tratarse de un estudio de caso, la muestra analizada se ha limitado únicamente a las que se exponen a continuación.

\subsection{La cadena de televisión Rede Globo}

Brasil cuenta actualmente con seis cadenas de televisión de cobertura nacional, aunque hay diferencias en relación al alcance tanto en relación a su audiencia como a su cobertura. Entre ellas destacan: Rede Globo, Sistema Brasileiro de Televisão (SBT), Record, Bandeirantes, Rede TV e CNT. Nos vamos a detener en Rede Globo por ser la mayor red de televisión abierta brasileña. Fundada en 1965, cubre el 98,44\% del territorio nacional, incluyendo 5.482 municipios y 99,50\% de la población. Cerca de $90 \%$ de su programación es de producción propia, tales como informativos, programas de periodismo, programas de variedades, de humor, deportes, novelas y reality shows (Rede Globo, 2016).

Entre sus programas periodísticos diarios destaca el Jornal Nacional (JN), que se emite desde 1969 y se mantiene como líder de audiencia 
en el horario primetime. En 2012, tuvo una audiencia media de 25 millones de espectadores diarios, lo que representa un 56\% de la audiencia total del país (Caron, Lefèvre y Lefèvre, 2015). En relación a la producción de noticias sobre salud, Caron, Lefèvre y Lefèvre (2015) estudiaron 246 inserciones sobre el tema, en 2012, distribuidas en 158 ediciones del JN. En este estudio, el tema de la salud ha aparecido en la mitad de estas ediciones. En 2012, los contenidos sobre salud se emitieron en la apertura del programa en 9 ediciones (Caron, Lefèvre y Lefèvre, 2015). Estos datos muestran la importancia que la salud alcanza en la cobertura en el medio de mayor impacto en la televisión brasileña.

Otro programa muy conocido por el público es Globo Repórter, un programa semanal, que está en el aire desde 1973, adoptando un único tema por edición y emitiendo grandes reportajes sobre viajes, salud, aventura, ciencia y actualidades. A menudo aborda temas relacionados con la salud y, algo curioso fue que, para celebrar sus 35 años en 2008, el público eligió, a través de su página web, el tema "Salud y calidad de la vida".

Actualmente, esta televisión también emite el programa Bem-Estar, que desde hace cinco años, de lunes a viernes, se define como un programa que aborda problemas de salud, consejos para adoptar buenos hábitos y mejorar la calidad de vida de las personas, contando con la presencia de expertos (Bem-Estar, 2016).

\subsection{Las revistas semanales}

Las revistas semanales de información general más representativas en términos de circulación son Veja, Istoé y Época. Todas estas revistas mantienen secciones fijas semanales que tratan sobre salud.

Nos vamos a detener en Veja por ser la que tiene una mayor circulación. La versión impresa tiene una tirada media semanal de 1.027.682 ejemplares ${ }^{27}$, con un alcance semanal de 8,9 millones de lectores $^{28}$. Tiene $\mathbf{6 0}$ mil suscriptores en la versión digital para tablets y

\footnotetext{
${ }^{27}$ Media de enero a septiembre de 2014.

${ }^{28}$ Media de junio de 2013 a julio de 2014.
} 
smartphones, y 12,3 millones de visitantes únicos en su portal web. Además, la publicación tiene más de $\mathbf{6}$ millones de seguidores en twitter y facebook (PubliAbril, 2016).

Como Veja tiene sección fija sobre salud, produce semanalmente reportajes en profundidad que, según Kuscinsky (2002), en cada tres o cuatro ediciones se anuncian en la portada de la revista. Para este autor, esta frecuencia se relaciona con el hecho de que las noticias sobre la salud atraen más fácilmente el interés de los lectores.

No hemos encontrado en la bibliografía otros estudios más actuales que analizaran la cobertura sobre salud de $V$ eja en su sentido amplio o que discutiesen el concepto de salud adoptado por esta revista lo que podría ofrecer más elementos para enriquecer este análisis. Sin embargo, hemos encontrado el análisis de temas específicos donde, en la mayoría, no se había realizado un análisis centrado en la cobertura de Veja, y sí en estudios que englobaran otros medios impresos. Villela y Natal (2014) han investigado la cobertura periodística sobre dengue en periódicos nacionales y en revistas, entre ellas, Veja. Los autores han encontrado que estos medios estaban más preocupados en polemizar que en alertar y esclarecer la epidemia al público.

Gomes y Ferraz (2012), que han estudiado las revistas Veja, Isto É y Época, verificaron que estos medios utilizan la muerte como uno de los valores principales a la hora de publicar noticias sobre la gripe H1N1. Castro (2009) ha investigado la cobertura sobre el cáncer en diarios y revistas, como en $V e j a$, y ha identificado que el foco principal de las noticias era la investigación científica, principalmente de estudios internacionales. Guarniero, Bellinghini y Gattaz (2012) han intentado comprender la cobertura de los medios (periódicos y revistas, como $V_{e j a}$ ) sobre esquizofrenia. Además han constatado que la mayoría de los contenidos publicados no han dado voz a los que sufren de esta enfermedad. En esta misma línea sobre alteraciones mentales, Soares y Capone (2011), al analizar la cobertura sobre la depresión en un periódico y $V_{e j a}$, identificaron el concepto de la medicalización de la vida (disease mongering, según literatura inglesa) presente en el abordaje de los textos periodísticos estudiados. 
Vaz y Portugal (2012), al estudiar la cobertura de Veja sobre los medicamentos, verificaron que en los reportajes estudiados se sugiere que todo tipo de dolor o sufrimiento tiene un origen orgánico y que la solución son los medicamentos. No se presentan los elevados costes ni los efectos adversos de estos medicamentos ofreciendo una descripción exagerada de los beneficios de los medicamentos.

Para ampliar este tema, hemos hecho una búsqueda en su base de datos y verificamos que, en las 52 ediciones de 2013, fueron publicados 21 contenidos relacionados con la salud en la portada. Entre estos, más del 50\% fueron el tema principal de portada y hay casos de más de una materia sobre salud en la portada en la misma edición. Estos datos muestran que la salud se mantiene como una noticia en evidencia para esta revista, como apuntaba Kuscinsky (2002). Los contenidos más frecuentes estaban relacionados con la belleza, la alimentación y el cuerpo, así como sobre enfermedades del corazón, cáncer y trastornos mentales.

\subsection{La salud en los periódicos con mayor circulación}

En cuanto a los periódicos, los cinco diarios de pago con mayor promedio de circulación en el país (impresos y digitales), según datos del año 2014 de la Associação Nacional de Jornais (ANJ, 2014), son los siguientes: Folha de São Paulo (351.745 mil), O Globo (333.860 mil), Súper Noticias (318.067), O Estado de São Paulo (Estadão) (237.901 mil) y Zero Hora (210.661 mil).

Procedemos a realizar una breve reseña sobre ellos, centrándonos después en nuestro estudio de caso. De esta relación, dos diarios tienen una circulación regional: Super Noticia, del Estado de Minas Gerais, y la Zero Hora, del Rio Grande do Sul. El resto tiene circulación nacional.

En Río de Janeiro, el diario O Globo, edición impresa y digital, inserta noticias sobre salud (investigación biomédica, consejos y cuidado con la salud) en la sección fija llamada Sociedade, con una circulación diaria donde publica también contenidos relacionados con la educación, 
entre otros. Las noticias sobre la actualidad de la salud relacionadas con Río de Janeiro se publican en la sección Río y, a las relacionadas con todo el territorio nacional, en la sección País. El periódico Estado de São Paulo (Estadão) publica noticias y consejos sobre la salud en su sección fija llamada Saúde (Estado de São Paulo, 2016).

El diario Super Noticia, de Minas Gerais, ocupa el tercer puesto de mayor tirada en Brasil, después de haber ocupado el primer puesto en años anteriores. Es considerado un fenómeno de venta y, en menos de una década, ha pasado de 6 mil ejemplares vendidos a cerca de 330 mil (Tristão, 2012). Es el único en esta relación que tiene como público las clases populares (Tristão, 2012) y no cuenta con sección específica de salud. Esporádicamente publica alguna noticia sobre salud producida por el periódico $O$ Tempo, que pertenece al mismo grupo. Los domingos, hay una columna llamada Meu problema é... donde especialistas contestan a las dudas enviadas por los lectores.

El periódico Zero Hora tiene un suplemento fijo, dedicado exclusivamente a la salud desde octubre de 1991, Caderno Vida, que circula los sábados con 12 páginas. Como es de tirada semanal, no tiene el compromiso de cobertura diaria y se dedica a temas que pueden ser hechos con mayor trayectoria en el tiempo, sin necesidad de depender del factor actualidad. Según su editora, Cándida Hansen $^{29}$, este espacio busca:

"Falar mais de saúde (ou "ser saudável") e menos de doenças. O caderno abrange matérias de comportamento, desde estresse até melhores formas de se comunicar com os outros; familia, desde saúde infantil/materna até matérias sobre relações familiares, alimentação, exercícios físicos e descobertas científicas. Recentemente, criamos a seção +Saúde que, a cada edição, traz um panorama geral sobre alguma doença (prevenção, sintomas e tratamento)".

Según la misma editora, todavía, no hay una sección fija dedicada únicamente a la salud para la cobertura de los eventos diarios, ya que se publican en secciones diferentes. En general, los temas

${ }^{29}$ Entrevista realizada por correo electrónico el 20 de abril de 2016. 
relacionados con gripe, vacunas y microcefalia, así como consejos sobre alimentación, por ejemplo, son publicados en la sección Vida, que también publica noticias sobre otros temas, como los relacionados con el comportamiento, los cuidados de las mascotas y consejos sobre decoración de ambientes. Los contenidos relacionados con servicios de salud públicos, por ejemplo, tiene espacio en la sección de Noticias.

\section{La salud en Folha de São Paulo}

Folha de São Paulo nació en 1921 cuando Olival Costa e Pedro Cunha fundaron el periódico Folha da Noite. En 1925, se creó su versión matutina, Folha da Manhã. 24 años después fue fundada Folha da Tarde. En 1960, estos tres títulos se agruparon, creando el diario Folha de $S$. Paulo. En 2010, Folha unificó las redacciones impresa y on-line (Folha de São Paulo, 2016b). Un año después, el diario pasó a publicar en la web ediciones en español e inglés (Folha de São Paulo, 2011a). Este diario pertenece al Grupo Folba junto con otros periódicos como Agora e Valor Econômico (Folha de São Paulo, 2016a).

Está organizado en cuadernos fijos diarios: Poder, Mundo, Mercado, Cotidiano, Ciência + Saúde, Esporte e Ilustrada (Folha de São Paulo, 2016c), además de cuadernos semanales (Tec, The New York Times, Comida, Ilustríssima, Veículos, Negócios Carreira e Empregos, Turismo, Folhinha, Imóveis) (Folha de São Paulo, 2016d). En cuanto a su línea editorial se define como un periódico crítico, no partidista, moderno y pluralista (Manual de Redación, 2002).

El perfil de sus lectores se compone por la clase A, según investigación realizada por el propio periódico. Tres cuartas partes de los mismos han realizado estudios universitarios de Grado y el 24\% de Postgrado, datos que contrastan con el $13 \%$ y el $2 \%$, respectivamente, de media en el país. La renta y posición social de este público son altas (Folha de São Paulo, 2011b).

Es el periódico con mayor circulación en el país y que tiene más secciones fijas dedicadas a salud. También es el único diario, de entre los citados, que trae, en su sitio web, una caracterización del perfil de sus secciones. 
Para entender cómo los espacios destinados a la salud han sido organizados en los últimos años, hicimos una búsqueda en la base de datos de este diario desde los años 90 hasta la actualidad (año 2016) para identificar cuándo comenzaron estas secciones y cuáles fueron los cambios que se han producido en este periodo. También identificamos cómo se caracteriza, de acuerdo con la definición del periódico, el perfil de estos espacios. No es nuestra intención analizar los textos periodísticos, pero si reflexionar sobre el concepto de salud a partir de la propia definición adoptada como linea editorial por el periódico.

Actualmente las noticias sobre este tema son publicadas en el Caderno Cotidiano y en las secciones Ciência + Saúde y Equilíbrio.

\subsection{Equilíbrio: de suplemento a sección}

Este suplemento fue el espacio fijo sobre salud más antiguo en Folha de São Paulo. Lanzado en mayo de 2000, recibió el siguiente título en su primera portada: "Folha lanza hoy cuaderno sobre calidad de vida".

La palabra equilibrio, que da nombre al suplemento, es tal vez la forma más clásica y antigua de conceptuar la salud, del filósofo y médico Galeno, en la Antigua Roma: "la salud es el equilibrio íntegro de los principios de la naturaleza, o de los humores que en nosotros existen, o la actuación sin ningún obstáculo de las fuerzas naturales. O, también, es la cómoda armonía de los elementos" (Moura, 1989: 42 apud Caponi, 1997).

Consideramos que esta definición, junto con la de la OMS ya presentada en la introducción, marca la pauta de lo que realmente propone esta sección, de acuerdo con lo que se describe en su página web: "Un cuaderno dedicado a la búsqueda de la salud y la calidad de vida. Trae las últimas técnicas y terapias para aquellos que quieren vivir más y mejor, y consejos precisos sobre el cuidado del cuerpo y de la mente" (Folha de São Paulo, 2016d). El documento se elaboró a partir de un objetivo muy en boga hoy en día: la búsqueda de la calidad de vida. 
Para Andrade, Wiik y Vasconcellos "El Suplemento pode ser entendido como um conjunto de informações, propostas e sugestões de conquista pessoal de aperfeiçoamento das condições de vida" (2004: 59).

De acuerdo con el testimonio de un periodista ${ }^{30}$, que trabajaba en Equilíbrio, éste ha traído diferentes temas relacionados con la salud y el bienestar (medicina, nutrición, fitness, masajes), centrándose en la prevención y las iniciativas que se ocupan de la salud y no sólo la enfermedad (Gomes, Vaz y Assmann, 2010).

En cuanto a sus contenidos, el suplemento presentaba tres espacios fundamentales: el reportaje central, y dos columnas escritas por consultores, SOS família y Outras Idéias. La primera contaba con la psicóloga y consultora educativa, Roseli Sayão, que publicaba temas sobre la educación de los niños y adolescentes. Esta profesional era conocida en la sociedad paulista y actuaba en los colegios privados de São Paulo, cuya población de estudiantes era formada, en su mayoría, por estudiantes de familias de clase media y alta. La otra columna publicaba textos sobre diversos temas, desde la meditación hasta los cambios en el estilo de vida en las grandes ciudades (Andrade et al, 2004).

El suplemento también tenía otras secciones como Pregunte Aquí, espacio para responder a las preguntas de los lectores, y Poucas e Boas, que publicaba cuestiones relacionadas con la vida moderna, y Alecrim, una sección sobre culinaria para mostrar recetas utilizando alimentos sanos (Andrade et al, 2004).

Inicialmente tenía de 16 a 20 páginas y circulaba una vez a la semana. Con el tiempo, el cuaderno, en formato tabloide, pasó a 12 páginas y luego a 8. La tendencia de reducción de espacios sobre salud continuó y, después de 13 años de existencia, Equilíbrio ha dejado de circular en el formato de suplemento y se ha transformado en una sección semanal, de una página, bajo el cuaderno Cotidiano. De acuerdo con la Associação Brasileira de Imprensa (ABI, 2013), estos cambios se produjeron como resultado de reformas en muchos cuadernos, lo que

${ }^{30}$ Los autores citados no han identificado el nombre del periodista. 
llevó al despido de unos 40 periodistas y profesionales de otras áreas del periódico.

Como ha pasado de 8 páginas a una, ha perdido las secciones Pregunte Aqui, Poucas e Boas y Alecrim, Outras Idéias y SOS familia, cuya consultora Roseli Sayão aún publica textos sobre educación en Folha, pero en otra sección. Con estos cambios, Equilíbrio publica ahora un texto periodístico - con el mismo enfoque en los consejos u orientaciones sobre salud o comportamiento como hacia anteriormente - y cuenta con dos especialistas (la neurocientista Suzana Houzel y la antropóloga Miriam Goldenberg) que se alternan publicando un texto en cada edición.

A pesar de la reducción drástica, la sección ha mantenido la misma línea del suplemento en relación a los contenidos elegidos para hablar sobre salud. Para Gomes, Vaz y Assmann, que han analizado las noticias publicadas en Equilíbrio, el enfoque adoptado es de responsabilizar a las personas sobre su salud, centrándose en las acciones individuales:

"A questão aqui não é a de menosprezar as informações fornecidas pelo Caderno, pois existem conhecimentos úteis para os indivíduos em seu cotidiano. Para além de tal aspecto, nossa análise propõe a discussão de que esse formato traz consigo um valor que reafirma a responsabilidade individual no campo de ação privado" (Gomes, Vaz y Assmann, 2010: 131).

En la sociedad actual, la tendencia de responsabilizar a los individuos por no tener estilos de vida saludables "tendería a desplazar la discusión sobre cuestiones relacionadas a factores sociales, ambientales, económicos y de condiciones de trabajo que influyen fuertemente en el proceso de salud-enfermedad" (Bastitella, 2007: 61). En el caso de los medios de comunicación, como Kuscinsky, resalta (2002), la cobertura de salud no escapa de una falla, que ya puede ser considerada clásica, tradicional, como también ocurre con la medicina, que es no abordar los procesos sociales de la enfermedad, mostrando solamente las manifestaciones de este proceso (Kuscinsky, 2002), lo que hemos podido también identificar en Equilíbrio. 


\subsection{Ciênciat Saúde}

En octubre de 2008, además del cuaderno Equilíbrio, Folha lanzó una sección diaria fija de salud, denominada Saúde. De acuerdo con la definición disponible en su sitio web, cuando empezó a circular, el objetivo fue publicar contenidos provenientes de investigaciones, nuevas tecnologías (medicamentos y equipos) para diagnósticos, tratamientos y nuevos abordajes de la medicina sobre antiguos problemas de salud.

En abril de 2012, cuatro años más tarde, el periódico introdujo nuevos cambios, llegando al despido de periodistas, en una ola de reducción del equipo en las redacciones de periódicos en todo el país. Por lo tanto, la sección de salud perdió su autonomía, uniéndose a la sección de ciencia (que existe en el periódico desde los años 90), compartiendo espacio con ella, formando así, la sección Ciência + Saúde. Con el nuevo diseño, el equipo perdió tres profesionales. En 2013, esta sección tenía un equipo formado por un editor, un editor asistente y tres reporteros para trabajar en la versión impresa y en línea (Lara, 2013).

En 2015, se produjo un nuevo cambio: las secciones que tenían equipos menores fueron reagrupadas en núcleos más grandes, como el caso de Ciência + Saúde que ha pasado a formar parte del Caderno Cotidiano. Es posible considerar que, en general, las secciones que no ocupan un espacio tan privilegiado son las primeras en ser eliminadas debido a que, en el caso de las noticias relacionadas con la salud, podrían ser publicadas en otras secciones o cuadernos. Este problema nos hace reflexionar que, en general, los periodistas con más experiencia y tiempo de servicio son los más afectados por estos recortes de recursos humanos. La cuestión es que exactamente estos son los que tienen más dominio del tema y la posibilidad de ser más críticos en la conducción de la pauta. Lo que vemos es, cada vez más, el predominio de los jóvenes en las salas de redacción. La reagrupación de los equipos en otras editoriales también puede significar la reducción de periodistas especializados en el área salud. 
La nueva sección de Ciência +Saúde comenzó a circular con dos páginas, pero ahora se ha reducido a una página, manteniendo la publicación diaria. En el sitio web del periódico aparece que esta sección publica noticias sobre los últimos descubrimientos e investigaciones más recientes e importantes en los ámbitos científicos y médicos en Brasil y en el mundo, con especial atención al didactismo y al uso de ayudas visuales para explicar cuestiones complejas (Folha de São Paulo, 2016c).

Al mirar las noticias publicadas en esta sección es posible darse cuenta de que hay un predominio del enfoque de las pautas relacionadas con otras áreas de la ciencia, así como la tendencia es que ocupen el espacio principal de la página, en detrimento de noticias sobre la salud. La sección de Ciência tiene una larga historia en Folha de São Paulo, existiendo desde los años 90. Algunos temas comunes están relacionados con el calentamiento global, la astronomía, la cosmología y la arqueología. Como la definición anterior que hemos presentado, el enfoque sobre la salud es direccionado al área médica en busca de legitimación científica. Otros estudios en el área de salud, que no pertenecen a medicina, difícilmente se abordan.

\subsection{La salud en el Caderno Cotidiano}

Además de los espacios fijos, el Caderno Cotidiano, con circulación diária, puede también traer noticias sobre la salud, pero, como su nombre indica, están más relacionadas con cuestiones del día a día y temas de actualidad (la falta de camas en los hospitales, el desarrollo de un programa en el área de la salud pública, la inauguración de un hospital, las epidemias, la vacunación).

De acuerdo con la definición disponible en el sitio web del periódico, Caderno Cotidiano ofrece al lector información útil para su día a día en la seguridad, la educación del consumidor y la Ley, y además publica noticias diarias sobre las principales capitales del país. La edición de São Paulo centra su cobertura en la capital del Estado y busca proporcionar un servicio al lector sobre temas tales como derechos 
de los consumidores, la salud, el tráfico y la meteorología (Folha de São Paulo, 2016c).

\section{Consideraciones finales}

Al organizar y distribuir los contenidos sobre salud en tres secciones diferentes, Folha de São Paulo publica una visión fragmentada sobre la salud, conforme a las características de cada sección. También se puede constatar que el enfoque dado en la sección Equilíbrio se centra en una perspectiva individual, dejando a las personas la responsabilidad de su prevención, así como resolver sus problemas de salud. En cuanto a la sección Ciência + Saúde, el interés se dirige a la legitimación científica y, en el caso de la salud, se basa en la autoridad médica. La prioridad en esta sección, sin embargo, son otras áreas de la ciencia, dejando las noticias sobre salud en segundo plano.

También consideramos que tanto Folha, como otros periódicos, solamente ofrecen secciones sobre salud cuando son entendidas como un espacio para aconsejar a las personas sobre cómo cuidar su salud, desde una perspectiva individual, o cuando están relacionas a la difusión científica. Otros temas de salud, considerados de actualidad, y que impactan el día a día de las personas, o relacionadas con la garantía de sus derechos, y que tiene una dimensión colectiva, no pertenecen a una sección de salud específica y son publicados en otros espacios, compitiendo con otros tipos de contenidos, como ocurre con el Caderno Cotidiano, de Folha.

Otro punto relevante es la pérdida gradual de espacios fijos dedicados a salud. A pesar de que hay aún un concepto todavía limitado que guía la cobertura en salud, la reducción de secciones fijas también es un motivo de preocupación porque son los espacios que podrían ofrecer mayor profundidad sobre los acontecimientos. También se supone que una sección de salud requiere un equipo especializado que pueda garantizar una mayor calidad del contenido publicado, aspecto que debería ser investigado en futuros estudios. 


\section{Bibliografía}

Almeida Filho, N (2000). "Conceito de saúde: ponto-cego da epidemiologia?” Rev. Bras. Epidemiol., 3(1-3): 4-20.

Andrade, C L, Wiik, C B y Vasconcellos, M P C (2004). "Corpo e cultura e corpo e saúde: análise do suplemento semanal de um jornal paulista". Saúde e Sociedade, 13(3): 58-67.

Batistella, C (2007). "Abordagens Contemporâneas do Conceito de Saúde". In: Fonseca, A F (Org.). O território e o processo saúdedoença. Rio de Janeiro: EPSJV/Fiocruz.

Castro, R (2009). "Câncer na mídia: uma questão de saúde pública. Revista Brasileira de Cancerologia, 55(1): 41-48.

Caponi, S (1997). “Georges Canguilhem y el estatuto epistemológico del concepto de salud". História, Ciências e Saúde, Manguinhos, IV(2): 287-307.

Caron, E, Lefèvre, F y Lefèvre, A M C (2015). “Afinal, somos ou não somos uma sociedade de consumo? Consequências para a saúde”. Ciência \& Saúde Coletiva, 20(1):145-153.

Godoi, G C S (2006). “A cobertura sobre saúde relativa à infância e à adolescência: uma análise comparativa do material veiculado por 50 jornais brasileiros". In: Santos, A. (Org.) (2006). Caderno Mídia e Saúde Pública. Belo Horizonte: Escola de Saúde Pública/Funed.

Gomes, I M, Vaz, A F y Assmann, S J (2010). “Conselheiros midiáticos: o "Caderno Equilíbrio" da Folha de São Paulo e suas ponderações na formação do indivíduo saudável". Movimento, 16 (04): 117-134.

Gomes, I M A M y Ferraz, L M R (2012). “Ameaça e Controle da Gripe A(H1N1): uma análise discursiva de Veja, IstoÉ e Época”. Saúde Soc., 21 (2), 302-313.

Guarniero, F B, Bellinghini, R H y Gattaz, W F (2012). "Estigma 
da esquizofrenia na mídia: um levantamento de notícias publicadas em veículos brasileiros de grande circulação". Rev Psiq Clin.; 39(3):80-4.

Kuscinsky, B (2002). “Jornalismo e saúde na era neoliberal". Saúde e Sociedade, 11(1): 95-103.

Nogueira, R P (2011). “Extensão fenomenológica dos conceitos de saúde e enfermidade em Heidegger". Ciência \& Saúde Coletiva, 16(1): 259-266.

Scliar, M (2007). "História do Conceito de Saúde". Ciência \& Saúde Coletiva, 17(1): 29-41.

Segre, M y Ferraz, F C (1997). "O Conceito de saúde”. Rev. Saúde, 31(5): 538-42.

Soares, G B y Caponi, S (2011). “Depressão em pauta: um estudo sobre o discurso da mídia no processo de medicalização da vida". Interface - Comunic., Saude, Educ., 15(37), 437-46.

Tristão, M B (2012). A representação da Polícia Militar de Minas

Gerais no "Super Noticia": o jornal mais lido pelos mineiros. Dissertação Mestrado. Universidade Federal de Juiz de Fora. Juiz de Fora.

Vaz, P y Portugal, D B (2012). "A nova "boa-nova": marketing de medicamentos e jornalismo científico nas páginas da revista brasileira Veja”. Comunicaşão, mídia e consumo, São Paulo, 9 (26), $37-60$.

Vieira, C. A. L., Bosi, M. L. M. (2013). “Corpos em confecção: considerações sobre os dispositivos científico e midiático em revistas de beleza feminina". Physis Revista de Saúde Coletiva, 23(3): 843-861.

Villela, E F M y Natal, D (2014). "Mídia, saúde e poder: um jogo de representações sobre dengue”. Saúde Soc., 23(3): 1007-1017.

VV.AA. (2002). Manual da Folha de São Paulo, $5^{a}$ ed. São Paulo: Publifolha. 
Xavier, C (2006). "Mídia e Saúde, Saúde na Mídia". In: Santos, A. (Org.). Caderno Mídia e Saúde Pública. Belo Horizonte: Escola de Saúde Pública/Funed.

\section{Otros documentos}

ABI (Associação Brasileira de Imprensa) (2013). “Após demissões, Folha anuncia reforma editorial". Disponible en: http://www.abi.org.br/apos-demissoes-folha-anuncia-reformaeditorial (fecha de consulta: 24/4/2016).

ANJ (Associação Nacional de Jornais) (2014). “Os maiores jornais do brasil de circulação paga por ano". Disponible en: http://www.anj.org.br/maiores-jornais-do-brasil//fecha de consulta: $24 / 4 / 2016)$.

Bem Estar (2016). "Nos 5 anos do Bem Estar, reveja 12 reportagens de destaque do programa”. Disponible en: http://g1.globo.com/bemestar/noticia/2016/02/nos-5-anosdo-bem-estar-reveja-12-reportagens-de-destaque-doprograma.html (fecha de consulta: 24/4/2016).

Estado de São Paulo (2012). "Saúde". Disponible en: http://saude.estadao.com.br/ (fecha de consulta: 24/4/2016).

Folha de São Paulo (2011a). "Folha de S. Paulo lança site em inglês e español”. Disponible en: http://www1.folha.uol.com.br/institucional/951540-folha-despaulo-lanca-site-em-ingles-e-espanhol.shtml (fecha de consulta: 24/4/2016).

Folha de São Paulo (2011b). "Leitor da Folha é ultraqualificado, mostra pesquisa. Disponible en:

http://www1.folha.uol.com.br/paineldoleitor/2011/10/991055 -leitor-da-folha-e-ultraqualificado-mostra-pesquisa.shtml (fecha de consulta: 24/4/2016). 
Folha de São Paulo (2016a). "Conheça o Grupo Folha”. Disponible en:

http://www1.folha.uol.com.br/institucional/conheca o grupo. shtml (fecha de consulta: 24/4/2016).

Folha de São Paulo (2016b). "Conheça a Folha de S. Paulo: história da Folha". Disponible en:

http://www1.folha.uol.com.br/institucional/historia da folha. shtml (fecha de consulta: 24/4/2016).

Folha de São Paulo (2016c). "Conheça a Folha de S. Paulo: cadernos diários". Disponible en:

http://www1.folha.uol.com.br/institucional/cadernos diarios.s html (fecha de consulta: 24/4/2016).

Folha de São Paulo (2016d). "Conheça a Folha de S. Paulo:

suplementos". Disponible en:

http://www1.folha.uol.com.br/institucional/suplementos.shtml (fecha de consulta: 24/4/2016).

Lara, B. (2013). "Entrevista com o jornalista Reinaldo José Lopes".

Disponible en:

http://dissertacaosobredc.blogspot.com.es/2013/02/edit or-de-ciencias-e-saude-da-folha-de.html (fecha de consulta: 24/4/2016).

OMS (Organización Mundial de Salud) (2014). Documentos

Básicos, $48^{\mathrm{a}}$ ed. Disponible en:

http://www.who.int/about/mission/es/ (fecha de consulta: 24/4/2016).

Publiabril (s/f). Marcas e plataformas: Veja. Disponible en:

http://publiabril.abr il.com.br/marcas/veja (fecha de consulta: 3/6/2016).

Rede Globo (s/f). TV Globo e Você. Disponible en:

http://redeglobo.globo.com/Portal/institucional/foldereletroni co/g tv globo.html (fecha de consulta: 3/6/2016). 



\title{
Riesgos y oportunidades del enfoque humano en la cobertura de salud mental de la prensa colombiana
}

\author{
Víctor García-Perdomo, ${ }^{C}$
}

Universidad de La Sabana, Colombia

Liliana Gutiérrez-Coba, $\mathrm{G}$

Universidad de La Sabana, Colombia

Yahira Guzmán-Sabogal,

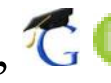

Universidad de La Sabana, Colombia

Andrea Salgado-Cardona, $\bar{G}$

Universidad de La Sabana, Colombia

\section{Resumen}

Introducción: La cobertura de los medios produce un impacto directo en la forma como la sociedad entiende y se comporta frente a asuntos relacionados con la salud mental. Objetivos. Este trabajo de investigación busca arrojar luces sobre la cobertura que hacen los medios escritos tradicionales colombianos de las informaciones relacionadas con salud mental. Metodología. Se realizaron una serie de asociaciones entre los encuadres (o frames) de las historias y los géneros periodísticos, las fuentes informativas y el ofrecimiento de tratamientos y soluciones a los problemas sociales derivados de esas enfermedades. Para el análisis hemos utilizado las categorías de Framing genéricas elaboradas por Semetko \& Valkenburg (2000) y las de calidad informativa desarrolladas por el equipo Valor Agregado Periodístico de la Pontificia Universidad Católica de Chile. Resultados. Los resultados muestran un uso frecuente del frame de 
interés humano en la cobertura de salud mental y una estrecha asociación entre la mayoría de los encuadres y el género noticioso, en detrimento de otras aproximaciones como las interpretativas y argumentativas. Así mismo, el estudio revela una falencia en la información de tratamientos y recomendaciones para ayudar a orientar a los enfermos y a sus familias y para combatir el estigma. Las implicaciones sociales y periodísticas de estos resultados son discutidos ampliamente. Conclusiones. La intención de esta investigación es contribuir a que la cobertura de medios y las herramientas que se usan en la narración y distribución de contenidos tengan un impacto positivo en la forma como la sociedad entiende y se comporta frente a temas relacionados con la salud mental.

Palabras clave: salud mental; framing; interés humano; prensa; cobertura.

\section{Medios y enfermedades mentales}

— L IMPACTO negativo que una mal cobertura de la información $\amalg$ en salud mental puede tener en la sociedad y las políticas públicas es uno de los fenómenos que ha centrado la atención de los estudiosos de las ciencias sociales y la medicina (Clarke, 2008; Corbett y Durfree, 2004; Holton et al, 2012). Aunque con menos interés, las posibilidades paliativas y de ayuda que ofrece una buena cobertura informativa también han sido motivo de estudio, sobre todo cuando se ha buscado reducir el estigma hacia los enfermos mentales, impulsar políticas públicas o hacer accesibles tratamientos y servicios de salud para las familias y personas afectadas (Holton et al., 2012). Estudios de contenido demuestran que la mayoría de las referencias que hacen los medios sobre la salud mental está relacionada con violencia, y que esas imágenes negativas aparecen en espacios destacados, mientras que las referencias positivas son relegadas a espacios secundarios (Philo, 1996).

Investigaciones han probado que la cobertura de los medios produce un impacto directo en la forma como la sociedad entiende y se comporta frente a asuntos relacionados con la salud mental (Secker y Platt, 1996). En particular, la audiencia puede generar respuestas emocionales hacia lo que se le presenta como un mundo impredecible 
y espeluznante (Philo, 1996). En efecto, existe una tendencia en las noticias y en la información de presentar las enfermedades mentales de una manera que promueve estigmas y reproduce mitos alrededor de los enfermos; particularmente, transmite una idea de violencia y peligrosidad sobre estos asuntos de salud que ocasiona un distanciamiento del público (Pirkis y Francis, 2012). Holton (2013), por ejemplo, ha puesto en evidencia las representaciones etéreas que hacen los programas de televisión de niños que sufren de autismo al centrarse en aislamiento y el miedo desde la perspectiva familiar y social, y no desde los individuos que padecen el desorden. El enfermo mental aparece representado en los medios de comunicación más como personaje de una narrativa de ficción que como una realidad médica, lo cual conlleva a la caracterización ficticia del enfermo mental a la creación de imágenes distorsionadas y finalmente a la especulación (Young et al, 2008).

Las representaciones y coberturas mediáticas pueden prevenir o desencadenar actitudes y comportamientos en el público. Entman (2010) considera que los ciudadanos son especialmente susceptibles a concebir una idea de la sociedad dentro de ciertos límites cuando son expuestos a patrones mediáticos repetitivos que contienen imágenes y palabras resonantes. Aunque los medios y las noticias no son la única fuente de información en esta área, la influencia que ejercen esas imágenes mediáticas en la percepción de la sociedad y en la formulación de políticas sociales resulta relevante. La representación de personas diagnosticadas con esquizofrenia o bipolaridad como psychos o asesinos en serie ha tenido serias consecuencias sociales para los pacientes que sufren esta enfermedad y sus familias (Senra-Rivera, De Arriba-Rossetto y Seona-Pequeira, 2008; Philo, 1996).

Iyengar (1991) ha mostrado cómo la cobertura episódica, anecdótica y superficial de las noticias en televisión hace que la sociedad culpe a los individuos y exima a las instituciones y políticas públicas por problemas sociales como la pobreza y la inmigración que tienen explicaciones profundas y estructurales. Bajo ciertas circunstancias, una mala cobertura de la información alrededor de fenómenos críticos como el suicidio ha desencadenado la imitación de los individuos de esas acciones autodestructivas (Chang, 2012; Gould, 2001) ha limitado el acceso a los servicios médicos o incluso el 
bloqueo de políticas públicas hacia la población vulnerable. Por otro lado, campañas públicas que han sido combinadas con información mediática han demostrado una alta efectividad en la educación del público y en el cambio de actitudes y creencias hacia las enfermedades y los enfermos mentales.

La forma que la información de salud es presentada a los pacientes ha probado también ser crucial en el éxito o fracaso de un mensaje. Campañas de salud que han pretendido incentivar en las mujeres el acceso a exámenes como mamografías para detectar el cáncer de mama (Schneider et al, 2001) o de sangre para detectar el VIH (Apanovitch, McCarthy y Salovey, 2003) han tenido mayor o menor efectividad dependiendo del enfoque que se le dé a la información ofrecida. Cuando la campaña adopta una aproximación positiva, de ganancia (vida, vitalidad, salud, por ejemplo), la efectividad del mensaje resulta distinta si se adopta un tono negativo o de pérdida (muerte, sufrimiento).

La evidencia también demuestra que los médicos y pacientes cambian sus preferencias hacia posibles terapias para curar enfermedades graves cuando los potenciales resultados del tratamiento son presentados en términos de mortalidad o supervivencia. Por ejemplo, a pacientes a los que se les ofreció la posibilidad de optar por cirugías o por terapias de radiación tendieron a seleccionar el tratamiento que presentaba menor riesgo durante el proceso de curación (Kahneman y Tversky, 1982). Otro ejemplo claro de esta tendencia ocurrió cuando los medios replicaron información científica errada, que relaciona casos de autismo con vacunas como la triple viral, no solo ha reducido los niveles de vacunación sino que también ha creado amenazas sanitarias y brotes epidémicos (Holton et al, 2012). Igualmente, tratamientos médicos sin mucho sustento en la investigación diseñados para curar los déficits de atención en niños han sido malentendidos por médicos y familias, y han sido replicados por los medios hasta crear una cultura de abuso en su implementación (Ray y Hinnant, 2009).

\section{Salud mental en Colombia}

Las secuelas que el conflicto armado colombiano ha dejado en buena parte de la población han despertado interés institucional por la salud 
mental en el país ahora que se adelantan procesos de pacificación y reparación. El gobierno colombiano expidió la Ley 1616, del 21 de enero de 2013 con el propósito de promover/priorizar la atención de los enfermos y regular/canalizar recursos destinados a la salud mental de los colombianos. Entre los aspectos más destacados que contiene la ley se encuentran la adecuación de los servicios en el marco del Plan Obligatorio de Salud (POS); la implementación de acciones integrales para prevenir conductas como el acoso escolar, la discriminación y las conductas suicidas, y el fortalecimiento de la salud mental comunitaria, con lo cual se quiere integrar a pacientes, cuidadores, familia, academia y todos los entes que puedan contribuir a generar un mejor entendimiento de la salud mental.

Una de las dificultades que enfrenta Colombia en este tema es la escasez de datos y estudios nacionales que ofrezcan una radiografía de la situación actual. El estudio nacional más reciente sobre el estado de la salud mental en Colombia corresponde al año 2015 (Encuesta Nacional de Salud Mental, 2015), cuando se encuestó a 16.147 personas (divididas en cuatro grupos etarios: de 7 a 11 años; de 12 a 17; de 18 a 44 y de 45 años en adelante), residentes de 13.555 hogares. La encuesta arroja entre sus principales resultados que 4 de cada 100 adolescentes (12 a 17 años de edad) presentaron más de 5 síntomas de ansiedad, y 14 de cada 100 presentaron más de 4 síntomas de depresión. Entre la población de 18 a 44 años se encontraron signos de problemas mentales como ansiedad, depresión o psicosis en el 9,6\% de los encuestados. Y entre los problemas más frecuentes entre las personas de 18 a 44 años está el abuso del alcohol, lo que representó una cifra del 12\%, mientras en los mayores de 45 años se encontró una prevalencia del 6\%.

Aunque la mayor prevalencia de estos trastornos ocurre en adultos jóvenes y maduros, durante la adolescencia hay un aumento dramático en la frecuencia de su presentación. Los más comunes son los de ansiedad. A su vez, la ideación y el intento de suicidio se encuentran entre las primeras causas de muerte también para este grupo de edad (Alba, 2010). Mundialmente, 121 millones de personas sufren de depresión. La prevalencia de esta enfermedad es hasta dos veces más frecuente en mujeres que en los hombres. La depresión afecta cada vez más a los jóvenes, y como una de sus consecuencias, 
se suicidan cada año más de 800 mil personas. Las tasas de suicidio más altas se presentan en poblaciones jóvenes, incluyendo niños y adolescentes, tanto para intento de suicidio, como para suicidio consumado (Organización Mundial de la Salud, 2001). En un estudio realizado en colegios del municipio de Chía, Cundinamarca, se encontró que de los 538 adolescentes encuestados 40,5\% mostraron síntomas de ansiedad o depresión, una proporción importante si se compara con los datos globales de prevalencia de enfermedad mental en la población pediátrica (10-20\%). Sin embargo, la prevalencia de síntomas depresivos fue similar a varios estudios realizados en otras ciudades de Colombia como Bucaramanga, Manizales y el Oriente Antioqueño (Vergara-Quintero, 2009). En las conclusiones de este estudio se plantea que la prevención efectiva de la depresión consiste en fortalecer los factores protectores como autoestima y resiliencia (Ospina-Ospina et al., 2011).

Adicionalmente, en un estudio sobre población mayor en la ciudad de Cali (Ocampo-Chaparro et al, 2013), se trazó como objetivo determinar el escaso auto reporte en salud e identificar factores de riesgo en adultos mayores. Los investigadores encontraron que los factores asociados fueron diabetes mellitus, depresión, temor a caer y síndrome de fatigabilidad. La depresión resultó ser un factor independiente muy marcado en esta población, probablemente el trastorno de salud mental más frecuente en adultos mayores. Los autores llaman la atención acerca de las políticas de salud mental que deberían estar encaminadas en la detección temprana y la prevención de la depresión, controlando los factores de riesgo asociados.

En general los trastornos mentales en Colombia tienen una prevalencia muy similar a la reportada por estudios en diferentes poblaciones. A pesar de ello, los síntomas o desórdenes mentales relacionados con la violencia, el conflicto armado y consumo de sustancias psicoactivas se han incrementado en el país, tal como señala el Estudio Nacional de Consumo de Sustancias Psicoactivas en Colombia (2013). La mortalidad por causas violentas es el principal indicador del nivel de desarrollo de una sociedad y ha sido objeto de un amplio análisis en la literatura científica, especialmente en la última década, según señala el mismo informe. Como resultado se han identificado importantes asociaciones con factores de riesgo, como el 
consumo de drogas o alcohol, y ciertos patrones temporales, con picos en los períodos vacacionales o festivos. Diferentes circunstancias socioeconómicas que afectan a una sociedad pueden influir en el nivel de violencia y esta a su vez en los trastornos mentales (Moreno y Sánchez, 2009). De lo anterior se puede concluir que la salud mental en nuestro país depende en parte del control gubernamental, no sólo en lo que tiene que ver con la prestación de servicios de salud, sino también en lo relacionado con el ambiente en que se desarrolla la juventud (factores protectores o factores de riesgo: satisfacción de necesidades básicas, educación, situación de conflicto armado, etc.).

A pesar de que la mayoría de los síntomas psiquiátricos se relacionan con trastornos depresivos y ansiedad, no se pueden descuidar otros trastornos mentales como los afectivos en general, que en la población colombiana se estiman con una prevalencia de 11,6\% para hombres y 17,5\% para mujeres (Sánchez, Velásquez y Navarro, 2011). La esquizofrenia, la enfermedad mental con mayor potencial de deterioro a lo largo del tiempo y de peor pronóstico, no es tan frecuente en la población general. Sin embargo, el impacto del compromiso en el funcionamiento de las personas que la padecen y la pobre respuesta a los tratamientos permiten que en muchos casos se prescriban medicaciones en mayores dosis a las recomendadas, cosa que tiene unos efectos adversos no deseables en esta población de pacientes (Machado-Alba y Morales-Plaza, 2013).

Otros trastornos frecuentes son los desórdenes en la conducta alimentaria, cuya edad media de diagnóstico inicial se encuentra en los 16 años de edad y el tipo más frecuentemente encontrado es la anorexia (Constaín et al, 2014), y el consumo de sustancias psicoactivas, que según el Estudio Nacional de 2013 va en aumento y muestra que el alcohol y el tabaco son las sustancias de mayor incidencia en el país. A pesar de ello, la incidencia de inicio de consumo de cigarrillo y tabaco en los últimos años se ha reducido. La conclusión central del estudio determina que el consumo global de drogas ilícitas (marihuana, basuco, cocaína, éxtasis o heroína) ha aumentado con relación al estudio realizado en 2008. La prevalencia de vida pasó de 8,8\% en el 2008 a 12,2\% en el 2013. También 
aumentó el reporte de uso de drogas en el último año (de 2,6\% a $3,6 \%$ ).

Un dato para destacar, reportado en estudios recientes, revela que el porcentaje de rehospitalización en pacientes psiquiátricos en Colombia es mucho más alto que el registrado por otros estudios (80\%). Esta cifra es importante debido al impacto que la rehospitalización tiene tanto en los pacientes como en sus familias desde el punto de vista emocional, y también por el impacto económico que tiene sobre los servicios de salud (Jaramillo-Gonzalez, Sanchez-Pedraza y Herazo, 2014). Además de las políticas relacionadas con destinar recursos para medicamentos cubiertos por la seguridad social, o facilitar medidas para evitar el consumo de sustancias psicoactivas, se requiere urgentemente la creación de estrategias de educación formal e informal en salud mental, dirigidas a todo tipo de población, asegurando principalmente la calidad en la formación que reciben todas aquellas personas encargadas del manejo de pacientes con síntomas de enfermedad mental.

\section{Framing como teoría}

En esta sección explicaremos la complejidad de Framing como concepto y la determinación de utilizarlo como fundamento teórico de esta investigación. La popularidad de los estudios de Framing en las ciencias sociales ha hecho que la teoría se enriquezca y adhiera un volumen considerable de investigaciones bajo su denominación. Al mismo tiempo su popularidad ha contribuido a disgregar la teoría con usos y significados dispares que le han impedido la generación de un conocimiento organizado que conduzca a la consolidación de un paradigma (Hertog y McLeon, 2001). Las ciencias políticas, los estudios de medios y la sociología, para mencionar solo algunas áreas, han empleado el concepto de Framing con aproximaciones diversas a la hora de analizar el significado de los discursos y los textos. Reese (2007) ha advertido sobre lo tentador que resulta abordar los encuadres de manera descriptiva dado el fácil acceso que los investigadores tienen de los textos producidos por los medios, y el riesgo de que los académicos redefinan esos frames de acuerdo con sus creencias y valores durante el proceso de investigación. Como resultado, muchos investigadores de Framing tienden a identificar y a 
analizar distintos encuadres en cada uno de los nuevos estudios que realizan (Tewksbury y Scheufele, 2009).

Para hacer aún más complejo el panorama de Framing, teóricos de la comunicación se han enfrascado en discusiones sobre los alcances y parámetros de la teoría. Una de las más vigorosas se centra alrededor de las similitudes y diferencias entre Agenda Setting, Priming y Framing (McCombs y Ghanem, 2001; Maher, 2001; Scheufele y Tewksbury, 2007; Weaver, 2007). Autores como McCombs y Ghanem, 2001 y Weaver (2007) piensan que el concepto hace parte de los niveles de análisis de Agenda Setting, mientras que Entman (2010) sugiere que son teorías distintas que deberían unirse en una sola corriente para entender mejor la distribución del poder que ejercen los medios. Reese (2007) considera que framing conecta diferentes perspectivas, disciplinas y métodos para explicar problemas complejos de la comunicación que van más allá de lo evidente.

Definir la teoría y encontrar puntos de encuentro entre los diversos métodos de análisis también ha sido un reto. Una de las definiciones más amplias e integrales, que va a la esencia de la teoría y es útil a la hora de analizar largos procesos sociales, históricos o ideologías, es la ofrecida por Reese (2011: 11): "frames son principios de organización compartidos socialmente y persistentes en el tiempo, que trabajan simbólicamente para estructurar y dar significado al mundo social".

Otras definiciones han delimitado el concepto para destacar sus facultades comunicativas y hacer más fácil el análisis del contenido noticioso. Una de las más utilizadas es la de Entman (1993: 52) que define los frames como partes de la realidad percibida, sobresalientes en un texto y que "promueven una definición del problema, una interpretación causal, una evaluación moral y/o la recomendación de un tratamiento".

La dispersión de la teoría ha permitido que uno de los principales retos de los teóricos sea precisamente dar cierto orden a esa confusión, identificando una serie de encuadres noticiosos genéricos y deductivos que se repitan en el tiempo y que sirvan como herramientas teóricas para analizar diversos textos y explicar distintas realidades (Hertog y McLeod, 2001; Van Gorp, 2005, 2010). Ese esfuerzo ha rendido sus frutos sobre todo en áreas como la protesta 
social (Hertog y McLeod, 2001), el progreso histórico (Gamson y Modigliani, 1989), la economía, el conflicto (Neuman y Crigler, 1992) y la estrategia política (Cappella y Jamieson, 1997; Entman, 2003; Semetko y Valkenburg, 2000; Lawrence 2010; Matthes, 2009). En contraposición, los encuadres temáticos se aplican a problemas específicos dependiendo del tema o del momento que se analiza (Nelson y Willey, 2001).

\section{Los frames de este estudio}

Para alcanzar los propósitos de este estudio, hemos utilizado cinco categorías de encuadre o frame descritas por Semetko y Valkenburg (2000) y que replican estudios canónicos que analizan los frames genéricos. La mayoría de estos cinco marcos noticiosos fueron identificados originalmente por Neuman y Crigler. (1992) e Iyengar (1996) como artefactos de representación presentes en el contenido de los medios. Estos encuadres procuran ir más allá de la simple identificación de temas específicos a la hora de utilizar framing como teoría, intentan repetirse, y sirven para analizar los contenidos de medios al abordar distintos fenómenos de la comunicación. Los encuadres seleccionados son Atribución de responsabilidad, interés bumano, conflicto, moralidad y consecuencias económicas. Aunque Semetko y Valkenburg adoptan principalmente la clasificación de Neuman y Crigler (1992) e Iyengar (1991), y utilizan estos cinco encuadres para explicar la cobertura que hacen los medios escritos y audiovisuales de la política europea, su universalidad hace posible implementarlos para explicar otras realidades sociales como la salud mental.

En la atribución de responsabilidades, Iyengar (1991, 1996) ha probado cómo la cobertura noticiosa por televisión de asuntos sociales como la pobreza determina percepción de los televidentes respecto a quién es responsable del problema. Iyengar distingue entre el encuadre episódico que reporta solo hechos aislados del problema y sin ningún contexto, y el encuadre temático que analiza de manera más abstracta las razones estructurales de la problemática. El formato rápido y episódico de la información televisiva hace que los individuos resulten responsables de los problemas sociales (la pobreza como resultado de las personas que no se esfuerzan o trabajan), mientras que los gobierno y los funcionarios terminan siendo exonerados de toda responsabilidad (Iyengar, 1996). El interés 
humano ha sido también uno de los marcos más comunes de la prensa en el esfuerzo por darle un rostro a los problemas sociales y acaparar la atención de la audiencia. El uso de una situación particular para personalizar e incluso dramatizar las noticias es uno de los recursos narrativos del que los periodistas echan mano (Neuman y Crigler, 1992; Semetko y Valkenburg, 2000). Igualmente, destacar el conflicto entre partes involucradas en un problema social es una técnica narrativa que apela al clímax de la ficción para aplicarlo a la realidad y ganar audiencia (De Vrese, 2000; Neuman y Crigler, 1992).

Los encuadres periodísticos tienen la facultad de arrojar luces u oscurecer problemas sociales (Iyengar, 1996). Aquellos que contienen información valiosa ayudan a los ciudadanos y a los gobiernos a entender, juzgar y adelantar políticas para responder a las dificultades sociales (Holton et al, 2012; Weiner, 2006). Por esa razón, las preguntas de investigación de este proyecto buscan entender la relación entre la calidad del contenido de los medios y el frame que se ofrece a las audiencias para que entiendan los problemas de salud mental que agobian a la sociedad colombiana:

PI1: ¿Cuáles son los encuadres informativos más utilizados por la prensa escrita colombiana cuando cubre asuntos relacionados con la salud mental?

PI2: ¿Existe alguna relación estadísticamente significativa entre los encuadres y los géneros periodísticos utilizado en la cobertura de la información?

PI3: ¿Hay alguna relación significativa entre los encuadres y las fuentes reseñadas en la información?

PI4: ¿Existe relación entre los encuadres y las causas y consecuencias expuestas dentro de la cobertura de salud mental?

PI5: ¿Hay relación estadísticamente significativa entre los encuadres informativos y el ofrecimiento de tratamientos y recomendaciones especiales en el contenido para paliar los efectos de las enfermedades? 


\section{Método}

Esta investigación siguió el método de análisis de contenido, una técnica de investigación que busca la "descripción objetiva, sistemática y cuantitativa del contenido manifiesto en un texto comunicativo" (Berelson, 1952: 489). Así mismo, se realizó un estudio correlacional con el objetivo de explorar las relaciones entre las variables. Los datos fueron procesados informáticamente utilizando el paquete estadístico SPSS utilizando los estadísticos Chicuadrado de Pearson, razón de verosimilitud y asociación lineal. Las notas periodísticas sobre salud mental incluidas en esta muestra fueron publicadas por la prensa escrita diaria nacional y regional del 1 julio de 2012 y hasta el 31 de junio de 2013. Todo el material publicitario fue excluido.

En total se analizaron 545 notas periodísticas, que hacían referencia directa o mencionaban en alguna de sus partes temas relacionados con salud mental. Las palabras clave de la búsqueda y las categorías asignadas para clasificar la muestra fueron las siguientes: Conductas suicida, Ansiedad, Depresión, Desórdenes alimenticios (anorexia, bulimia), Enfermedad bipolar, Esquizofrenia, Estrés, Salud mental, Adicciones (alcoholismo, drogadicción), Otros (señalar cuáles).

La recolección de esta muestra fue posible gracias al convenio entre la Universidad de La Sabana y la firma de monitoreo de medios Siglo Data - MMI. Se rastrearon 12 meses completos de información publicada por los periódicos colombianos que ofrecen información general, dos de carácter nacional y cinco regionales. Los diarios seleccionados poseen el mayor número de lectores en sus respectivas ciudades, según el más reciente Estudio General de Medios, primera ola 2012 ${ }^{32}$ : El Tiempo (1.137.500 lectores diarios en el ámbito nacional) y El Espectador (250.300, también nacional); Vanguardia Liberal, de Bucaramanga (77.100); El Heraldo (130.200), de Barranquilla; El Colombiano (157.300), de Medellín; La Patria (61.200), de Manizales, y El País (178.100), de Cali.

Tres estudiantes con educación universitaria pertenecientes al semillero de investigación del Grupo de Investigación en Periodismo (GIP) fueron entrenados para codificar el contenido noticioso, con un proceso previo de entendimiento de los temas, las variables y los 
encuadres sobre los que se realizó el análisis. Se eligió de forma aleatoria una parte pequeña de la muestra para hacer una prueba de codificación. Se trabajó con los estudiantes-codificadores hasta que se logró un acuerdo en la matriz de las variables que superó el 90 por ciento. Una vez lograda la confiabilidad sobre la codificación de esta sub-muestra, los estudiantes procedieron a codificar todo el contenido producido por los siete medios durante un año.

Utilizamos las cinco categorías de encuadres genéricos descritas por Semetko y Valkenburg (2000) y que replican estudios canónicos como los de Neuman y Crigler (1992) e Iyengar (1996): Atribución de responsabilidad, interés bumano, conflicto, moralidady consecuencias económicas.

-Atribución de responsabilidades: ¿Se sugiere que el tema o problema requiere una acción urgente por parte del gobierno o de funcionarios? ¿Se sugieren soluciones al tema o problema abordado? ¿Alguna institución, que tiene el poder para resolver o aliviar el problema, es responsable del tema o problema abordado?

-Interés humano: ¿Se muestra la cara humana de un tema o problema? ¿Se utilizan adjetivos o descripciones personales que generan sentimientos de agravio, empatía, simpatía o compasión? ¿Se adentra en las vidas privadas de los protagonistas? ¿Se enfatiza cómo los individuos o los grupos están afectados por el tema o problema abordado? ¿Se incluyen testimonios desgarradores de personas implicadas en el suceso?

-Conflicto: ¿Se alude a dos o más posturas diferentes en abierta confrontación frente al tema o problema abordado? ¿Un individuo, grupo, partido político, institución o país realiza algún tipo de reproche a otro individuo, grupo, partido político, institución o país? ¿Se hace alusión a ganadores y vencidos?

-Moralidad: ¿Se hace referencia a la moral, principios religiosos o éticos? ¿El relato contiene algún tipo de mensaje moral? ¿Se ofrecen prescripciones sociales específicas que indican cómo se debería actuar?

-Costos o beneficios económicos: ¿Se hace referencia a las consecuencias económicas por seguir o no una determinada acción? ¿Se mencionan ganancias o pérdidas financieras que pueden 
producirse en el presente o en el futuro? ¿Se alude a los costos asociados a un tema o problema abordado?

-Calidad de la información: Para analizar la calidad de los contenidos informativos sobre salud mental y cruzarlos con los encuadres noticiosos, se utilizó la escala de Valor Agregado Periodístico de la Facultad de Comunicaciones de la Pontificia Universidad Católica de Chile, VAP-UC ${ }^{34}$, que establece las siguientes variables: género periodístico (informativos, interpretativos y de opinión), tipo de titular (valorativo o informativo), manejo de fuentes según su número (ninguna fuente, una sola fuente, entre 2 y 3 fuentes), sustrato (documentales, personales, otros medios, indefinidas) y filiación (gubernamentales, oficiales públicas, oficiales privadas, expertas, testimoniales), sesgo (existencia de puntos de vista diversos); contextualización (presencia de antecedentes, consecuencias, recomendaciones de prevención y tratamiento o indicaciones de cómo tratar el problema).

\section{Resultados}

Un total de 545 notas periodísticas sobre salud mental fueron encontradas durante el año en los siete periódicos seleccionados. El análisis descriptivo de las variables arrojó como resultado que los temas de salud mental más recurrentes en el contenido de los periódicos son, en su orden, las adicciones (65,5\%); conductas suicidas (22,4\%); depresión (4,6\%); esquizofrenia (2,8\%); salud mental $(1,8 \%)$; desórdenes alimenticios $(1,7 \%)$ y enfermedad bipolar $(1,3 \%)$.

La primera pregunta de este estudio indaga por el uso de los cinco encuadres informativos en la prensa escrita colombiana cuando se cubre salud mental. Los frames más usados por los diarios son interés humano $(38.5 \%)$, moralidad (17.2\%), asignación de responsabilidades $(13.8 \%)$, conflicto $(5.3 \%)$ y costos o beneficios económicos $(2.6 \%)$. Un $22.6 \%$ de las notas no contenía ninguno de los cinco encuadres genéricos específicos. En resumen, interés humano, moralidad y atribución de responsabilidades son los marcos que se presentan con mayor recurrencia en este tipo de información.

La segunda pregunta indaga si existe relación entre los encuadres y los géneros periodísticos empleados en la cobertura. El análisis de las 
variables arrojó una relación estadísticamente significativa entre ellas $X^{2}(10, N=545)=90,213, p<.001$. La mayor parte de notas con el frame de interés humano apelaron al género informativo (64.3\%), seguidas por el interpretativo (9.7\%) y el argumentativo (4\%). De la misma manera, muchas más notas con el encuadre de conflicto estuvieron asociadas al género informativo (65.5\%), seguidas por el argumentativo $(20.7 \%$ ) y el interpretativo (13.8). Del total de la muestra, los cinco encuadres utilizaron mayoritariamente el género informativo $(68.8 \%)$ como género periodístico para cubrir la información de salud mental. Sólo un $15.8 \%$ de todos ellos usó géneros interpretativos y un $15.4 \%$, el argumentativo o de opinión.

Respecto a la pregunta 3, el estudio también halló una asociación importante entre los encuadres informativos y las fuentes utilizadas por los periodistas para reportear la información. En la clasificación por sustrato (documentales, personales y otros medios), el $38.5 \%$ de las notas con encuadres utilizan fuentes documentales. 11\% de ellas están presentes en las notas de interés humano, $10.1 \%$ en moralidad y $8.4 \%$ en asignación de responsabilidades $X^{2}(5, N=545)=79,848$, $p<.001$, con un coeficiente de contingencia de .357. Así mismo, el $41.5 \%$ de las historias y sus encuadres usan fuentes personales $X^{2}(5$, $N=545)=81,867, p<.001$, con un coeficiente de contingencia de .361 , mientras que el $17.1 \%$ de las notas acuden a los propios medios para reportar la información $X^{2}(5, N=545)=18,730, p<.005$, con un coeficiente de contingencia de .182 .

En la clasificación de fuentes por filiación, se encontró que 20.7\% utilizan fuentes gubernamentales $X^{2}(5, N=545)=26,943, p<.001$, con un coeficiente de contingencia de .217 . El 20.6\% de las notas con encuadres usa fuentes oficiales privadas $X^{2}(5, N=545)=38,701, p<$ .001 , con un coeficiente de contingencia de .257. Un 38.7\% fuentes expertas $X^{2}(5, N=545)=43,890, p<.001$, con un coeficiente de contingencia de .273 , y un $34.3 \%$ acude a fuentes testimoniales $X^{2}$ (5, $N=545)=35,484, p<.001$, con un coeficiente de contingencia de .247 .

La cuarta pregunta busca una relación significativa entre los encuadres genéricos y la presencia de causas y consecuencias en la información de salud mental. $65.5 \%$ de la información con encuadres trata de explicar las causas del problema social $X^{2}(5, N=545)=$ 
$15,434 \mathrm{p}<.01$, mientras que el $66.2 \%$ incluye las consecuencias derivadas de estas enfermedades $X^{2}(5, N=545)=11,691 \mathrm{p}<.05$.

La quinta pesquisa indaga si hay una asociación significativa entre los encuadres y el ofrecimiento de tratamientos y recomendaciones especiales en el contenido para paliar los efectos de las enfermedades. Los resultados muestran que solo el $28.8 \%$ de los frames incluye recomendaciones especiales frente a un 71.2 que no incluyen este tipo de sugerencias. Más notas de interés humano (15.4\%) y de atribución de responsabilidades $(6.2 \%)$ incluyen recomendaciones frente a los problemas de salud mental que aquellos artículos con encuadres de conflicto (1.7) y de costo/beneficio económico $(.6 \%) X^{2}(5, N=545)$ $=55,231 \mathrm{p}<.001$. Así mismo, solo el 25.7\% del total de los encuadres de la muestra menciona un tratamiento en los artículos frente a un $74.3 \%$ que no lo hacen. De aquellos encuadres que incluyen un tratamiento en su texto, de nuevo interés humano $(13.8 \%)$ es más recurrente en presentar esta ayuda que otros encuadres como moralidad $(1.3 \%)$ y conflicto $(1 \%) X^{2}(5, N=545)=$ $32,414 \mathrm{p}<.001$.

\section{Discusión y conclusiones}

El frame de interés humano es al que más recurren los medios para retratar el problema de la salud mental, de manera que se suele tomar el caso particular de una persona, su historia de vida, para intentar reflejar una problemática más general. Lo anterior comienza siendo un recurso narrativo para captar la atención del lector por parte de los medios, que como señalan Idoyaga et al. (2012: 33) "tratan de crear un producto que pueda captar y retener el interés público. Ese sería el objetivo de este marco, personalizando las noticias, dramatizándolas o incluyendo emociones".

Pero investigaciones como las de Cho y Gower (2000) han señalado que el frame de interés humano tiene cierta influencia en aspectos emocionales de los receptores de la información y, por lo general, abona el campo para dar paso al frame de responsabilidad que busca señalar a los culpables de una situación o a quienes tendrían en sus manos la tarea de darle solución. Como el segundo tema de salud mental más recurrentes en la cobertura informativa resultó ser el suicidio-cuya representación mediática tiene un impacto en la 
morbimortalidad-personalizar el relato de los medios y llenarlo de detalles podría resultar una aproximación contraproducente en estos casos por el alto riesgo de imitación de esta conducta por parte de la población (audiencia) vulnerable.

Resulta interesante también que otros de los frames más utilizados después del de interés humano sean el de moralidad y el de atribución de responsabilidades. La recurrencia en la atribución de responsabilidades podría interpretarse de dos maneras: Por un lado, como cierta "indignación" del periodista ante la falta de decisiones o ejecución de aquellos encargados de atender la problemática de salud mental. Esos responsables, como han señalado Ann y Gower (2009), suelen ser aquellos actores con mayor poder de control sobre la sociedad (Gobierno, políticos, etc.). En este sentido, el periodista realiza su labor de guardián (watchdog), garante del correcto funcionamiento de las instituciones y la sociedad. Por otro lado, existe el riesgo de que los medios asignen responsabilidades a las víctimas, enfermos o a las familias en casos relacionados con adicción y suicidio, que son bastante comunes en la muestra, lo que pondría en situación de mayor riesgo a sectores vulnerables y no contribuiría a la prevención del consumo o la ideación suicida en la población. Así mismo, el hecho de que el frame de moralidad sea el segundo más usado en la representación de este tema, resulta interesante por cuanto otras investigaciones han revelado que es poco utilizado (Valencia et al, 2010).

El predominio de los géneros informativos (noticia, reportaje) para reportar periodísticamente sobre los temas de salud mental puede interpretarse como la tendencia de los medios a favorecer relatos incidentales sobre lo que ocurre diariamente y a no privilegiar la búsqueda de historias y la escritura de textos que trasciendan y ofrezcan comprensión sobre la problemática de salud mental, atención sobre la prevención y los tratamientos, y guía para la desestigmatización. Tal como señalan Agüero (2010) y Sánchez, Terrón y Lozano (2016), en la difusión de información de corte científico —incluida la salud mental— es recomendable usar los géneros interpretativos, pero para ello se requiere que el periodista domine el tema porque para abordar este tipo de textos se requiere de mayor contextualización y comprensión. Así mismo, los géneros 
interpretativos requieren de mayor espacio para su difusión. El espacio en los periódicos para los géneros interpretativos es estructural porque se requiere del compromiso e interés del medio y de los editores para que se dé mayor despliegue a los temas de salud mental. De tal suerte que asuntos como la depresión, la enfermedad bipolar o los desórdenes alimenticios, que reciben una baja exposición mediática según los resultados de este estudio, necesitarían ser repensados. Sobre todo la depresión, que ha sido identificada como una de las principales causas de morbilidad en la literatura médica, debe ser debatida y explicada ampliamente.

De igual manera resulta interesante que encuadres como los de interés humano y conflicto contengan en sus historias mayormente el género informativo y releguen los géneros interpretativos $\mathrm{y}$ argumentativos a un segundo plano. Ambos frames han sido recurrentemente encontrados en los discursos periodísticos y de las audiencias como forma eficaz de narrar historias y captar el interés del público (Semetko y Valkenburg, 2000; De Vreese 2004; Mutz y Reese, 2005). Pero el hecho de que esos frames tan populares y controvertidos contengan narraciones escuetas, desde los simples hechos y sin ningún tipo de interpretación, abre interrogantes respecto al efecto que esa forma de abordar las historias de salud mental tenga sobre las audiencias y su entendimiento descarnado de estos problemas sociales. Podríamos decir que la falta de interpretación y opinión sobre las historias humanas y de conflicto referentes a la salud mental dejan un vacío en el entendimiento de esas problemáticas.

La relación entre los encuadres y los géneros periodísticos está igualmente ligada a la necesidad de consultar fuentes expertas, cuya presencia es baja en las notas periodísticas analizadas. El predominio de fuentes gubernamentales en relación con los encuadres de interés humano, moralidad y asignación de responsabilidades revela no solo la tendencia de los periodistas a dar mayor voz a fuentes oficiales cercanas al status quo sino también a la posible intención de señalar a mandatarios o entidades que detentan el poder como responsables de generar soluciones sobre los temas de salud mental, tal como ya lo había anotado Ann y Gower (2009). Como se trata de asuntos especializados que requieren de la orientación de personas 
conocedoras de las enfermedades y las políticas públicas, resulta desalentador que las fuentes expertas no sean consultadas ampliamente en estos temas o que se consulte siempre a las mismas fuentes para diferentes tipos de enfermedades de salud mental.

De la misma manera, la escasez de tratamientos y recomendaciones especiales en las notas para aliviar los efectos y desestigmatizar las enfermedades en relación con los encuadres noticiosos abre preguntas respecto a la responsabilidad social de los medios en la creación de imágenes y el fortalecimiento de políticas públicas. El hecho de que el encuadre de interés humano sea uno de los pocos que incluye tratamientos y recomendaciones para los enfermos mentales y sus familias arroja luces sobre una asociación que podría ser más explotada desde el ámbito periodístico. En otras palabras, los artículos periodísticos con toque humano podrían estar relacionadas con formas de explicar tratamientos y recomendaciones porque el protagonista de la historia encuentra una salida o un desenlace de esperanza en su testimonio de vida. Sin embargo, en esa mezcla entre encuadre humano y la ayuda habría que tener especial cautela: expertos han advertido que la explicación de tratamientos especializados debe ser manejada por los medios con responsabilidad y ética especialmente en países como Colombia, en los que los pacientes se auto-medican con fármacos de venta libre. En estos casos, ofrecer tratamientos a la ligera en ocasiones obstaculiza la búsqueda de ayuda profesional y empeora los síntomas de los pacientes. Otro punto a favor de la cobertura periodística y que arroja esperanzas es la inclusión de causas y consecuencias en seis de cada diez notas informativas. A pesar de que el género noticioso no da espacio a la interpretación, los medios se aseguran de contar el origen e implicaciones de la problemática.

\section{Bibliografía}

Alba, L (2010). "Salud de la adolescencia en Colombia: bases para una medicina de prevención”. Univ. Méd. 51 (1), 29-42.

Ann, S K y Gower K (2009). "How do the news media frame crises? 
A content analysis of crisis news coverage". Public Relations Review, 35, 107-112.

Apanovitch, A, McCarthy, D y Salovey, P (2003). "Using message framing to motivate HIV testing among low-income, ethnic minority women". Health Psychology, 22(1), 60-67.

Cappella J y Jamieson K (1997) Spiral of Cynicism: The Press and the Public Good. Oxford: Oxford University Press.

Chang, C (2012). "News coverage of health-related issues and its impacts on perceptions: Taiwan as an example". Health Communication, 27(2), 111-23.

Cho, S y Gower, K K (2006). "The Effect of Framing on Public's

Perception of Crisis: Human Interest Frame Effect on Attributions to Responsibility and Blame". Trabajo presentado en Annual meeting of the International Communication Associatio,. 1923, junio, Dresden.

Clarke, C (2008). “A question of balance: The autism-vaccine controversy in the British and American elite press". Science Communication, 30, 77-107.

Constaín, G, Ramírez, C, Rodríguez-Gázquez, M, Álvarez, M, Marín, C y Acosta, C (2014).'Validez y utilidad diagnóstica de la escala EAT-26 para la evaluación del riesgo de trastornos de la conducta alimentaria en población femenina de Medellín, Colombia". Atención Primaria, 46 (6), 283-289.

Corbett, J B y Durfree, J L (2004). "Testing public (un)certainty of science: Media representations of globalwarming". Science Communication, 26, 129-151.

De Vreese, C (2005). “The Spiral of Cynicism Reconsidered”.

European Journal of Communication 20 (3), 283-301.

Encuesta Nacional de Salud Mental (2015). Ministerio de Salud y

Protección Social, Colciencias, Pontificia Universidad Javeriana. Bogotá.

Entman, R (1993). "Framing: Toward clarification of a fractured 
paradigm”. Journal of Communication, 43 (4), 51-58.

Entman, R (2003). "Cascading Activation: Contesting the White

House's Frame After 9/11". Political Communication, 20, 415-422.

Entman, R (2010) “Framing Media Power", en P D'Angelo y J

Kuypers (eds.). Doing News Framing Analysis: Empirical, Theoretical, and Normative Perspectives. New York: Routledge.

Gamson, W y Modigliani, A (1989). "Media discourse and public

opinion on nuclear power: A constructionist approach". American Journal of Sociology, 95(1), 1-37.

Gould, M S (2001). "Suicide and the media". Annals of the New York Academy of Sciences, 932, 200-21; discussion 221-4.

Hertog, JK y D McLeod (2001) “A Multiperspectival Approach to Framing Analysis: A Field Guide", 139-63. En S Reese, O Gandy and A Grant (eds). Framing Public Life: Perspectives on Media and Our Understanding of the Social World. London: Lawrence Erlbaum.

Holton, A, Weberling, B, Clarke, C E y Smith, M J (2012). “The blame frame: media attribution of culpability about the MMR-autism vaccination scare. Health Communication, 27(7), 690-701.

Holton, E (2013). "What's wrong with Max? Parenthood and the portrayal of autism spectrum disorders". Journal of Communication Inquiry, 37(1), 45-63.

Idoyaga et al (2012). "Efectos del Framing y representaciones sociales de epidemias sanitarias: El Caso de la Gripe A". Escritos de Psicología (Internet), 5(3), 31-42.

Iyengar, S (1991). Is anyone responsible? How television frames political issues. Chicago: University of Chicago Press.

Iyengar, S (1996). "Framing responsibility for political issues". Annals of the American Academy of Political and Social Science, 546, 59-70.

Jaramillo-Gonzalez, Sanchez-Pedraza y Herazo (2014). “The 
frequency of rehospitalization and associated factors in Colombian psychiatric patients: a cohort study". BMC Psychiatry, 2, 14-161.

Kahneman, D y Tversky, A (1982). The psychology of preferences.

Scientific American, 247, 160-173.

Lawrence, R (2010). "Researching political news framing: Established ground and new horizons", 265-285. En P. D’Angelo y J A. Kuypers (eds.). Doing news framing analysis: Empirical and theoretical perspectives. New York, NY: Routledge.

Ley No 1616. (21 de Enero de 2013). Por medio de la cual se expide la Ley de Salud Mental y se dictan otras disposiciones. Bogotá. Machado-Alba, J y Morales-Plaza, C D (2013). "Patrones de prescripción de antipsicóticos en pacientes afiliados al Sistema General de Seguridad Social en Salud de Colombia". Biomédica, 33 (3), 418-28.

Maher, T (2001). "Framing: An emerging paradigm or a phase of agenda setting", 83-94. En S D Reese, O H Gandy y A E Grant (Eds.), Framing public life. Perspectives on media and our understanding of the social world. Mahwah, NJ: Erlbaum.

Matthes, J (2009). "What's in a Frame? A Content Analysis of Media Framing Studies in the World's Leading Communication Journals, 1990-2005”. Journalism \& Mass Communication Quarterly, 86(2), 349-367.

McCombs, M y Ghanem, S (2001). "The convergence of agenda setting and framing", 67-81. In S D Reese, O H Gandy y A E Grant (Eds.), Framing public life. Perspectives on media and our understanding of the social world. Mahwah, NJ: Erlbaum.

Estudio Nacional de Consumo de Sustancias Psicoactivas en Colombia (2013). Bogotá: Ministerio de Salud y Protección Social-Ministerio de Justicia.

Moreno, J y Sánchez, R (2009). "Muertes por causas violentas y ciclo 
económico en Bogotá, Colombia: un estudio de series de tiempo, 1997-2006". Revista Panamericana de Salud Pública, 26 (1), 23-30.

Mutz, D y Reese, B (2005). “The New Video-malaise.” American Political Science Review, 99 (1), 1-15.

Nelson, T E y Willey, E A (2001). "Issue Frames That Strike a Value Balance. A Political Psychology Perspective”, 245-266. En Reese, S., Gandy Jr., O.H. y Grant, A. Framing Public Life: Perspectives on Media and Our Understanding of the Social World. Nueva Jersey: Lawrence Erlbaum, pp.245-266.

Neuman, W, Just, M y Crigler, A (1992). Common knowledge. News and the construction of political meaning. Chicago, IL: University of Chicago Press.

Ocampo-Chaparro, J M et al (2013). "Prevalence of poor self-rated health and associated risk factors among older adults in Cali, Colombia”. A. Colombia Médica, 44 (4), 224-231.

Organización Mundial de la Salud (2001). Informe sobre la salud en el mundo 2001. Salud mental: nuevos conocimientos, nuevas esperanzas. Ginebra: OMS.

Ospina-Ospina, F, Hinestrosa-Upegui, M F, Paredes, M C, Guzmán, Y y Granados, C (2011). "Síntomas de ansiedad y depresión en adolescentes escolarizados de 10 a 17 años en Chía, Colombia". Revista Salud Pública, 13 (6), 908-920.

Philo, G (1996). “The media and public belief”. En Philo, G (ed.). Media and Mental Distress. Essex: Addison Wesley Longman.

Pirkis, J y Francis, C (2012). Mental illness in the news and the information media. A critical Review. Canberra: Commonwealth of Australia.

Ramón, J, Abad, B, José, F y Luján, M (2005). "Prensa y representaciones sociales de la enfermedad mental". Intervención Psicosocial 14(2), 131-159.

Ray, L y Hinnant, A (2009). "Media Representation of Mental 
Disorders: A Study of ADD and ADHD Coverage in Magazines from 1985 to 2008". Journal of Magazine \& New Media Research, 11 (1), 1-21.

Reese, S (2001). "Framing public life: A bridging model for media research", 7-31. En S D Reese, O H Gandy y A E Grant (Eds.). Framing public life: Perspectives on media and our understanding of the social world. Mahwah, NJ: Lawrence Erlbaum Associates.

Reese, S (2007). “The Framing Project: A Bridging Model for Media Research RevisitedW. Journal of Communication, 57(1), 148-154.

Reese, S (2009) "Finding frames in a web of culture: The case of the War on Terror”. En P D’Angelo y J Kuypers (Eds.) Doing News Framing Analysis: Empirical, Theoretical, and Normative Perspective. New York: Routledge.

Sánchez, M, Terrón, J L y Lozano, J C (2016). “Estigmatización y usos léxicos en el tratamiento informativo del VIH/sida en cinco diarios mexicanos de 2012 a 2013". Comunicación y Sociedad, 25, 71-100.

Sánchez, R, Velásquez, J y Navarro, A (2011). "Validación de la escala para manía de la Universidad Nacional de Colombia usando el análisis de Rasch”. Biomédica, 31 (3), 410-418.

Scheufele, D y Tewksbury, D (2007). "Framing, Agenda Setting, and Priming: The Evolution of Three Media Effects Models". Journal of Communication, 57(1), 9-20.

Schneider, T R, Salovey, P, Apanovitch, A M, Pizarro, J, McCarthy, D, Zullo, J y Rothman, A J (2001). "The effects of message framing and ethnic targeting on mammography use among lowincome women". Health Psychology, 20(4), 256-266.

Secker, J y Platt, S (1996) "Why media images matter", 1-17. En Philo, G (Ed). Media and mentaldistress, Londres: Logman.

Semetko, H A y Valkenburg, P M (2000). "Framing European 
Politics : A Content Analysis of Press and Television News". Journal of Communication 50, 93-109.

Senra-Rivera C, De Arriba-Rossetto, A y Seona-Pequeira, G (2008).

"Papel de la experiencia en la aceptación vs. rechazo del paciente con esquizofrenia". Revista Latinoamericana de Psicología, 40(1), 73-83.

Tewksbury, D y Scheufele D A (2009). "News framing theory and researchW. En J Bryant y M B Oliver (Eds). Hillsdale Media effects: Advances in theory and research. NJ: Erlbaum.

Valencia, J, Gil De Montes, L, Ortiz, G, Larrañaga, M e Idoyaga, N (2010). "Enmarcamiento y el rechazo o aceptación de los aspectos generales y específicos de la Ley de igualdad de Género en España: representaciones sociales y regulaciones normativas". Revista de Psicología Social, 25, 145-155.

Van Gorp, B (2005). "Where is the Frame?: Victims and Intruders in the Belgian Press Coverage of the Asylum Issue". European Journal of Communication, 20(4), 484-507.

Van Gorp, B (2010) "Strategies to Take Subjectivity Out of Framing Analysis". En P. D’Angelo y J Kuypers (Eds.) Doing News Framing Analysis: Empirical, Theoretical, and Normative Perspectives. New York: Routledge.

Vergara-Quintero, M (2009). "Representaciones sociales sobre salud, de algunos grupos de jóvenes de Manizales". Revista Latinoamericana de Ciencias Sociales, Niñezy Juventud, 7 (1), 105-133.

Weaver, D (2007). “Thoughts on Agenda Setting, Framing, and Priming”. Journal of Communication, 57(1), 142-147.

Weiner, B. (2006). Social motivation, justice, and the moral emotions: An attributional approach. Mahwah, NJ: Lawrence Erlbaum Associates.

Young, S D , Boester, A, Whitt, M T y Stevens, M (2008). 
"Character Motivations in the Representation of Mental 11(1), 82-99. Health Professionals in Popular Film”. Mass Comunication and Society.

\section{Agradecimientos:}

Esta investigación fue realizada gracias al apoyo de Siglo Data - MMI en la consecución de los textos analizados y a la financiación del Carter Center Mental Health Program y la Universidad de La Sabana. Participaron como auxiliares de investigación los estudiantes:

Manuela Vallejo, Salomé Mejía, Nathalia Ramírez, María del Mar Gonzáles Orejuela, Nathalia Suárez Díaz, Juan Manuel Álvarez, Laura Orjuela, Melanie Cedeño, María Paula Rada Hidalgo, Sandra Juliana Tenjo, María Camila Martínez. 


\title{
El dengue y la importancia de su comunicación como factor de prevención y control en la ciudad de Bucaramanga, Colombia
}

\author{
Antonia Moreno Cano (B) \\ Universidad Manuela Beltrán (UMB), Colombia \\ Lizandro Angulo Rincón \\ Universidad del Tolima (UT), Colombia
}

\section{Resumen}

Objetivo. Esta investigación tiene como propósito determinar el grado de conocimiento que tienen los bumangueses (Bucaramanga, Colombia) a través de los medios de la enfermedad del dengue, sus manifestaciones y factores de transmisión y prevención. Metodología. Se realizó una encuesta en línea a 1.212 ciudadanos -durante 2012 y 2013-, a hombres y mujeres mayores de 17 años, con diferentes niveles de estudios e ingresos económicos. Resultados. Los bumangueses saben que la transmisión de la enfermedad se produce a través del mosquito (79\%) y reconocen los síntomas más frecuentes: fiebre (92\%); dolor de cabeza (80\%); dolor de huesos o músculos (79\%). Obtienen mayoritariamente información sobre esta patología a través de la televisión (80\%) e Internet (79\%). Conclusiones. Para controlar la enfermedad es necesaria la participación activa de la comunidad, el fortalecimiento de las leyes sanitarias nacionales, la promoción de campañas de divulgación, la formación de personal y la vigilancia y control de la lucha antivectorial.

Palabras clave: dengue; comunicación en salud; salud pública; Colombia. 


\section{Introducción: la comunicación científica y sanitaria}

E L DENGUE es un reto para la salud pública en el mundo. Más de 2.500 millones de personas, es decir, más de dos quintas partes de la población mundial, viven en zonas en riesgo de dengue y más de 100 países han informado de la presencia de esta enfermedad en su territorio, entre los que se encuentra Colombia. Esta patología es causada por el virus del dengue y transmitida por mosquitos del género Aedes. La primera epidemia conocida de dengue en territorio americano ocurrió en el siglo XVIII, y en la actualidad el mayor número de casos se concentra en América Latina y el Caribe.

La Organización Mundial de la Salud (OMS) y la Organización Panamericana de la Salud (OPS) han establecido cuatro elementos básicos o principios que son necesarios para controlar el dengue: la voluntad política de los gobiernos; la coordinación intersectorial; la participación activa de la comunidad y el fortalecimiento de las leyes sanitarias nacionales. Los nuevos programas de prevención y control del dengue en América respaldan estos principios, complementados con acciones de vigilancia y control de la transmisión, aunque en la gran mayoría de los países de las regiones afectadas éstos no se aplican de una forma lógica y no se cuenta con programas preventivos, integrados y sustentables.

En este sentido, una correcta comunicación para la salud puede promover en la ciudadanía conductas saludables para prevenir enfermedades como el dengue y mejorar su calidad de vida, pese a que no puede garantizar que los individuos adopten efectivamente esas conductas (Instituto Nacional del Cáncer de Estados Unidos, 2004: 3). Inclusive, puede aportarnos herramientas para informar a la comunidad sobre cuándo demandar atención y cómo hacer un uso adecuado de los recursos del sistema sanitario, pero no puede cubrir la carencia de esos recursos. Y, por último, puede facilitar y dinamizar cambios de conductas de salud, pero difícilmente podrá hacer que sean sostenibles en el tiempo si no van acompañados por otras acciones.

Para la adopción de comportamientos saludables, hay que tener en cuenta que las personas necesitan poseer la información sobre qué 
hacer y cómo hacerlo. La información científica y la sanitaria son precisas para fomentar la aparición de nuevas creencias que las incluyan, así como para mezclarse con las distintas tradiciones culturales (Guibert, Grau y Prendes, 1999: 176-177). Las actitudes, comportamientos y valores, trasmitidos a través de la televisión, radio, prensa, etc. y reafirmados por los agentes sanitarios influyen en el valor que la salud tiene para los individuos, en los comportamientos saludables que éstos exhiben, en el incremento de su motivación hacia el autocuidado y en la autorresponsabilidad con respecto a la salud.

La salud, entendida como fenómeno social, es una realidad presente en la vida cotidiana de los sujetos o, dicho de otra manera, es una práctica social atravesada por procesos comunicacionales. Al afrontar problemáticas de salud es necesario tener en cuenta que toda acción en ese campo se ejerce sobre sujetos y grupos sociales que, además de dar significado a sus propios problemas y situaciones, aportan sobre todo significados subjetivos y sociales (Díaz y Uranga, 2012: 118). La cuestión de la salud es, desde este punto de vista y ante todo, una cuestión subjetiva y comunitaria, que requiere un análisis transversal nunca reducible exclusivamente a los mensajes mediáticos. Por este motivo, en el presente trabajo pretendemos ir más allá y abordar la apropiación desde la comunicación, conocimiento, interés y prevención, que tiene una determinada comunidad sobre una problemática sanitaria: el dengue.

La comunicación social en salud debe estar dirigida a la prevención y no a la curación. La comunicación preventiva busca corregir los comportamientos insalubres y propiciar aquellos que ayudan a conservar la salud y una buena calidad de vida. La Organización Mundial de la Salud (OMS) propone dirigir la comunicación social sobre el dengue en dos direcciones (San Martín y Prado, 2004: 136137). La primera consiste en sustituir la información por la práctica y, la segunda, en lograr que la comunidad se apropie de las medidas de prevención y control. De esta manera, las estrategias centrales de comunicación social sobre el dengue quedarían conformadas por la inducción del cambio de conductas individuales y por la participación comunitaria. 
La Organización Panamericana de la Salud (OPS), por su parte, ha definido la promoción de la salud como el resultado de todas las acciones emprendidas por los diferentes sectores sociales para el desarrollo de mejores condiciones de salud personal y colectiva en toda la población, en el contexto de su vida cotidiana (Barcaz, 2002: 22-23). La educación y la información constituyen la base del conocimiento y las destrezas que habilitan a las personas, las familias y las comunidades para realizar elecciones positivas en materia de salud. Los programas de comunicación, en este caso, pueden informar, convencer, fortalecer y educar.

Los gobiernos deben seguir las recomendaciones de la OMS y de la OPS expresadas en varias de sus resoluciones, además de reforzar y aplicar adecuadamente las leyes sanitarias relacionadas directa o indirectamente con el control de los vectores. Es necesario tomar conciencia de que si las grandes sumas de dinero que se gastan cuando ocurren epidemias se invirtieran en eliminar o atenuar los macrofactores determinantes de las mismas, se podrían evitar o disminuir muchas de esas epidemias (Kourí, 2011).

Para lograr cambios en el comportamiento de la comunidad, se debe partir del conocimiento previo del problema de salud, del dengue en este caso, identificar los comportamiento actuales de la población afectada, desarrollar actividades dirigidas a eliminar o reducir las barreras entre el comportamiento actual y el saludable y, finalmente, crear entornos favorables para la adopción de comportamientos deseados y factibles.

Las estrategias que se han probado efectivas para apuntalar diversos programas de salud en muchos países, pasan por la inducción de modificaciones en las conductas individuales, con lo cual se busca persuadir sin manipular a las personas y ayudarlas a que adopten conocimientos, actitudes y prácticas propicios a su salud (Beltrán, 2001). Estas estrategias son:

-La movilización comunitaria, con la participación sostenida y protagónica de los individuos, grupos y organizaciones naturales de la comunidad, para la toma de decisiones consensuadas que incidan en 
el planeamiento, la ejecución y la evaluación de acciones en pro de resolver problemas de salud.

-La movilización social, a través de la concertación voluntaria e intensa de los recursos y esfuerzos de agrupaciones sociales.

-La abogacía, que es la sensibilización de la opinión pública para forjar conciencia sobre un asunto de amplia trascendencia nacional, así como con la argumentación para ganar la comprensión solidaria de la población y sus dirigentes, en favor de la causa de salud.

\subsection{La información sanitaria en los medios}

Un ciudadano sano requiere ser un ciudadano informado sobre las opciones de salud disponibles. Esto incluye desde sus estilos de vida hasta su constitución genética. El modelo de salud pública, que entiende la salud como una cuestión fundamentalmente de decisiones individuales, pone el acento en la existencia de información que permita una sociedad más sana. La información permite saber quiénes están expuestos y son proclives a ciertas enfermedades, qué conductas son recomendables y cuáles no son deseables. En este proceso, la comunicación, ya sea en el ámbito masivo (campañas de información), organizacional o interpersonal (interacción proveedores de servicios y paciente) es crucial (Del Valle, 2002: 5-6). La información compete a la distribución social de la cobertura de salud y, por ende, a las políticas de salud. La definición de salud y su distribución social es una cuestión política, en la que se necesita que la información obre como insumo para decidir cursos de acción.

Podemos afirmar que los mensajes mediáticos contribuyen a la creación y consolidación de identidades y roles en los grupos y las sociedades en general, en tanto presentan modelos de comportamiento en sus mensajes que son incorporados en algún grado por los públicos a los que se dirigen. En este sentido, no podría discutirse hoy el potencial de los medios en la conformación de una "cultura de la salud" (Silva Pintos, 2011: 126). Sin embargo, hay que entender que no debe tratarse como la única modalidad efectiva para las estrategias y acciones de la Comunicación en Salud. 
Para conseguir que los medios de comunicación social puedan influir positivamente en el grado de salud de la población, se ha de trabajar en un equipo multidisciplinar e interdisciplinar y desde un punto de vista totalmente integrador y holístico. Así, los profesionales de la salud pueden contribuir a la consecución de los objetivos de los profesionales de los medios de comunicación y viceversa. Ciertamente, los profesionales de la salud conocen el contenido de los mensajes que necesita saber la población para adoptar una postura independiente y autorresponsable en la consecución de un adecuado nivel de salud, pero son exactamente los profesionales de la información quienes conocen los medios y las técnicas más apropiados para transmitir esos mensajes de la forma más atractiva y eficaz (Sánchez Martos, 2008: 83).

Cuando todo esto falla aparecen las consecuencias negativas de un mensaje pocas veces contrastado, mal elaborado, mal estructurado y sobre todo mal transmitido, en el que la percepción del receptor y el rumor juegan un protagonismo especial confundiendo $y$, en ocasiones, alarmando innecesariamente.

Además, resulta evidente la importancia de la comunicación social en los modelos integradores de salud tales como la transmisión de información que permita a los ciudadanos conocer las diferentes opciones de conducta saludable o de riesgo; la creación de hábitos de conducta saludables mediante la implantación de programas de educación; la creación y propagación de marcos de referencia sociales (frames) que facilitan la adaptación o desajuste al entorno, mediante la creación de estándares de meta y creación de disonancias (Cuesta, Menéndez y García, 2008: 19).

En una investigación realizada en Colombia se determinó que, para desarrollar y ejecutar programas de control del dengue basados en la participación comunitaria, haría falta reunir datos sociales o culturales que permitieran entender mejor las percepciones y prácticas de los miembros de la comunidad en relación con la enfermedad. Dicha experiencia demostró que, la comunidad no interiorizó los mensajes educativos que las autoridades de salud diseminaron a través de los medios de comunicación y, en consecuencia, no participó en los 
esfuerzos de prevención y control que les solicitaron (Fajardo, Monje, Lozano, Realpe y Hernández, 2001: 167).

\section{Objetivos}

El objetivo general que motiva esta investigación es el de diseñar, aplicar y analizar un estudio dirigido a identificar preferencias y consumo de los habitantes de Bucaramanga, Colombia, sobre temas de ciencia, salud, medio ambiente, etc., pero en particular sobre el conocimiento, fuentes de acceso a la información (medios) y hábitos de prevención del dengue, en función de variables como la edad, sexo, estrato socioeconómico y nivel de estudios. Esta información nos permitirá comprender los comportamientos de los bumangueses hacia esta enfermedad y servir de insumo para poner en marcha futuras campañas de comunicación y concienciación en la sociedad colombiana.

\section{Metodología}

En la metodología propuesta para el cumplimiento del objetivo planteado en el presente estudio, elegimos el enfoque cuantitativo como estrategia de investigación (Bryman y Teeman, 2005: 50). Justamente, una de las técnicas de este enfoque es la encuesta, la técnica que hemos elegido para esta investigación. Vale anotar que la encuesta, según Simelio (2011: 173-174), es un método de investigación cuantitativo que se basa en la interrogación que permite obtener una gran cantidad de datos en poblaciones amplias asentadas en zonas geográficas alejadas y en un marco ambiental más realista. Para Weerakkody (2009: 125), las encuestas recaban información acerca de las "características demográficas de los encuestados, opiniones, elecciones, preferencias, metas, actitudes, creencias, percepciones, sentimientos, prácticas, motivaciones, planes, conocimientos personales, conductas, para describirlas, compararlas o explicarlas". Un método como este, de naturaleza cuantitativa, da la oportunidad al investigador de indagar diversos fenómenos sociales con un cierto grado de precisión y exactitud, gracias que se tiene un relativo control de las variables que se han de medir (Hernández, 2010: 4-6). 
En este caso, se empleó una encuesta con carácter descriptivo/correlacional, puesto que nuestro interés es el de reflejar o documentar las condiciones o actitudes presentes (Wimmer y Dominick, 1996: 113) de los habitantes de Bucaramanga -en función de sus condiciones socioeconómicas, de edad, educativas y de género-, relacionadas con el consumo de información sobre ciencia, salud, medioambiente, etc., pero en particular sobre el conocimiento, fuentes de acceso a la información (medios) y hábitos de prevención hacia el dengue.

\subsection{Población y muestra}

Bucaramanga es una ciudad colombiana capital del departamento de Santander, situada en el nordeste del país sobre la Cordillera Oriental, rama de la cordillera de los Andes, a orillas del río de Oro. Floridablanca, Girón y Piedecuesta conforman su área metropolitana que junto con el municipio de Bucaramanga superan el millón de habitantes.

$\mathrm{N} \sigma^{2} \mathrm{Z}^{2}$

$\mathrm{n}=$

$(\mathrm{N}+1) \mathrm{e}^{2}+\sigma^{2} \mathrm{Z}^{2}$

$$
\mathrm{N}=519.385
$$$$
\sigma=0,5 \quad(50 \% \text { prevalencia })
$$$$
\mathrm{Z}=2,58 \quad(99 \% \text { confianza })
$$$$
\mathrm{e}=\mathbf{0 , 0 4} \quad \text { (error muestral) }
$$$$
\mathrm{n}=1.037,98 \approx 1.038
$$

$\mathrm{n}=$ tamaño de la muestra

$\mathrm{N}=$ tamaño de la población

$\sigma=$ desviación estándar de la población

$\mathrm{Z}=$ para nivel de confianza del $99 \%$ se toma 2,58

$\mathrm{e}=$ límite aceptable de error muestral

A la hora de calcular la muestra (Suárez y Tapia, 2011) y considerando el tamaño de la población estimada por el Departamento Administrativo Nacional de Estadística (2011) -en el año 2012 en la ciudad de Bucaramanga, 519.385 individuos- para una respuesta de prevalencia de $50 \%$ y un intervalo de confianza del $99 \%$, se necesitaban 1.038 participantes. Además, añadimos un margen superior al $15 \%$ para evitar posibles pérdidas de información con el que obtuvimos una muestra de 1.212 encuestados. 


\subsection{Selección de la muestra}

Como se puede observar, la muestra es de tipo probabilístico puesto que acude a fórmulas matemáticas para que el grupo estudiado sea representativo de la población y, por ende, se puedan generalizar los resultados (Hernández, 2010: 177). La clasificación de los 1.212 sujetos estudiados, en función de sus condiciones socioeconómicas o estrato (en Colombia van del 1 -el de más bajos ingresos- al 6 -el de más altos ingresos-), edad, género y nivel de estudios, se presenta en estas tablas.

Tabla 1. Estrato, nivel de estudios, edad y sexo de los encuestados

\begin{tabular}{|c|c|c|c|c|c|c|}
\hline Estrato & 1 & 2 & 3 & 4 & 5 & 6 \\
\hline Número & 30 & 87 & 303 & 483 & 178 & 131 \\
\hline Porcentaje & $2,3 \%$ & $7,2 \%$ & $25,0 \%$ & $40,0 \%$ & $14,7 \%$ & $10,8 \%$ \\
\hline $\begin{array}{l}\text { Nivel } \\
\text { estudios }\end{array}$ & PC & SI & SC & UI & UC & \\
\hline Número & 132 & 25 & 297 & 508 & 250 & \\
\hline Porcentaje & $10,9 \%$ & $2,1 \%$ & $24,5 \%$ & $41,9 \%$ & $20,6 \%$ & \\
\hline \multirow{2}{*}{ Edad } & \multicolumn{2}{|c|}{ Hombres } & \multicolumn{2}{|c|}{ Mujeres } & & \\
\hline & Número & Porcentaje & Número & Porcentaje & & \\
\hline $15-20$ & 154 & $12,7 \%$ & 213 & $17,7 \%$ & & \\
\hline $21-35$ & 339 & $27,7 \%$ & 274 & $22,8 \%$ & & \\
\hline $36-50$ & 44 & $3,5 \%$ & 106 & $8,8 \%$ & & \\
\hline $51-65$ & 26 & $2,1 \%$ & 56 & $4,7 \%$ & & \\
\hline Sexo & Número & Porcentaje & & & & \\
\hline Femenino & 649 & $54 \%$ & & & & \\
\hline Masculino & 563 & $46 \%$ & & & & \\
\hline Total & 1212 & $100 \%$ & & & & \\
\hline
\end{tabular}

"PC": Primara Completa; "SI": Secundaria Incompleta; "SC": Secundaria Completa; "UI": Universidad Incompleta y "UC": Universidad Completa.

Fuente: elaboración propia

Muestra temporal: la encuesta fue aplicada en los meses de octubre, noviembre y diciembre del año 2012 por los estudiantes de la Universidad Autónoma de Bucaramanga (UNAB). 


\subsection{Diseño del instrumento}

El instrumento fue diseñado con el fin de auscultar la opinión de las 1.212 personas residentes en Bucaramanga sobre sus preferencias y consumo de información sobre ciencia, salud, medioambiente, etc., pero en particular sobre el conocimiento que ellas tienen acerca del dengue, las fuentes de las que adquieren la información correspondiente (medios) y las formas para prevenirlo. Esta población se estudió, asimismo, mediante la formulación de variables relacionadas con la edad, estrato socioeconómico, nivel de estudios y género. La encuesta fue validada a través de la discusión en grupo de estudiantes y docentes pertenecientes a la Universidad Autónoma de Bucaramanga y a la Universidad del Tolima.

El instrumento, que empleó una escala de respuestas cerradas con la posibilidad de que los encuestados eligieran varias opciones en la mayoría de las preguntas formuladas, se estructuró en tres partes:

1. Relevancia de la ciencia y salud para los consumidores de medios de comunicación y motivaciones para seguir con interés este tipo de secciones.

2. Conocimiento del dengue (medidas para prevenirlo, síntomas, etc.), en función de variables como la edad, sexo, estrato socioeconómico y nivel de estudios.

3. Fuentes de información (medios) por los cuales las personas se enteran de todo lo relacionado con el dengue. Estas preferencias también se miden en función de variables como la edad, sexo, estrato socioeconómico y nivel de estudios.

\subsection{Aplicación del instrumento}

El instrumento se aplicó previa capacitación a 20 estudiantes del pregrado de comunicación. Se capacitó a todos los estudiantes sobre las variables y escalas contenidas en la encuesta. Así las cosas, los alumnos aplicaron el instrumento a diferentes personas o bien conocidos; algunas encuestas se hicieron en papel acudiendo a los diferentes barrios de Bucaramanga pertenecientes a todos los estratos sociales y luego subieron los resultados de cada una a la plataforma en línea; otros estudiantes acompañaban a las personas mientras 
rellenaban el cuestionario de forma online, el cual no dejaba avanzar si no se cumplimentaba cada página hasta pasar a la siguiente, o bien los estudiantes mandaban el link de la encuesta e invitaban a conocidos a diligenciarla.

\section{Resultados de la investigación}

Tabla 2. Cuáles son los temas que más interesan a los bumangueses de los medios de comunicación

\begin{tabular}{|l|l|l|}
\hline Tema & Número & Porcentaje \\
\hline Medicina y salud & 929 & $77 \%$ \\
\hline Deportes & 759 & $63 \%$ \\
\hline Trabajo y empleo & 811 & $67 \%$ \\
\hline Alimentación y nutrición & 744 & $61 \%$ \\
\hline Economía y empresas & 675 & $56 \%$ \\
\hline Educación & 790 & $65 \%$ \\
\hline Medio ambiente y ecología & 768 & $63 \%$ \\
\hline Arte y cultura & 752 & $62 \%$ \\
\hline Política & 503 & $42 \%$ \\
\hline Temas sociales & 672 & $55 \%$ \\
\hline Cine y espectáculo & 716 & $59 \%$ \\
\hline Agresión y violencia & 455 & $38 \%$ \\
\hline Ciencia y tecnología & 789 & $65 \%$ \\
\hline Sucesos & 550 & $45 \%$ \\
\hline Viajes y turismo & 783 & $65 \%$ \\
\hline Farándula & 481 & $40 \%$ \\
\hline Astrología y ocultismo & 339 & $28 \%$ \\
\hline Vivienda & 534 & $44 \%$ \\
\hline Inmigración & 382 & $32 \%$ \\
\hline Noticias en general & 764 & $63 \%$ \\
\hline Transportes y vías & 584 & $48 \%$ \\
\hline Situación internacional & 663 & $55 \%$ \\
\hline Ocio & 517 & $43 \%$ \\
\hline Otros & 377 & $31 \%$ \\
\hline & &
\end{tabular}

Fuente: elaboración propia

Los temas relacionados con la medicina y la salud (77\%) son los que más interesan a los bumangueses en los medios de comunicación que consumen. En un segundo lugar y 10 puntos por debajo, se encuentran las temáticas relacionadas con el trabajo y el empleo 
$(67 \%)$, seguidos de la educación, ciencia y tecnología y viajes y turismo, con un $65 \%$.

Tabla 3. Motivos de interés en las noticias relacionadas con la ciencia, la salud, el medio ambiente, etc.

\begin{tabular}{|l|l|l|}
\hline Motivación & Número & Porcentaje \\
\hline Me parece interesante & 829 & $68 \%$ \\
\hline Me afecta de cerca & 294 & $24 \%$ \\
\hline Lo necesito para mi trabajo & 268 & $22 \%$ \\
\hline Es una información accesible & 203 & $17 \%$ \\
\hline Es una información bien hecha & 118 & $10 \%$ \\
\hline Es importante para estar bien informado & 666 & $55 \%$ \\
\hline $\begin{array}{l}\text { Es una información que utilizo en mis } \\
\text { conversaciones con amigos o familia }\end{array}$ & 257 & $21 \%$ \\
\hline Insumos para proyectos sociales & & \\
\hline Salud & 0 & $0 \%$ \\
\hline Gusto & 4 & $0 \%$ \\
\hline Estudio & 2 & $0 \%$ \\
\hline Mayor conocimiento de las cosas & 1 & $0 \%$ \\
\hline Generales & 0 & $0 \%$ \\
\hline Formación de interés & 0 & $0 \%$ \\
\hline $\begin{array}{l}\text { La situación actual del mundo con lo que respectan } \\
\text { los temas }\end{array}$ & 3 & $0 \%$ \\
\hline Es necesaria & 3 & $0 \%$ \\
\hline Fundamentales para el desarrollo del país & 1 & $0 \%$ \\
\hline No Sabe/No Contesta & 1 & $0 \%$ \\
\hline & 0 & $0 \%$ \\
\hline
\end{tabular}

Fuente: elaboración propia

Las razones o motivos por los que los bumangueses señalan a las noticias sobre ciencia, salud y medio ambiente como que "les parecen interesantes" (68\%), supone la respuesta que presenta más frecuencia de entre todas las planteadas. En segundo lugar, se ubica la categoría de "importante para estar informado" (55\%). Llama la atención que ninguno de los encuestados se sintió motivado a seguir estas informaciones por "salud".

Las razones por las que no se sienten motivados para seguir los temas sobre ciencia, salud, medioambiente, etc., son "no despierta mi 
interés" (25\%) y "no hay razón específica" (22\%). No hay porcentajes significativos en otras respuestas.

Tabla 4. Motivos de no interés en las noticias relacionadas con la ciencia, la salud, el medio ambiente, etc.

\begin{tabular}{|l|l|l|}
\hline Motivos & Número & Porcentaje \\
\hline No lo entiendo & 109 & $9 \%$ \\
\hline No despierta mi interés & 308 & $25 \%$ \\
\hline No hay razón especifica & 269 & $22 \%$ \\
\hline Nunca he pensado sobre ese tema & 125 & $10 \%$ \\
\hline No lo necesito & 113 & $9 \%$ \\
\hline No tengo tiempo & 164 & $14 \%$ \\
\hline No tengo motivos & 4 & $0 \%$ \\
\hline Ninguno & 5 & $0 \%$ \\
\hline Poca divulgación & 4 & $0 \%$ \\
\hline No me gusta & 2 & $0 \%$ \\
\hline No tiene beneficio social & 1 & $0 \%$ \\
\hline
\end{tabular}

Fuente: elaboración propia

Estos resultados parten del hecho de que el 95\% de los encuestados dijo tener conocimiento sobre el dengue y un $5 \%$ señala no saber nada sobre esta enfermedad.

Tabla 5. Conocimiento del dengue por estrato, nivel de formación y sexo y edad

\begin{tabular}{|c|c|c|c|c|c|c|}
\hline Estrato & 1 & 2 & 3 & 4 & 5 & 6 \\
\hline Porcentaje & $100 \%$ & $97 \%$ & $94 \%$ & $95 \%$ & $93 \%$ & $92 \%$ \\
\hline Nivel de estudios & PC & SI & SC & UI & UC & \\
\hline Porcentaje & $92 \%$ & $96 \%$ & $92 \%$ & $95 \%$ & $96 \%$ & \\
\hline \multirow{2}{*}{ Sexo } & \multicolumn{4}{|c|}{ Edad } & & \\
\hline & $15-20$ & $21-35$ & $36-50$ & $51-65$ & & \\
\hline Femenino & $92 \%$ & $96 \%$ & $98 \%$ & $95 \%$ & & \\
\hline Masculino & $95 \%$ & $94 \%$ & $91 \%$ & $96 \%$ & & \\
\hline
\end{tabular}

"PC": Primara Completa; "SI": Secundaria Incompleta; "SC": Secundaria Completa; "UI": Universidad Incompleta y "UC": Universidad Completa.

Fuente: elaboración propia

Todos los estratos tienen un elevado nivel de conocimientos sobre el dengue, pero destaca que el 100\% del estrato 1, el de menores 
ingresos, sabe de la enfermedad. Los encuestados del estrato 6, el de más ingresos, conoce esta patología en un 92\%.

Por nivel de estudios, los de secundaria incompleta (SI), universidad incompleta (UI) y universidad completa (UC) son los que más conocen sobre el dengue (entre el 95 y 96\%). Se presenta una disminución en los de primaria completa (PC) y secundaria completa (SC), ambos con el 92\%.

Las mujeres de todas las edades, excepto en las del rango entre los 5165 años (95\% para ellas y 96\% para ellos), superan a los hombres en conocimiento sobre el dengue. La diferencia más significativa se encuentra en el rango entre los 36 y 50 años: en el sexo femenino es del 98\%, mientras que en los del sexo masculino es del $91 \%$.

Tabla 6. Medios por los que ha recibido información sobre el dengue y su control

\begin{tabular}{|l|l|l|}
\hline Medio de información & Número & Porcentaje \\
\hline Televisión & 968 & $80 \%$ \\
\hline Radio & 744 & $61 \%$ \\
\hline Prensa / periódicos & 855 & $71 \%$ \\
\hline Internet & 956 & $79 \%$ \\
\hline Amigos, familiares o vecinos & 654 & $54 \%$ \\
\hline Funcionarios de la Secretaría de Salud & 742 & $61 \%$ \\
\hline $\begin{array}{l}\text { Médicos que los han atendido en instituciones de } \\
\text { salud }\end{array}$ & 191 & $16 \%$ \\
\hline
\end{tabular}

Fuente: elaboración propia

Televisión (80\%) e internet $(79 \%)$ son los medios más consultados por los encuestados para informarse del dengue. De la radio (71\%) también reciben información sobre la enfermedad, aunque hay que advertir que de los "funcionarios de la Secretaría de Salud" (61\%) y de los "médicos que los han atendido en instituciones de salud" $(16 \%)$ se les ha suministrado información sobre el tema en un porcentajes altos, si se suman las dos categorías (77\%). 
Tabla 7. Medios por los que ha recibido información sobre el dengue y su control, según estrato

\begin{tabular}{|c|c|c|c|c|c|c|}
\hline \multirow[t]{2}{*}{ Medios } & \multicolumn{6}{|c|}{ Estrato } \\
\hline & 1 & 2 & 3 & 4 & 5 & 6 \\
\hline Televisión & $83 \%$ & $79 \%$ & $75 \%$ & $80 \%$ & $80 \%$ & $76 \%$ \\
\hline Radio & $63 \%$ & $60 \%$ & $58 \%$ & $61 \%$ & $63 \%$ & $65 \%$ \\
\hline Prensa / periódicos & $58 \%$ & $65 \%$ & $70 \%$ & $70 \%$ & $71 \%$ & $75 \%$ \\
\hline Internet & $71 \%$ & $69 \%$ & $76 \%$ & $80 \%$ & $80 \%$ & $76 \%$ \\
\hline Amigos, familiares o vecinos & $58 \%$ & $50 \%$ & $50 \%$ & $53 \%$ & $56 \%$ & $65 \%$ \\
\hline Funcionarios de la Secretaría de Salud & $63 \%$ & $52 \%$ & $59 \%$ & $62 \%$ & $64 \%$ & $61 \%$ \\
\hline $\begin{array}{l}\text { Médicos que los han atendido en } \\
\text { instituciones de salud }\end{array}$ & $21 \%$ & $11 \%$ & $14 \%$ & $14 \%$ & $17 \%$ & $24 \%$ \\
\hline
\end{tabular}

Fuente: elaboración propia

El estrato 1 es el que más consume televisión (83\%) para informarse sobre el dengue; el estrato 6 lo hace en radio $(65 \%)$ y prensa/periódicos (75\%); los estratos 4 y 5 , ambos con el $80 \%$, en internet; el estrato 6 es el que más se entera de la enfermedad a través de amigos, familiares y vecinos (65\%) y de médicos que los han atendido en instituciones de salud (24\%); el estrato 5 es el que más se informa por medio de funcionarios de la Secretaría de Salud (64\%).

Tabla 8. Medios por los que ha recibido información, según sexo y edad

\begin{tabular}{|c|c|c|c|c|c|c|c|c|}
\hline \multirow[t]{3}{*}{ Sexo } & \multicolumn{8}{|c|}{ Edad } \\
\hline & \multicolumn{2}{|c|}{$15-20$} & \multicolumn{2}{|c|}{$21-35$} & \multicolumn{2}{|c|}{$36-50$} & \multicolumn{2}{|c|}{$51-65$} \\
\hline & F & M & F & M & $\mathrm{F}$ & M & $\mathrm{F}$ & M \\
\hline Televisión & $79 \%$ & $76 \%$ & $78 \%$ & $81 \%$ & $78 \%$ & $75 \%$ & $79 \%$ & $70 \%$ \\
\hline Radio & $60 \%$ & $58 \%$ & $59 \%$ & $62 \%$ & $66 \%$ & $66 \%$ & $58 \%$ & $74 \%$ \\
\hline Prensa / periódicos & $71 \%$ & $71 \%$ & $69 \%$ & $70 \%$ & $62 \%$ & $70 \%$ & $58 \%$ & $74 \%$ \\
\hline Internet & $80 \%$ & $80 \%$ & $82 \%$ & $75 \%$ & $75 \%$ & $68 \%$ & $66 \%$ & $70 \%$ \\
\hline $\begin{array}{l}\text { Amigos, familiares o } \\
\text { vecinos }\end{array}$ & $50 \%$ & $58 \%$ & $57 \%$ & $54 \%$ & $51 \%$ & $47 \%$ & $53 \%$ & $61 \%$ \\
\hline $\begin{array}{l}\text { Funcionarios de la } \\
\text { secretaría de salud }\end{array}$ & $58 \%$ & $67 \%$ & $62 \%$ & $64 \%$ & $58 \%$ & $45 \%$ & $47 \%$ & $43 \%$ \\
\hline $\begin{array}{l}\text { Médicos que los han } \\
\text { atendido en instituciones... }\end{array}$ & $15 \%$ & $8 \%$ & $21 \%$ & $15 \%$ & $14 \%$ & $17 \%$ & $21 \%$ & $9 \%$ \\
\hline
\end{tabular}

"F": femenino; " $M$ ": masculino.

Fuente: elaboración propia 
Las mujeres entre 15 y 20 años y entre 51 y 65 (ambos rangos con el $79 \%$ ) y los hombres entre 21 y 35 años, son los que más consumen televisión para informarse sobre el dengue. En el caso de la radio, la relación es mujeres entre 36 y 50 años $(66 \%)$ y hombres, entre 51 y 65 años (74\%); en prensa/periódicos: mujeres entre 15 y 20 años $(71 \%)$ y hombres entre 51-65 años (74\%); en internet: mujeres entre 21 y 35 años $(82 \%)$ y hombres entre 15 y 20 años (80\%); se informan por medio de amigos, familiares o vecinos: mujeres entre 15 y 20 años (58\%); mediante funcionarios de la Secretaría de Salud: mujeres entre 21 y 35 años $(62 \%)$ y hombres entre 15 y 20 años (67\%) y a través de médicos que los han atendido en instituciones de salud: mujeres entre 21 y 35 años y entre 51 y 65 años (ambos con 21\%) y hombres entre 36 y 50 años $(17 \%)$.

Tabla 9. Medios por los que ha recibido información, según nivel de estudios

\begin{tabular}{|l|l|l|l|l|l|}
\hline Medio & PC & SI & SC & UI & UC \\
\hline Televisión & $83 \%$ & $82 \%$ & $79 \%$ & $77 \%$ & $81 \%$ \\
\hline Radio & $66 \%$ & $67 \%$ & $62 \%$ & $60 \%$ & $62 \%$ \\
\hline Prensa / periódicos & $73 \%$ & $68 \%$ & $71 \%$ & $71 \%$ & $68 \%$ \\
\hline Internet & $87 \%$ & $77 \%$ & $76 \%$ & $80 \%$ & $78 \%$ \\
\hline Amigos, familiares o vecinos & $64 \%$ & $66 \%$ & $57 \%$ & $52 \%$ & $58 \%$ \\
\hline Funcionarios de la secretaría de salud & $68 \%$ & $78 \%$ & $62 \%$ & $62 \%$ & $60 \%$ \\
\hline $\begin{array}{l}\text { Médicos que los han atendido en instituciones } \\
\text { de salud }\end{array}$ & $25 \%$ & $32 \%$ & $20 \%$ & $16 \%$ & $20 \%$ \\
\hline
\end{tabular}

"PC": Primara Completa; "SI": Secundaria Incompleta; "SC": Secundaria Completa; "UI": Universidad Incompleta y "UC": Universidad Completa. Fuente: elaboración propia

Los encuestados con primaria completa $(83 \%, 73 \%$ y $87 \%)$ son los que más emplean la televisión, prensa/periódicos e internet, respectivamente, para informarse sobre el dengue; los de secundaria incompleta $(67 \%)$ lo hacen gracias a la radio; los de secundaria incompleta (66 y 78\%) lo hacen a través de amigos, familiares o vecinos y de médicos que los han atendido en instituciones de salud, respectivamente. 
Tabla 10. Cuáles son las manifestaciones del dengue

\begin{tabular}{|l|l|l|l|}
\hline Síntomas & Sí & NO & NS/NC \\
\hline Fiebre alta & $92 \%$ & $2 \%$ & $6 \%$ \\
\hline Dolor de cabeza & $80 \%$ & $9 \%$ & $11 \%$ \\
\hline Dolor detrás de los ojos o en los ojos & $57 \%$ & $24 \%$ & $19 \%$ \\
\hline Dolor de huesos o músculos & $79 \%$ & $9 \%$ & $12 \%$ \\
\hline Somnolencia/postración/desaliento & $73 \%$ & $13 \%$ & $14 \%$ \\
\hline Congestión nasal & $33 \%$ & $45 \%$ & $22 \%$ \\
\hline Tos & $33 \%$ & $45 \%$ & $22 \%$ \\
\hline Vómito & $65 \%$ & $20 \%$ & $15 \%$ \\
\hline Diarrea & $59 \%$ & $23 \%$ & $18 \%$ \\
\hline Dolor de estómago & $45 \%$ & $33 \%$ & $22 \%$ \\
\hline Disminución de plaquetas & $77 \%$ & $8 \%$ & $15 \%$ \\
\hline Disminución de tensión o presión arterial & $43 \%$ & $25 \%$ & $30 \%$ \\
\hline
\end{tabular}

\section{"NS/NC": No Sabe/No Contesta.}

Fuente: elaboración propia

Los encuestados sí asocian el dengue con cinco síntomas:

"fiebre" (92\%); "dolor de cabeza" (80\%); "dolor de huesos o músculos" (79\%); "disminución de plaquetas" (77\%) y "somnolencia/postración/desaliento" (73\%). No lo asocian con "tos" (45\%), "dolor de estómago" (33\%) y "disminución de tensión o presión arterial" (25\%).

Los valores más altos en la categoría No Sabe/No Contesta se refieren a respuestas como congestión nasal, tos y dolor de estómago, las tres con el $22 \%$.

Una amplia mayoría de los encuestados señala a la "picadura de un mosquito" (71\%) como el transmisor del dengue y un 16\% lo asocia a todas las formas de transmisión categorizadas en el instrumento, esto es, virosis, agua contaminada, por no lavarse las manos antes de comer, de persona a persona cuando el enfermo tose y por la picadura de un mosquito. 


\section{Ilustración 1. Cómo se transmite el dengue}

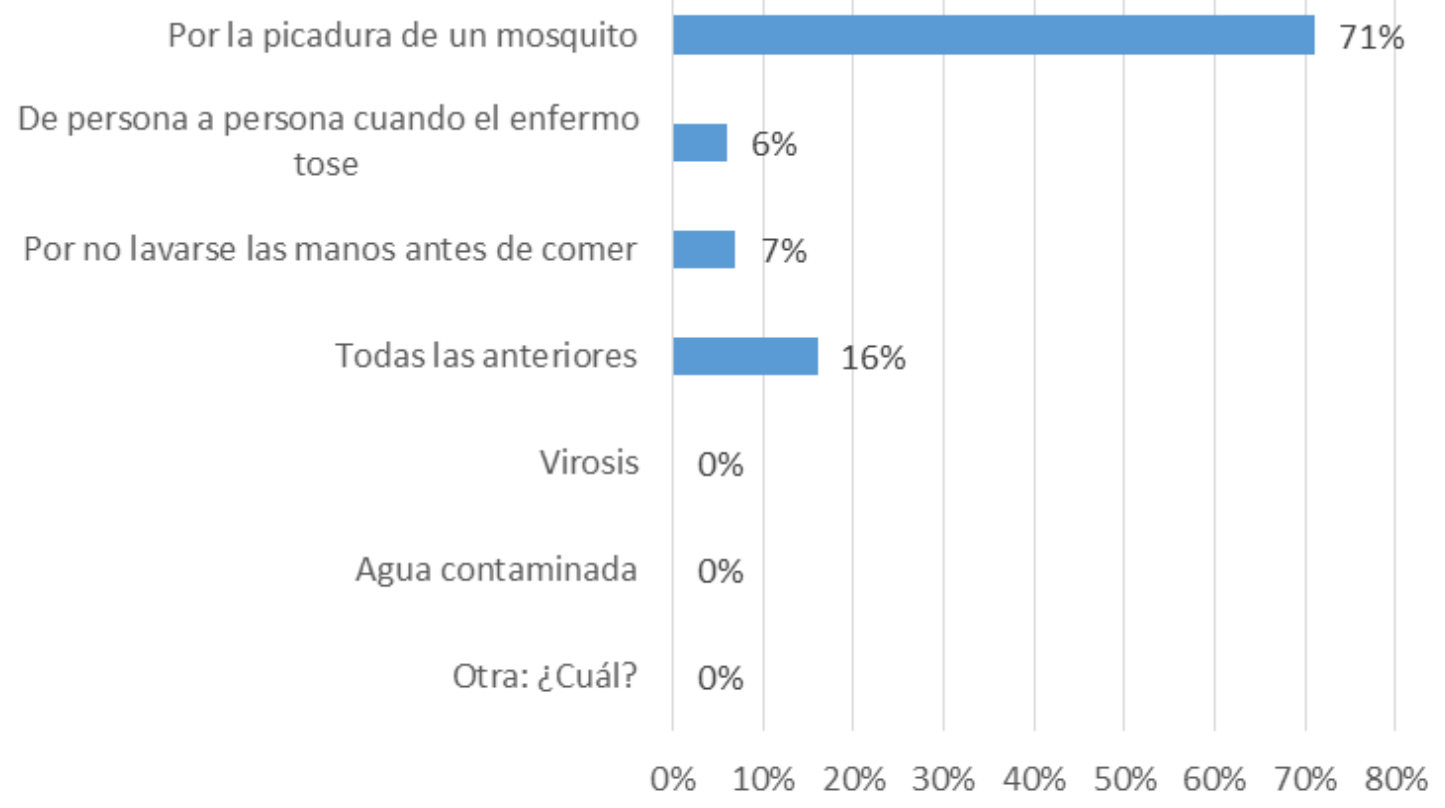

Fuente: elaboración propia

Tabla 11. Qué medidas conoce para prevenir el dengue

\begin{tabular}{|l|l|l|l|}
\hline Respuesta & $\mathbf{C}$ & $\mathbf{N C}$ & $\mathbf{C P}$ \\
\hline $\begin{array}{l}\text { Destrucción o relleno de recipientes que puedan acumular } \\
\text { agua }\end{array}$ & $56 \%$ & $13 \%$ & $31 \%$ \\
\hline Protección o cubrimiento de depósitos de agua & $57 \%$ & $18 \%$ & $25 \%$ \\
\hline Recolección de inservibles & $41 \%$ & $42 \%$ & $17 \%$ \\
\hline Uso de toldillos para todos los que viven en la casa & $61 \%$ & $28 \%$ & $10 \%$ \\
\hline Uso de toldillos para los pacientes que tienen dengue & $58 \%$ & $31 \%$ & $11 \%$ \\
\hline Fumigación & $65 \%$ & $13 \%$ & $22 \%$ \\
\hline Uso de tapabocas & $54 \%$ & $35 \%$ & $11 \%$ \\
\hline Lavar la alberca o el lavadero & $52 \%$ & $17 \%$ & $31 \%$ \\
\hline Evitar acumular agua & $53 \%$ & $15 \%$ & $32 \%$ \\
\hline Lavarse las manos antes de comer y después de ir al baño & $44 \%$ & $23 \%$ & $33 \%$ \\
\hline Consulta oportuna en caso de presentarse los síntomas. & $42 \%$ & $22 \%$ & $36 \%$ \\
\hline Limpieza en general & $52 \%$ & $16 \%$ & $32 \%$ \\
\hline
\end{tabular}

"C": La conoce; "NC": No la conoce; "C": la Conoce y la Practica.

Fuente: elaboración propia 
Los resultados indican que todas las personas tienen un amplio conocimiento de las medidas que se deben tomar para prevenir el dengue. Sin embargo, las medidas que más conocen (C) los encuestados son "fumigación" (65\%), "uso de toldillo para todos los que viven en la casa" (61\%) y para los pacientes que tienen dengue $(58 \%)$. Las que menos se conocen (NC) son "recolección de inservibles" (42\%), "uso de tapabocas" (35\%) y "uso de toldillos para los pacientes que tienen dengue" (31\%). Las medidas que más conocen y practican (CP) son "consulta oportuna en caso de presentarse los síntomas", "lavarse las manos" (36\%) y "limpieza en general" $(32 \%)$.

Tabla 12. Cuándo han ocurrido estos eventos

\begin{tabular}{|l|l|l|l|l|}
\hline Evento & $\mathbf{1}$ & $\mathbf{2}$ & $\mathbf{3}$ & $\mathbf{4}$ \\
\hline Se han eliminado criaderos en su domicilio & $56 \%$ & $15 \%$ & $13 \%$ & $16 \%$ \\
\hline Se ha lavado el tanque del agua & $17 \%$ & $56 \%$ & $14 \%$ & $13 \%$ \\
\hline $\begin{array}{l}\text { Ha sido visitado por un trabajador de } \\
\text { saneamiento ambiental }\end{array}$ & $48 \%$ & $15 \%$ & $21 \%$ & $16 \%$ \\
\hline $\begin{array}{l}\text { Ha recibido atención médica por el dengue } \\
\text { Algún familiar ha recibido atención médica } \\
\text { por el dengue }\end{array}$ & $58 \%$ & $13 \%$ & $20 \%$ & $9 \%$ \\
\hline $\begin{array}{l}\text { Le han hablado o le han dado alguna charla } \\
\text { sobre cómo prevenirlo }\end{array}$ & $23 \%$ & $32 \%$ & $34 \%$ & $83 \%$ \\
\hline
\end{tabular}

"1": nunca ha pasado; "2": ocurrió en los últimos seis meses; "3": ocurrió pero hace más de seis meses y "4" "ns/nc": no sabe/ no contesta.

Fuente: elaboración propia.

Los eventos que más han ocurrido en la categoría 1, "nunca ha pasado", son "ha recibido atención médica por el dengue" (58\%) y "se han eliminado criaderos en su domicilio" (56\%). En la categoría 2, "ocurrió en los últimos seis meses", las respuestas más frecuentes son "se ha lavado el tanque del agua" (56\%) y "le han hablado o le han dado alguna charla sobre cómo prevenirlo" (32\%). En la categoría 3, "ocurrió pero hace más de seis meses", las respuestas más asiduas son 
"algún familiar ha recibido atención médica por el dengue" (34\%) y "le han hablado o le han dado alguna charla sobre cómo prevenirlo" $(33 \%)$. En la categoría no saben/no contestan, los porcentajes más altos se ubican en las respuestas "se han eliminado criaderos en su domicilio" y "ha sido visitado por un trabajador de saneamiento ambiental", ambas con el 16\%.

\section{Discusión y conclusiones}

La posición que ocupa la información médico-sanitaria respecto al interés que expresan los ciudadanos por conocerla, la primera, demuestra los altos niveles de sensibilidad e impacto social frente a las problemáticas de esta índole y, en definitiva, pone de manifiesto que los asuntos sobre la salud nos afectan y tocan de cerca a todos. Los motivos del posible interés por estas noticias pueden estar dirigidos hacia la prevención, ya que son temas que les parecen interesantes o necesarios para estar informados.

En general, se puede decir que existe un conocimiento del dengue en la ciudad de Bucaramanga, sin que existan matices que diferencien significativamente este conocimiento por razones de edad, sexo, estrato o nivel de estudios. No olvidemos que obtenemos estos resultados en una zona endémica de dengue. La transmisión ocurre por debajo de los 2.000 metros, con mayor intensidad en la estación de lluvias, y es interrumpida por el clima frío. La temperatura de la ciudad de Bucaramanga oscila anualmente entre los 27 y $17^{\circ} \mathrm{C}$ y se encuentra a una altitud de 950 metros. De esta manera el mosquito queda infectado durante toda su vida y puede transmitir el virus a su progenie. Vale anotar que, después de la picadura, el período de incubación de la enfermedad puede ir desde 3 hasta 14 días.

La incidencia del dengue ha crecido de forma espectacular en todo el mundo en las últimas décadas. Más del $40 \%$ de la población mundial está ahora con riesgo de dengue y es endémico en unos 105 países de Asia, el Pacífico, América Latina, África y el Caribe. La Organización Mundial de la Salud (OMS) calcula que puede haber entre 50 y 100 millones de casos de dengue en todo el mundo cada año y 22.000 muertes, principalmente entre los niños. Como todavía no hay 
ninguna vacuna para prevenir la infección por este virus, las medidas de protección más eficaces son las que evitan las picaduras de mosquitos. Por todo ello, es importante que en las zonas de población en riesgo, como es el caso de la ciudad de Bucaramanga y de muchas otras en el país, se conozcan las medidas de transmisión, prevención y diagnóstico del dengue, para que disminuyan los índices de mortalidad. Los gobiernos deben hacerse responsables de mantener políticas públicas de información y prevención de la enfermedad.

Al respecto, una amplia mayoría de los encuestados señala acertadamente a la picadura de un mosquito (71\%) como el transmisor del dengue, y un 16\% lo asocia a todas las formas de transmisión categorizadas en el instrumento, esto es, "virosis", "agua contaminada", "por no lavarse las manos antes de comer", "de persona a persona cuando el enfermo tose" y "por la picadura de un mosquito". Esto pone en evidencia que todavía existe una pequeña parte de la población que no conoce las formas de transmisión, ya que no se trasmite de persona a persona, y sobre la que habría que focalizar las campañas de comunicación y prevención.

La enfermedad es conocida popularmente en África como "fiebre quebrantahuesos", porque lo que destaca más en su sintomatología son los fuertes dolores musculares y articulares generalizados, además de la fiebre elevada, cefaleas, dolores retro-orbitarios, faringitis, rinitis o tos. En casos raros, principalmente niños que ya habían sido infectados con anterioridad, el cuadro banal se puede complicar con un cuadro hemorrágico generalizado (dengue hemorrágico) o un síndrome de shock hipovolémico, que presenta una mortalidad elevada (cerca del 40\%). En este sentido, encontramos que el reconocimiento del dengue por parte de los encuestados efectivamente coincide con los síntomas más frecuentes por este orden; fiebre (92\%); dolor de cabeza (80\%); dolor de huesos o músculos (79\%); disminución de plaquetas (77\%) y somnolencia / postración / desaliento (73\%). Esto quiere decir que la comunidad está prevenida y sabría distinguir la aparición de la enfermedad, aunque hay que recordar que el tratamiento es puramente sintomático: analgésicos / antipiréticos e hidratación y que los casos graves de dengue 
hemorrágico o de shock hipovolémico necesitan tratamiento urgente en medio hospitalario.

Los resultados indican que todas las personas saben ampliamente las medidas que se deben tomar para prevenir el dengue. La medida que más conocen los encuestados es la fumigación (65\%). No hay que olvidar que, al no existir quimioprofilaxis, la mejor prevención es evitar las picaduras de los mosquitos. El dengue es causante de cerca de 390 millones de infecciones al año.

Los medios que los bumangueses consultan para recibir información acerca del dengue son la televisión (80\%) e internet (79\%), seguidos de prensa y periódicos (71\%). Por un lado, los resultados obtenidos en la encuesta, sugieren que los proyectos que dirigen las entidades gubernamentales para frenar la enfermedad, no tienen una repercusión sólida en la ciudadanía o, por lo menos, es menor que la que consiguen los medios de comunicación masiva. Por otro, los médicos con un $16 \%$, están todavía muy lejos de ser un canal de información que esté aunando esfuerzos para prevenir a la comunidad. Estos datos son coincidentes con los de otros estudios, en tanto demuestran que los ciudadanos de hoy se encuentran cada vez más expuestos a la información relacionada con la salud a través de los medios de comunicación masiva que a través de visitas a médicos o a profesionales de la salud (Signorielli, 1993). Incluso, en muchos casos algunos individuos sólo cuentan con la información proveniente de los medios masivos como fuente primaria en el campo de la salud (Wahl, 1995).

Desde la comunicación para la salud se dan múltiples elementos para promover y facilitar cambios saludables en nuestras sociedades, tanto en lo que refiere al fortalecimiento de los actores y redes comunitarias como en la promoción de nuevas concepciones y habilidades individuales y colectivas relacionadas con la salud (Díaz y Uranga, 2012: 122-123). Pero la promoción de conductas saludables no debe ser el resultado exclusivo de campañas publicitarias, sino la consecuencia lógica de la apropiación de otro sentido más responsable, respecto a la calidad de vida y a la salud por parte de la ciudadanía. 
En una investigación realizada en el Atlántico colombiano entre 2003 y 2005, con el propósito de mejorar la efectividad y sostenibilidad de los programas de control de Fiebre Dengue (FD), a través de una estrategia de comunicación participativa basada en los recursos comunicacionales locales y en los conocimientos, prácticas y percepciones de la comunidad, se obtuvieron resultados que mostraron la adopción de prácticas deseadas para reducir la formación de criaderos de mosquitos, especialmente entre los jóvenes. Adicionalmente, la población manifestó realizar acciones preventivas frente a la enfermedad, en particular frente a sitios de cría del vector, aunque éstas no eran lo suficientemente eficaces. Las mujeres lavaban sus tanques de agua pero no con la frecuencia y la forma eficaz para interrumpir el ciclo de vida del mosquito. A su vez, se detectó que el trabajo de comunicación y movilización social influyó de manera importante en la adopción de comportamientos que contribuyen al control de criaderos (Mosquera, Obregón, Lloyd, Orozco y Peña, 2010: 137-147).

En este sentido, las acciones de comunicación en salud y su impacto, no deben centrarse en intervenciones aisladas localizadas en cambios de conductas a nivel individual, ya que no serían efectivas a largo plazo. Por ello, se requiere una amplia gama de intervenciones que trasciendan el individuo, a distintos niveles, por un tiempo suficiente y de acuerdo con las necesidades de cada comunidad.

Las teorías o los modelos del cambio de comportamiento postulan que la adopción de comportamientos sanos es un proceso en el cual los individuos avanzan, a través de diversas etapas, hasta que el nuevo comportamiento se convierte en parte de la vida diaria. Los modelos recalcan que los mensajes y programas transmitidos por los medios de comunicación son más eficaces en las etapas iniciales, aunque las comunicaciones interpersonales y las redes comunitarias de apoyo social son sumamente importantes durante las etapas posteriores (Coe, 1998: 27).

Algunos investigadores han señalado que, a pesar de los niveles crecientes del conocimiento y la toma de conciencia acerca del dengue y los mosquitos, mucha gente todavía no está haciendo lo que 
debería hacer. En algunos países, como ha sido el caso de Colombia en esta investigación, las personas saben que el dengue es causado por los mosquitos y que éstos pueden reproducirse en los recipientes de almacenamiento de agua. Sin embargo, aún no están haciendo lo que es mejor para ellas y dejan estos recipientes sin protección. Lamentablemente, un individuo informado $y$ culto no es necesariamente receptivo a nivel conductual (Park y Lloyd, 2004: 4).

Pese a ello, muchos programas todavía se centran sólo en modificar el conocimiento y aumentar la conciencia de la gente, creyendo que la conducta cambiará, cuando en realidad no cambia -por lo menos, cuando se hace solamente a través de la publicidad y los medios de comunicación-. En general, la mayoría de los programas logran informar y convencer, pero a menudo no obtienen una conducta nueva que sea eficaz y factible, ni incitan a las personas a tomar medidas hacia la adopción y el mantenimiento de una nueva conducta.

En resumen, podemos afirmar que los procesos de comunicación que se realizan desde los medios de masas, así como las intervenciones directas sobre las comunidades, están resultando más eficaces como herramientas para modificar conductas y favorecer los procesos de prevención y tratamiento del dengue. Habría que sumar esfuerzos y divulgar más conocimientos sobre la enfermedad, que produzcan la apropiación social de la misma y que mejoren los que ya parecen poseer los bumangueses. Los gobiernos, tanto en el orden local como nacional, junto con los profesionales sanitarios y los medios de comunicación, deben hacerse responsables y propiciar las actividades oportunas que conduzcan a un cambio real a medio y largo plazo.

\section{Bibliografía}

Barcaz, E. (2002). Estrategia de comunicación social para la atención primaria de salud en la provincia Las Tunas. Educación Médica Superior, 16(1), 3-4.

Beltrán, L. R. (2001). La importancia de la comunicación en la promoción de la salud. Midia e Saúde. Adamantina: 
UNESCO/UMESP/FAI. Disponible

en https://encipecom.metodista.br/mediawiki/images/c/c9/0

04 - Luis Ramiro Beltran.pdf. Recuperado el 06/03/2016.

Bryman, Alan \& Teevan, James (2005). Social Research Methods.

Canadá: Oxford.

Coe, G. A. (1998). Comunicación y promoción de la salud. Chasqui. Revista Latinoamericana de Comunicación, (63).

Cuesta, U., Menéndez Hevia, T. \& García Guardia, M. L. (2008). Comunicación social y salud: Un nuevo planteamiento estratégico. Comunicación y salud: avances en modelos y estrategias de intervención. Editorial Complutense. Madrid, 19-38.

Del Valle, C. (2002). Comunicar la salud: entre la equidad y la diferencia. Ediciones Universidad de la Frontera, Chile.

Departamento Administrativo Nacional de Estadística, DANE. (2011). Proyecciones de población total por sexo y grupos de edad de 0 hasta 80 y más años (2005 - 2020). Disponible en http://www.dane.gov.co/index.php/poblacion-ydemografia/proyecciones-de-poblacion. Recuperado el 12/03/2016.

Díaz, H., \& Uranga, W. (2012). Comunicación para la salud en clave cultural y comunitaria. Revista de Comunicación y Salud, 1(1), 113124.

Fajardo, P., Monje, C. A., Lozano, G., Realpe, O., \& Hernández, L. E. (2001). Nociones populares sobre "dengue" y

"rompehuesos", dos modelos de la enfermedad en

Colombia. Rev Panam Salud Pública, 10(3), 161-8.

Guibert, W., Grau, J., \& Prendes, M. D. L. C. (1999). ¿Cómo hacer más efectiva la educación en salud en la atención primaria? Revista Cubana de Medicina General Integral, 15(2), 176183. 
Hernández, Roberto; Fernández, Carlos y Baptista, Pilar (2010).

Metodología de la investigación (quinta edición). Lima:

McGraw Hill.

Instituto Nacional del Cáncer de los Estados Unidos (2004): Making bealth communication programs work. Disponible en http://www.cancer.gov/pinkbook. Recuperado el 15/03/2016.

Kourí, Gustavo. (2011). El dengue, un problema creciente de salud en las Américas. Revista Cubana de Salud Pública, 37(Supl. 5), 616618. Disponible

en http://scielo.sld.cu/scielo.php script $=$ sci_arttext\&pid=S086 4-34662011000500010\&lng=es\&tlng=es. Recuperado el 09/04/2016.

Mosquera, M., Obregón, R., Lloyd, L. S., Orozco, M., \& Peña, A. (2010). Comunicación, movilización y participación: lecciones aprendidas en la prevención y control de la fiebre dengue (FD). Investigación \& Desarrollo, 14(1).

Park, Will \& Lloyd, Linda. (2004). Planificación de la movilización y comunicación social para la prevención y el control del dengue. Guía paso a paso. Disponible en http://www.who.int/tdr/publications/documents/planificacio n dengue.pdf. Recuperado 27/3/2106.

Sánchez Martos, Javier (2008). Influencia de los medios de comunicación en la salud de la población. Comunicación y salud: avances en modelos y estrategias de intervención. Editorial Complutense. Madrid, 77-98.

San Martín, J. L., \& Prado, M. (2004). Percepción del riesgo y estrategias de comunicación social sobre el dengue en las Américas. Rev Panam Salud Pública, 15(2), 135-9. 
Silva Pintos, Virginia (2001). Comunicación en salud. Inmediaciones de la comunicación. Escuela de Comunicación de la Universidad ORT Uruguay, 3(3), 119-136. Disponible en http://www.ort.edu.uy/fcd/pdf/revista-inmediaciones-dela-comunicacion-3.pdf. Recuperado 27/3/2016.

Signorielli, N. (1993). Mass Media Images and Impact on Health: A Sourcebook. Westport, CT: Greenwood.

Simelio, Nuria (2011). Técnicas cuantitativas: la encuesta (173-188). Vilches, Lorenzo (Edit.). La investigación en comunicación. Métodos y técnicas en la era digital. Barcelona: Gedisa.

Suárez, M., \& Tapia, F. (2011). Interaprendizaje de estadística básica. Ibarra Ecuador.

Wahl, O.F. (1995). Media Madness: Public Images of Mental Illness. New Brunswick, NJ: Rutgers University Press.

Weerakkody, Niranjala (2009). Research Methods for Media and Communication. Sidney: Oxford.

Wimmer, Roger \& Dominick, Joseph (1996). La investigación científica de los medios de comunicación. Barcelona: Bosch. 



\title{
El tratamiento de la obesidad en diarios brasileños: $O$ Globo y Folha de S. Paulo
}

\author{
Carolina Menezes (1) ICICT/Fiocruz \\ José Luis Terrón \\ Universitat Autònoma de Barcelona, UAB
}

\section{Resumen}

Introducción: En Brasil se ha producido una transición nutricional. Por otro lado, ha aumentado el interés de la población por la información sobre salud $y$, en concreto, por las noticias que tratan la obesidad. Objetivo. Determinar cómo se trata el tema de la obesidad en los dos periódicos con más circulación y penetración de Brasil: $O$ Globo, de Río de Janeiro y Folha de S. Paulo, de São Paulo. Método. Utilizamos el método de análisis de contenido y la revisión bibliográfica. Se seleccionaron y analizaron los artículos publicados sobre la obesidad en el período comprendido entre el 1 de enero y el 31 de junio de 2013, para lo cual se utilizaron los buscadores de los periódicos estudiados, mediante las palabras clave obesidad, grasa y sobrepeso (palabras usadas por la OMS para definir la obesidad). Resultados. Se encontraron 170 piezas en relación al objeto de estudio, 94 (55,2\%) en Folha de S. Paulo, con un promedio mensual de 15 informaciones, y $76(44,8 \%)$ en $O$ Globo, lo que supone un promedio de 12 informaciones al mes. Cabe destacar que 21 piezas aparecían en las portadas de los periódicos (el 6,5\% sobre el total); en la Folba de S. Paulo en 12 casos (12,7\% sobre el total de piezas, de las que cinco fueron publicadas en el mes de marzo, el mes con más portadas, $41,7 \%)$ y en $O$ Globo en $9(11,8 \%$, de las que 4 piezas fueron 
publicadas en el mes de junio, en este caso el mes con más portadas). En cuanto a los contenidos de las informaciones, cabe destacar que Folha de S. Paulo realiza un tratamiento más científico, abordando la obesidad como un riesgo de enfermedad y usando como fuentes a revistas científicas internacionales y a expertos; $O$ Globo, en cambio, relaciona más la obesidad con la imagen corporal. Por otra parte, se insertan pocas informaciones en torno a la obesidad infantil (en Folha más que en $O$ Globo), aunque en casi todas ellas se sigue al menos una recomendación de la OMS en relación a la prevención de la obesidad infantil. Conclusiones. La obesidad se trata cada vez con más frecuencia en los periódicos brasileños. No obstante, encontramos una gran diferencia en el tratamiento de la misma, con un enfoque desde la salud en la Folha de S. Paulo y otro desde la imagen corporal en $O$ Globo, adaptándolo cada diario a lo que presuponen que su audiencia quiere leer; Folha de S. Paulo también se dirige a los niños cuando informa sobre la obesidad.

Palabras clave: salud; periódicos; obesidad; nutrición, imagen corporal; Brasil.

\section{Introducción}

R RASIL ha cambiado en los últimos cincuenta años (Filho \&

1 Rissin, 2003) y entre esos cambios debemos considerar los que conciernen al ámbito de la salud, que se deben, a grandes rasgos, a (i) una rápida transición demográfica (de una población principalmente rural a la condición actual de un país urbano, la reducción en las tasas de natalidad y una mayor esperanza de vida); (ii) el cambio en la estructura económica $y$, por ende, en los puestos de trabajo (incremento de la actividad centrada en el sector secundario y, especialmente, en el sector terciario de la economía); (iii) la mejora en el acceso y en la cobertura de la salud; (iv) el desarrollo y la mejora de las condiciones de saneamiento; y (v), un mayor consumo de contenidos mediáticos, una mayor influencia de la publicidad y el marketing. En definitiva, han variado ostensiblemente los estilos de vida, lo que conlleva un cambio en las demandas y hábitos 
nutricionales (Filho \& Rissin, 2003). Hablamos, pues, de transición nutricional.

La transición nutricional es un fenómeno por el cual hay una inversión en los patrones de distribución de los problemas nutricionales de una población en un tiempo dado. Desde el punto de vista nutricional, este proceso se caracteriza por un aumento en el consumo de alimentos procesados, fuente de grasas, sal y azúcares, en detrimento de una alimentación que se basa en la ingesta de frutas, legumbres y verduras. A la vez, disminuye el ejercicio físico y aumenta el sedentarismo (Ferreira, 2006).

Esta transición nutricional provoca el aumento de la incidencia y la prevalencia de la obesidad en gran parte del mundo. En el caso que nos ocupa, Brasil, surge y crece la obesidad a la par que disminuye la desnutrición (Filho \& Rissin, 2003).

Pero, ¿qué es la obesidad? Empecemos apuntando que obesidad es una palabra que deriva del latín, obesitas, que significa exceso de grasa. Se trata de un fenómeno multifactorial cuyo origen involucra componentes genéticos, endocrínicos, metabólicos, conductuales, psicológicos y sociales, que culminan con un balance energético positivo, resultante del consumo excesivo de energía, asociado o no a la vida sedentaria.

La obesidad se define a partir del Índice de Masa Corporal (IMC) ${ }^{31}$, que surge de la relación entre el peso y la altura al cuadrado. Con valores superiores a $25 \mathrm{~kg} / \mathrm{m}^{2}$ hablamos de sobrepeso; por encima de $30 \mathrm{~kg} / \mathrm{m}^{2}$ consideramos que los individuos son obesos.

La obesidad es un factor de riesgo para el surgimiento y desarrollo de las Enfermedades Crónicas no Transmisibles (ECNT), tales como la diabetes, enfermedades cardiovasculares, problemas respiratorios, la hipertensión arterial, cánceres o las dislipidemias (alteración de los metabolismos de los lípidos), por citar algunas. De otra manera, la

\footnotetext{
${ }^{31}$ Advertimos que esta manera de calcular la obesidad cada vez se cuestiona más, dado que ofrece una imagen imprecisa de la pandemia. Véase al respecto, "Obesidad desenfocada" (Casino, 2016).
} 
obesidad puede dar origen a depresiones y comportamientos de aislamiento social, así como puede conllevar estigmatización y menos oportunidades en relación al trabajo, la educación o los ingresos, lo que acarrea graves perjuicios en la calidad de vida de los individuos (Ades \& Kerbauy, 2002; Ferreira, 2006; Miqueleiz et al, 2015; Tyrrell, J. et al, 2016).

Según la Organización Mundial de Salud (OMS), en el año 2005 hubo en el mundo 1,6 billones de personas de más de 15 años de edad con sobrepeso y 400 millones de personas obesas. En 10 años los datos han evolucionado a peor; en 2015 se cuantificaron 2,3 billones de personas con sobrepeso y 700 millones de personas obesas. Lo que indica un aumento del 75\% en la incidencia de la obesidad en estos 10 años (Vigitel, 2009). En América del Sur vemos como Chile es el país con más obesos (25,1\%), seguido por Paraguay (22,8\%), Argentina $(20,5 \%)$, Uruguay $(19,9 \%)$ y Brasil $(17,9 \%)$, que ocupa la $77^{a}$ posición mundial (Vigitel, 2015).

En Brasil, el 52,2\% de la población adulta tiene sobrepeso y el 17,9\% es obesa (Vigitel, 2015). La investigación de Vigitel $^{32}$, realizada en adultos de las capitales de los 26 estados brasileños y del Distrito Federal, indica un aumento en la frecuencia de sobrepeso y obesidad en la población brasileña. Entre 2006 y 2011 se dio un incremento del sobrepeso (del 43\% al 49\%), siendo mayor entre los hombres $(56,5 \%$ ) en relación a las mujeres $(49,1 \%)$ y, a la vez, hubo un incremento en la obesidad (se pasa del 11\% al 16\%); siendo mayor entre las mujeres $(18,2 \%)$ que en entre los hombres $(17,9 \%)$. En definitiva, los hombres presentan más sobrepeso y las mujeres son más obesas.

Este fenómeno, incremento de la obesidad y del sobrepeso, también se da entre los niños y los adolescentes de los países desarrollados y en vías de desarrollo. En 15 años el número de los niños obesos pasó de los 7,7 millones en 1990 a los 15,5 millones en 2014. Se da la paradoja que el $25 \%$ vivían en África, el continente con mayores tasas de malnutrición aguda (WHO, 2016). En América Latina los últimos datos nos hablan de que alrededor de 52 millones de niños y

\footnotetext{
${ }^{32}$ Vigitel es una investigación del Ministerio de la Salud de Brasil cuyo objetivo es monitorear los comportamientos de riesgo en relación a las ECNT.
} 
adolescentes están obesos o tienen sobrepeso. Por su parte, en Brasil, según la Pesquisa de Orçamento Familiar (POF, 2010) había un $33,5 \%$ de niños entre los 5 y los 9 años con sobrepeso y un 14,3\% obesos. Por otro lado, hemos de tener en cuenta que el exceso de peso en la infancia aumenta la posibilidad de obesidad cuando se es adulto.

Estos datos, evidentemente, preocupan a los profesionales e instituciones del ámbito de la salud y, en paralelo, cada vez más, a los ciudadanos (Santos \& Filho, 2002), que, de manera continua, reciben informaciones de qué hacer para prevenir el sobrepeso y la obesidad (Bruno, 1992). Y si bien es cierto, como veremos, que los medios de comunicación tratan cada vez más estas problemáticas, también lo es que se tratan de dispositivos periodísticos con unas especificidades (están condicionados por patrones estructurales, culturales, sociales y económicos) que construyen los sentidos de sus discursos (Mouillaud, 2002).

\section{Objetivos, muestra y metodología}

Esta investigación pretende determinar cómo se trata el tema de la obesidad en los periódicos de más circulación en Brasil: O Globo, de Río de Janeiro y Folha de S. Paulo, de São Paulo, para intentar comprender las formas en que los periódicos analizados abordan la cuestión. Esta investigación tiene como objetivos:

1.- Verificar la cantidad de material sobre obesidad publicada en cada periódico y, en concreto, en sus portadas

2.- Identificar en qué secciones se insertan las piezas que tratan sobre la obesidad

3.- Analizar las características estructurales de las piezas

4.- Observar qué fuentes médicas se utilizan

5.- Detectar qué sentidos se construyen sobre la obesidad

6.- Determinar cómo se trata la obesidad infantil 
La muestra del estudio incluye a todos los ejemplares de $O$ Globo y de Folha de S. Paulo entre los meses de enero y junio de 2013, y contempla un total de 362 ejemplares. Se eligieron periódicos de estados diferentes para ver si el tema de la obesidad se trataba de manera distinta teniendo en cuenta el contexto geográfico. Por otro lado, se tratan de dos diarios de referencia en Brasil, con líneas editoriales distintas, de diferentes empresas y con estilos periodísticos y destinatarios diferenciados.

Folha de S. Paulo pertence al Grupo Folha, uno de los conglomerados de medios de comunicación más importantes del país, cuenta con siete secciones diarias: Poder (política nacional), Mundo (eventos internacionales sociales y políticos), Ciência, Mercado (economía), Cotidiano (noticias locales), Esporte (deportes) e Ilustrada (cultura y ocio), además de siete suplementos semanales - Folhinha (para niños), Tec (tecnologías y redes sociales), Equilíbrio (salud y calidad de vida), Turismo (destinos de viajes nacionales e internacionales), Ilustríssima (arte, ciencia y humanidad), Comida (cultura gastronómica y consejos para cocinar) y The New York Times (Folha de S.Paulo, 2014b). Folha de S. Paulo tiene una media de 1.086 .000 lectores, con una circulación de 319.351 ejemplares los días laborales y 344.636 los domingos. Su audiencia se sitúa en una mayor proporción entre los hombres, con un $54 \%$, el grupo de edad entre los 25 y los 44 años (43\%) y las clases A (22\% de los lectores) y B (61\% de los lectores) (Folha de S.Paulo, 2014b).

Por su parte, O Globo pertenece al Grupo Globo, el conglomerado de medios de comunicación más grande de Brasil y uno de los mayores de América Latina. O Globo cuenta con las siguientes separatas: Primer Cuaderno (contenidos sobre economía, política, ciencia, además de los hechos principales de Río y del mundo), Segundo Cuaderno (entretenimiento), Cuaderno de Deportes, Rio Show (cultura y gastronomía carioca), Revista O Globo (personalidades, moda, estilo de vida), Revista de la TV (noticias y programación de los canales abiertos y por suscripción), Prosa y Verso (literatura), Boa Viagem (viajes), Ela (noticias y tendencias), Boa Chance (mercado laboral) y Morar Bem (estilos de vida) (O Globo, 2013). El diario O Globo tiene un promedio 882 mil lectores diarios, con una difusión de 178.828 
ejemplares los días de diario y 259.521 los domingos. La mayor parte de sus lectores se concentran en las clases B (55\%) y C (28\%). Los hombres representan el $51 \%$ de su audiencia y la mayoría de sus lectores tienen 60 años o más (24\%) (Infoglobo, 2015).

La selección de las informaciones se hizo cotejando las versiones digitales de los periódicos mediante búsquedas con las palabras clave que utiliza la OMS para referirse a la obesidad: sobrepeso, grasa y obesidad. A las piezas seleccionadas se las analizó aplicando el análisis de contenido que, recordemos, es un método que culmina en las descripciones numéricas de algunas de las características del corpus de texto. Para averiguar qué sentidos subyacentes podíamos encontrar sobre la obesidad en el material seleccionado utilizamos los criterios y premisas preestablecidos por Boreo (2007), Carvalho (2007) y Figueiro (2009):

1.- Caracterización de la obesidad y obeso: identificación de los temas relativos a conceptos y definiciones; causas y consecuencias de la obesidad (emocional, social, económico, cultural y biológica); comportamiento del obeso; características epidemiológicas de la obesidad; prevención y reducción del riesgo de la obesidad.

2.- Credibilidad de las fuentes más usadas por los periódicos y cómo tratan dichas fuentes la obesidad.

Por último, y para profundizar más en cómo la muestra trata la obesidad infantil, comparamos los contenidos de las piezas analizadas que hablaban sobre obesidad infantil con las recomendaciones de la OMS para prevenir la obesidad infantil mediante el programa ECHO, y de esta manera ver hasta qué punto dichas informaciones abordaban la prevención (y desde qué perspectiva)- Tabla 1- (WHO, 2016). 
Tabla 1. Consejos de la ECHO para prevenir la obesidad infantil

\begin{tabular}{|c|c|c|c|c|c|}
\hline C1 & C2 & C3 & C4 & C6 & \\
\hline $\begin{array}{c}\text { Promover el } \\
\text { consumo de } \\
\text { alimentos } \\
\text { saludables }\end{array}$ & $\begin{array}{c}\text { Promover la } \\
\text { práctica de } \\
\text { actividad } \\
\text { física }\end{array}$ & $\begin{array}{c}\text { Cuidados } \\
\text { durante el } \\
\text { embarazo }\end{array}$ & $\begin{array}{c}\text { Dieta en la } \\
\text { primera } \\
\text { infancia y } \\
\text { actividad física }\end{array}$ & $\begin{array}{c}\text { Salud, } \\
\text { nutrición y } \\
\text { actividad } \\
\text { física en la } \\
\text { etapa escolar }\end{array}$ & $\begin{array}{c}\text { Control del } \\
\text { peso }\end{array}$ \\
\hline
\end{tabular}

Fuente: WHO, 2016.

\section{Resultados}

En total se encontraron 170 informaciones que trataban sobre la obesidad. Folha inserta $94(55,2 \%)$ y $O$ Globo incluye 76 (44,8\%). El promedio mensual en Folha fue de 15; el mes que más insertó fue marzo (20 piezas, el $21,3 \%$ de la informaciones). Por su parte, el promedio mensual de $O$ Globo fue 12 informaciones, con una mayor proporción en junio (20 piezas, el 26.3\% sobre el total) -Tabla 2-.

Tabla 2. Cantidad de informaciones acerca de la obesidad, por mes, en Folha de São Paulo y O Globo

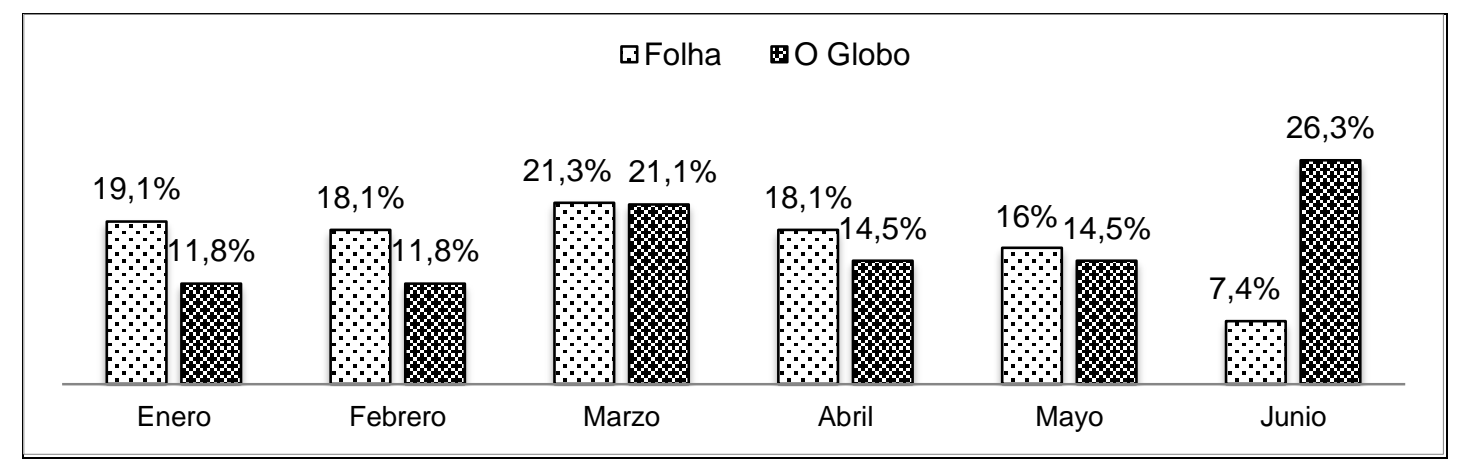

Fuente: elaboración propia

En cuanto a los días de la semana, en Folha las informaciones predominaron los martes (22,3\%), seguidos de los lunes (19,2\%), los domingos $(17 \%)$, los miércoles $(14,9 \%)$ y los sábados $(13,8 \%)$. Los jueves y los viernes contaron ambos con un 6,4\% de informaciones insertadas. En $O$ Globo se concentran más de la mitad de sus publicaciones los domingos (54\%), seguidos por los sábados (17.1\%), los jueves $(11.8 \%)$, los martes $(6,5 \%)$, los lunes y los miércoles (ambos con un 4\%) y, por último, los viernes (con el 2.6\%) - Tabla 3-. 
Tabla 3. Informaciones acerca de la obesidad en Folha de S. Paulo y $O$ Globo por días de la semana

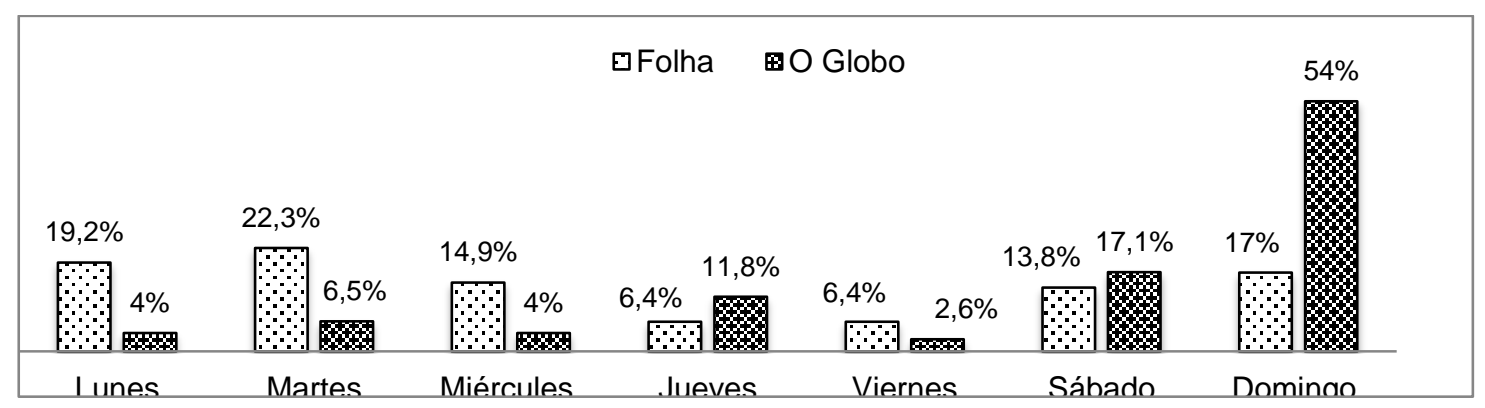

Fuente: elaboración propia

Cabe destacar que 21 piezas aparecían en las portadas de los periódicos (el 6,5\% sobre el total). En la Folha de S. Paulo en 12 casos $(12,7 \%$ sobre el total de piezas del diario; cinco fueron publicadas en el mes de marzo, el mes con más portadas, 41,7\%). Se insertaron en los suplementos Equilíbrio (50\% de las piezas), Saúde + Ciência (25\% de las piezas), Ilustrada (8,4\% de las piezas), Cotidiano (8,4\% de las piezas) y el sabatino dirigido a los niños "Folbinha" (con el 8,4\% de las piezas).

Tabla 4. Distribución mensual de las portadas de Folha de $S$. Paulo y de O Globo

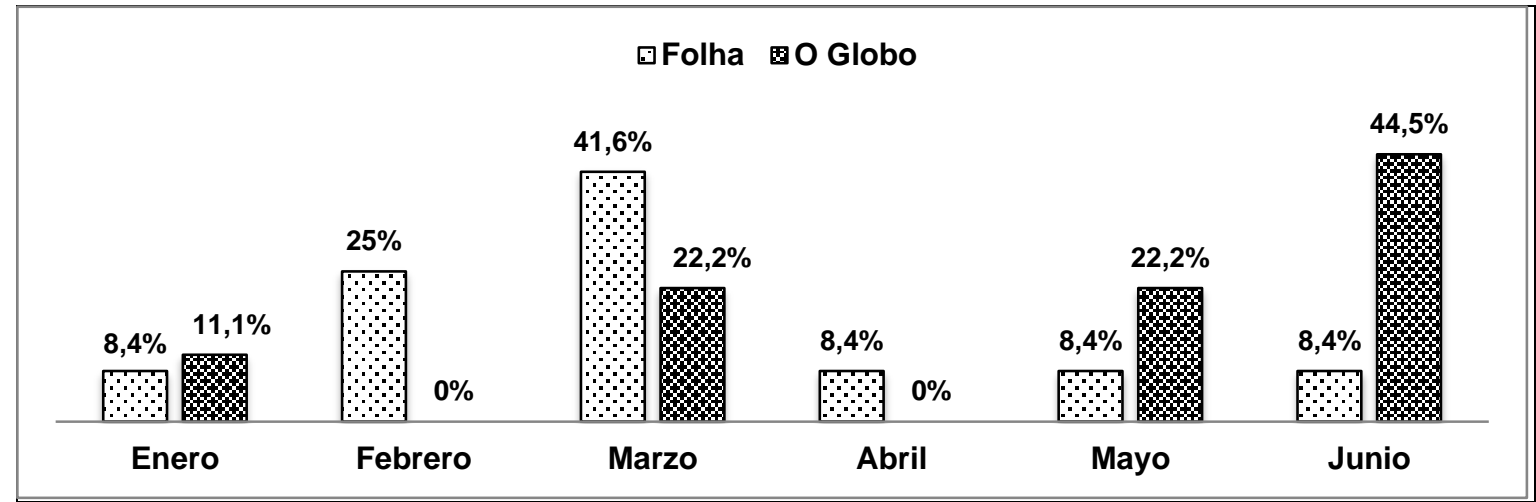

Fuente: elaboración propia

O Globo insertó informaciones sobre obesidad en 9 portadas $(11,8 \%$ sobre el total de piezas del diario, de las que 4 piezas fueron publicadas en el mes de junio, en este caso el mes con más portadas), 
incluidas en los suplementos Saúde y Ciências (ambos con un 44,4\% de las piezas) y el sabatino Formou (11,2\% de las piezas).

Por otro lado, si miramos el conjunto de las piezas examinadas en los dos diarios (recordemos que son 170), la mayor parte de las mismas se insertan en las secciones de Saúde + Ciência de la Folha $(38,3 \%)$ y Saúde $(32.9 \%)$ y Ciência $(11.8 \%)$ del O Globo. Al examinar por separado las secciones de los dos periódicos, se observa que en Folha la mayor parte de las piezas las encontramos en Saúde + Ciência (38.3\%), seguida por Ilustrada (10.6\%), Equilíbrio (9,6\%), Folha Corrida $(6,4 \%)$ y Cotidiano $(5,3 \%)$-Tabla 5 -.

Tabla 5. Informaciones acerca de la obesidad, por secciones, de Folha de S. Paulo

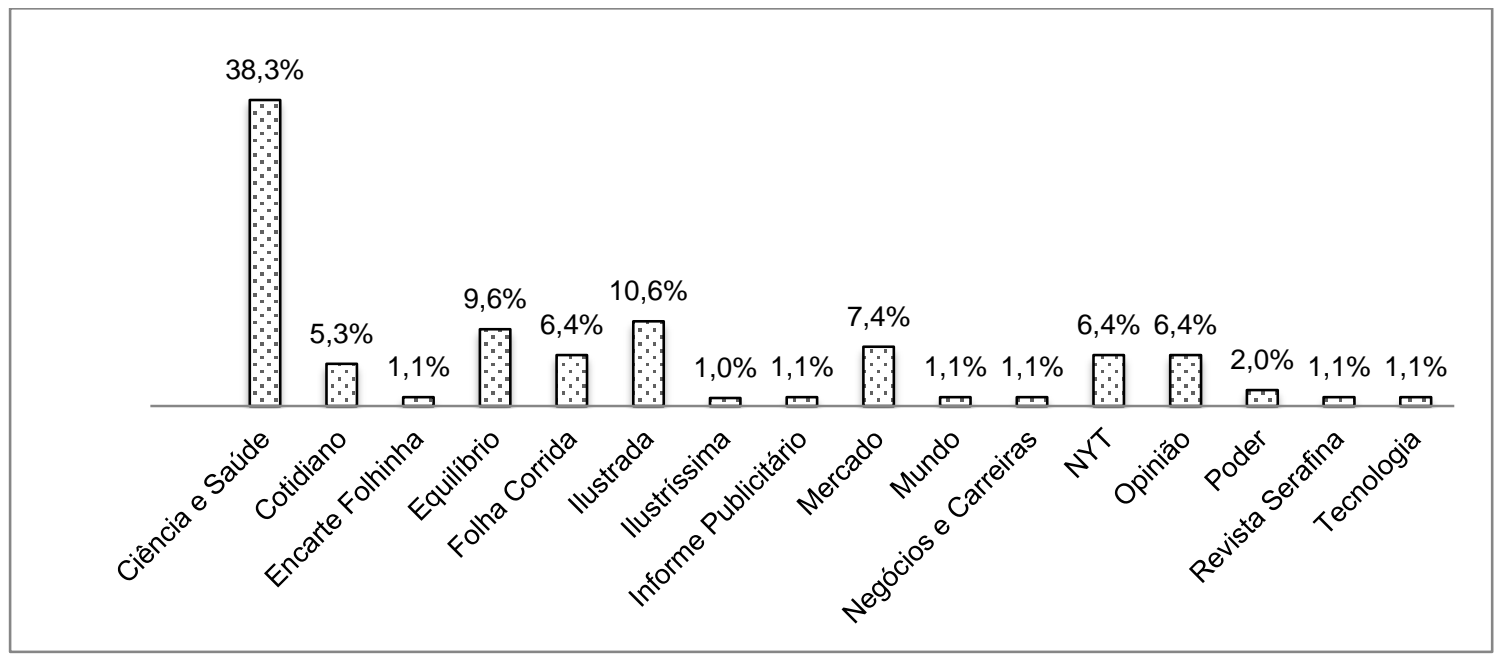

Fuente: elaboración propia

En relación a $O$ Globo, vemos que la mayor parte de los textos se incluyen en Saúde (32.9\%), seguida por Ciência (11.8\%), Rio (10.5\%) y el suplemento Jornal de Bairro (9.2\%) -Tabla 6-. 
Tabla 6. Informaciones acerca de la obesidad, por secciones, de $O$ Globo

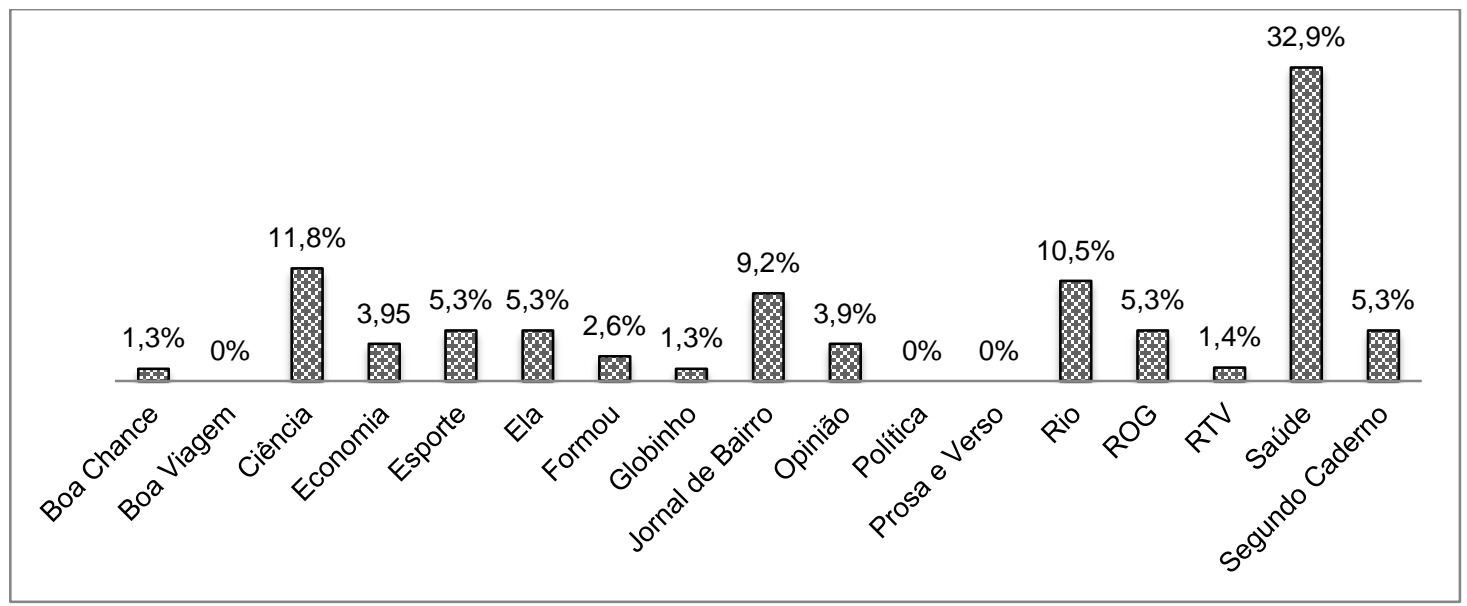

Fuente: elaboración propia

Si atendemos a los géneros periodísticos, vemos que en Folha prevalecen las noticias $(37,2 \%)$, seguidas por los reportajes $(23 \%)$ y breves $(15,9 \%)$. En $O$ Globo la mayoría de las informaciones son noticias $(56,5 \%)$, seguidas de reportajes $(10,5 \%)$ y breves $(13,1 \%)-$ Tabla 7-.

Tabla 7. El género más frecuente en los periódicos Folha de São Paulo y O Globo

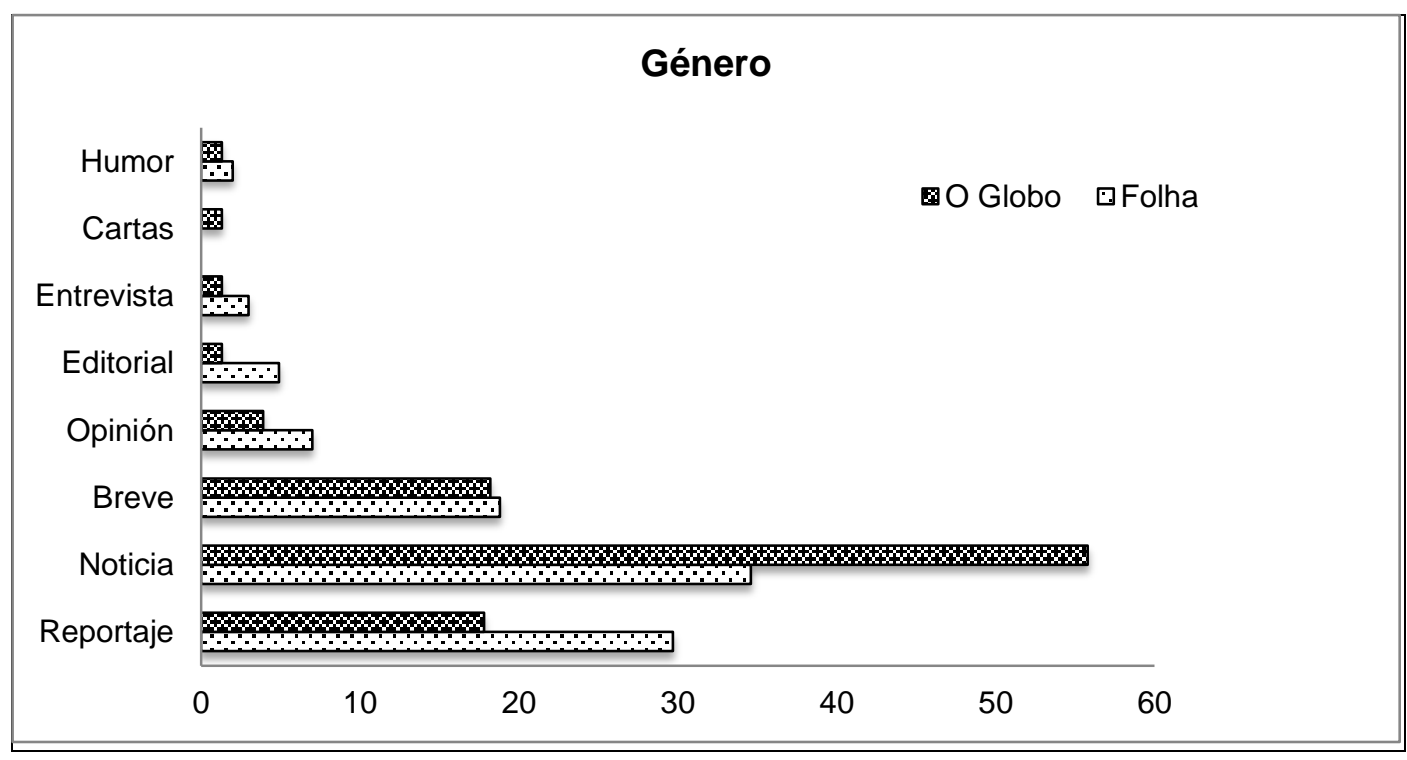

Fuente: elaboración propia 
En cuanto a las ilustraciones que inserta Folha, estas aparecen en el $76 \%$ de las informaciones analizadas y destacamos que el 28,7\% fueron infografías y el $42,4 \%$ fotografías. Por el contrario, en $O$ Globo están presentes en el $81,5 \%$ de las piezas examinadas del periódico y sobresale la inserción de fotografías (en el 79\% de los casos).

\section{Tabla 8. Ilustraciones más usadas por Folha de São Paulo y O Globo}

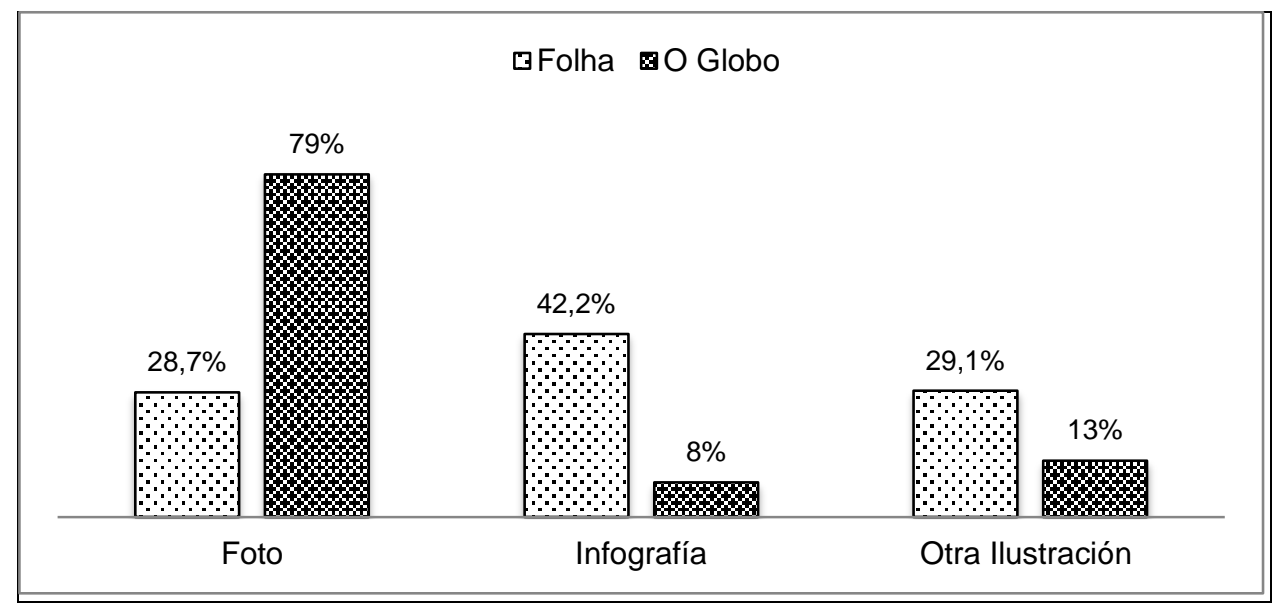

Fuente: elaboración propia

En relación a los sentidos subyacentes sobre la obesidad en los dos periódicos, podemos observar que de manera conjunta prevalece, en un $22 \%$ de los casos, los contenidos que se refieren a la importancia de combatir la obesidad, en un $18 \%$ a la necesidad de la prevención y reducción de riesgos y en un 16\% se trata la obesidad como a un mal. Es decir, en el $56 \%$ de los contenidos examinados se incidía, de alguna forma, en la prevención así como en las consecuencias y daños para la salud que conlleva el sobrepeso. En definitiva, la obesidad fue tratada, prioritariamente, como un factor de riesgo y como una dolencia a combatir.

No obstante, debemos constatar que los enfoques sobre la imagen corporal y la estética (11\%), el comportamiento del obeso $(10 \%)$ y las características epidemiológicas $(6 \%)$ también tienen relevancia en ambos periódicos -Gráfico 1-. 
Gráfico 1. Los sentidos acerca de la obesidad en Folha de $S$. Paulo y $O$ Globo.

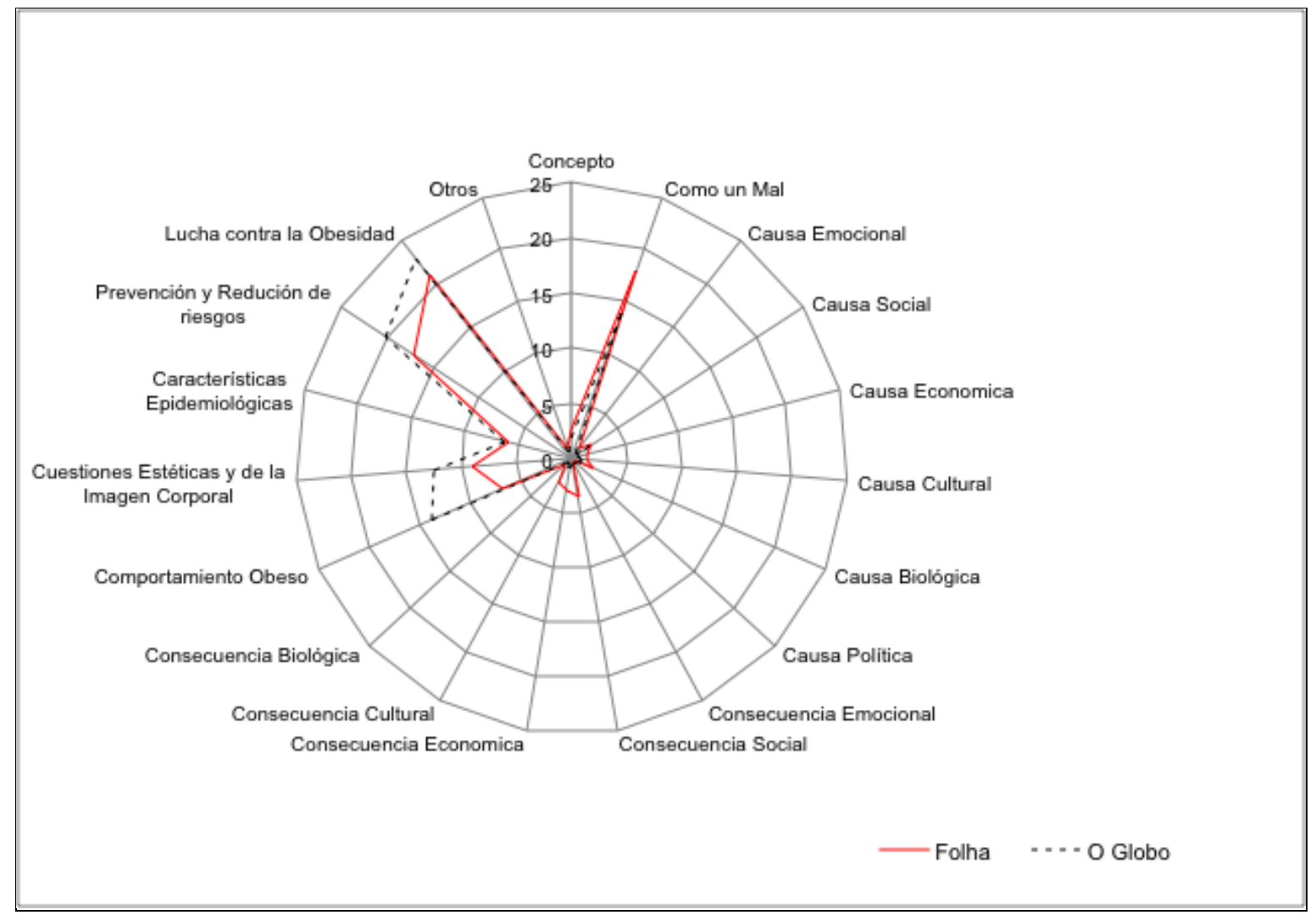

Fuente: elaboración propia

Por otro lado, al analizar las piezas, vemos que, sumando los resultados de ambos diarios, aparecen como fuentes o expertos 127 profesionales de la salud (en el 74,7\% de las piezas). En Folba, de los $71,2 \%$, profesionales de la salud identificados, la voz de los médicos (47,7\% de los casos) fue la de mayor recurrencia para legitimar el discurso informativo, seguida por la de los nutricionistas $(13,5 \%)$ y la de los investigadores (16,5\%). Mientras que en $O$ Globo aparecen en primer lugar los médicos $(36,6 \%)$, tras los cuales debemos tener en cuenta a los nutricionistas $(20 \%)$ y a los educadores físicos $(15 \%)$. 
Tabla 9. Profesionales de la salud presentes en los discursos acerca de la obesidad en Folha de São Paulo y O Globo

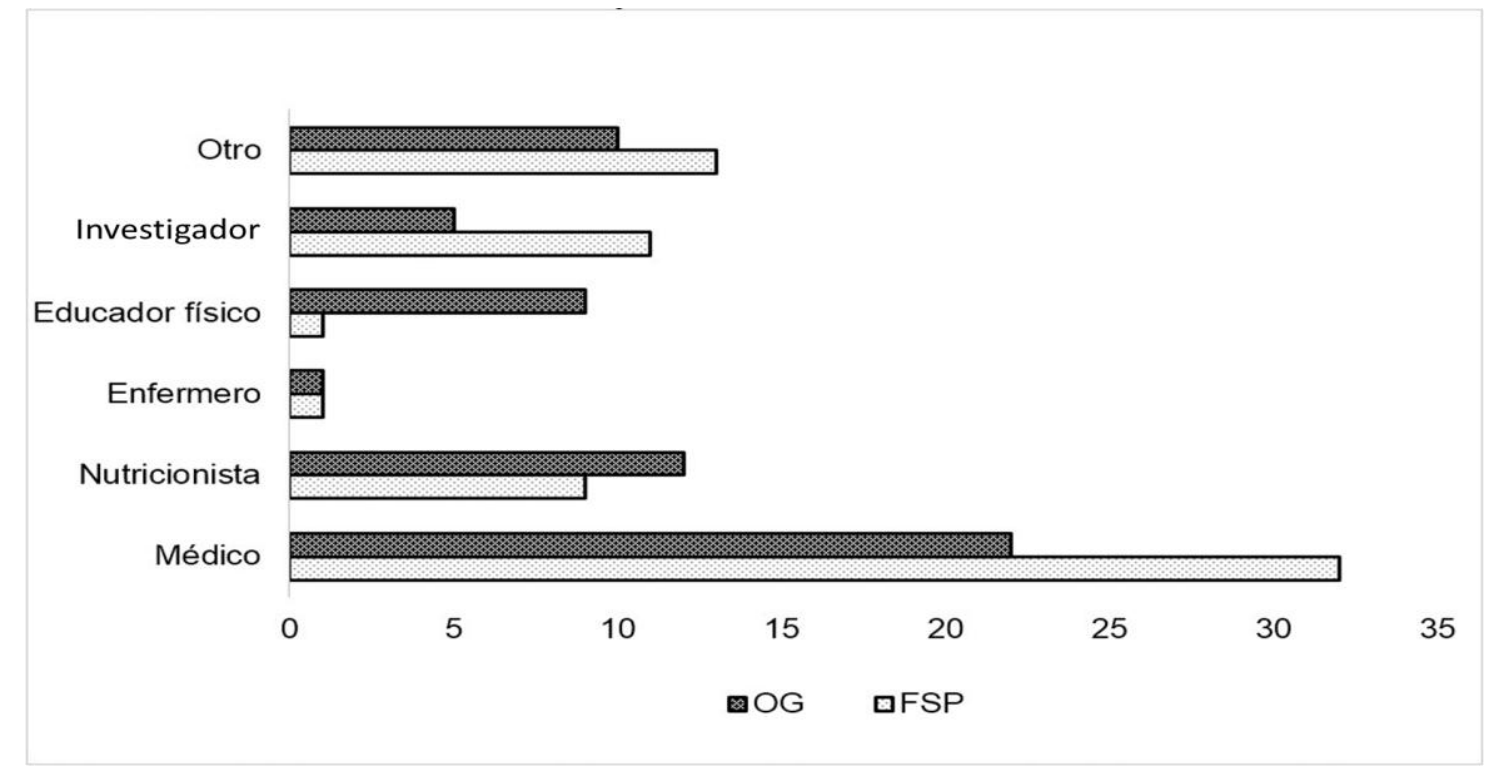

Fuente: elaboración propia

Si deparamos en la cantidad de informaciones que tratan sobre la obesidad infantil, de un total de 20 piezas publicados en los seis meses estudiados en los dos periódicos $(11,7 \%$ del total de las informaciones; en ambos diarios es febrero el mes con más inserciones $-O$ Globo solo incluye piezas en febrero y en junio; en Folha hay una mayor distribución a lo largo de los meses-). Folha incluyó un total de 14 piezas $(70 \%$ del total), distribuidas entre las secciones Saúde + Ciência (8 informaciones $-58 \%$ del total-), Mercado, Opinião, Ilustrada, Cotidiano Infome Publicitário y Suplemento Folhinha (1 información en cada una de ellas). Mientras que en $O$ Globo se isertaron 6 piezas $(30 \%$ del total de los diarios), que aparecen en las secciones Rio (3), Opinión, Ciencia y Globinho (1 en cada una de ellas).

En relación con las seis recomendaciones de la OMS para prevenir la obesidad infantil (ECHO, 2016), verificamos que los consejos referentes a la alimentación y a incentivar el ejercicio físico son los que prevalecen en las informaciones analizadas. 
Tabla 10. Consejos de la OMS para reducir la obesidad infantil presentes en los diarios analizados

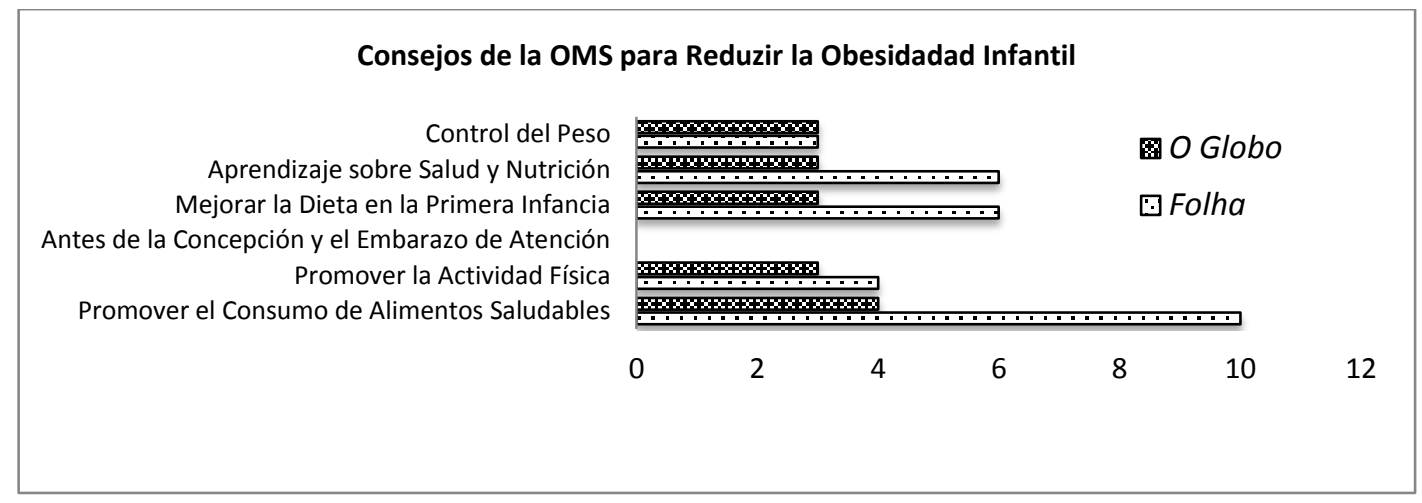

Fuente: elaboración propia

$\mathrm{Y}$, en cuanto a la frecuencia de las recomendaciones de la OMS presentes en las informaciones de los diarios analizados, vemos que ninguno de los periódicos abordan en una pieza las seis recomendaciones y que los 'cuidados durante el embarazo' no es tratado en ningún caso. Prevalecen, claramente, las piezas con algún consejo; de ellas, cinco, contemplan 5 recomendaciones.

Tabla 11. Frecuencia de las recomendaciones de la OMS (ECHO, 2016) presentes en los diarios analizados

\begin{tabular}{|c|c|c|c|c|c|c|c|}
\hline \multirow[t]{2}{*}{ Diarios } & \multicolumn{7}{|c|}{$\begin{array}{l}\text { Recomendaciones de la OMS (ECHO, 2016) presentes } \\
\text { en los dos diarios }\end{array}$} \\
\hline & Ninguna & Una & Dos & Tres & Cuatro & Cinco & Seis \\
\hline $\begin{array}{l}\text { Jornal Folha de } \\
\text { São Paulo } \\
(\mathrm{N}=14)\end{array}$ & 2 & 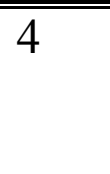 & 2 & 3 & 1 & 2 & 0 \\
\hline $\begin{array}{l}\text { Jornal O Globo } \\
(\mathrm{N}=6)\end{array}$ & 2 & 1 & 0 & 0 & 0 & 3 & 0 \\
\hline Total $(\mathrm{N}=20)$ & 4 & 5 & 2 & 3 & 1 & 5 & $\mathbf{0}$ \\
\hline
\end{tabular}

Fuente: elaboración propia

\section{Discusión}

Comparando los resultados entre los dos periódicos, se ve como Folha (55.2\%) inserta más contenidos sobre obesidad que $O$ Globo 
(44.8\%). Ahora bien, ni los diarios publican el mismo número de piezas, ni lo hacen, como veremos, de igual manera.

En el semestre que comprende este estudio se encontraron en total 170 informaciones. Si comparamos nuestros resultados con los de Figueiredo (2009), podemos aventurar que los medios tratan con más frecuencia el tema de la obesidad. Recordemos que Figueiredo (2009) estudió el diario Folha de S. Paulo, entre 1998 y 2008, detectando 305 artículos en 10 años; nosotros hemos encontrado 94 artículos en seis meses en el mismo diario. Consideramos que este incremento viene dado por un aumento en la preocupación de las personas por su salud, bienestar e imagen física, lo que comporta una mayor oferta informativa sobre el tema, que, a su vez, supone que los destinatarios no dejen de preocuparse por esta cuestión y demanden más información. Con otras palabras, estamos frente a un círculo virtuoso con retroalimentaciones de las agendas mediáticas y ciudadanas. Recordemos que este interés se sustenta en parte debido a que la obesidad es más que sobrepeso y medicina, pues también involucra aspectos relacionados con la alimentación, el comportamiento, la autoestima y la imagen corporal. En definitiva, lo que en nutrición se denomina un entorno obesogénico (Swinburn, Egger, Raza, 1999) ${ }^{33}$.

En relación a la frecuencia de publicaciones respecto a los días de la semana, Folha presenta una distribución más equilibrada. Por su parte, O Globo insertó la mayoría de las informaciones los domingos, lo que puede deberse a que ese día los lectores son más proclives a dedicar más tiempo a la lectura y a que esta no se ciña a los contenidos 'duros'; por otro lado, ese día, O Globo, prácticamente duplica su difusión. Además, hemos de considerar que existe el mito de que las dietas de restricción alimentaria deben comenzarse un lunes. En cuanto a la frecuencia de publicación si nos atenemos a los meses, se observa también un mayor equilibrio en la oferta informativa de Folha. O Globo, ofreció el $26.3 \%$ de los contenidos en junio -mes que antecede a las vacaciones-; o sea, las vacaciones marcan su agenda y,

\footnotetext{
${ }^{33}$ Para abundar en el tema desde la perspectiva de la producción de subjetividades nos parece imprescindible la lectura de "Consumo e risco: mídia e experiência do corpo na atualidade" (Vaz, 2006a).
} 
en correspondencia, los contenidos se elaboran no tanto con una finalidad salubrista como con una estética: construcción de una imagen corporal, construcción de un cuerpo ideal. En coherencia, la mayor parte de estos contenidos los encontramos en el suplemento Jornal do Bairro. Pensamos que esta oferta mediática de O Globo también guarda relación con la ciudad en la que se edita el diario, Rio de Janeiro, en la que se da un mayor culto al cuerpo. El mismo $O$ Globo señala que el 88\% de sus lectores tiene interés en informaciones sobre salud, bienestar y calidad de vida y el 63\% en cuestiones relacionadas con la belleza (O Globo, 2013).

"É comum a ideia de que a preocupação com a aparência e a juventude, que chega a ser uma obsessão nos dias de hoje, está cada vez mais disseminada em todas as classes, profissões e faixas etárias e que teria maior expressão aqui no Rio de Janeiro, em função de sua natureza e história" (Giacomini 2004: 8).

A su vez, O Globo concentra la mayor parte de las portadas el mes de junio, lo que vendría a subrayar lo que acabamos de exponer: el diario construye una relación entre obesidad e imagen corporal. Por contra, Folha nos ofrece portadas sobre obesidad a lo largo de todos los meses analizados y de una manera más equilibrada, y en coherencia con una mayor oferta informativa sobre la obesidad, el número de portadas que tratan sobre la misma $(57,2 \%)$ es mayor que la de $O$ Globo (43,8\%).

En cuanto a los géneros periodísticos, subrayemos que la mayoría de las informaciones en ambos periódicos son noticias y breves. Nuestros resultados coinciden con los que obtuviera Figueiredo (2009), que encontró que el 41\% de las piezas que trataban sobre la obesidad eran noticias. Estos datos nos muestran que no se profundiza en exceso en el tema y que, por tanto, es difícil encontrar piezas divulgativas y que abunden en la prevención de manera argumentativa. Eso sí, en Folha se profundiza más y se trata, por ende, los temas con más detalle (por ejemplo, hay más reportajes). En $O$ Globo el número de noticias y breves es superior, o sea, se profundiza, se argumenta menos. Cabe por tanto que, de nuevo, nos hagamos una pregunta en vOz alta: ¿se puede incidir en la prevención sin un 
argumentario que incite a la acción al destinatario? Parece claro que la finalidad última de $O$ Globo no es esta.

Cuando nos fijamos en las infografías, vemos que son más abundantes en Folha (o sea, se desea explicar más y mejor), mientras que en $O$ Globo prevalecen las fotografías (que suelen ser recursivas). Es evidente que Folha le da más importancia al qué y al cómo a la hora de tratar los temas de salud y, concretamente, el de la obesidad. Por otro lado, vemos que la mayor parte de las informaciones se publicaron en las secciones de salud y de ciencia. Si deparamos en Folha, constatamos que el 38,3\% de las piezas se insertan en Saúde + Ciência, que cubre informaciones sobre los últimos descubrimientos e investigaciones biomédicas en Brasil y en el mundo. Esta sección tiene 228.000 mil lectores, principalmente masculinos (59\%), entre 35 y 54 años (47\%) y clase B -clase media- (67\%) (Folha de S.Paulo, $2014 b)$. En este diario, la segunda sección con mayor porcentaje de publicaciones fue Ilustrada (10.6\%), en la que aparecen informaciones sobre cultura y entretenimiento, en muchas ocasiones de manera irreverente, y en las que tiene un espacio proprio la gastronomía. Según los datos de Folha (2014), el 65\% de los lectores pertenecen a la clase B, y prevalecen la audiencia femenina (51\%), con edades de 35 a 44 años $(33 \%)$ y es habitual que se aborde el tema de la obesidad informalmente. La tercera sección de Folba con un mayor número de piezas fue Equilíbrio (9,6\%), cuaderno de publicación semanal dedicado a la 'búsqueda' de la salud y de la calidad de vida y en el que se trata sobre técnicas y terapias para el bienestar, además de consejos sobre el cuidado del cuerpo y de la mente (Folha de S.Paulo, n.d.). Por un lado, vemos como las informaciones científicas las leen más los hombres y aquellas con otros registros no científicos, las mujeres, lo cual pone de relieve la necesidad de abundar en la alfabetización científica de las mujeres (y puede que denote su mayor preocupación por su imagen física). Por otro, como la obesidad es tratada desde perspectivas muy distintas, en las que el tema central no es la salud, aunque de una forma u otra (quizás inconscientemente) se incida en ella.

En O Globo, las secciones de Ciência y de Saúde insertaron la mayor proporción de las informaciones sobre la obesidad (44,7\%). Se trata 
de secciones en las que se tratan los contenidos biomédicos junto a temas sobre calidad de vida y bienestar, así como problemas que afectan el cuidado del cuerpo y de la mente (o sea, que de nuevo estamos a esa diferencia tan etérea, y nada casual, entre salud y bienestar). La tercera sección con más piezas sobre obesidad fue Río, en la que se abordaron, sobre todo, cuestiones relacionadas con el entretenimiento y la gastronomía. En resumen, podemos decir, sin miedo a equivocarnos, que en Folha se escribe más desde la perspectiva biomédica.

En relación a los sentidos que subyacen en las informaciones, destacamos que prevalece el de la obesidad como un riesgo y/o como un mal. Se muestran a los individuos como los responsables de su propia salud, culpabilizándolos por su condición nutricional y simplificando la obesidad como una mera cuestión de alimentación y de actividad física, sin tener en cuenta a los determinantes sociales y a la epigenética. Nos encontramos ante la que algunos epidemiólogos llaman 'salud persecutoria' ${ }^{34}$.

Lo que escribimos está en concordancia con lo que podemos leer en Vaz (2006a, 2006b, 2009) cuando nos habla del factor riesgo. En relación a la salud, se ha pasado a establecer una relación de causa efecto entre prácticas de vida cotidiana y futuras enfermedades (como en el caso la obesidad), a través de una relación probabilísticadeterminista. Este autor también hacen hincapié en que los medios de comunicación promueven una ideología individualista que se

\footnotetext{
34 “Es importante señalar la noción de responsabilidad que predomina en muchos discursos de salud (...). La idea de responsabilidad, en términos generales, se vincula a la noción de obligación de individuos y/o instituciones de responder a instancias de vigilancia y control por determinadas acciones, y relativas a objetos que, por medio de algún compromiso, están bajo la confianza de alguien. La responsabilidad consiste en una idea normativa que permite pactos esenciales para la organización de los colectivos humanos. Es inevitable la asociación de "responsabilidad" con "culpa", especialmente cuando las obligaciones no se cumplen. La retórica de la responsabilidad personal y de los cambios de conducta que predominan en la promoción de la salud ocurre es coetánea del ambiente individualista y moralista de las sociedades postmodernas y de las crisis fiscales y económicas de los sistemas de bienestar social de muchas naciones" (Castiel; Álvarez-Dardet, 2007: 464).
} 
ajusta a la idea de factor de riesgo, amplificándolo: se trata de una tendencia de sobrevaloración de las noticias sobre las enfermedades en las que el individuo puede actuar con medidas preventivas, centrándose en la genética y los hábitos, en detrimento, por ejemplo los factores ambientales. A la par, crece la tendencia a que las noticias sean un agente de medicalización, en las que nos hablan, sobre todo, de estilos de vida. Y la medicalización, a su vez, hace que proliferen los contenidos acerca de la salud (Vaz 2006a, 2006b, 2009).

Como sabemos, los medios construyen o transmiten ciertas representaciones en relación a la estética y la imagen corporal. Lo que puede verse con claridad en los dos periódicos que hemos analizado, aunque con mayor profusión en $O$ Globo. Sus informaciones (discursos) están repletas de dietas adelgazantes, de alimentos para adelgazar y rejuvenecer, de alimentos funcionales que ayudan a perder peso, de productos dietéticos, de tablas gimnásticas, etc. Sin olvidar el uso que hacen de los personajes famosos para mostrarnos o convencernos de estilos de vida concretos, presentándolos como aquellos a los que debemos imitar o a los que debemos parecernos (los llamados influencers, que amplifican dichas perspectivas en las redes sociales y que, en muchos casos, tienen intereses económicos en aquello que promueven).

En la actualidad hay una sobrevaloración y un culto a la delgadez, que se relaciona con la felicidad y con un estado de plena realización, a la par que la obesidad es una condición altamente estigmatizada y rechazada, lo que provoca el deseo de la búsqueda frenética del cuerpo ideal, sin que se midan esfuerzos y recursos para lograrlo. Los medios refuerzan los discursos del culto al cuerpo. El cuerpo perfecto es un cuerpo sano (joven, activo, hermoso y sin defectos) y la cuestión de la salud se convierte en una ideología individualista y optimista. Un discurso que se basa en un consumismo que favorece intereses comerciales de diferentes industrias de la belleza y del bienestar, en el que prevalece la vigilancia y el control corporal, la obligación de poseer un cuerpo según dictan e imponen tendencias y así poder ser exhibido públicamente, sometiéndose a la mirada del otro en un juego de espejos en los que se refleja la competitividad, el individualismo y la inseguridad permanente (Díaz Rojo et al, 2007). Y 
uno de los pilares sobre los que se construye el cuerpo sano como artefacto es la idea de culpa. Cada individuo se convierte en responsable de poseer el cuerpo ideal y, por tanto, culpable si no lo tiene, convirtiéndose, en este caso, en un enfermo para la mirada del otro (Díaz Rojo et al, 2007).

En el caso de las mujeres la presión para la sumisión y aceptación de estos discursos es aún mayor; los medios de comunicación como mínimo refuerzan dichos discursos. El rechazo de la sociedad al individuo obeso causa un número creciente de mujeres que pierden la salud buscando ser saludables (Fiates; Salles, 2001). Y debemos remarcar que, como hemos visto, la mayoría de estos discursos están legitimados por la voz de un experto en salud, en una gran proporción, por los propios médicos. Como nos muestra Figueiredo (2009), el médico, como fuente informativa, es uno de los pilares sobre los que se legitima el discurso sobre la medicalización de la obesidad. Fausto Neto (1999) mantiene que los contenidos periodísticos actúan como una especie de dictamen médico con la finalidad de mostrar diagnósticos y de indicar prescripciones. Así, el diario se convierte en el lugar en el que se realiza la tarea de exponer y explicar sobre la obesidad (su etiología y sus consecuencias para la salud), por lo que, en cierta forma, la presencia del especialista se hace imprescindible (transformándose en un 'lugar clínico').

Por último, debemos deparar en cómo tratan los periódicos estudiados la obesidad infantil. La conclusión principal es muy evidente: en ambos diarios se trata poco (en $O$ Globo prácticamente nada). Por contra, los estudios epidemiológicos muestran como la obesidad infantil está aumentando significativamente, y su prevalencia y su incidencia en esta etapa se manifestará posteriormente a lo largo de toda la vida. Según se desprende de la Pesquisa de Orçamento Familiar (POF, 2010) la prevalencia de sobrepeso y obesidad en niños brasileños de 5 a 9 años de edad fue de 33,5\% y 14,3\% respectivamente.

Por otro lado, en ambos diarios predominan las publicaciones en enero y febrero; este dato coincide con el que ya observaran Silveira y Pessoni (2005) cuando mapearon la presencia de la obesidad en los 
suplementos infantiles de los diarios de más circulación del Estado de São Paulo (Folha de S. Paulo y O Estado de S. Paulo). Enero y febrero son los meses en los que los niños están de vacaciones y se considera que es un buen momento para cambiar sus rutinas alimentarias. En coherencia con lo que decimos, estos dos meses no son, en ninguno de los diarios que estudiamos, los de más presencia del tema de la obesidad, sólo de la obesidad infantil.

En el periodo estudiado sólo hemos encontrado un caso de información dirigida específicamente a los niños y fue publicada en Folhinha (cuadernillo infantil de Folha) e incluyó varios enfoques sobre la obesidad: i] la toma de conciencia de los buenos hábitos como un factor preventivo para reducir la incidencia de la obesidad; II] alimentación saludable y buenos hábitos alimenticios; III] influencia del marketing en la alimentación infantil. Por contra y paradójicamente, se da poca importancia a los padres o a los tutores del niño.

Este resultado coincide con el del Silveira y Pessoni (2005), que estudiaron los diarios Folha de S. Paulo y Estado de S. Paulo (y de sus respectivos suplementos infantiles) para conocer las informaciones que insertaron sobre obesidad infantil y saber qué enfoques le habían dado. Hubo una total ausencia del tema en las 48 ediciones de cada uno de los suplementos infantiles de los dos periódicos. El editor de Estadinho (suplemento infantil del Estado de S. Paulo) lo justificaba afirmando que un tema como ese, de vital importancia, se insertaba en el periódico y las informaciones se dirigían a los padres de los niños. Ahora bien, en caso de que lo editores tuviesen razón (no interés y no comprensión por parte de los niños), también deberían considerar, como nos apuntan Tenorio y Cobayashi (2011), que los padres suelen tener una percepción distorsionada del peso corporal de sus hijos y cuando este es excesivo no suelen verlo como un potencial problema para la salud física y mental de sus hijos.

En relación con las recomendaciones de la OMS cabría decir que ambos diarios coinciden en tratar el tema incidiendo en la vida sana: nutrición saludable y ejercicio. Ahora bien, los datos y las conclusiones del estudio cuestionan cómo se trata, en qué cantidad, 
quiénes son los destinatarios y qué efectividad pueden tener estos discursos, por tanto, desde la perspectiva de la prevención.

\section{Conclusiones}

Esta investigación ha pretendido analizar la forma en que Folha de $S$. Paulo y O Globo, dos periódicos de amplia circulación y de referencia en Brasil, abordan el tema de la obesidad. Consideramos que podemos llegar a las siguientes conclusiones:

- Los diarios tratan de manera distinta e, incluso, confrontada el tema de la obesidad. Mientras Folha es más riguroso, divulgativo y se basa en evidencias científicas, el discurso de $O$ Globo es más popular e, incluso, populista. Mientras Folha incide más en la salud, O Globo lo hace en la imagen corporal.

- Señalamos que en Brasil hay un aumento en el número de noticias relacionadas con la obesidad a lo largo de los años, que coincide con el creciente interés de los medios de comunicación y de sus audiencias por la salud.

- Sin embargo, el aumento de la cantidad de informaciones no tiene por qué conllevar un aumento de su calidad. Se hacen necesarias nuevas investigaciones que incidan específicamente en la calidad de los contenidos a partir de criterios preestablecidos y contrastados.

- Se observa que ambos periódicos presentaron una mayor producción de contenidos como noticias, también Folha, que inserta más géneros interpretativos, lo cual implica que se profundiza poco en las informaciones y pone en cuestión una supuesta alfabetización en salud.

- En ambos periódicos, las secciones Ciência y Saúde son las que incluyen más piezas sobre la obesidad. Sin embargo, dichas informaciones a pesar de estar en las secciones comentadas no tienen por qué tratar temas sobre la salud; en numerosos casos lo hacen sobre la enfermedad.

- Los relatos periodísticos examinados en este estudio producen varios sentidos en relación a la obesidad. En general, ambos periódicos la consideran un riesgo. Sin embargo, para Folha este sentido es más importante que para $O$ Globo que, en muchas de sus 
narraciones, incide en la representación de un cuerpo ideal, que relaciona, con belleza, triunfo y bienestar, y al que se llega mediante las dietas y el ejercicio. Los profesionales de la salud legitiman este discurso, incluso los médicos. En este sentido, recordamos que las otras fuentes que más se citan son los nutricionistas y los educadores físicos (sobre todo en $O$ Globo).

- A pesar de que el tema de la obesidad infantil es de gran importancia, se trata por los dos diarios, aunque Folha dedica algo más de espacio.

- Los destinatarios de las informaciones sobre obesidad casi nunca son los propios niños, sino sus padres, que suelen tener una percepción distorsionada del peso de sus hijos y de las implicaciones que pueden tener en su salud.

- En relación con las recomendaciones de la OMS observamos que ningún diario hace mención a los cuidados que debe tener la gestante. La mayoría de las piezas contienen entre una y tres recomendaciones (Folha incluye más que O Globo) y prevalece la de la promoción de consumos de productos saludables.

Consideramos que esta investigación puede ser el inicio de otras que incidan en las representaciones que construyen los medios sobre la nutrición. Investigaciones que deberían contemplar más medios de comunicación y no solo diarios y en un espacio de tiempo mayor, para así obtener datos más representativos. Para terminar, debemos abordar en próximas investigaciones la calidad de los contenidos, lo que supone establecer previamente los criterios que nos permitan la evaluación de las informaciones objeto de estudio. Creemos que las evaluación de la calidad de las informaciones es el gran reto que tenemos por delante en el campo de la comunicación y la salud.

\section{Bibliografía}

Ades, L, Kerbauy, R R (2002). · Obesidade: realidades e indagações”. Psicologia USP, 13(1): 197-216.

Boero, N (2006). "All the News that's Fat to Print: The American 
"Obesity Epidemic" and the Media". Qualitative Sociology, 30(1): 4160 .

Bruno, F (1992). "Dietética: a Saúde a Mídia". ECO-Publicaşão de Pós-Graduação em Comunicação e Cultura, 5th ed.: 69-82

Castiel, L D; Álvarez-Dardet, C (2007) ."La salud persecutoria". Rev. Saúde Pública, 41(3):461-466.

Carvalho, M (2007). Obesidade e Pobreza na Imprensa: Epidemiologia de uma questão social. Rio de Janeiro : Universidade Federal do Rio d Janeiro.

Casino, G (2016). "Obesitat desenfocada", en El Diari de la Sanitat. Disponible en:

http://diarisanitat.cat/obesitat-desenfocada/ (fecha de consulta: 10/1/2016).

Díaz Rojo, J A, Morant, R, Westall Pixton, D (2007). El

culto a la saludy la belleza (la retorica del bienestar). Madrid. Biblioteca Nueva.

Fausto Neto, A (1999). Comunicacao e midia impressa. Rio de Janeiro: Hacker.

Ferreira, C M (2006). Avaliação Nutricional de Crianças em Escolas Públicas no Município de São Paulo - SP. Universidade de São Paulo.

Fiates, G, Salles, R (2001). "Fatores de risco para o desenvolvimento de distúrbios alimentares: um estudo em universitárias". Revista de Nutrição. Disponible en: http://agris.fao.org/agrissearch/search.do? recordID=XS2001W00 1 (fecha de consulta: 30/10/2011).

Figueiredo, S. de. (2009). Medicalização da obesidade: a epidemia em notícia. UNICAMP. Retrieved from http:/ / cutter.unicamp.br/document/?did $=40261$

Filho, M B, Rissin, A (2003). A transição nutricional no Brasil: 
tendências regionais e temporais. Cadernos de Saúde Pública, 19, S181S191. Disponible en:

http://doi.org/10.1590/S0102-311X2003000700019 (fecha de consulta: 21/9/2012).

Fiocruz (2013). Observatório Saúde na Mídia.Disponible en:

http://www.icict.fiocruz.br/content/observatoriosaude-na-midia-0 (fecha de consulta: 14/11/2013).

Folha de S.Paulo (2014a). "Maior jornal do Brasil, Folha é líder em diferentes plataformas". Disponible en: http://www1.folha.uol.com.br/poder/2014/03/1433100-folha-eo-maior-jornal-do-brasil-nas-diferentes-plataformas-apontaivc.shtml (fecha de consulta: 15/9/2015).

Folha de S.Paulo (2014b). "Folha mantém liderança de circulação no país, mostra IVC". Disponible en: http://www1.folha.uol.com.br/mercado/2014/06/1478097-folhamantem-lideranca-de-circulacao-no-pais-mostra-ivc.shtml (fecha de consulta: 15/9/2015).

Giacomini, S M (2004). "O corpo como cultura e a cultura do corpo: uma explosão de significados". Physis: Revista de Saúde Coletiva, 14(2): 406-416.

Giddens, A (1991). As consequências da modernidade. São Paulo: UNESP.

Infoglobo (2015). "INFOGLOBO". Disponible en: https://www.infoglobo.com.br/anuncie/ProdutosDetalhe.aspx?Id Produto $=91$ (fecha de consulta: 15/9/2015).

Miqueleiz, E et al (2015). "Hábitos de vida y estilos de cuidado de los progenitores relacionados con la obesidad infantil. Comparación de una población española con poblaciones de países del Norte de Europa: ENERGY-Project". Revista Española de Salud Pública, vol.89 n.5 Disponible en: http://www.scielosp.org/scielo.php?script $=$ sci arttext\&pid=S1135 -57272015000500009 (fecha de consulta: 20/11/2015).

Mouillaud, M (2002). O jornal: da forma ao sentido. Brasília: 
Universidade de Brasília.

O Globo (2013). "Perfil dos Leitores". Disponible en:

https://www.infoglobo.com.br/Anuncie/ProdutosDetalhe.aspx?Id Produto $=91$ (fecha de consulta: 15/9/2015).

POF. (2010). Pesquisa de orçamentos familiares 2008-2009: antropometria e estado nutricional de crianças, adolescentes e adultos no Brasil. Rio de Janeiro: IBGE.

Santos, K M O, Filho, A de A B (2002). "Fontes de informação sobre nutrição e saúde utilizadas por estudantes de uma universidade privada de São Paulo". Revista de Nutrição, 15(2): 201210.

Silveira, S, Pessoni, A (2005). "Obesidade como pauta nos suplementos jornalísticos infantis: presença subliminar ou ausência premeditada?". ComSaúde.

Disponible en: http://goo.gl/5Dsdh (fecha de consulta: 10/9/2015).

Swinburn, B, Egger, G, Raza, F (1999). "Dissecting obesogenic environments: the development and application of a framework for identifying and prioritizing environmental interventions for obesity". Preventive Medicine, 29(6 Pt 1): 563-70.

Tenorio, A, Cobayashi, F (2011). "Obesidade infantil na percepção dos pais". Rev.Paul. Pediatr, 29(4): 634-639.

Tyrell, J. et al (2016). "Height, body mass index, and socioeconomic status:

mendelian randomisation study in UK Biobank". BMJ, 352.

Disponible en: http://www.bmj.com/content/352/bmj.i582 (fecha de consulta 2/4/2016).

Vaz, P (2006a). " Consumo e risco: mídia e experiência do corpo na atualidade". Comunicação, Mídia e Consumo, vol 3 (6): 37-61.

Vaz, P (2006b). "As narrativas midiáticas sobre cuidados com saúde ea construção da subjetividade contemporânea". Logos, 85-95. 
Disponible en:

http://www.logos.uerj.br/PDFS/25/08_Paulo_Vaz.pdf (fecha de consulta: 2/9/2014).

Vaz, P. (2009). "Mídia, moralidade e fatores de risco em saúde".

Cadernos de Saúde Pública, 25(3). Disponible en:

http://doi.org/10.1590/S0102-311X2009000300001 (fecha de consulta: $2 / 9 / 2014)$.

Veron, E (2004). As midias na recepcao: os desafios da complexidade. São Leopoldo: Unisinos.

Vigitel. (2009). Vigitel Brasil 2008: vigilância de fatores de risco e proteção para doenças crônicas por inquérito telefônico. Brasília: Ministério da Saúde; Secretaria de Vigilância em Saúde; Secretaria de Gestão Estratégica e Participativa.

Vigitel. (2015). Estimativas de indicadores para 2014. In Secretaria de Vigilância em Saúde \& Departamento de Vigilância de Doenças Agravos não Transmissíveis e Promoção da Saúde (Eds.), Vigitel Brasil 2014 : vigilância de fatores de risco e proteção para doenças crônicas por inquérito telefônico. Brasília: Editora MS.

WHO (2016). Ending Childhood Obesity. Geneva: WHO.

\section{$\rightarrow$ Agradecimientos, Colaboraciones y Menciones Especiales:}

A CAPES (Proc. $n^{\circ}$ 99999.010643/2014-01), por su apoyo para el desarrollo de esta investigación.

También a Helena Lúcia Menezes Ferreira, Wisley Velasco por sus colaboraciones y, muy especialmente a Valdir de Castro Oliveira, por su dirección y sin el que no hubiera sido posible llevar a cabo esta investigación. 


\title{
Los medios de comunicación y la cobertura de medicamentos
}

\author{
Daniel Catalán Matamoros \\ Universidad Carlos III de Madrid (UC3m) \\ Carmen Peñafiel \\ Universidad del País Vasco \\ Euskal Herriko Unibertsitatea (UPV/EHU)
}

\section{Resumen}

Introducción: Un mal consumo de medicamentos ocasiona graves problemas de salud. Los medios juegan un papel muy importante en informar a la población y son considerados una herramienta esencial para un consumo correcto y eficaz de medicamentos.

Objetivos. Analizar los estudios sobre la cobertura de medicamentos por los medios de comunicación. Metodología. Se ha desarrollado una revisión de literatura en las bases de datos Pubmed y Google Académico desde 2012 a 2017. Resultados. 23 publicaciones fueron seleccionadas agrupándose en las siguientes categorías: a) publicidad, b) redes sociales e Internet, y c) otros medios. Conclusiones. Los medios de comunicación pueden fomentar el uso prudente de medicamentos, pero también pueden perjudicar la salud a través de publicaciones sesgadas o incluso mediante la mera publicación.

Palabras clave: medicamentos; medios de comunicación; televisión; prensa; radio; salud pública. 


\section{Introducción}

Muchos han dicho de la alquimia, que es para la fabricación de oro y plata. Para mí, ese no es el objetivo, sino considerar sólo la virtud y el poder puede estar en medicamentos (Paracelsus 1493 - 1541)

L OS MEDICAMENTOS constituyen un elemento esencial en la salud de los ciudadanos y gracias a ellos la sanidad actual tiene la capacidad de interrumpir o modificar el curso natural de las enfermedades, de prevenirlas o, en cualquier caso, de hacer su peso más liviano. En efecto, los medicamentos han contribuido de forma notable a mejorar la salud de la población; enfermedades que hasta hace poco eran intratables hoy tienen tratamiento, la mortalidad de personas con cáncer o con infarto de miocardio se ha reducido gracias a los medicamentos, las vacunas han hecho disminuir la incidencia de enfermedades infantiles y la mortalidad ligada a ellas, etc. Por lo que no cabe duda, que los medicamentos desempeñan un papel muy importante en la sociedad y en la salud pública.

Escribir este capítulo sobre medicamentos únicamente haciendo referencia a sus aspectos positivos sería imparcial. Por ello, es importante también abordar las consecuencias negativas que todo medicamento puede producir en el cuerpo humano. De hecho, todo medicamento produce que el organismo funcione de una manera diferente y esto conlleva efectos adversos. Es decir, todos los medicamentos producen tanto beneficios como efectos secundarios, por ello, la estrategia de la farmacoterapia persigue conseguir el máximo beneficio con el menor efecto adverso para cada paciente.

\subsection{El consumo de medicamentos en España}

En España, el 88,9\% de la población mayor de 65 años consume a diario medicamentos, porcentaje que se eleva al 93\% en el caso de los que ya han cumplido 75 años (Penny Montenegro y Melgar Cuellar, 2012). Por otro lado, el consumo de medicamentos antidepresivos en España ha pasado de 26,5 DHD en el año 2000 a 79,5 DHD en el año 2013, representando un incremento de 200\% (AEMPS, 2015). Otros estudios sitúan a España como uno de los países con mayor 
consumo de medicamentos, como por ejemplo el realizado por la farmaindustria británica (O’Neill y Sussex, 2015), en el que España es el segundo mayor consumidor de medicamentos, superando a países como Estados Unidos y Reino Unido, estando únicamente precedida por Francia. Organizaciones como la OCU han alertado del consumo excesivo de medicamentos en España haciendo referencia que la "medicalización de la vida" un gasto sanitario innecesario y la causa de que mueran casi 200.000 personas al año en la UE (OCU, 2014).

Además del consumo excesivo de medicamentos, hay otros problemas que merecen una mención especial debido a su gran auge. Nos referimos a los casos de compraventa ilegal de medicamentos por Internet (Catalán-Matamoros et al, 2016) así como al uso indebido de medicamentos como los antibióticos (Earnshaw et al, 2014). Ambas cuestiones son consideradas como graves problemas de salud pública a los que se enfrenta la sociedad actual.

En cuanto a la compraventa ilegal de medicamentos por Internet, nos referimos a la comercialización de fármacos fuera de la cadena de distribución legal y avalada por las autoridades sanitarias. Este tipo de negocio ha sido impulsado debido al auge de las nuevas tecnologías de la información y la comunicación, en el que Internet se ha convertido en un importante canal de acceso a estos productos por parte de los ciudadanos. Este medio de comunicación ha originado una nueva forma para adquirir productos sanitarios mediante la rápida proliferación de sitios web dedicados a la venta de productos farmacéuticos. De hecho, un estudio reflejó que el medio más usado para la venta ilegal de medicamentos era Internet siendo el medio de contacto con los clientes en un 45\% de los casos (Jordá Sanz y Giménez-Salinas Framis, 2015). En España, la Agencia Española de Medicamentos y Productos Sanitarios (AEMPS) desarrolla diversas actividades para reducir este problema. En este contexto, durante el periodo 2012-2015 se realizaron más de 1.100 investigaciones de páginas web de venta ilegal de medicamentos en España, habiéndose iniciado 340 procedimientos administrativos (AEMPS, 2016). Sin embargo, la investigación, detección y cierre de páginas web resulta ser una estrategia costosa. Además, estas actuaciones producen un bajo impacto debido a que el proceso para cerrar una página web, 
además de ser largo y complejo, es en muchas ocasiones ineficaz, debido a que al día siguiente del cierre, se puede abrir la misma página web con un dominio diferente. Por ello, la solución más eficaz ante este problema de salud pública consiste en concienciar a los consumidores sobre los riesgos asociados al consumo de medicamentos ilegales y falsificados (Catalán-Matamoros et al, 2016). En este sentido, durante los años 2013-2016, España ha participado en un proyecto europeo en el que se han desarrollado campañas de comunicación (Fakeshare, 2017), así como otras actuaciones para conseguir un aumento de la concienciación ciudadana y la disminución de esta práctica tan peligrosa para la salud, tales como la creación del logotipo común europeo y la aplicación web DISTAFARMA. Debido a la complejidad y magnitud de este tema, y considerando que, en este caso, el medio de comunicación Internet es usado con fines únicamente dirigidos a la compraventa online de medicamentos, no se ha incluido su análisis en este capítulo. En las referencias anteriormente indicadas, se mencionan estudios que han evaluado la calidad de medicamentos adquiridos en farmacias ilegales por Internet. En estos estudios se muestra cómo la calidad de los fármacos varía, siendo en ocasiones peligrosa para la salud del paciente.

Como se mencionó anteriormente, otro tema de actualidad sobre los medicamentos es el incremento de las resistencias microbianas que se están presentando ante numerosos antibióticos. Los antibióticos son un grupo de medicamentos cuya utilización en medicina humana ha supuesto en el último siglo un progreso extraordinario para la calidad de vida de las personas. Su uso requiere que sean utilizados adecuadamente, en las circunstancias y con las condiciones específicas necesarias para cada paciente, con el fin de obtener el máximo nivel de eficacia con el menor riesgo. Sin embargo, no siempre son administrados de una manera prudente tanto por parte de los profesionales sanitarios como por los pacientes y, por ello, los antibióticos plantean el problema de las resistencias microbianas. Esto hace que, cada vez más, los antibióticos sean más ineficaces ante gérmenes cada vez más resistentes y por lo tanto más peligrosos para la salud humana (Portalfarma, 2016). En muchos lugares hay un abuso y mal uso de los antibióticos tanto en las personas como en los 
animales, y es frecuente que se administren sin supervisión de un profesional. Como ejemplos de uso incorrecto se pueden citar su administración para tratar infecciones víricas, como los resfriados o la gripe, o su uso como promotores del crecimiento del ganado y los peces (OMS, 2016). Tal y como indica el Centro Europeo de Prevención y Control de Enfermedades (ECDC, según sus siglas en inglés), una comunicación eficaz con los pacientes es la clave para abordar este problema creciente (ECDC, 2016). En este sentido, tal y como indica la Estrategia Mundial de la OMS para contener las resistencias a los antimicrobianos (OMS, 2001), los grupos a los que se debe dirigir las campañas de comunicación son los trabajadores de la salud que recetan antimicrobianos y los que los dispensan, veterinarios, consumidores, instancias normativas de hospitales y de los sectores de salud pública y agricultura, asociaciones profesionales e industria farmacéutica.

Para poder abordar estos y otros asuntos sobre la concienciación y el buen uso de los medicamentos, el uso de los medios de comunicación resultan ser una de las estrategias más eficaces. De hecho, los medios constituyen una herramienta muy potente en salud por estar al alcance de gran parte de la población y ofrecer muchas posibilidades para informar y educar sobre temas tan importantes como un uso prudente de los medicamentos. Los periódicos ofertan secciones de salud algunos días a la semana o de forma mensual, existen programas específicos en buena parte de las emisoras de radio y televisión, las revistas de información general, la prensa rosa y las publicaciones de divulgación científica también incorporan temas de salud dirigidos a los ciudadanos (Aranceta-Bartrina, 2016). Pero no solo para los ciudadanos, sino que para los médicos los medios también son a menudo el primer punto de acceso a la información sobre los resultados de la investigación con medicamentos y las novedades terapéuticas, aunque no tanto en su especialidad sino en el conjunto de la medicina (Casino, 2007).

Los medios de comunicación también son un instrumento esencial en la publicidad de productos de salud. La industria farmacéutica desarrolla campañas publicitarias en los medios para dar a conocer sus productos a la sociedad y así estimular sus ventas. En este caso, la 
publicidad de medicamentos sujetos a prescripción médica está restringida por la legislación vigente en España. De hecho, la publicidad de fármacos que requieren de receta es una actividad permitida solo en EE.UU. y Nueva. No obstante, la ausencia de fronteras en Internet provoca que la publicidad pueda llegar a cualquier rincón, lo que hace necesario una legislación global. Sin embargo, los productos de venta libre si pueden ser publicitados a través de los medios de comunicación, apareciendo fundamentalmente en anuncios de televisión y revistas, aunque también tienen algunas limitaciones legales (Galmés-Cerezo y Arjona-Martín, 2014). Algunos autores defienden que el aumento de conocimiento de fármacos por los consumidores es un efecto de las campañas de publicidad de la industria farmacéutica (Applbaum, 2006), estando este fenómeno relacionado con una cierta tendencia a transformar los medicamentos en objetos de consumo y a convertir al paciente en consumidor, con el consiguiente deterioro de la figura del médico (Casino, 2007).

Según un estudio previo (Francescutti, 2012) que analizó los temas de salud más frecuentes en los informativos de televisión entre 2007 y 2008, ordenados por número de apariciones fueron: patologías, política sanitaria española, innovaciones terapéuticas, gestión del sistema sanitario español, hábitos sanitarios de la población, política sanitaria extranjera, curiosidades médicas, medicamentos y acciones solidarias. Como se puede observar, los medicamentos ocuparon el octavo lugar, con el 5,4\% del total de contenidos sobre salud. Estos espacios presentaban noticias sobre los precios, nuevas patentes y efectos secundarios. Se excluyeron los avances farmacológicos que figuraban en el capítulo de innovaciones terapéuticas. En este sentido, y como afirma Casino (2007), la presencia de los medicamentos en los medios de comunicación españoles es relevante y notoria, y el volumen de información sobre fármacos ha ido creciendo en los últimos 25 años. Las referencias a fármacos, e incluso la mención de sus nombres comerciales, es habitual, y son frecuentes los artículos periodísticos que abordan con detalle las novedades terapéuticas así como los beneficios y riesgos de los tratamientos. 
No cabe duda que los medios son cruciales en la difusión de la información sobre medicamentos. Por lo tanto, el objetivo de este capítulo consiste en analizar los estudios sobre las apariciones en los medios de comunicación de los medicamentos para recopilar y sintetizar los aspectos más relevantes sobre este binomio tan importante en nuestra sociedad actual.

\section{Resultados de la muestra}

Se ha desarrollado una revisión de literatura en las bases de datos Google Académico y Pubmed con el límite temporal de cinco años (enero 2012 - enero 2017). Además se revisaron los listados de referencias de los artículos seleccionados para identificar algún otro estudio. Los criterios de inclusión han sido artículos en lengua inglesa o española, que analicen la cobertura de los medicamentos por los medios de comunicación incluyéndose tanto televisión, prensa, radio, Internet y redes sociales. Para el análisis, se incluyeron los artículos que seguían una metodología de investigación cualitativa o cuantitativa. Las revisiones y los artículos de opinión no fueron incluidos en el análisis, y como se mencionó en la introducción, los artículos que investigaban el uso de Internet para la compraventa de medicamentos tampoco. En la Tabla 1 se puede consultar la estrategia de búsqueda, las palabras clave así como los operadores booleanos utilizados en cada una de las bases de datos.

Tabla 1. Estrategias de búsqueda en Google Académico y Pubmed

\begin{tabular}{|l|c|}
\hline Google académico & $\mathbf{3 0 9}$ \\
\hline Búsqueda en español & 21 \\
\hline $\begin{array}{l}\text { ES: allintitle: medicamentos medios OR comunicación OR televisión OR radio OR internet } \\
\text { OR prensa OR revistas OR periódicos OR twitter OR facebook OR Instagram }\end{array}$ & \\
\hline Búsqueda en inglés & 288 \\
\hline $\begin{array}{l}\text { EN: allintitle: medicines OR drugs media OR communication OR television OR radio OR } \\
\text { internet OR press OR magazines OR newspapers OR twitter OR facebook OR Instagram }\end{array}$ & $\mathbf{3 4 1}$ \\
\hline Pubmed & $\begin{array}{l}\text { ((((medicines[Title]) OR drugs[Title])) AND ((((((((((media) OR communication[Title]) OR } \\
\text { television[Title]) OR radio[Title]) OR internet[Title]) OR press[Title]) OR magazines[Title]) } \\
\text { OR newspapers[Title]) OR twitter[Title]) OR facebook[Title]) OR instagram[Title])) AND } \\
\text { "last 5 years"[PDat]) }\end{array}$ \\
\hline Total & $\mathbf{6 5 0}$ \\
\hline
\end{tabular}

Fuente: elaboración propia 
La búsqueda se limitó a que aparecieran las palabras clave en el título para obtener artículos que realmente tratasen sobre el objeto de estudio y no aquellos que lo mencionaran de forma anecdótica. Una vez obtenidos los artículos, se revisaron los títulos y se eliminaron los duplicados y los artículos que a juicio de los investigadores no reunían los criterios de inclusión. Posteriormente, los artículos que permanecían fueron revisados de forma más exhaustiva mediante el resumen. Finalmente, los artículos seleccionados fueron incluidos en el análisis que se presenta en la sección de resultados.

\section{Resultados de la muestra}

Los criterios de búsqueda ofrecieron 651 publicaciones las cuales fueron analizadas como se muestra en el diagrama de flujo que se presenta en la tabla 2. Finalmente 23 artículos fueron seleccionados para el análisis.

\section{Tabla 2. Diagrama de flujo}

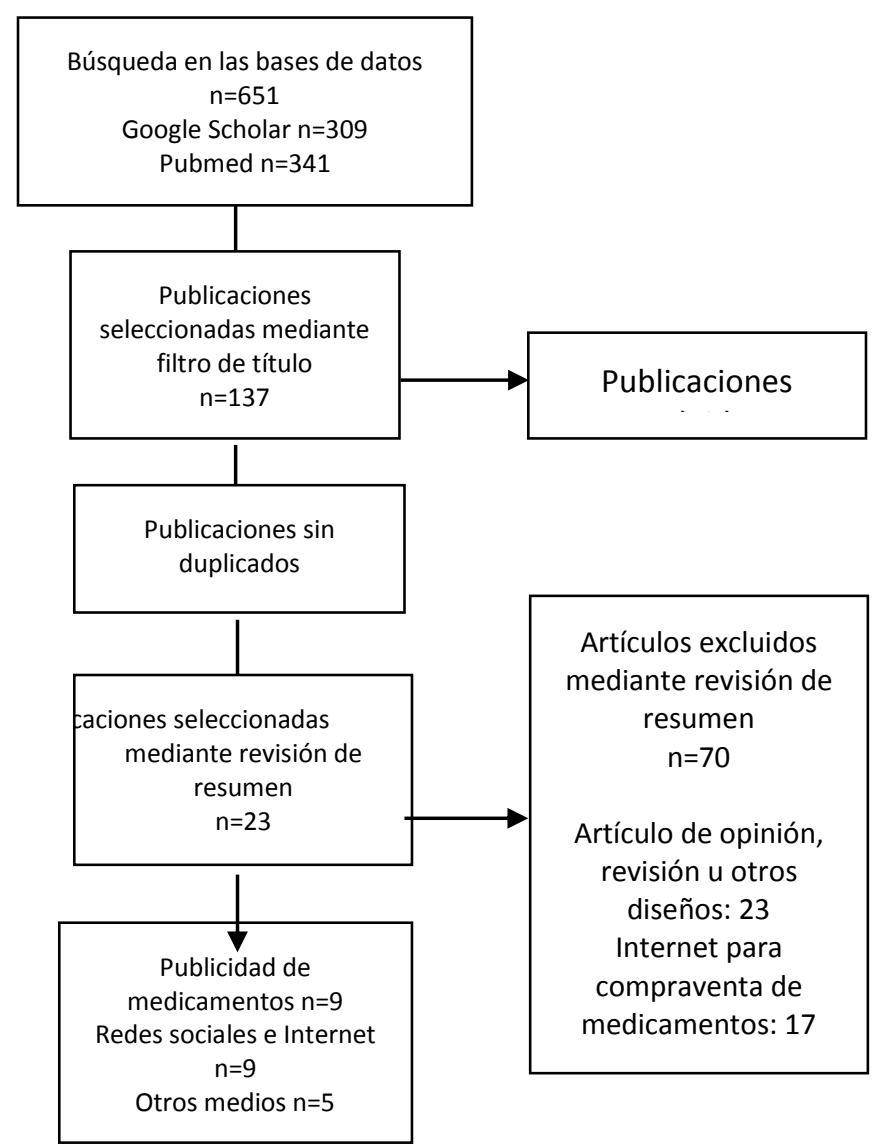

Fuente: Elaboración propia 
Los artículos seleccionados se muestran en la tabla 3 y han sido agrupados en las siguientes categorías:

- Publicidad de medicamentos ( $n=9)$. Esta categoría engloba aquellos artículos que analizan las campañas de publicidad realizada en los medios de comunicación mediante las empresas farmacéuticas.

- Medicamentos en las redes sociales e Internet (n=9). Esta categoría incluye los estudios que han analizado la presencia de medicamentos, sus efectos adversos, u otras características en las redes sociales.

- Medicamentos en otros medios de comunicación (n=5). Esta categoría incluye los estudios que han analizado los contenidos publicados sobre medicamentos en medios tradicionales, tales como prensa escrita o televisión.

Tabla 3. Artículos seleccionados bajo cada categoría

\begin{tabular}{|l|l|}
\hline Publicidad & $\begin{array}{l}\text { Ahmad, Patel, Parimalakrishnan, Mohanta y Nagappa, } \\
\text { 2015; Bhangale, 2013; Daubresse } \text { et al, 2015; Diez y } \\
\text { Hidalgo, 2012; Díez Díaz, 2012; Adrienne E Faerber, } \\
\text { 2012; Adrienne E Faerber y Kreling, 2014; A E } \\
\text { Faerber y Kreling, 2012; Roblek, 2015 }\end{array}$ \\
\hline $\begin{array}{l}\text { Redes sociales e } \\
\text { Internet }\end{array}$ & $\begin{array}{l}\text { Benetoli, Chen, Spagnardi, Beer y Aslani, 2015; } \\
\text { Buechner, 2013; Coloma, Becker, Sturkenboom, van } \\
\text { Mulligen y Kors, 2015; Dunne et al, 2013; Dunne et al., } \\
\text { 2013; Gesualdo } \text { et al, 2015; Lombardo y Cosentino, } \\
\text { 2016; Nörby, Källén, Shemeikka, Korkmaz y } \\
\text { Winbladh, 2015; Tyrawski y DeAndrea, 2015 }\end{array}$ \\
\hline $\begin{array}{l}\text { Otros medios de de } \\
\text { comunicación }\end{array}$ & $\begin{array}{l}\text { Buer, 2015; Gyasi, 2013; Kruger, Niederdeppe, Byrne, } \\
\text { y Avery, 2015; Lu et al, 2014; Robertson, Walkom, } \\
\text { Bevan y Newby, 2013 }\end{array}$ \\
\hline
\end{tabular}

Fuente: elaboración propia 


\section{Análisis y discusión}

Este capítulo ha recopilado y resume la evidencia existente sobre los medicamentos en los medios de comunicación. Las categorías en las que se han agrupado las publicaciones son tres: la publicidad de medicamentos, la presencia de contenidos sobre medicamentos en redes sociales e Internet, y finalmente los contenidos publicados en otros medios de comunicación. A continuación, se va a desarrollar la discusión atendiendo a estas tres categorías.

\section{A.- La publicidad de medicamentos}

La presencia de contenidos sobre medicamentos en los medios de comunicación con fines publicitarios ha sido analizada en diversos estudios. Estos se centran en las actividades de marketing o publicidad realizados por la industria farmacéutica a través de los medios de comunicación. De hecho, estas empresas destinan gran porcentaje de sus recursos a estas actividades y en numerosas ocasiones se ha llegado a indicar que esta industria gasta más en publicidad que en $\mathrm{I}+\mathrm{D}$. De hecho, los gastos de promoción y publicidad de medicamentos suponen entre el doble o triple del presupuesto destinado a investigar (Bolaños Dávila y Herrera Cedeño, 2012). Unos investigadores (Daubresse et al, 2015) demostraron que la publicidad a través de televisión de medicamentos para el asma tiene una relación directa con el aumento de venta de esos medicamentos. Además, paralelamente, también encontraron un aumento de visitas a urgencias debido a problemas de asma.

Otra investigación (Diez y Hidalgo, 2012) analizó la publicidad de fármacos que aparece en las revistas científicas de ginecología. Observaron que hubo incumplimiento legislativo en el 82,14\% de los anuncios y el 22,22\% de los eslóganes. Además, el 41,6\% de los mensajes publicitarios eran engañosos. Los autores plantean que se promocionan productos de marca con el fin de crear una preferencia por éstas frente a los genéricos. Otro estudio realizado sobre la publicidad en periódicos sobre medicamentos en India (Ahmad et al, 2015) encontró que más de un $90 \%$ de anuncios violaban la legislación vigente dando información falsa no basada en la evidencia. 
Urgen al gobierno que tome medidas contra este problema para proteger al público de estos anuncios. Otro estudio realizado en Estados Unidos (Faerber y Kreling, 2014) analizó anuncios de medicamentos en televisión. Encontraron que únicamente un 33\% estaban basados en datos objetivos, $57 \%$ eran potencialmente engañosos y el 10\% eran falsos. Añadían que los medicamentos sujetos a receta médica eran más objetivos que los de venta libre.

Por otro lado, otro estudio encontró que los anuncios de televisión sobre medicamentos para el resfriado o la fiebre eran la fuente más utilizada por encima del médico o familiares (Bhangale, 2013).

\section{B.- Redes sociales e Internet}

Las redes sociales y en general Internet están tomando un gran protagonismo en la visibilidad, promoción y comercialización de medicamentos. Muchas marcas de medicamentos se pueden encontrar en Facebook, Twitter, Instagram así como en páginas web, blogs y otros formatos digitales. En muchas ocasiones, el objetivo es la promoción del medicamento, y en otras, son los propios pacientes quienes comparten sus experiencias con otros cibernautas.

Como se mencionaba en la introducción, Internet es un medio que está siendo altamente utilizado para la compraventa de medicamentos y aunque esta práctica esté regulada, existen muchas farmacias ilegales que se saltan dicha regulación poniendo en riesgo la salud de los ciudadanos (Catalán-Matamoros et al, 2016). Cabe recordar que en este capítulo no se han incluido aquellos artículos que hayan analizado Internet como medio para realizar la compraventa de medicamentos tanto de forma legal o ilegal, sino que se han analizado los artículos que consideraban Internet como un medio de comunicación para informar al público sobre temas relacionados con medicamentos.

Es importante el estudio de la información sobre medicamentos en redes sociales debido al vacío legal existente en cuanto a la información que las empresas farmacéuticas pueden publicar en las mismas. Un estudio analizó la legislación en relación a la publicidad 
de medicamentos en redes sociales por las empresas farmacéuticas (Buechner, 2013). Ante la carencia encontrada, la autora urgía a los gobiernos a regular esta práctica en Europa y Estados Unidos.

En cuanto a una de las redes sociales más populares, Facebook, un estudio (Benetoli et al, 2015) analizó un caso en el que se ofrecía información sobre medicamentos a través de Facebook. Los usuarios podían realizar cualquier pregunta y un conjunto de farmacéuticos eran los responsables de responder. Las cuestiones más comunes realizadas por los usuarios estuvieron relacionadas con los efectos adversos, opciones de tratamiento para problemas de salud concretos, así como interacciones de medicamentos. El estudio concluye que Facebook ofrece un nuevo medio para promover un uso de calidad de medicamentos porque responde a las necesidades de información de los consumidores y además, de forma indirecta, promueve otros productos farmacéuticos.

Un estudio (Tyrawski y DeAndrea, 2015) analizó las publicaciones realizadas por las 15 empresas farmacéuticas más importantes a nivel mundial, y los 20 medicamentos más comprados en Estados Unidos en varias redes sociales (Facebook, Twitter y YouTube). El 40\% de las publicaciones analizadas por las farmacéuticas estaban relacionadas con la promoción de sus productos. Los problemas de los efectos adversos de los medicamentos únicamente se publicaron en el 1,6\%. Un número amplio de usuarios (24\%) interactuaron con las empresas farmacéuticas mediante comentarios. En relación al análisis de los medicamentos, encontraron que la mayoría eran observaciones por parte de usuarios (69\%) siendo referentes al beneficio del medicamento más frecuentes $(49 \%)$ que los riesgos $(27 \%)$. El 25\% de publicaciones en Twitter y YouTube hacían mención a testimonios personales. Un 17\% de publicaciones en Facebook hacían referencia a farmacias ilegales.

En otra investigación (Dunne et al, 2013) evaluaron la información publicada en Internet sobre medicinas genéricas en relación a la calidad de la información. Todas las páginas web analizadas tenían carencias informativas que hubieran enriquecido la calidad de las mismas. Sin embargo, no se detectaron errores intencionados dirigidos a confundir al consumidor con el objetivo de incrementar 
las ventas. Wikipedia fue la primera fuente en Internet para buscar información sobre medicamentos genéricos.

Un estudio realizado en Italia (Lombardo y Cosentino, 2016) analizó el perfil de personas que navegan por la red en búsqueda de información sobre medicamentos. El 26\% de los encuestados revelaron que habían buscado información por Internet, y de estos predominaban las mujeres, solteras que trabajaban. La franja de edad que reportó un mayor uso de la red para este propósito era entre 26 a 35 años y aumentaba a mayor nivel de educación.

Las redes sociales e Internet también son utilizadas para conocer el estado de salud de la población y detectar brotes o problemas de salud pública, debido al uso de estas herramientas para recibir información, datos que se recogen para realizar vigilancia epidemiológica. En este sentido, un estudio (Gesualdo et al, 2015) relacionó el incremento de publicaciones en Twitter sobre antihistamínicos con la subida de los niveles de polen en Italia. Otra investigación (Coloma et al, 2015) analizó las apariciones de posts sobre medicamentos realizados por usuarios de diferentes redes sociales tales como Facebook, Twitter y Google+. Aunque el objetivo principal era usar este análisis como una herramienta de fármacovigilancia para detectar casos de seguridad o reacciones adversas de medicamentos, finalmente concluyeron que dicho análisis era más útil para medir la concienciación de los ciudadanos sobre los medicamentos. Son ejemplos en los que las redes sociales han mostrado ser una herramienta útil en la prevención y control de enfermedades.

\section{C.- Contenidos publicados en otros medios de comunicación}

Los medios de comunicación y su cobertura sobre medicamentos pueden jugar un papel importante en influir la opinión pública así como su uso prudente (Robertson et al, 2013). Por otro lado, los medios también pueden influir y presionar a la esfera política para producir cambios legislativos (Robertson et al, 2013). Sin embargo no hay muchos análisis sobre los medicamentos en los medios de comunicación. Un estudio analizó los folletos más difundidos en 
farmacias y hospitales sobre los medicamentos para la malaria en Ghana (Gyasi, 2013). Se encontraron numerosas carencias en cuanto al formato y legibilidad. Por ejemplo, el $71,4 \%$ de los folletos tenían un tamaño de letra inferior a 10 y ningún folleto estaba escrito en alguna de las lenguas mayoritarias de Ghana además del inglés y francés. Como conclusión, el estudio reflejó que los folletos que informaban sobre las medicinas para la malaria no eran legibles para la mayoría de la población. Comprender la información que contienen dichos folletos puede suponer la vida o la muerte para estos enfermos, por lo que las empresas farmacéuticas deberían mejorar la legibilidad y comprensión de estos folletos.

Otro estudio (Kruger et al., 2015) mostró que los anuncios en televisión sobre medicamentos para el colesterol influyen en el bienestar emocional del público en relación a que se sienten culpables sobre su alimentación y ejercicio realizados. Estos cambios emocionales de culpabilidad producidos por la televisión pueden alterar la adherencia a dietas para el control de peso.

En cuanto a prensa escrita, un estudio analizó la cobertura de medicamentos en un periódico de Australia (Robertson et al, 2013). En el mismo encontraron que algunas enfermedades aparecen más frecuentemente en el medio que otras, por ejemplo el cáncer de mama aparece frecuentemente y sin embargo el cáncer de colón a pesar de tener más prevalencia en la población, aparece con menor frecuencia. Por otro lado, la aparición de caras humanas como víctimas de enfermedades presentando el medicamento como solución suele ser la representación más común encontrada. Finalmente, el estudio defiende que se necesitan guías de redacción sobre medicamentos dirigidas a las asociaciones profesionales de periodismo, creación de checklists para periodistas sobre los elementos principales a incluir en la redacción, y programas de formación para la especialización de periodistas en estos temas.

Finalmente, un estudio analizó el efecto en la población de las campañas de salud pública y su cobertura en los medios de comunicación ( $\mathrm{Lu}$ et al., 2014). Concretamente, estudiaron el efecto de las campañas de prevención del suicidio mediante medicamentos 
antidepresivos. En este caso, encontraron que las campañas de prevención de suicidio con antidepresivos produjeron un efecto contrario al deseado, encontrándose una reducción de la toma de antidepresivos y un aumento de consumo de sustancias psicotrópicas. Los casos de suicidios completos (1 de cada 10 intentos de suicidios) resultaron ser los mismos que en años previos, sin embargo los intentos de suicidio sufrieron un ligero aumento en población joven. Por lo que estas campañas realizadas en medios de comunicación disminuyeron el consumo de antidepresivos y no produjeron una reducción de suicidios. Los autores alertan de que un mal diseño de las campañas de salud en medios de comunicación puede producir efectos no deseados en la población, tal y como se encontró en este estudio. Además, añaden que durante las campañas se debe realizar una vigilancia exhaustiva para detenerlas si aparecen efectos no deseados.

\section{Reflexiones finales}

Los medios de comunicación son una fuente de información principal sobre salud para la población. Los medicamentos aparecen de forma frecuente en los medios en diversos formatos: fundamentalmente con fines comerciales anunciando nuevos productos, o con fines informativos para presentar nuevos hallazgos o curas a enfermedades. Además, gracias a las redes sociales, los usuarios pueden compartir sus experiencias con los medicamentos y de esta manera alertar de algún efecto adverso desconocido y su detección por parte de los equipos de vigilancia epidemiológica.

La información publicada en los medios sobre medicamentos está sujeta a una regulación por parte de las autoridades. Sin embargo, varios estudios han encontrado carencias en el seguimiento de dicha regulación, así como vacíos legales en cuanto a la promoción de medicamentos en las redes sociales.

Por lo tanto, en este capítulo se ha reflejado cómo los medios de comunicación pueden ayudar a concienciar en el uso prudente de medicamentos, pero también, pueden perjudicar la salud con publicaciones sesgadas. No obstante, se han encontrado muy pocos 
estudios científicos con diseños cualitativos o cuantitativos que analicen la cobertura de medicamentos por los medios de comunicación, por lo que la evidencia existente sobre la calidad de la información disponible al público es reducida. Se sugiere la realización de estudios centrados en formatos concretos de medios, tales como la radio, la televisión o la prensa. Además, se recomienda la realización de estudios sobre la cobertura de medicamentos en Internet y/o redes sociales debido a su uso emergente y los daños que publicaciones sesgadas pueden producir a la salud de la población.

\section{Bibliografía}

AEMPS (2015). Utilización de medicamentos antidepresivos en España durante el periodo 2000-2013. Disponible en: https://www.aemps.gob.es/medicamentosUsoHumano/observ atorio/docs/antidepresivos-2000-2013.pdf (fecha de consulta: 21/01/2016)

AEMPS (2016). Nota informativa: Nueva estrategia frente a medicamentos falsificados 2016-2019. Agencia Española de Medicamentos y Productos Sanitarios (AEMPS). Disponible en: https://www.aemps.gob.es/publicaciones/publica/docs/Estrat egia_falsificados_2016-2019.pdf (fecha de consulta 20/01/2016)

Ahmad, A, Patel, I, Parimalakrishnan, S, Mohanta, G P y Nagappa, A N (2015). "Advertisement on Medicines / Treatment in Newspapers Violating Indian Laws?". Current Pharmaceutical Review and Research, 6(1), 49-58.

Applbaum, K (2006). "Pharmaceutical Marketing and the Invention of the Medical Consumer". PLoS Medicine, 3(4), e189.

Aranceta-Bartrina, J (2016). "Los medios de comunicación, la educación nutricional y la información al consumidor $=$ Mass Media, nutrition education and consumer information". Revista Española de Comunicación en Salud, 7(Sup1). 
Benetoli, A, Chen, T F, Spagnardi, S, Beer, T y Aslani, P (2015).

"Provision of a Medicines Information Service to Consumers on Facebook: An Australian Case Study". Journal of Medical Internet Research, 17(11), e265.

Bhangale, V (2013). "A study on impact of media advertising on consumption of OTC cough and cold medicines". International Journal of Healthcare Management, 6(2), 136-140.

Bolaños Dávila, R X y Herrera Cedeño, J M (2012). Análisis de la publicidad farmacéutica en la construcción del imaginario de la salud, enfocado a la automedicación (Master Thesis). Universidad Politécnica Salesiana, Quito. Disponible en: http://dspace.ups.edu.ec/bitstream/123456789/3946/1/QT03 373.pdf (fecha de consulta 12/01/2017)

Buechner, B (2013). "A comparative legal analysis of social media advertising of drugs in Germany and the United States". Food and Drug Law Journal, 68(3), 259-279, i-ii.

Buer, L-M (2015). "Is There a Prescription Drug "Epidemic" in Appalachian Kentucky?: Media Representations and Implications for Women Who Misuse Prescription Drugs", 85116. En Recovery, Renewal, Reclaiming: Anthropological Research toward Healing. Knoxville, TN: Newfound Press.

Casino, G (2007). "Los medicamentos en los medios de comunicación". En Baños, J.E., Bigorra, J. La proyección social del medicamento

(Fundación Antonio Esteve, pp. 67-74). Barcelona: Fundación Antonio Esteve.

Catalán-Matamoros et al (2016). Los medicamentos falsificados en Internet y el proyecto europeo Fakeshare: experiencias y actuaciones en España. Revista Española de Salud Pública, 90, e1e14. 
Coloma, P M, Becker, B, Sturkenboom, M C J M, van Mulligen, E M y Kors, J A (2015). "Evaluating Social Media Networks in Medicines Safety Surveillance: Two Case Studies". Drug Safety, 38(10), 921-930.

Daubresse, M et al (2015). "Effect of Direct-to-Consumer Advertising on Asthma Medication Sales and Healthcare Use". American Journal of Respiratory and Critical Care Medicine, 192(1), 40-46.

Diez, B y Hidalgo, A (2012). "Análisis de la publicidad de medicamentos en revistas españolas de ginecología". Gaceta Sanitaria, 26(3), 270-273. h

Díez Díaz, B (2012). Publicidad de medicamentos en revistas cientificas del ámbito de la salud. Universidad de Oviedo: Servicio de Publicaciones, Oviedo.

Dunne, S S, Cummins, N M, Hannigan, A, Shannon, B, Cullen, W y Dunne, C P (2013). "What answers does the Internet provide for patients in Ireland with questions about generic medicines?". Journal of Generic Medicines, 10(3-4), 205-213.

Dunne, S S, Cummins, N M, Hannigan, A, Shannon, B, Dunne, C y Cullen, W.(2013). "Generic medicines: an evaluation of the accuracy and accessibility of information available on the Internet". BMC Medical Informatics and Decision Making, 13(1).

Earnshaw, S. et al (2014). "European Antibiotic Awareness Day: a fiveyear perspective of Europe-wide actions to promote prudent use of antibiotics". Euro Surveillance: Bulletin Europeen Sur Les Maladies Transmissibles $=$ European Communicable Disease Bulletin, 19(41).

ECDC (2016). Mensajes principales. Día europeo para el uso prudente de los antibióticos. ECDC. Disponible en: http:/ / ecdc.europa.eu/es/eaad/antibiotics-get-informed/keymessages/Pages/key-messages.aspx\#sthash.ECecRots.dpuf (fecha de consulta 23/01/2017) 
Faerber, A E (2012). Systematic assessment of true, misleading and false claims in advertisements for prescription and nonprescription drugs on television (Ph.D.). The University of Wisconsin - Madison. Disponible en: http://gradworks.umi.com/35/23/3523958.html (fecha de consulta 11/01/2017)

Faerber, A E y Kreling, D H (2014). Content Analysis of False and Misleading Claims in Television Advertising for Prescription and Nonprescription Drugs. Journal of General Internal Medicine, 29(1), 110-118.

Faerber, A E y Kreling, D H (2012). "Content Analysis of Television Advertising for Drugs That Switch From Prescription to Over-the-Counter: Balancing Information and Appeals". Therapeutic Innovation \& Regulatory Science, 46(2), 226-234.

Fakeshare (2016). El proyecto europeo Fakeshare. AIFA. Disponible en: www.fakeshare.eu (fecha de consulta: 23/01/2017)

Francescutti, P (2012). "Epidemiología televisiva: las patologías de los españoles según los informativos", 31-38. En Semir, V., Revuelta, G. El periodismo biomédico en la era 2.0. Barcelona: Fundación Dr. Antonio Esteve.

Galmés-Cerezo, M y Arjona-Martín, J B (2014). "La situación de la publicidad y las comunicaciones de marketing del sector de la salud en España". Revista Española de Comunicación En Salud, 5(2), 183-194.

Gesualdo, F et al (2015). "Can Twitter Be a Source of Information on Allergy? Correlation of Pollen Counts with Tweets Reporting Symptoms of Allergic Rhinoconjunctivitis and Names of Antihistamine Drugs". PLOS ONE, 10(7).

Gyasi, W K (2013). Readability and Health Communication: An Analysis of the Readability of Commonly Used Malaria Drugs 
Information Leaflets in Cape Coast, Ghana". IOSR Journal of Research \& Method in Education, 2(4), 17-25.

Jordá Sanz, C y Giménez-Salinas Framis, A (2015). "El tráfico ilícito de medicamentos. Un nuevo mercado ilegal para el crimen organizado". Revista Electrónica de Ciencia Penal Y Criminología, 17 (10), 1-22.

Kruger, C, Niederdeppe, J, Byrne, S y Avery, R J (2015). "Effects of exposure to direct-to-consumer television advertising for statin drugs on food and exercise guilt". Patient Education and Counseling, 98(9), 1150-1155.

Lombardo, S y Cosentino, M (2016). "Internet Use for Searching Information on Medicines and Disease: A Community Pharmacy-Based Survey Among Adult Pharmacy Customers". Interactive Journal of Medical Research, 5(3), e22.

Lu, C. Y et al (2014). "Changes in antidepressant use by young people and suicidal behavior after FDA warnings and media coverage: quasi-experimental study". BMJ, 348(jun18 24), g3596-g3596.

Nörby, U, Källén, K, Shemeikka, T, Korkmaz, S y Winbladh, B (2015). "Pregnant women's view on the Swedish Internet resource Drugs and Birth Defects intended for health care professionals". Acta Obstetricia et Gynecologica Scandinavica, 94(9), 960-968.

OCU (2014). Consumo excesivo de medicamentos. OCU. Disponible en: https://www.ocu.org/organizacion/que-hacemos/areas-deactividad/salud/consumo $\% 20$ excesivo $\% 20 \mathrm{de} \% 20$ medicamento s (fecha de consulta 23/01/2017)

OMS (2001). Estrategia mundial de la OMS para contener la resistencia a los antimicrobianos. OMS. Disponible en: http://www.antibioticos.msssi.gob.es/PDF/resist_OMS_estrat egia_mundial_contra_resistencias.pdf (fecha de consulta $15 / 01 / 2017)$ 
OMS (2016). Resistencia a los antimicrobianos. OMS. Disponible en: http:/ /www.who.int/mediacentre/factsheets/fs194/es/ (fecha de consulta 13/01/2017)

O’Neill, P y Sussex, J (2015). International Comparison of Medicines Usage: Quantitative Analysis. ABPI. Disponible en: http://www.abpi.org.uk/ourwork/library/industry/Documents/meds_usage.pdf (fecha de consulta 10/01/2017)

Penny Montenegro, E y Melgar Cuellar, F (2012). Geriatría y gerontología para el médico internista. Bolivia: La hoguera investigación.

Portalfarma. (2016, November 15). Día Europeo para el uso prudente de los antibióticos. Consejo General de Colegios Oficiales de Farmacéuticos. Disponible en:

http://www.portalfarma.com/ciudadanos/saludpublica/antibio ticos/diaeuropeouso/Paginas/diaeuropeousoantibiotic.aspx (fecha de consulta 20/12/2016)

Robertson, J, Walkom, E J, Bevan, M D y Newby, D A (2013).

"Medicines and the media: news reports of medicines recommended for government reimbursement in Australia". BMC Public Health, 13(1).

Roblek, V (2015). "Impact of Internet and social media on organisational change of OTC medicines marketing management". International Journal of Electronic Marketing and Retailing, 6(3), 239.

Tyrawski, J y DeAndrea, D C (2015). "Pharmaceutical Companies and Their Drugs on Social Media: A Content Analysis of Drug Information on Popular Social Media Sites". Journal of Medical Internet Research, 17(6), e130. 



\title{
Prensa, Alzheimer y funeral de Estado: E1 caso de Adolfo Suárez
}

\author{
Luisa Fernanda Giraldo Gil \\ Universidad Rey Juan Carlos (URJC) \\ Raquel Rodríguez Díaz (D) \\ Universidad Rey Juan Carlos (URJC)
}

\section{Resumen}

Introducción: Este trabajo es el resultado de una investigación más amplia que pretende comprobar la importancia que tienen los personajes públicos a la hora de incentivar la agenda de los medios temas relacionados con la salud. El 23 de marzo de 2014 fallecía a los 81 años el ex presidente del Gobierno español Adolfo Suárez González a causa de una neumonía. En 2005 su hijo, Alfonso Suárez Illana, había hecho público que el ex mandatario padecía Alzheimer. Objetivos. Motivados por este acontecimiento, se marcó como objetivo analizar el tratamiento que se hace en la prensa española del Alzheimer en relación a una figura pública. Partimos de la hipótesis de que gran parte de la información en los medios de comunicación relativa a salud va ligada a personajes conocidos. Metodología. Se plantea un estudio empírico centrado en el análisis de contenido de las informaciones relacionadas con el Alzheimer que se publicaron entre el 1 de enero y el 31 de marzo de 2014 (los tres meses previos al funeral de Estado de Suárez) en El País, El Mundo y Abc. Resultados. La prensa tiene una mejor predisposición a hablar de la enfermedad del Alzheimer si se encuentra asociada a un personaje público que, en esta investigación, se centra en Adolfo Suárez. 
Palabras clave: Salud; calidad; Alzheimer; personaje; agenda; prensa.

\section{Introducción y antecedentes del objeto de estudio}

— STE trabajo surge en el contexto de una investigación más amplia en la que se analizan los principales aspectos asociados a la enfermedad del Alzheimer desde una perspectiva de visibilidad mediática. Los resultados que mostramos en las siguientes líneas se centran en una parte del estudio inicial que aborda el tratamiento informativo del Alzheimer cuando va ligado a un personaje público o conocido. Es por ello que hemos empleado un estudio de caso: el desenlace del fallecimiento y funeral de Estado de Adolfo Suárez, ex presidente del gobierno español.

\subsection{La salud en la agenda mediática}

Antes de ver cómo afecta la figura del personaje conocido en la agenda de los medios, es necesario comprender la importancia de esos medios a la hora de fijar la agenda del público. Tal y como ponen de manifiesto cientos de estudios empíricos de los que disponemos en la actualidad sobre la teoría de la agenda-setting (McCombs, 2006), los medios continúan desempeñando un papel relevante en la construcción de la realidad social (McCombs y Shaw, 1972).

Según esta teoría, y parafraseando a Lippmann (1922), las imágenes que nos hacemos del mundo que nos rodea -principalmente de aquellos ámbitos que no podemos conocer de primera mano- tienen muchos orígenes, pero de entre las diversas fuentes resultan especialmente destacados los medios de comunicación. Existe así una relación entre las propuestas de temas informativos de la agenda mediática y lo que posteriormente el público considera prioritario (McCombs, 2006).

En este sentido, consideramos que los medios de comunicación pueden realizar una función social difundiendo informaciones del ámbito de la salud desde un punto de vista pedagógico al tiempo que 
contribuir en la concienciación y prevención (Blake, Taylor-Clark y Viswanath, 2010; Ugarte, Menéndez y Cuesta, 2010; Revuelta, 2012; Peñafiel, Camacho, Aiestaran, Ronco y Eizaguirre, 2014).

Como afirma Gema Revuelta (2006), la salud no suele ser un tipo de información prominente en la prensa, es decir, son escasas las veces que aparece en portadas, editoriales o incluso con algo tan simple como apoyo gráfico. Hay que tener en cuenta que se recuerdan mejor las noticias que ocupan mucho espacio que las que se repiten a menudo de forma discreta, y que hay géneros que favorecen más la divulgación que otros, como el reportaje o la opinión. En España, las noticias sobre salud no tienen secciones propias en los medios, salvo en contadas excepciones, y es frecuente encontrarlas en la sección de 'Sociedad', donde deben competir con piezas normalmente más espectaculares (Revuelta, 2006).

A este respecto, Carmen Costa (2008) considera que el problema de los artículos sobre salud -a pesar de su parcelación- no es tanto de cantidad como de calidad en el tratamiento informativo. El periodista no tiene un papel activo, no interpreta los hechos sino que se limita a transmitir, en muchos casos textualmente, lo que su única fuente le explica. Otra de las características que resalta la autora es que existe una dependencia directa de la actualidad. Los actos programados son los que reciben más cobertura, especialmente cuando van ligados a personajes mediáticos, que llaman la atención del lector. Los profesionales se ven arrastrados por la actualidad que marcan otros actores y no toman iniciativa para decidir qué interesa a sus receptores.

\subsection{La salud en un caso concreto: la Enfermedad de Alzheimer}

La enfermedad de Alzheimer (EA) es la principal causa de demencia en el mundo, así como la enfermedad neurodegenerativa con mayor incidencia. Se calcula que en cuatro décadas el 35\% de la población mundial tendrá más de 60 años, un aumento de la esperanza de vida que viene aparejado con el incremento de las demencias, de las cuales muchas de ellas son diagnosticadas con Alzheimer (Fundación Pasqual Maragall, 2016). Dicha fundación refleja que actualmente hay 
más de 46 millones de personas afectadas en el mundo por esta enfermedad.

Sólo en España existen algo más de un millón de enfermos de Alzheimer (CEAFA, 2016), una cifra que los expertos matizan, subrayando que hay un importante número de pacientes sin diagnosticar. Sumando además familiares y cuidadores, el total de afectados directa e indirectamente por la enfermedad es de unos 3 millones y medio de ciudadanos (Fundación Caja Madrid, 2013). Tal y como ponen de manifiesto diversos informes ${ }^{35}$, estos datos se traducen en un problema sociosanitario y económico de gran calado al que hacer frente en nuestra, cada vez más envejecida sociedad. En el año 2005 el gasto en España en demencias superó los 8.200 millones de euros, lo que hubiera supuesto un 10\% del presupuesto sanitario de nuestro país si este importe se hubiera cargado íntegramente en el presupuesto del Estado. La realidad no es tanto así, ya que en más del 80\% de los casos el gasto del cuidado de los pacientes con EA lo realizan las familias. Esto significa que el 13\% de los gastos asociados a la enfermedad se pagan con fondos públicos, mientras que el resto, el 87\%, son asumidos por los pacientes o familiares, pudiendo ser directos (gasto sanitario, gasto derivado de la atención domiciliaria reglada y de la institucionalización y aspectos técnicos: remodelación de las viviendas, transporte sanitario, etc.) o indirectos (tiempo dedicado al paciente; pérdida de productividad del enfermo y de sus cuidadores y los gastos sanitarios derivados de la carga del cuidador).

A pesar de que existen multitud de frentes abiertos en la investigación de la EA -y de que existen tratamientos con y sin medicamentos que pueden ayudar con los síntomas cognitivos y de comportamientohoy por hoy no se dispone de una cura (Asociación de Alzheimer, 2016). Los investigadores destacan varios factores que aumentan el

${ }^{35}$ Fundación Española de Enfermedades neurológicas (2011). Impacto social de la enfermedad del Alzhbimery otras demencias. p 25. Disponible en http://www.fundaciondelcerebro.es/docs/imp_social_alzheimer.pdf [fecha de consulta 19/11/2015] 
riesgo de padecer Alzheimer como puedan ser la diabetes, la obesidad (entorno a los 50 años), la depresión e incluso el bajo nivel de educación. Según recoge la Fundación Alzheimer España (2013), de reducirse estos factores disminuirían el riesgo de la exposición a la dolencia entre el 10 y el 25\%. Una mejor y más amplia información en los medios podrá contribuir en una formación adecuada del público sobre esta enfermedad. Así, los ciudadanos aprenderán a detectar tanto los factores de riesgo, a fin de evitarlos y prevenir la enfermedad, como los primeros síntomas, con lo que se podrá conseguir una detección más rápida y comenzar un tratamiento adecuado de forma más inmediata.

\subsection{Las caras conocidas del Alzheimer}

En el año 1996 se inició el Proyecto Quiral, una iniciativa realizada por la Fundación Vila Casas en colaboración con el Observatorio de la Comunicación Científica de la Universidad Pompeu Fabra, que busca reflexionar sobre el papel de los medios de comunicación en la difusión de la información sanitaria. En los últimos años la Fundación Vila Casas ha presentado un informe sobre un tema sanitario concreto. En el año 2010 el monográfico -de 94 páginas- estuvo destinado al Alzheimer, una elección motivada tanto por la celebración del Año Internacional del Alzheimer en 2011 como por la preocupación por el incremento de esta enfermedad en la sociedad española.

Varios de los principios que manejamos en nuestro trabajo parten de este informe, en el que se analizó el tratamiento de la EA en Internet, prensa, radio y televisión (tanto nacional como extranjera). El documento examina las informaciones difundidas por estos medios en un periodo de 13 años (1997-2009), por lo que permite ver la evolución del tratamiento informativo de la enfermedad a lo largo del tiempo.

Así, el Informe Quiral dedica un capítulo al objeto de esta investigación, titulado 'los rostros de la enfermedad', asegurando que "la repercusión mediática de los personajes públicos es clave en la toma de conciencia de la sociedad sobre las enfermedades" (Informe Quiral, 
2010: 53). Dicho informe señala que para el caso del Alzheimer, se contempla como el número de impactos en la prensa aumenta si un famoso reconoce su enfermedad o contribuye a la causa.

En el periodo estudiado en el Informe Quiral destacan casos internacionales como el de Rita Hayworth o el de Ronald Reagan, pero también pacientes españoles como Adolfo Suárez o Pasqual Maragall.

Rita Hayworth (1981). Esta actriz neoyorquina se convirtió en el primer personaje mediático en relacionarse con el Alzheimer. Su caso ocupó portadas tanto en su país natal como en España, donde recibieron cobertura sobre todo los temas relacionados con avances científicos, estadísticas oficiales y galas benéficas (Informe Quiral, 2010). En este caso, cabe destacar la figura de su hija, la princesa Yasmina Aga Khan, quien se convirtió en una activista a favor de los enfermos de Alzheimer y despertó también la atención de los medios.

Ronald Reagan (1994). Hizo pública su enfermedad a través de una carta manuscrita dirigida a toda la nación. "Al abrir nuestro corazón confiamos en que se promueva una mayor atención sobre la enfermedad y que estimule la comprensión de todos. Por desgracia, mientras avanza el mal, la familia [de la víctima] debe llevar una pesada carga" 36 , explicaba en la misiva como motivo al acto de revelar su enfermedad. Al año siguiente, el político republicano y su esposa crearon una fundación para la investigación de la dolencia que padecía.

Adolfo Suárez (2005). El anuncio del hijo de Suárez, indicando que su padre tenía Alzheimer, conmocionaba a la sociedad española. Sin embargo, este caso no fue uno de los más mediáticos en el momento de su revelación, posiblemente por la discreción de la familia y las

\footnotetext{
${ }^{36}$ Calvo, José Manuel. "Ronald Reagan revela que padece la enfermedad de Alzheimer". En Archivo El Pais. Disponible en: http://elpais.com/diario/1994/11/06/internacional/784076408_850215.html [Consulta 12/02/2016]
} 
escasas apariciones públicas del ex mandatario durante su enfermedad. Como veremos más adelante, tras su fallecimiento el número de noticias relacionadas con esta dolencia y su persona aumentó.

Pasqual Maragall (2007). Este caso ha tenido impacto en España y ha dado una visibilidad mayor al Alzheimer. Esto se debe a que el ex presidente de la Generalitat de Catalunya no solo ha escrito un libro y ha sido el protagonista de un documental sobre la enfermedad, sino que también ha aparecido en diversos actos públicos y ha creado una fundación con gran visibilidad.

Carmen Sevilla (2009). A pesar de no aparecer en el ya citado Informe Quiral, sí es necesario hacer una mención a esta reconocida cantante y actriz española, diagnosticada con Alzheimer en 2009. Su enfermedad se dio a conocer tiempo después. Su última aparición televisiva se produjo en diciembre de 2010.

\subsection{Adolfo Suárez: figura histórica}

Cuando se hace pública una enfermedad por parte de personajes conocidos, se alcanza una mayor repercusión mediática sobre dicha dolencia además de favorecer que sea noticiable e interesante, tal y como expresa el Informe Quiral señalado anteriormente. En el caso de Suárez, no se trata solo de un personaje conocido, sino también de una figura histórica, elemento que contribuye aún más a convertirlo en noticia o reclamo mediático.

En la década de los 70, el panorama político español se encontraba en una difícil tesitura y tenía diferentes opciones ante la continuidad del Régimen sin Franco. En medio de este escenario, en el año 1976, Adolfo Suárez González, vinculado a los sectores reformistas del Movimiento, lidera la transición política española convirtiéndose en presidente del primer gobierno democrático de España después de la dictadura. Fue en el año 1977 cuando se convirtió en presidente de Gobierno electo por las urnas, encabezando el partido político de Unión del Centro Democrático (UCD) y en el año 1981 presentó la dimisión de su cargo. 
La figura de Suárez representa un papel destacado en la memoria colectiva de España pese a que no fuera su intención, como él mismo señaló en una entrevista inédita realizada por el periódico $A B C$ en 198037: "No. Yo no tengo vocación de estar en la Historia. Además, creo que ya estaré; aunque sólo ocupe una línea (...). Pero eso no compensa (...) Mi mayor preocupación actual es la convivencia (...) Hay que crear las condiciones necesarias para que los españoles convivan por encima de sus ideas políticas; que las ideologías no dañen las relaciones de amistad, de vecindad".

\section{Objetivos e hipótesis de la investigación}

El principal objetivo de este estudio es analizar el tratamiento que se hace en los medios generalistas españoles del Alzheimer en relación a una figura conocida, para determinar la importancia que tienen los personajes públicos a la hora de motivar la agenda de los medios en temas relacionados con la salud.

Intentaremos conocer así la cantidad de información que se ofrece sobre esta materia en algunos de los principales medios escritos españoles en relación a sólo los últimos días de Adolfo Suárez y -más importante aún- la calidad y el tipo de estos contenidos, buscando saber si aportan elementos de ayuda a los afectados y si se contemplan elementos pedagógicos adecuados o de calidad informativa que contribuyan a la prevención o la detección en fases precoces de la enfermedad.

Teniendo en cuenta estos elementos, establecemos dos hipótesis principales:

\footnotetext{
${ }^{37}$ Martínez del Álamo, J. (2007). Entrevista inédita a Adolfo Suárez: "Soy un hombre completamente desprestigiado" $A B C$. Disponible en http://www.abc.es/hemeroteca/historico-23-09$2007 / \mathrm{abc} / \mathrm{Domingos} /$ entrevista-inedita-a-adolfo-suarez-soy-un-hombrecompletamente-desprestigiado 164932329050.html\# [fecha de consulta $19 / 11 / 2015]$
} 
- H1. Cuando los temas informativos de salud van ligados a un personaje conocido la prensa realiza una mayor cobertura informativa.

- H2. La prensa, cuando informa sobre salud ligada a un personaje público, incorpora elementos de prevención y concienciación sobre la enfermedad.

\section{Metodología de la investigación}

Se realizará un análisis de contenido de las informaciones relacionadas con el Alzheimer que se publicaron entre el 1 de enero de 2014 y el 31 de marzo de 2014 en El País, El Mundo y Abc.

Si bien podíamos haber escogido solo marzo como periodo de estudio, momento en el que fallece Adolfo Suárez, consideramos necesario estudiar también los dos meses previos para observar el contraste en el volumen y los temas de unos y otros periodos. Prescindimos de elegir meses posteriores debido a la rápida pérdida de actualidad y, por tanto, igualmente de interés para el objeto de estudio pese a que hubiera sido interesante continuar con el análisis de contenido.

Para la creación de la muestra se ha utilizado la herramienta Lexis Nexis Academic, una base de datos en línea que recoge artículos de los principales medios del mundo valiéndose de una amplia cobertura en el tiempo. Dentro de esta base de datos, la búsqueda se ha realizado de la siguiente forma:

Periódicos: Se analizarán tres medios españoles: El País, El Mundo y $A b c$. Se han escogido estos diarios por ser considerados prensa de referencia además de encontrarse entre los más leídos de la prensa generalista española, según el Estudio General de Medios (EGM) ${ }^{38}$.

\footnotetext{
${ }^{38}$ Asociación para la Investigación de Medios de Comunicación (2016). Estudio General de Medios (Resumen General). p 6. Disponible en http://www.aimc.es/Datos-EGM-Resumen-General-.html [fecha de consulta 14/01/2016]
} 
Perído: El estudio comprende un lapso de tres meses, desde el 1 de enero de 2014 hasta el 31 de marzo de 2014. Como se ha explicado, un período de tiempo significativo que permite realizar una aproximación al tema que nos ocupa.

Palabras contenidas en la búsqueda: $\mathrm{Al}$ tener un objeto de estudio tan concreto, la palabra que se ha utilizado para obtener la muestra ha sido solamente una: 'Alzheimer'. Se buscaba que el vocablo estuviera en el titular y/o Lead (primer párrafo) de cada unidad de análisis. De esta forma evitamos una acumulación de noticias que no se centren exclusivamente en el tema de estudio.

Sección: Se ha optado por no introducir ninguna sección específica a la hora de realizar la búsqueda, ya que, asumimos que la mayoría de informaciones sobre salud sufren dispersión dentro del medio. Además, al centrarnos en Adolfo Suárez, entendemos que podremos encontrar noticias en secciones tan variadas como 'Sociedad', 'Política' o 'Nacional'.

Géneros periodísticos y temática: No se discriminará ningún género.

Tras haber establecido estos criterios de búsqueda se obtuvieron los siguientes resultados:

Tabla 1. Selección y filtrado de la muestra

\begin{tabular}{|l|l|l|l|}
\hline Diarios & $\begin{array}{l}\text { Palabra ‘Alzheimer' } \\
\text { entre el 1 de enero y } \\
\text { el 31 de marzo de } \\
2014\end{array}$ & $\begin{array}{l}\text { Palabra ‘Alzheimer' } \\
\text { en el titular y/o en el lead } \\
\text { entre el 1de enero y el 31 } \\
\text { de marzo de 2014 }\end{array}$ & $\begin{array}{l}\text { Total de la muestra a } \\
\text { analizar: noticias filtradas }\end{array}$ \\
\hline El Pais & 45 & 15 & 10 \\
\hline El Mundo & 31 & 15 & 12 \\
\hline Abc & 64 & 45 & 26 \\
\hline Totales & 140 & 75 & 48 \\
\hline
\end{tabular}

Fuente: elaboración propia

En la tabla observamos el cribado de nuestra muestra en la fecha señalada. En un primer momento obtuvimos un total de 140 noticias, 
pero necesitábamos que la palabra 'Alzheimer' estuviera exclusivamente en el titular y/o primer párrafo de la información, con lo que las unidades de análisis se redujeron a 75. Tras aplicar el filtro de repetición de la base de datos Lexis Nexis volvimos a filtrar la muestra para eliminar piezas que no se relacionaran con nuestro tema.

Descartamos noticias de sucesos ('Cuando la muerte llega a bastonazos' 13/01/2014, El País), aquellas en las que la enfermedad se utiliza como recurso literario ('Chola de cholo' 13/04/2014, El Mundo) o en las que simplemente se menciona la dolencia para explicar otro tipo de enfermedades como el Síndrome de Sanfilippo ('Vivimos contra reloj' 28/02/2014, Abc). Así, finalmente hemos obtenido un total de 48 unidades de análisis.

Tras realizar un pre-test compuesto por un 50\% de la muestra, 24 informaciones, optamos por utilizar una ficha de análisis, de la que destacamos las variables consideradas más importantes para el estudio:

1. Relación con Adolfo Suárez. Con esta variable intentamos determinar qué informaciones sobre Alzheimer toman como punto de partida la figura de Adolfo Suárez y cuáles, por el contrario, no tienen ninguna relación con el político. Como resultado obtenemos las categorías 'Sí', para aquellas unidades de análisis que se centran en el ex presidente -ya sea para hablar de su trayectoria, su dolencia o como punto de partida para un especial sobre el Alzheimer- y 'No', para las noticias que no mencionan a Suárez.

2. Temas específicos. Tras realizar el pre-test, descubrimos que la mayoría de noticias relacionadas con Adolfo Suárez tratan temas distintos, por lo que consideramos apropiado crear una variable que midiera con qué frecuencia aparecen cada uno de estos temas específicos o subtemas en las informaciones. Esta variable se medirá exclusivamente en las noticias que tengan la categoría 'Sí' en el punto anterior.

2.1. Síntomas y consecuencias de la enfermedad: aquellas piezas en las que el tema central sean los síntomas del Alzheimer, como la 
desorientación o la falta de reconocimiento de los seres queridos. Se recogen también noticias en las que se hable de las consecuencias de la dolencia, como las complicaciones de tipo respiratorio de las que falleció Suárez ('Una enfermedad para la que no hay curación ni fármaco eficaz’ 24/03/2014, Abc).

2.2. Hábitos y comportamiento de Adolfo Suárez: artículos que hablen de las rutinas que seguía el ex mandatario una vez diagnosticada su dolencia. Dado que Suárez desapareció de la vida pública en los primeros estadios de la enfermedad, este tipo de informaciones se basan en testimonios de familiares y amigos que visitaban al reconocido político ('La luz de una vela cuando está apagada' 24/03/2014, El País).

2.3. Vida, obra y trayectoria de Adolfo Suárez: informaciones que se centren en la trayectoria profesional y personal del I Duque de Suárez. Se recogen unidades de análisis en las que se habla de la evolución de su enfermedad, así como aquellas en las que se menciona la dolencia, pero ocupa un lugar secundario frente a otros hechos importantes en la vida del fallecido líder ("Adiós al mito de la Transición’ 24/03/2014, El Mundo).

2.4. Otras: informaciones que no estén recogidas en ninguno de los puntos anteriores, como aquellas en las que se explica qué es el Alzheimer ('La tercera plaga 22/03/2014, El Mundo) o el tratamiento que siguió Suárez ("Vimos que era el final al tener gran dificultad para respirar y no poder tragan» 25/03/2014, Abc).

\section{Resultados de la investigación}

El total de noticias que conformaron la muestra en las que se citaba el Alzheimer como tema principal fueron 48, de las cuales 26 procedían del diario $A b c$ (lo que supone un 54\% de la muestra), 12 del El Mundo (un $25 \%$ de la muestra) y 10 del El País (un 20\% de la muestra). De esas 48 noticias, solo 20 (un 41\% de la muestra) cumplían el requisito explicado previamente que consistía en estar vinculadas con nuestro personaje conocido, Adolfo Suárez. 
Al producirse el fallecimiento de esta figura histórica que padecía la enfermedad, y tal y como era de esperar, aumentaron las noticias relativas al Alzheimer en los medios analizados. Esto se aprecia con claridad en el siguiente gráfico al observar la distribución de la muestra en los tres meses objeto de estudio.

\section{Gráfico 1. Distribución de las noticias por meses (\%)}

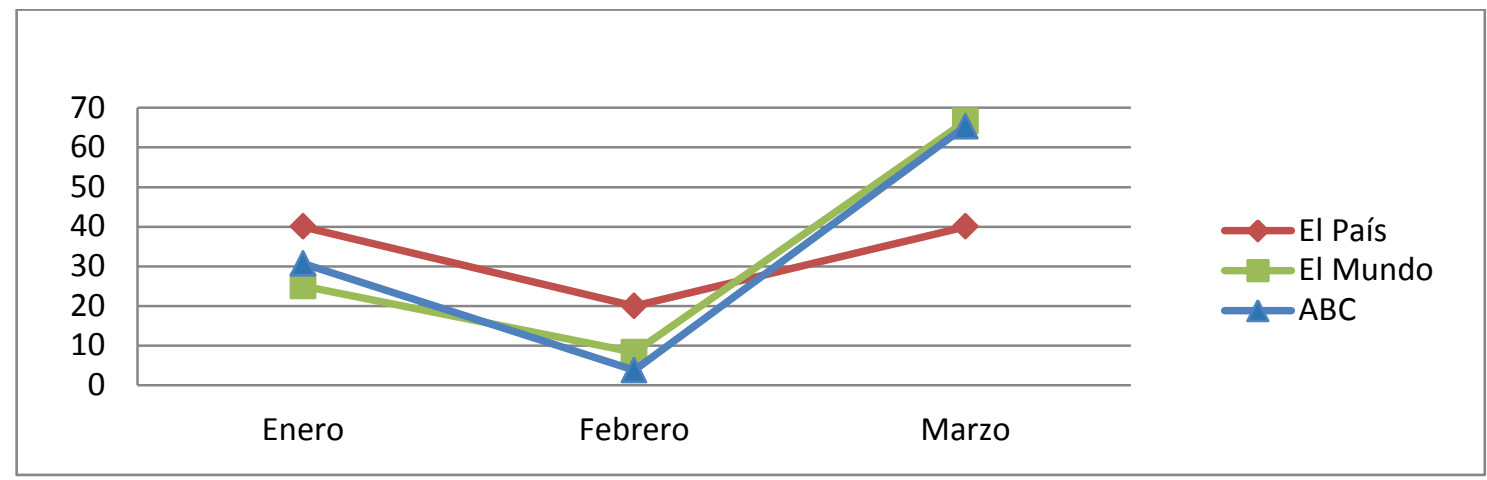

Fuente: elaboración propia

Como se aprecia en la Gráfico 1, el mayor flujo de informaciones se concentra marzo. En total, un $60 \%$ de la muestra (29 informaciones) se sitúa en este mes, en contraposición a los meses de enero y febrero, que tan solo aportan un 31\% (15 informaciones) y un $8 \%$ (4 informaciones) de la muestra respectivamente.

Poniendo nuestra atención en cada periódico, contemplamos que, a pesar de que $A b c$ es el diario que más unidades aporta, vemos que, en proporción, es El Mundo el que más espacio dedica a noticias sobre Alzheimer en relación con Adolfo Suárez, con un $60 \%$ de sus informaciones (8 unidades de análisis dedicadas a Suárez de 12 sobre el Alzheimer). Por su parte, El País se sitúa en segunda posición con un $40 \%$ de sus artículos (4 unidades de análisis sobre Suárez de 10 sobre el Alzheimer). En $A b c$, sin embargo, el ex mandatario tiene menos peso a la hora de informar sobre el Alzheimer con un 30\% de sus aportaciones (8 unidades de análisis dedicadas a Suárez de 26 sobre el Alzheimer). 
Gráfico 2. Espacio dedicado a Suárez por medio (\%)

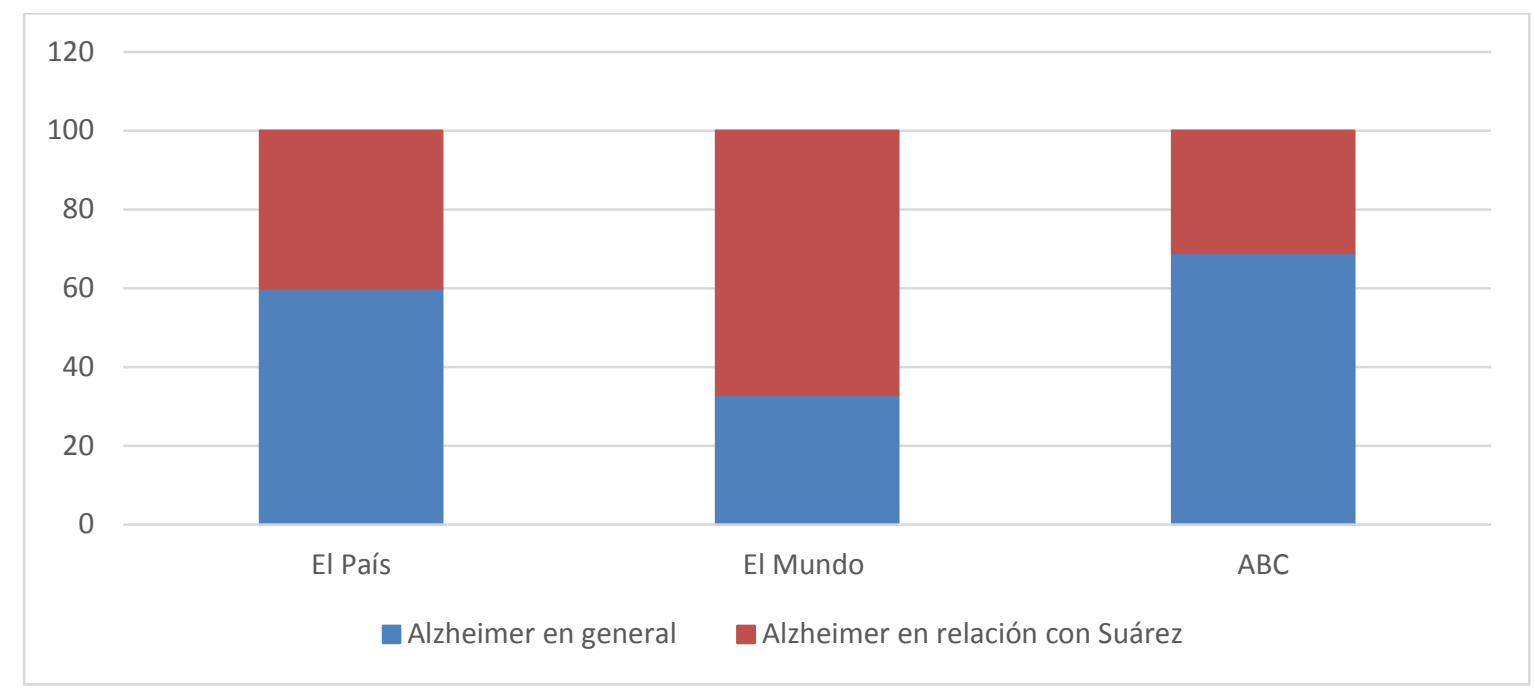

Fuente: elaboración propia

En esta serie de informaciones dedicadas a Suárez, encontramos que se abordan diferentes subtemas (Tabla 2). La mayoría de noticias que se publicaron durante los tres meses objeto de estudio sobre Adolfo Suárez se centraron en su vida. Aproximadamente un 50\% de las informaciones (10 unidades de análisis) relacionadas con el ex mandatario se agrupan en 'Vida y trayectoria', mientras que un 30\% (6 unidades de análisis) lo hacen en 'Síntomas y consecuencias', seguida de 'Hábitos y comportamientos' y 'Otros' con un 10\% (2 unidades de análisis cada uno).

Diferenciando estos temas por medios, obtenemos los siguientes resultados (en valores absolutos y en porcentajes):

Tabla 2. Recurrencia de subtemas por medios

\begin{tabular}{|c|c|c|c|c|}
\hline & $\begin{array}{c}\text { Síntomas y } \\
\text { consecuencias de } \\
\text { la enfermedad }\end{array}$ & $\begin{array}{c}\text { Hábitos y } \\
\text { comportamiento } \\
\text { de Adolfo Suárez }\end{array}$ & $\begin{array}{c}\text { Vida, Obra y } \\
\text { trayectoria de } \\
\text { Adolfo Suárez }\end{array}$ & Otros \\
\hline El País & 2 & 1 & 1 & 0 \\
\hline ElMundo & 2 & 0 & 5 & 1 \\
\hline ABC & 2 & 1 & 4 & 1 \\
\hline Totales & $\mathbf{6}$ & $\mathbf{2}$ & $\mathbf{1 0}$ & $\mathbf{2}$ \\
\hline
\end{tabular}

Fuente: elaboración propia 
Gráfico 3. Recurrencia de subtemas por medios (\%)

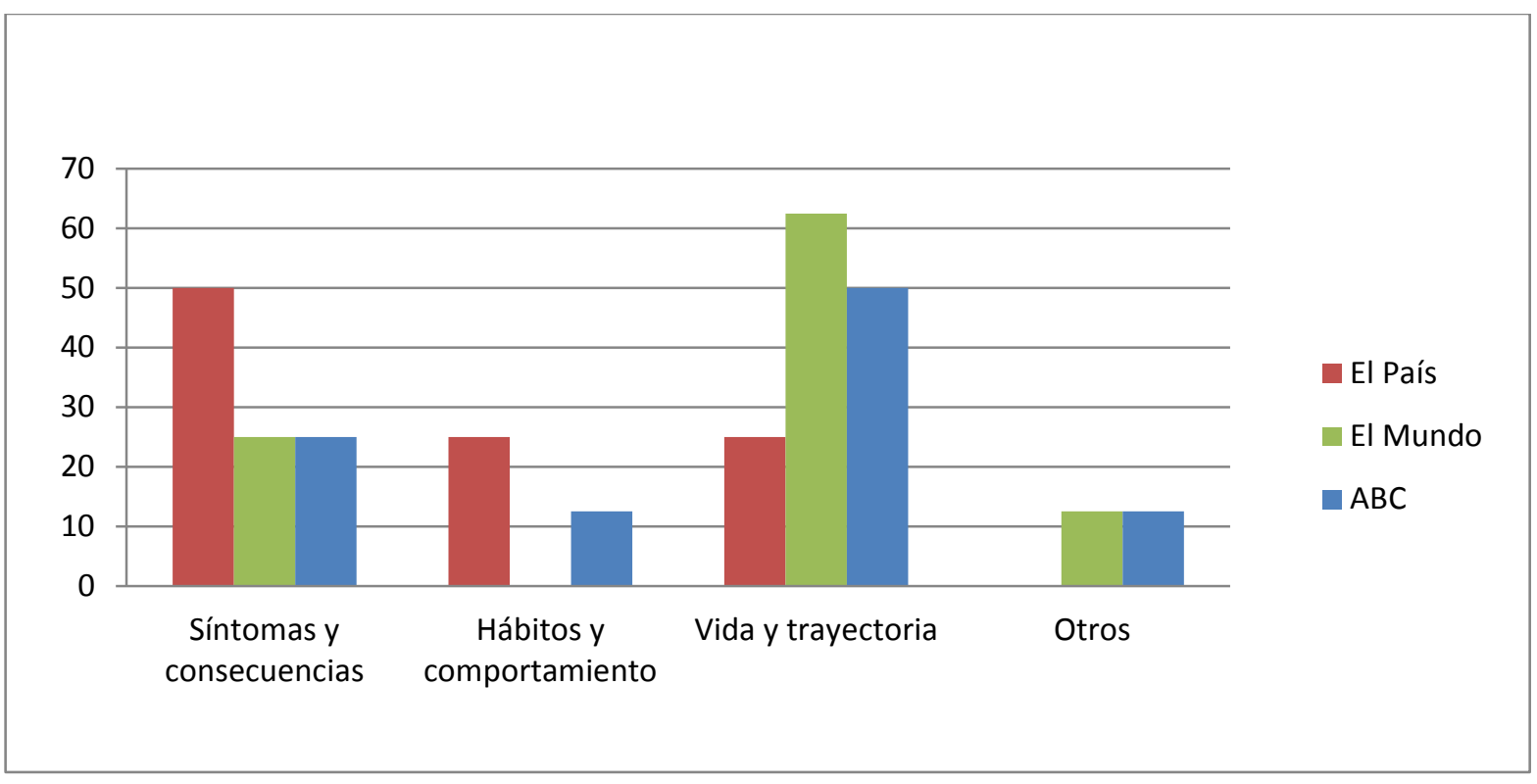

Fuente: elaboración propia

En general, los medios estudiados optaron por centrarse en la vida, obra y trayectoria de Adolfo Suárez, relatando la evolución de su enfermedad y el desempeño tanto en su vida personal como profesional. El País es la única excepción, ya que aportó un mayor número de informaciones en la categoría de 'Síntomas y consecuencias', ofreciendo informaciones más relacionadas con el Alzheimer en sí, en los signos de la dolencia y las consecuencias que provoca.

\section{Discusión y conclusiones}

A pesar de que con este pequeño estudio no se puedan ofrecer respuestas definitivas sobre el tema que nos ocupa, sí realizamos una aproximación al complejo ámbito del tratamiento de la información sanitaria en medios generalistas y más concretamente sobre el Alzheimer. De esta forma, nos acercamos a nuestro objetivo principal, analizar el tipo de información que realizan los diarios de referencia con respecto al Alzheimer cuando esta dolencia aparece motivada por un personaje conocido. 
Teniendo en cuenta los resultados expuestos, podemos concluir que, en general, la prensa tiene una mejor predisposición a hablar de una enfermedad si se encuentra asociada a un personaje público, tal y como se expresaba en la primera hipótesis. Los diarios analizados muestran un especial interés por el caso de Adolfo Suárez, una figura histórica con una amplia trayectoria política asociada al Alzheimer.

No obstante, estamos también ante informaciones que contribuyen de un modo u otro a la estigmatización de la enfermedad y de quienes la padecen, repitiendo con metáforas, acontecimientos, o imágenes que fomentan los tópicos sobre la dolencia. Esto quedó patente desde la realización del pre-test, en la que nos vimos obligados a descartar noticias en la que la enfermedad se utilizaba como recurso literario o metafórico, frivolizando en gran medida este trastorno. Es el caso, por ejemplo del texto que llevaba por título 'Chola de cholo' (13/04/2014, El Mundo), un artículo de opinión firmado por Raúl de Pozo en la que se utiliza la enfermedad para describir la ciudad de Madrid: "En el Madrid destartalado, imperfecto, calle del mundo, pasarela de chiflados, cada hígado es un producto que se puede vender en el mercado. Veo a chicas de la cordillera de los Andes acompañando a puretas con Alzheimer, caminata más triste que llevar el cobre en el rodete de sus cabezas. Camareros bolivarianos...".

Por otro lado y como apuntaba el citado Informe Quiral, vemos que los periodistas se rigen por la actualidad del momento (fallecimiento y funeral de Suárez) para realizar informaciones en profundidad o de mayor recorrido sobre Alzheimer. El aumento de noticias sobre la enfermedad va ligado al anuncio del empeoramiento y posterior fallecimiento del ex presidente.

Los resultados del estudio muestran una exigua labor de prevención y concienciación de la enfermedad ya que la categoría de "síntomas y consecuencias de la enfermedad" ocupa un lugar secundario en la mayor parte de los artículos analizados. Escasean las informaciones que respondan a un interés personal del lector como puedan ser consejos sobre qué hay que hacer en determinadas situaciones, elementos que contribuyan a detectar el Alzheimer o nombrar 
costumbres que puedan resultar nocivas para el desarrollo o el agravamiento de la enfermedad.

Por consiguiente, de la investigación se desprende que sería interesante analizar, en futuros trabajos, cómo es el tratamiento informativo de la prensa cuando aborda el Alzheimer desde la prevención, concienciación y diagnóstico. Algunas de estas cuestiones son objeto de otra investigación, actualmente en curso, que surge en el contexto de un estudio más amplio en el que ya se comienzan a vislumbrar algunos resultados. Por ejemplo, sobre todo se publican noticias y breves, con escasa presencia de la divulgación y la prevención, se destaca más la cobertura de eventos, la información no se concentra en una sección y esta aumenta notoriamente cuando se acerca el día mundial del Alzheimer.

Desde las propias rutinas profesionales de los periodistas, sería interesante analizar con un enfoque cualitativo cuáles son o serían los planteamientos de los redactores cuando informan sobre salud y construyen su agenda informativa. ¿Se informa prioritariamente de algo nuevo (innovaciones, investigaciones, tratamientos, etc.) o existe una conciencia de contribuir a la divulgación, a la prevención, más allá de la novedad informativa? Preguntas a las que más pronto que tarde debemos encontrar respuesta.

\section{Bibliografía}

Calvo, M. (1992). La divulgación científica en una sociedad tecnológica. Madrid: Paraninfo.

Costa, C. (2008). "Medicina y salud en la prensa. Las noticias de salud en los principales diarios de Galicia". Revista Latina de Comunicación Social, 11 (63), 15-21.

Lippmann, W. (1922). Public Opinion. New York: Free Press.

McCombs, Maxwell E. y Shaw, Donald L. (1972). “The agenda- 
setting function of mass media". Public Opinion Quarterly, 36 (2). Chicago, University of Chicago Press, 176-187.

McCombs, M. (1996). "Influencia de las noticias sobre nuestras imágenes del mundo". En Bryant, J. y Zilmann, D. (v.o. 1994). Los efectos de los medios de comunicación. Investigaciones y teorías. Barcelona: Paidós, 13-34.

McCombs, M. (2006). Estableciendo la agenda. Barcelona: Paidós; traducido al español en McCombs, M. (2004). Setting the agenda: The mass media and public opinion. UK: Polity Press.

Peñafiel, C., Camacho, I., Aiestaran, A., Ronco, M. y Eizaguirre, L. (2014). "La divulgación de la información de salud: un reto de confianza entre sectores implicados". Revista Latina de Comunicación Social, 69, 135-151.

Revuelta, G. (2006): "Salud y medios de comunicación en España". Gaceta sanitaria 20, 203- 208.

Revuelta, G. (2012). "Salud en España durante el periodo 20002009: aproximación a través del análisis de la prensa". Medicina Clínica, 138 (14), 622-626.

Ugarte, A., Menéndez, T. y Cuesta, U. (2010). Prensa escrita y salud en Madrid. Una revisión del modelo de la Agenda Setting y su aplicación a la dinámica de las noticias sobre salud en Madrid. Madrid, Ed. Complutense.

Wallington, S., Blake, K., Taylor-Clark, K. y Viswanath, K. (2010). "Antecedents to agenda setting and framing in health news: an examination of priority, angle, source, and resource usage from a national survey of U.S. health reporters and editors". Journal of Health Communication, 15, 76-94. 


\section{Otros documentos}

Asociación para la Investigación de Medios de Comunicación (2016). Estudio General de Medios (Resumen General). p 6. Disponible en http://www.aimc.es/-Datos-EGM-Resumen-General-.html [fecha de consulta 14/01/2016]

Asociación de Alzheimer (2016). Tratamientos. Disponible en http://www.alz.org/espanol/treatment/tratamientos.asp [fecha de consulta: 14/01/2016].

Calvo, José Manuel (1994). "Ronald Reagan revela que padece la enfermedad de Alzheimer". Archivo El Pais. Disponible en: http://elpais.com/diario/1994/11/06/internacional/784076408_850 215.html [fecha de consulta: 12/02/2016].

Confederación Española de Asociaciones de Familiares de Personas con Alzheimer y otras Demencias (CEAFA). Disponible en: http://www.ceafa.es/es/el-alzheimer/la-enfermedad [fecha de consulta: 16/05/2016].

El Mundo (2004). Todo sobre el Alzheimer. Disponible en http://www.elmundo.es/elmundosalud/especiales/2004/04/alzheim er/quees.htm [fecha de consulta: 19/11/2015].

Observatorio de la Comunicación Científica / Fundación Vilá Casas. Informe Quiral 2010: Alzheimer.

Disponible en: http://www.fundaciovilacasas.com/es/informe-quiral [fecha de consulta: 19/11/2015].

Fundación Alzheimer España (2013). Vivir con el Alz̧heimer. Disponible en http://www.alzfae.org/index.php/vivir-alzheimer [fecha de consulta: 19/11/2015].

Fundación Caja Madrid (2013) Hoy es el Día Mundial del Alz̧heimer. Disponible en http://cuidadoalzheimer.com/atencionalzheimer/hoy-es-el-dia-mundial-del-alzheimer/ [fecha de consulta: 12/11/2015]. 
Fundación Española de Enfermedades neurológicas (2011). Impacto social de la enfermedad del Alzheimer y otras demencias. p 25. Disponible en http://www.fundaciondelcerebro.es/docs/imp social alzheimer.pdf fecha de consulta: 19/11/2015].

Fundación Pasqual Maragall (2016) Alz̧heimer. Disponible en https://fpmaragall.org/la-fundacion/ [fecha de consulta 12/02/2016].

Martínez del Álamo, J. (2007). Entrevista inédita a Adolfo Suárez: "Soy un hombre completamente desprestigiado" Abc. Disponible en http://www.abc.es/hemeroteca/historico-23-092007/abc/Domingos/entrevista-inedita-a-adolfo-suarez-soy-unhombre-completamente-desprestigiado 164932329050.html\# [fecha de consulta 19/11/2015]. 


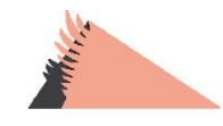

\section{Los autores}

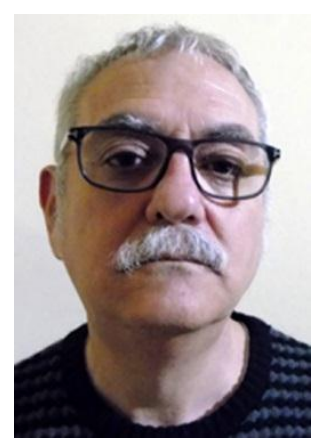

JOSÉ LUIS TERRÓN. Doctor por la Universitat Autònoma de Barcelona. Profesor Titular del Departament Comunicació Audiovisual i Publicitat de la Universitat Autònoma de Barcelona. Director del Observatorio de Comunicación y Salud (integrado en el InCom-UAB), del que es fundador marzo de 1996-. Forma parte del Consejo Editor de Cuadernos de Comunicación, Salud y de Revista Española de Salud Pública y Revista Internacional de Comunicación y Desarrollo (RICD) y del Comité Científico de las revistas científicas Communication Papers, Revista Internacional de Comunicación y Desarrollo (RICD) y de la colección de libros Cuadernos Artesanos de Comunicación (CAC).

$\mathrm{Ha}$ sido miembro del $\mathrm{I}+\mathrm{D}+\mathrm{i}$ 'La publicidad de tv entre otros factores socioculturales influyentes en los TCA', del FIS 'Elaboración de guías prácticas para el uso responsable de la información obtenida en Internet y del correo electrónico con fines sanitarios' y Codirector de 'Estrategias de evaluación de las campañas de salud. El caso de las campañas sobre el ictus', financiada por el Plan de Calidad para el Sistema Nacional de Salud. Desde 2006 y hasta la fecha, IP de una serie de investigaciones sobre el tratamiento del VIH/sida en los medios escritos españoles, mexicanos dominicanos. Autor de artículos y comunicaciones en publicaciones y congresos españoles e internacionales en torno a la comunicación y la salud.

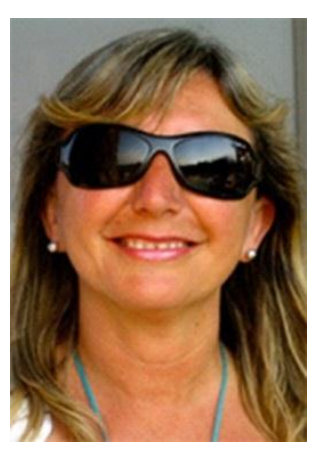

CARMEN PEÑAFIEL. Profesora Titular, acreditada Catedrática en el Departamento de Periodismo (UPV/EHU) y Doctora en Ciencias de la Información por la Universidad del País Vasco/Euskal Herriko Unibertsitatea (1992). En su etapa anterior a la Universidad, ha trabajado como Redactora-Locutora en la Cadena SER, Radio Popular de Bilbao y Radio Euskadi-EITB, desempeñando puestos de dirección y 
realización de programas informativos, culturales y de entretenimiento. Es miembro fundador del Grupo de Investigación Europeo sobre la Radio-IREN (International Radio Research Network) y miembro del Comité Científico del Grupo francés de Estudios de Radiodifusión-GRER. Ha sido Coordinadora de la Sección 'Comunicación y Cultura Digital' de la AE-IC, de la que actualmente es Vocal en la Junta Directiva.

Ha realizado estancias de investigación en: University of Nevada (USA), Basque Studies Center-Reno (USA); Facultad de Comunicación y Humanidades-TEC de Monterrey (México); Institut for Informasjons og Medievitenskap-Bergen (Noruega) y en la prestigiosa University of California-San Diego (USA).

Ha sido Responsable del Master en Comunicación Social y es miembro del Consejo Directivo de la Escuela de Master y Doctorado de la UPV/EHU. Ha sido miembro del Consejo de Gobierno de la UPV/EHU; del Claustro de la Universidad y Directora del Departamento de Periodismo. Actualmente, es Coordinadora de la Titulación de Periodismo y forma parte de la Junta de la Facultad de Ciencias Sociales y de la Comunicación.

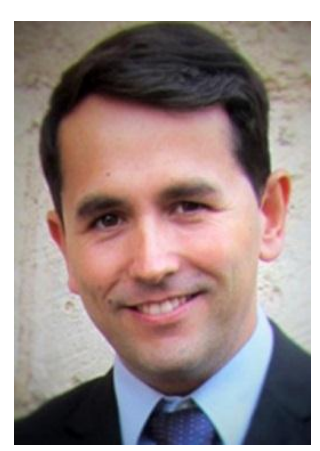

DANIEL CATALÁN. Licenciado por la Facultad de Ciencias de la Comunicación y Doctor con mención Europea por la Universidad de Málaga. MBA y Máster en Salud Pública por la Escuela Nórdica de Salud Pública. Autor y revisor de artículos en revistas científicas de comunicación y salud como Patient Education and Counselling, Gaceta Sanitaria y Revista Española de Salud Pública. Ha participado como profesor invitado en diversas Universidades y Congresos nacionales e internacionales.

Ha trabajado en diversas organizaciones nacionales e internacionales, como en el Ministerio de Sanidad, Servicios Sociales e Igualdad de España, la Comisión Europea y en la Organización Mundial de la Salud. Es socio-fundador y vicepresidente de la Asociación Española de Comunicación en Salud, así como Editor-Jefe de la Revista Española de Comunicación en Salud. Actualmente, es profesor del Departamento de Periodismo y Comunicación Audiovisual de la 
Universidad Carlos III de Madrid, y coordinador de la Conferencia Internacional de Comunicación en Salud.

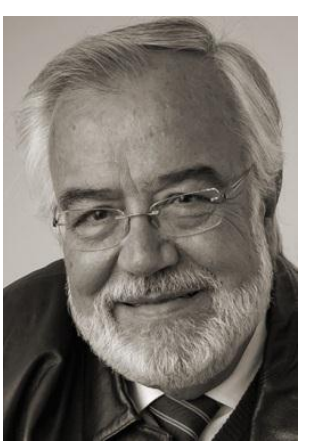

MIGUEL MUÑOZ-CRUZADO. Licenciado en Ciencias de la Comunicación. Publicidad y Relaciones Públicas, Máster en Traducción e Interpretación de Textos biosanitarios alemanes por la Universidad de Sevilla y Doctor por la Universidad de Málaga. Profesor de la Universidad de Málaga desde 1995. Ha sido Vicepresidente del Ilustre Colegio Profesional de Fisioterapeutas de Andalucía; Consejero del Ilustre Consejo General de Colegios de Fisioterapeutas de España; Secretario del Departamento de Psiquiatría y Fisioterapia de la Universidad de Málaga; Director del Departamento de Psiquiatría y Fisioterapia de la Universidad de Málaga.

Presidente de la Asociación Española de Comunicación Sanitaria; Vicepresidente de la Asociación Española de Fisioterapeutas en Salud Mental y Coordinador del Área de Fisioterapia de la Universidad de Málaga. Es autor de una centena de publicaciones en revistas científicas y libros. Ha participado como ponente en 47 Congresos internacionales y 124 nacionales. Traductor de libros del alemán, tiene una patente. Fue director y presentador del Programa de TV "Por su salud" (VTV) con 24 emisiones. Ha sido colaborador de varias revistas médicas y actualmente es Director de la Revista Española de Comunicación en Salud desde 2010 y Director, guionista y presentador del programa "Con el debido respeto" en Onda Líder Radio 107.4 FM. Ondalider.com y Axarquía Digital.es. Estas experiencias las compagina con las de revisor editorial de revistas científicas como Fisioterapia, Fisioterapia y Kinesiologia y Cuestiones de Fisioterapia.

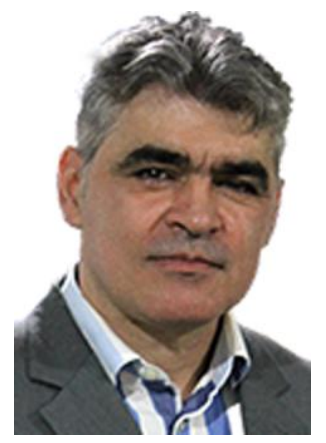

LIZANDRO ANGULO. Comunicador social periodista y organizacional, con especialización en creación e innovación de medios, maestría en Participación y Desarrollo Comunitario y Doctor en Comunicación, posgrados realizados en la Universidad del País Vasco (España). Su tesis doctoral abordó los medios comunitarios, con 
especial énfasis en la televisión comunitaria de Colombia. Es codirector del grupo de investigaciones en Comunicación sobre Ciencia, Tecnología y Sociedad de la Universidad del Tolima. Ha realizado dos estancias posdoctorales en Barcelona, España: sobre el campo de la Comunicación y el Deporte, en el Centro de Estudios Olímpicos de la Universidad Autónoma de Barcelona y sobre el periodismo de investigación en la Universidad Pompeu Fabra. Es profesor asociado de la Universidad del Tolima. Sus investigaciones versan sobre la comunicación para el desarrollo, el periodismo especializado y la comunicación y el deporte.

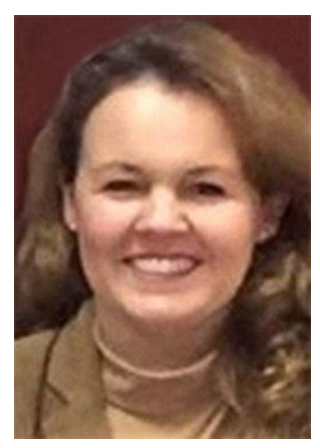

ELENA BECERRA. Doctora del Departamento de Comunicación Audiovisual y Publicidad de la Universidad de Málaga. Es docente y coordinadora de la asignatura Comunicación y Salud en docencia de grado y de la asignatura Comunicación en el Sector Sanitario en docencia de posgrado, ambas en la Universidad de Málaga. Autora del libro titulado Comunicación y gestión de la imagen en el sector sanitario. Estudio de los procesos, revisión de políticas y propuesta de comunicación en el año 2012. Entre las publicaciones en revistas científicas más recientes destaca la titulada: "Comunicación en imagen de los servicios sanitarios. El caso de los centros hospitalarios andaluces (2004-2013)" en la Revista de Ciencias Sociales Prisma Social en el año 2015. Es miembro investigador en el Proyecto de Investigación de la Fundación Española para la Ciencia y la Tecnología (FECYT)- FCT-14-8751, titulado: "Encuentros con la Ciencia. Modalidad 2.1.: Fomento de la Creatividad y de las Vocaciones científicas" desde 2014. IP del Proyecto de Innovación Educativa (2013-2015): "Sinergia docente: Modelo de aprendizaje de disciplinas basado en el intercambio de contenidos entre alumnos de distintos grados de comunicación y ciencias de la salud". 


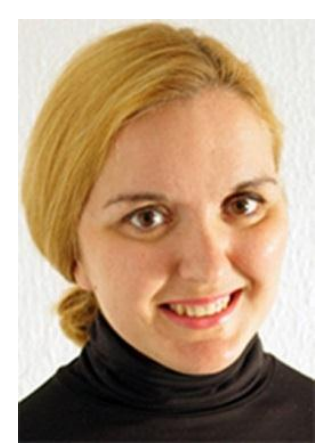

MARIA ANTONIA CALLEJA. Licenciada en Periodismo por la Universidad de Málaga (España) en 2004, y con más de diez años de experiencia en el ámbito de la comunicación y cooperación internacional. Ha trabajado para la Organización Mundial de la Salud, la Empresa Pública de Emergencias Sanitarias y como voluntaria en Médicos Sin Fronteras, entre otros. Actualmente, estudiante de doctorado de la Facultad de Ciencias de la Comunicación de "Comunicación en Crisis 2.0: Mejores Prácticas de la Comunicación en Emergencias Médicas" en Málaga. Visiting Scientist en la Escuela de Salud Pública de la Universidad de Harvard (2015) y estancia en la Universidad Nacional del Nordeste de Argentina (2016).

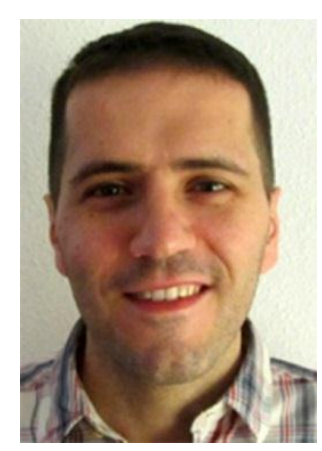

MIGUEL CEMBELLÍN. Facultad de Derecho, Universidad de Alcalá. Diplomado en Biblioteconomía y Licenciado en Documentación (especialidad Documentación Sanitaria) por la Facultad de Ciencias de la Información de la Universidad Complutense. Posteriormente se graduó en Derecho y realizó el Máster en Derechos Fundamentales y Libertades Públicas, Facultad de Derecho de la Universidad de Alcalá. En la actualidad es Doctorando en Derecho, Rama de Bioética y Documentación, también en la Universidad de Alcalá. Recientemente participó como miembro del Comité Organizador de I Congreso Internacional de Telemedicina e Investigación Sanitaria 2016 y tiene una larga trayectoria profesional como documentalista en empresas del sector.

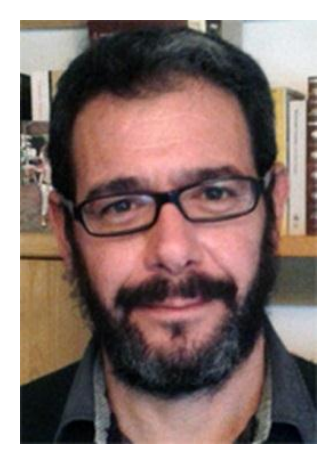

LÁZARO ECHEGARAY. Es Doctor por la Universidad del País Vasco/ Euskal Herriko Unibertsitatea (2012) y Licenciado en Sociología por la Universidad de Granada (1998). En la actualidad es profesor de Sociología e Investigación de Mercados en la Escuela Universitaria de la Cámara de Comercio de Bilbao y Coordinador de Investigación en el mismo centro. Ha trabajado diferentes aspectos en el campo de los medios de comunicación y en la relación de estos con la 
educación, la accesibilidad, las audiencias, los contenidos y la salud. También en el campo de la innovación social y educativa.

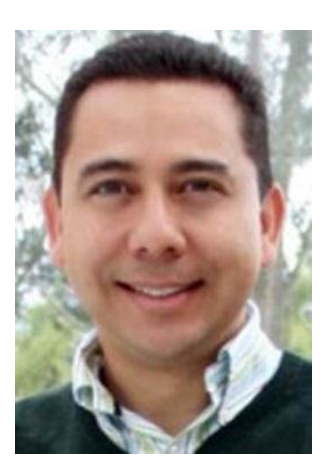

VÍCTOR GARCÍA. Profesor de la Facultad de Comunicación de la Universidad de La Sabana, en Bogotá, Colombia, y candidato a doctor por la Universidad de Texas en Austin, en Estados Unidos. Obtuvo su maestría en Estudios Latinoamericanos también en la Universidad de Texas. Su investigación se centra en el impacto de las tecnologías digitales en los medios, en el periodismo y en las audiencias a través de una perspectiva socio-tecnológica. Así mismo, ha analizado la cobertura de los medios en temas relacionados salud mental. Forma parte del Digital Media Research Program (DMRP), de la Universidad de Texas, y del Grupo de Investigación en Periodismo (GIP), de La Sabana. Es editor del libro Manual de Géneros Periodísticos, y coautor de The Evolution of Television. Ha sido director de la Maestría en Periodismo y Comunicación Digital y jefe de Área de Periodismo en la Universidad de La Sabana. Desde 2013 es director en Colombia de la Beca Rosalynn Carter para Periodismo en Salud Mental, que lidera el Carter Center de Atlanta. Trabajó durante 14 años como periodista profesional para diferentes medios y plataformas, incluyendo el periódico El Espectador, Univision Online, Univision Radio y Terra TV. Su experiencia profesional y académica le ha permitido ejercer como consultor para diversas compañías de medios en Colombia y Venezuela.

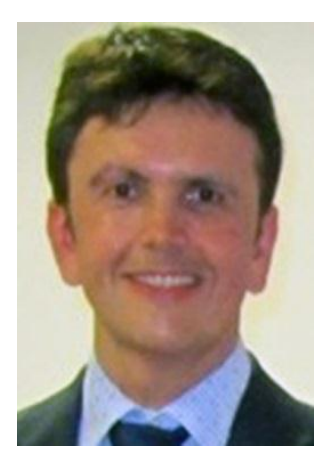

ANTONIO LÓPEZ. Licenciado en Psicología y Doctor con mención Internacional por la Universidad de Almería. MBA y Máster en Administración Sanitaria por la Escuela Nacional de Salud (Instituto de Salud Carlos III, Madrid). Autor de artículos publicados en revistas científicas de cardiología, geriatría y salud pública y revisor de artículos en Patient Education and Counselling y, Clinical Research in Cardiology. Ha participado como ponente en diversas Conferencias y Congresos nacionales e internacionales. Ha trabajado en diversas organizaciones nacionales e internacionales, como en la Agencia 
Pública Sanitaria Poniente (Consejería de Salud de la Junta de Andalucía) y Nordland Hospital (Noruega). Es Secretario de la Asociación Española de Comunicación Sanitaria, así como EditorAsociado de la Revista Española de Comunicación en Salud. Actualmente, es técnico de proyectos de investigación en el Instituto de Medicina Clínica de la Universidad de Tromsø (Noruega), y coordinador de la Escuela de Verano de la Asociación Española de Comunicación Sanitaria.

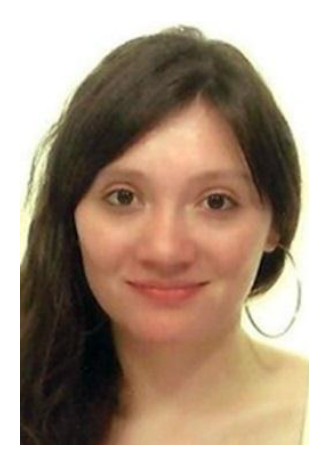

LUISA FERNANDA GIRALDO. Técnico de Comunicación y Área Digital en el Alto Comisionado del Gobierno para la Marca España, graduada en periodismo por la Universidad Rey Juan Carlos de Madrid. Ha trabajado en distintos medios de comunicación locales y en la agencia de noticias Europa Press. Actualmente se interesa por la comunicación institucional y corporativa. Sus líneas de investigación están marcadas por aspectos ligados a los temas de salud en medios de comunicación.

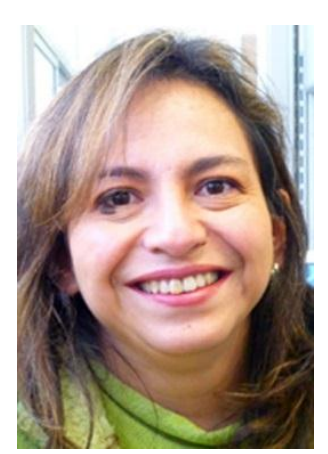

LILIANA GUTIÉRREZ. Doctora en Ciencias de la Información por la Universidad del País Vasco/Euskal Herriko Unibertsitatea. Comunicadora social y periodista. Egresada de la Universidad de La Sabana (Colombia), donde actualmente es directora de la Maestría en Periodismo y Comunicación Digital. Anteriormente fue jefa del Área de Periodismo. Es directora de la revista Palabra Clave y coordinadora de Investigación de la Facultad de Comunicación. Ha ejercido como jefa de Comunicaciones y Mercadeo de la Cámara Colombiana del Libro, entidad organizadora de la Feria Internacional del Libro de Bogotá. Ha trabajado como periodista en El Espectador, entre otras actividades. Es directora del Grupo de Investigación en Periodismo, GIP, donde investiga sobre Calidad Informativa en el Periodismo, tanto analógico como digital. 


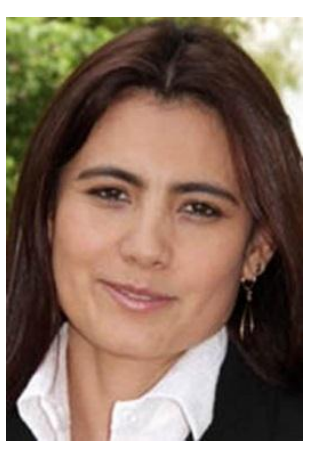

YAHIRA R. GUZMÁN. Profesora de la Facultad de Medicina de la Universidad de La Sabana (Área de Psiquiatría) en Bogotá, Colombia, y candidata a doctora en investigación médica aplicada, por la Universidad de Navarra, en España. Obtuvo su pregrado en Medicina y su especialización de Psiquiatría en la Universidad Nacional de Colombia y una especialización en Bioética en la Universidad de La Sabana, en Colombia. Es la directora del grupo de investigación de Psiquiatría y salud mental de la Universidad de La Sabana. Así mismo, ha realizado investigaciones relacionadas con el diagnóstico y prevención de conductas suicidas, educación en psiquiatría, terapia electro-convulsiva, depresión y suicidio y percepciones en la implementación de planes caseros de rehabilitación integral. Recientemente ha desarrollado su tesis doctoral en calidad de vida en pacientes con Evento Cerebral Vascular. Ha sido la jefa del área de Salud mental de la Universidad de La Sabana desde 2005 y Docente Ad-honorem del Departamento de Psiquiatría de la Universidad Nacional de Colombia. Desde 2013 es administradora en Colombia de la Beca Rosalynn Carter para Periodismo en Salud Mental, que lidera el Carter Center de Atlanta. Ha trabajado durante 14 años como psiquiatra en la Clínica Universidad de La Sabana, coordinando el área de Salud mental.

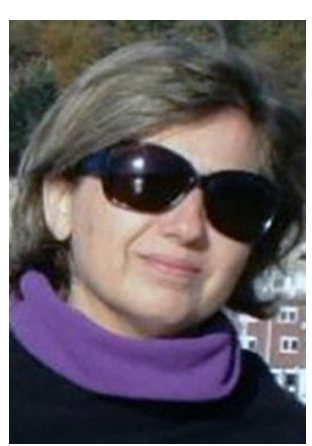

ANDREA LANGBECKER. Realiza el doctorado en el posgrado en Salud Colectiva en la Universidad Federal de Bahía (Ufba) con sanduíche en la Universidad Carlos III de Madrid. Licenciada en Periodismo por la Universidad Federal de Santa María, en Rio Grande do Sul, y Máster en Salud Pública por la Universidad Estadual Paulista, en São Paulo. Es revisora ad hoc en las revistas científicas Interface Comunicación, Salud, Educación y Revista Española de Comunicación en Salud. Ha trabajado como reportera en periódicos brasileños en la Universidad Federal de Viçosa. Ha actuado como asesora de prensa en una institución científica y en proyectos en el área de comunicación y salud en la Ufba. 


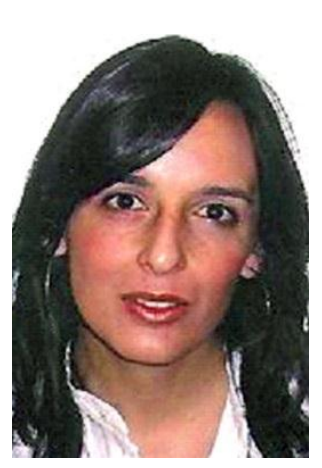

PALOMA LÓPEZ. Doctora en Dirección Estratégica en Comunicación con mención internacional por la Universidad de Málaga. Máster Oficial en Gestión Estratégica e Innovación y Licenciada en Comunicación Audiovisual y Periodismo por la Universidad de Málaga. Desde 2009 es profesora en el Departamento de Comunicación Audiovisual y Publicidad de la Universidad de Málaga. En 2011 inició su línea de investigación en torno a la comunicación y situaciones de crisis sanitarias así como la representación de grupos minoritarios, centrando su línea de investigación en las organizaciones de pacientes con enfermedades raras.

En 2014 ha realizado una estancia predoctoral en Departament of Journalism Studies en la Universidad de Sheffield (Sheffield, Inglaterra). Universidad Incluida en el Academic Ranking of World Universities, para finalizar su tesis doctoral "Comunicación y Salud. Enfermedades Raras y Estrategias de Comunicación”. Ha trabajado como periodista para el Grupo Prisa, Recoletos, empresa privada y entidades municipales, además de colaborar en RNE.

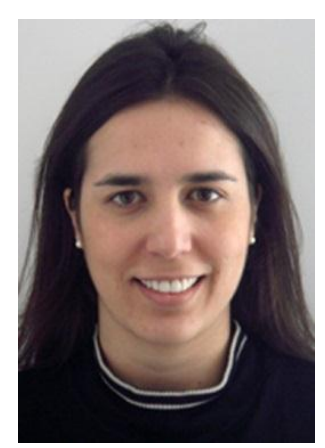

CAROLINA MENEZES. Doctora en Información y Comunicación en Salud por Fiocruz (PPGICS / Fiocruz). Miembro del grupo de investigación $\mathrm{CNPq}$ en la línea Salud y Medios de Comunicación (ICICT/Fiocruz).

Máster en Salud Pública por la Universidad de São Paulo (FSP/USP). Master en Marketing de Alimentos, Venta y Consumo en el Ámbito Internacional (CESMA - Madrid).

Profesora Titular en la Universidad Paulista (Unip). Consultora en Comunicación para la Salud. 


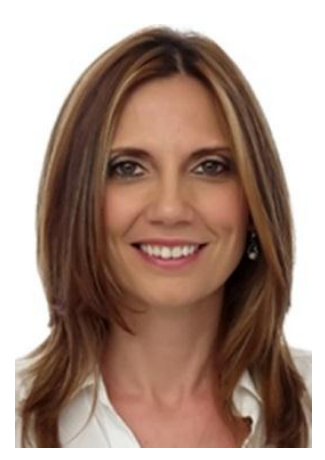

ANTONIA MORENO. Periodista y Doctora en Comunicación por la Universidad del País Vasco. Posdoctorado en Comunicación, divulgación científica y apropiación social del conocimiento en Ikerbasque-Gobierno Vasco y en la Fundación Cardiovascular de Colombia. Asesora de Investigaciones de la Universidad Manuela Beltrán y Co-directora del Grupo de Investigación en Arte, Comunicación y Diseño-GIACODI. Líder del grupo de Investigación en Comunicación, Ciencia, Tecnología y Sociedad reconocido por Colciencias en Categoría C.

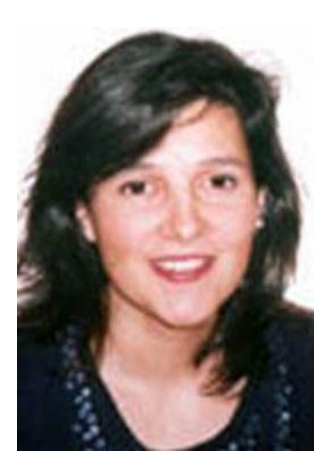

RAQUEL RODRÍGUEZ. Profesora del área de Periodismo en la Facultad de Ciencias de la Comunicación de la Universidad Rey Juan Carlos de Madrid, doctora y licenciada en Ciencias de la Información por la Universidad Complutense. Realizó estudios de tercer ciclo en la Universidad degli Studi di Trento, Univ. of Texas at Austin y Harvard University. Los efectos de los medios de comunicación son una de sus líneas de investigación, marcada por aspectos ligados a la comunicación política, a la información sobre salud, a la teoría del framing y de la agenda-setting junto a los temas de la agenda pública española. Cuenta con dos sexenios de investigación reconocidos por la Comisión Nacional Evaluadora de la Actividad Investigadora (CNEAI) y ha participado en diferentes proyectos de financiación pública y privada, nacionales e internacionales.

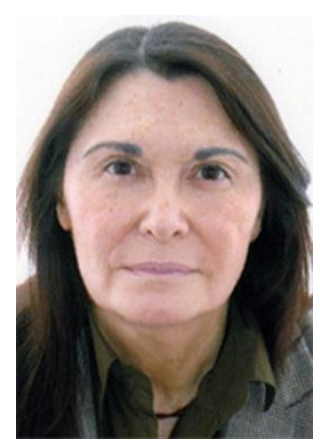

MILAGROS RONCO. Profesora Titular de Universidad por la especialidad de Documentación. Ha trabajado en Centros de Documentación de Medios de Comunicación escritos y audiovisuales, así como en bases de datos especializadas. Ha participado en Proyectos de Investigación financiados por UNESCO y por la UPV-EHU. Actualmente es miembro investigador (Equipo del Área 2, Zona Norte) en el Proyecto El sistema de investigación en España sobre prácticas sociales de Comunicación. Mapa de Proyectos, Grupos, Lineas, Objetos de estudio 
y Métodos, Proyecto de Investigación $\mathrm{I}+\mathrm{D}+\mathrm{i}$ del Ministerio de Economía y Competitividad (CSO2013-47933-C4-1P), 2014-2016. Ha publicado diversos contenidos directamente relacionados con la organización de la información, así como con la salud en los medios de comunicación y en los websites como miembro del grupo de investigación COMSA de la UPV-EHU. Es miembro fundador de la Asociación Vasca de Bibliotecarios, Archiveros y Documentalistas (ALDEE, 1991, integrada en la FESABID). Es miembro de la Asociación Española de Investigación de la Comunicación (AE-IC). Es miembro del Consejo Científico de la Revista "Documentación de las Ciencias de la Información" (Ed. U.C.M) desde 2004. Es miembro de la Comisión Española de la UNESCO como Vocal del Grupo de Comunicación desde el año 2000.

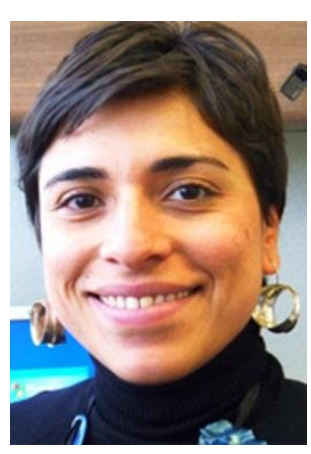

ANDREA SALGADO. Miembro del Grupo de Investigación en Periodismo (GIP) de la Universidad de La Sabana. En la actualidad, desempeña su carrera de docente en la Maestría de Escrituras Creativas de la Universidad Nacional de Colombia y en el programa de Creación Literaria de la Universidad Central. Se especializa en ayudarle a los escritores en los procesos de construcción de sus obras narrativas tanto de ficción como de no-ficción, así como conducirlos al estudio de diferentes subgéneros narrativos que enriquezcan sus procesos creativos.

Ha trabajado con el IDARTES (Instituto distrital de las artes), dirigiendo diferentes talleres de narrativa y en la actualidad dirige el taller de escritura de no-ficción en la librería Casa Tomada. Ha realizado su formación centrada en dos áreas: el Periodismo, donde obtuvo el grado de comunicadora social y periodista; y Creación Literatura, donde obtuvo un MFA (Maestría en Bellas Artes) en escrituras creativas.

Es escritora e investigadora académica. Sus cuentos, crónicas, fragmentos de novela y artículos, se encuentran publicados en distintos medios digitales, revistas especializadas y antologías literarias. 